TALES ADRIANO FERREIRA

\title{
AVALIAÇÃO NUMÉRICA E EXPERIMENTAL DE UM VEÍCULO DE COMPETIÇÃO DE MILHAGEM
}

Dissertação apresentada à Escola

Politécnica da Universidade de São Paulo como parte dos requisitos para a obtenção do título de Mestre em Engenharia

São Paulo

2011 
TALES ADRIANO FERREIRA

\section{AVALIAÇÃO NUMÉRICA E EXPERIMENTAL DE UM VEÍCULO DE COMPETIÇÃO DE MILHAGEM}

Dissertação apresentada à Escola

Politécnica da Universidade de São Paulo como parte dos requisitos para a obtenção do título de Mestre em Engenharia

Área de Concentração:

Engenharia Mecânica

Orientador:

Prof. Dr. Fábio Saltara

São Paulo

2011 
AUTORIZO A REPRODUÇÃO E DIVULGAÇÃO TOTAL OU PARCIAL DESTE TRABALHO, POR QUALQUER MEIO CONVENCIONAL OU ELETRÔNICO, PARA FINS DE ESTUDO E PESQUISA, DESDE QUE CITADA A FONTE.

Este exemplar foi revisado e alterado em relação à versão original, sob responsabilidade única do autor e com a anuência de seu orientador.

São Paulo, 22 de junho de 2011.

Assinatura do autor

Assinatura do orientador

FICHA CATALOGRÁFICA

Ferreira, Tales Adriano

Avaliação numérica e experimental de um veículo de competição de milhagem / T.A. Ferreira. -- ed.rev. -- São Paulo, 2011.

$207 \mathrm{p}$.

Dissertação (Mestrado) - Escola Politécnica da Universidade de São Paulo. Departamento de Engenharia Mecânica.

1.Veículos de competição 2.Aerodinâmica veicular 3.Simulação I.Universidade de São Paulo. Escola Politécnica. Departamento de Engenharia Mecânica II. t. 
Aos meus pais Fátima e Toninho,

e ao meu irmão Michel. 


\section{AGRADECIMENTOS}

A Deus por todas as oportunidades que me oferece na vida.

Aos meus pais, Fátima e Toninho, e ao meu irmão Michel pelo apoio incondicional em todas as minhas decisões.

Ao meu professor orientador Dr. Fábio Saltara por ter me aceitado como aluno e pelo suporte sempre que necessário durante a realização do trabalho.

Aos professores Dr. Ernani Vitillo Volpe, Dr. Cesareo de La Rosa Siqueira e Dr. Paulo Eduardo Mello pelas valiosas contribuições para o aprimoramento desse trabalho. Ao professor Dr. Arlindo Tribess, pelo incentivo e ensinamentos no período da graduação que serviram de base para esse trabalho.

À Volkswagen do Brasil, na figura do supervisor Leandro Macedo, pelo incentivo e suporte para a realização dessa dissertação e por acreditar no desenvolvimento de seus funcionários. Aos meus colegas do setor de Cálculos Veiculares pela paciência que tiveram no meu início de vida profissional.

Aos engenheiros Daniel Toledo e Fernando Sacomano pelo fornecimento da geometria e dados sobre o projeto aerodinâmico do veículo de milhagem.

Ao engenheiro Ivan Korkischko pela idéia do tema do presente trabalho e pelas dicas durante o ensaio experimental.

Um agradecimento especial ao engenheiro Cesar Monzu Freire, por todo o empenho e dedicação na realização dos ensaios no canal de água. Sem ele a parte experimental desse trabalho com certeza não teria a mesma qualidade ou talvez não existisse.

Por fim, a todos os meus amigos, primos e primas, especialmente à minha namorada Claudia Dorea, pela paciência que tiveram comigo nesses últimos três anos quando por muitas vezes não pude sair porque "tenho que fazer as coisas do mestrado". Muito obrigado a todos! 
"Existirá alguém tão esperto que aprenda pela experiência dos outros?" 


\section{RESUMO}

FERREIRA, T. A. Avaliação numérica e experimental de um veículo de competição de milhagem. 2011. 205 f. Dissertação (Mestrado em Engenharia) - Escola Politécnica, Universidade de São Paulo, São Paulo, 2011.

Dentre as competições nas quais estudantes são desafiados a construir protótipos com finalidades específicas, está a de fazer um veículo que transporte uma pessoa e percorrera a maior distância com um litro de combustível. Um dos fatores que contribuem para o consumo é a resistência aerodinâmica, assim prever seus efeitos é essencial para um bom projeto. Nesse contexto o presente trabalho teve por objetivo avaliar de forma numérica e experimental o escoamento ao redor de um veículo de milhagem e calcular os coeficientes aerodinâmicos de arrasto e sustentação dessas duas formas. Também foi estudada a sensibilidade desses coeficientes ao número de Reynolds e, no caso do teste virtual, aos modelos de turbulência. Através dos resultados de simulações verificou-se que a porção frontal do veículo é a maior responsável pelo arrasto e pela sustentação negativa. Os coeficientes de arrasto caíram com o aumento do número de Reynolds tanto nos ensaios virtuais quanto nos experimentais. $\mathrm{Na}$ comparação entre os modelos de turbulência, k- $\varepsilon$ e k- $\omega$ em suas formas padrão foram os que mais destoaram em relação aos outros apresentando valores de $C_{D}$ maiores. Os resultados experimentais apresentaram a mesma tendência dos numéricos, e ficaram mais próximos do k- $\omega$ padrão, mas acredita-se que um ângulo de ataque negativo do modelo devido à montagem tenha provocado um aumento no $\mathrm{C}_{\mathrm{D}}$ obtido experimentalmente. Os valores dos coeficientes de sustentação baixaram com o número de Reynolds nos testes numéricos e aumentaram nos ensaios experimentais. Nas simulações observou-se que a alta velocidade entre as rodas dianteiras devido à pequena distância entre o veículo e o piso era responsável por boa parte da 
sustentação negativa. Por questões de montagem não foi possível repetir esse efeito solo de forma similar nos experimentos. Os resultados numéricos de visualização do escoamento apresentaram boa concordância com os experimentais.

Palavras-chave: Veículo de milhagem. Aerodinâmica veicular. CFD. Aerodinâmica experimental. 


\begin{abstract}
FERREIRA, T. A. Numerical and experimental evaluation of a Supermileage competition vehicle. 2011. 205 f. M. Sc. Thesis - Escola Politécnica, Universidade de São Paulo, São Paulo, 2011.
\end{abstract}

Among the many competitions in which students are challenged to build up prototypes with specific purposes there, is one in which the goal is to design a car to carry one person and make it go as long as it can with one liter of fuel. One of the factors that contribute for fuel consumption is the aerodynamic resistance, so to predict its effects is essential for a good design. In this context, the present work had as goals the numerical and experimental evaluation of flow around a Supermileage vehicle and to calculate its drag and lift coefficients in these both ways. It was also studied the sensitivity of these forces to Reynolds number and, in the virtual case, to turbulence models. Thanks to simulation results it was verified that the front part of the model is responsible for great part of drag and negative lift. The drag coefficients fell with the increase of Reynolds number in both numerical and experimental tests. In a comparison of turbulence models comparison, $\mathrm{k}-\varepsilon$ and $\mathrm{k}-\omega$ in their standard forms presented higher $C_{D}$ values than the other models. Experimental $C_{D}$ results showed the same tendency of numerical ones, and were closer to standard k- $\omega$, although it was believed that a negative angle of attack due to experimental assembly issues has made for a higher experimental $C_{D}$. Lift coefficients values fell with the increase of Reynolds number in virtual analysis and grew in experimental tests. In the simulations it was observed that the high velocity between the two front wheels, due to the short distance between the vehicle and the ground, is responsible for a large portion of the negative lift. Owing to assembly issues it was 
not possible to reproduce this ground effect on experimental tests. Flow visualization results presented good agreement between experimental and numerical testing.

Keywords: Supermileage vehicle. Vehicle aerodynamics. CFD. Experimental aerodynamics. 


\section{LISTA DE FIGURAS}

Figura 1-1: Espiral de projeto de uma análise de CFD.

Figura 2-1: Resultados dos coeficientes de arrasto em função do tamanho da aresta dos triângulos na superfície do veículo obtidos por Buscariolo (2009, p. 78). 9

Figura 2-2: Resultados do coeficiente de arrasto em função do tipo de piso do túnel de vento utilizado nas simulações realizadas por Buscariolo (2009, p. 105) 10

Figura 2-3: Resultados numéricos e experimentais dos coeficientes de arrasto em função do ângulo de guinada, com o veículo encostado no piso, obtidos por Carregari (2006, p. 62). 11

Figura 2-4: Resultados numéricos e experimentais dos coeficientes de força lateral em função do ângulo de guinada, com o veículo encostado no piso, obtidos por Carregari (2006, p. 65)

Figura 2-5: Resultados numéricos e experimentais dos coeficientes de pressão, $\operatorname{com} \beta=0^{\circ}$, obtidos por Carregari (2006, p. 81)

Figura 2-6: Visualização do escoamento obtida por fios de lã ("tufs") realizada por Carregari (2006, p. 69) para $\beta=0^{\circ}$ 13

Figura 2-7: Visualização do escoamento obtida com um composto de dióxido de titânio, para $\beta=0^{\circ}$ realizada por Carregari (2006, p. 73)

Figura 2-8: Domínio numérico utilizado por Korkischko (2006, p. 75) 15

Figura 2-9: Resultados de pressão no plano central do modelo de Gagnon e Richard (2010) para as geometrias 6 (acima) e 5 (abaixo). Escoamento da esquerda para a direita. 
Figura 2-10: Coeficiente de arrasto em função do número de Reynolds e geometrias testadas experimentalmente por Burban, Hegna e Zvodney (2008), velocidades de 4 a 5 mph.

Figura 2-11: Coeficiente de arrasto em função do número de Reynolds obtidos através de simulação por Burban, Hegna e Zvodney (2008), velocidades de 5 a 15 mph. .... 19

Figura 3-1: Forças de pressão $(\mathrm{p})$ e cisalhamento $\left(\tau_{\mathrm{W}}\right)$ num elemento de área infinitesimal $(\mathrm{dS})$ localizado na superfície de um corpo imerso (HUCHO, 1998, p. 68) 22

Figura 3-2: Definição de área frontal projetada (HUCHO, 1998, p. 4). 24

Figura 4-1: Exemplo de elemento fluido infinitesimal e suas coordenadas ..... 27

Figura 4-2: Divisões da camada limite em um escoamento turbulento (TANNEHIL;

ANDERSON; PLETCHER, 1997, p. 302).

Figura 5-1: Vista isométrica do domínio de cálculo utilizado, sem os subdomínios de refinamento.

Figura 5-2: Vista isométrica do domínio de cálculo utilizado, com o volume de refinamento 1.

70

Figura 5-3: Vista isométrica do domínio de cálculo utilizado, com os volumes de refinamento

2 e na esteira. 70

Figura 5-4: Vista lateral do domínio utilizado, com as dimensões explicitadas. 71

Figura 5-5: Vista lateral do domínio utilizado, com as dimensões explicitadas. 71

Figura 5-6: Corte AA referenciado na Figura 5-5. 71

Figura 5-7: Vista isométrica da malha superficial no veículo. 72

Figura 5-8: Vistas em planta da malha superficial no veículo. Na vista inferior pode-se ver a diferença das regiões com elementos de 5 e $10 \mathrm{~mm}$ 73

Figura 5-9: Valores do tamanho da aresta dos elementos no piso 74 
Figura 5-10: Dimensões dos elementos superficiais no veículo e nos volumes de refinamento.

Figura 5-11: Detalhes dianteiro e traseiro da malha do veículo e da simetria. 75

Figura 5-12: Visão geral da malha volumétrica. Plano y = -270 mm. 76

Figura 5-13: Visão mais próxima da malha volumétrica no plano y = $-270 \mathrm{~mm}$. Detalhe do círculo vermelho ampliado na próxima figura. .76

Figura 5-14: Aproximação do destaque na figura 4-2, onde se pode observar a diferença entre a camada de prismas do veiculo e do piso. 77

Figura 5-15: Condição de contorno de simetria no teto e na lateral do túnel. 79

Figura 5-16: Condições de contorno de simetria no eixo longitudinal do veículo, e de velocidade constante e pressão constante na entrada e saída do túnel respectivamente. 80

Figura 5-17: Gráfico de convergência da força de arrasto na velocidade de $7.2 \mathrm{~m} / \mathrm{s}$

$$
\left(\operatorname{Re}=12.3 \times 10^{5}\right)
$$

Figura 5-18: Gráfico de convergência da força de sustentação na velocidade de $7.2 \mathrm{~m} / \mathrm{s}$

$$
\left(\operatorname{Re}=12.3 \times 10^{5}\right)
$$

Figura 5-19: Gráfico de convergência do momento de arfagem na velocidade de $7.2 \mathrm{~m} / \mathrm{s}$

$$
\left(\operatorname{Re}=12.3 \times 10^{5}\right)
$$

Figura 5-20: Força e momento resultantes calculados no pólo O. 84

Figura 5-21: Força e momento resultantes transportados do pólo O para o pólo V. 84

Figura 5-22: Forças de arrasto e sustentação em cada eixo. 85

Figura 6-1: Gráfico dos coeficientes de arrasto em função do número de Reynolds para cada modelo de turbulência. .88

Figura 6-2: Gráfico das forças de arrasto em função do número de Reynolds para cada modelo de turbulência. 90 
Figura 6-3: Gráfico dos coeficientes de sustentação em função do número de Reynolds para cada modelo de turbulência

Figura 6-4: Gráfico das forças de sustentação em função do número de Reynolds para cada modelo de turbulência.

Figura 6-5: Gráfico dos coeficientes de sustentação no eixo dianteiro em função do número de Reynolds para cada modelo de turbulência 94

Figura 6-6: Gráfico das forças de sustentação no eixo dianteiro em função do número de Reynolds para cada modelo de turbulência 95

Figura 6-7: Gráfico dos coeficientes de sustentação na roda traseira em função do número de Reynolds para cada modelo de turbulência. 96

Figura 6-8: Gráfico das forças de sustentação no eixo traseiro em função do número de Reynolds para cada modelo de turbulência. 97

Figura 6-9: Gráfico dos momentos de arfagem (momento em y) em função do número de

Reynolds para cada modelo de turbulência.

Figura 6-10: Tempo de simulação para cada modelo de turbulência com $\operatorname{Re}=12.3 \times 10^{5} \ldots 101$

Figura 6-11: Contornos de y+ na superfície do veículo. 102

Figura 6-12: Contornos de Cp na superfície do veículo. 103

Figura 6-13: Componente da pressão do arrasto na superfície do veículo. 104

Figura 6-14: Componente da pressão da sustentação na superfície do veículo. 105

Figura 6-15: Linhas de corrente a $5 \mathrm{~mm}$ da superfície do veículo coloridas por velocidade. 106 Figura 6-16: Linhas de corrente coloridas por velocidade ao redor do veículo. 107

Figura 6-17: Campo de velocidades no plano de simetria longitudinal. 108

Figura 6-18: Campo de pressões no plano de simetria longitudinal 109

Figura 6-19 Campo de razão de viscosidades no plano de simetria longitudinal......... 110

Figura 6-20: Campo de magnitude da vorticidade no plano de simetria longitudinal. 111 
Figura 6-21: Ilustração da posição do plano horizontal z = -0.11 m.

Figura 6-22: Campo de velocidades no plano $\mathrm{z}=-0.11 \mathrm{~m}$

Figura 6-23: Campo de pressões no plano $\mathrm{z}=-0.11 \mathrm{~m}$.

Figura 6-24: Campo de razão das viscosidades no plano $\mathrm{z}=-0.11 \mathrm{~m}$

Figura 6-25: Campo de magnitude da vorticidade no plano $\mathrm{z}=-0.11 \mathrm{~m}$

Figura 6-26: Comparação dos coeficientes aerodinâmicos entre o piso parado e em

movimento (Spallart-Almaras, $\mathrm{v}=7.2 \mathrm{~m} / \mathrm{s}$ e $\mathrm{Re}=12.3 \times 10^{5}$ )

Figura 6-27: Velocidade no plano de simetria para o piso parado e em movimento. (Spallart-

Almaras, $\mathrm{v}=7.2 \mathrm{~m} / \mathrm{s}$ e $\left.\mathrm{Re}=12.3 \times 10^{5}\right)$

Figura 6-28: Pressão no plano de simetria para o piso parado e em movimento. (Spallart-

Almaras, $\mathrm{v}=7.2 \mathrm{~m} / \mathrm{s}$ e $\left.\mathrm{Re}=12.3 \times 10^{5}\right)$

Figura 6-29: Componente da pressão do arrasto para o piso parado e em movimento (SpallartAlmaras, $\mathrm{v}=7.2 \mathrm{~m} / \mathrm{s}$ e $\operatorname{Re}=12.3 \times 10^{5}$ )

Figura 6-30: Componente da pressão da sustentação para o piso parado e em movimento

$\left(\right.$ Spallart-Almaras, $\mathrm{v}=7.2 \mathrm{~m} / \mathrm{s}$ e $\left.\operatorname{Re}=12.3 \times 10^{5}\right)$. 118

Figura 6-31: Formação dos “duals” da malha poliédrica. (ANSYS FLUENT, 2009a, p. 6-59).

Figura 6-32: Elemento poliédrico (ANSYS FLUENT, 2009a, p. 59)

Figura 6-33: Transformação da camada de prismas em poliedros (ANSYS FLUENT, 2009a,

p. 6-51) 121

Figura 6-34: Vista geral plano de simetria da malha poliédrica

Figura 6-35: Vista aproximada do veículo do plano de simetria da malha poliédrica. Destaque mostrado na figura seguinte.

Figura 6-36: Ampliação do detalhe da última figura.O número de faces de cada poliedro é variável. 
Figura 6-37: Convergência da força de arrasto das malhas original e poliédrica com o piso parado (Spallart-Almaras, $\mathrm{v}=7.2 \mathrm{~m} / \mathrm{s}$ e $\left.\mathrm{Re}=12.3 \times 10^{5}\right)$

Figura 6-38: Detalhe da convergência da força de arrasto da malha original. 123

Figura 6-39: Detalhe da convergência da força de arrasto da malha poliédrica 123

Figura 6-40: Comparação dos coeficientes aerodinâmicos entre a malha original e poliédrica para o piso parado (Spallart-Almaras, $\mathrm{v}=7.2 \mathrm{~m} / \mathrm{s}$ e $\mathrm{Re}=12.3 \times 10^{5}$ ) 124

Figura 6-41: Comparação dos coeficientes aerodinâmicos entre a malha original e poliédrica para o piso em movimento (Spallart-Almaras, $\mathrm{v}=7.2 \mathrm{~m} / \mathrm{s}$ e $\mathrm{Re}=12.3 \times 10^{5}$ )

Figura 6-42: Comparação dos coeficientes aerodinâmicos entre o piso parado e em movimento com malha poliédrica (Spallart-Almaras, $\mathrm{v}=7.2 \mathrm{~m} / \mathrm{s}$ e $\mathrm{Re}=12.3$ $\left.\mathrm{x} 10^{5}\right)$ 126

Figura 6-43: Comparação da variação dos coeficientes aerodinâmicos entre o piso parado e em movimento utilizando as malhas original e poliédrica. (Spallart-Almaras, v = $7.2 \mathrm{~m} / \mathrm{s}$ e $\left.\operatorname{Re}=12.3 \times 10^{5}\right)$

Figura 7-1: Veículo com a carenagem ligada ao piso. 128

Figura 7-2: Região amarela sem prismas em baixo do modelo.

Figura 7-3: Modelo elevado em $50 \mathrm{~mm}$ do solo com uma ligação com a carenagem. 129

Figura 7-4: Coeficiente de arrasto em função do número de Reynolds nas primeiras simulações (A) e calculados no cluster (B).

Figura 7-5: Coeficiente de arrasto em função do número de Reynolds nas primeiras simulações (A) e calculados no cluster (B). 133

Figura 8-1: Esquema de funcionamento do processo de impressoras 3D ( ZCORP apud CANCIGLIERI JUNIOR et al., 2007) 136

Figura 8-2: Máquina de prototipagem rápida utilizada nesse trabalho (3D PRINTERS, 2011). 
Figura 8-3: Modelo projetado para a impressão 3D

Figura 8-4: As duas partes do modelo.

Figura 8-5: Cortes em y $=0 \mathrm{~mm}$ (imagem à esquerda) e $\mathrm{z}=-14 \mathrm{~mm}$ (direita) representados respectivamente na Figura 8-6 e na Figura 8-7 com a geometria do veículo e

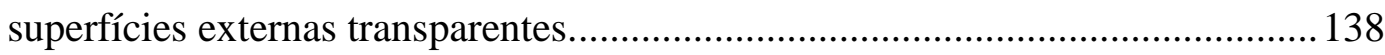

Figura 8-6: Corte em y=0 no modelo. Dimensões em mm. .............................................. 139

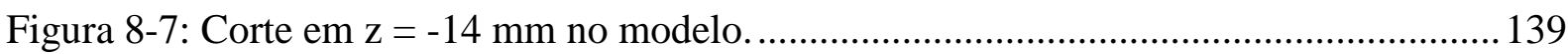

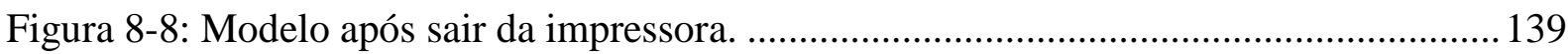

Figura 8-9: Modelo durante o processo de pintura, parte frontal e traseira........................... 140

Figura 8-10: Detalhe das peças plásticas coladas para evitar a rotação dos modelos durante a colagem

Figura 8-11: Perspectivas do modelo finalizado.

Figura 8-12: Canal de água circulante do laboratório NDF utilizado nesse trabalho (ÁSSI, 2005, p. 268).

Figura 8-13: Representação em vistas do canal de água (Ássi, 2005, p. 268).

Figura 8-14: Exemplo de extensômetros (PORTAL, 2011).

Figura 8-15: Esquema de funcionamento de um circuito em Ponte de Wheatstone (THE STRAIN, 2011)

Figura 8-16: Célula de carga utilizada.

Figura 8-17: Transmissor MAG 5000 (SIEMENS, 2011).

Figura 8-18: Esquema de funcionamento da indução eletromagnética provocada pelo escoamento (SIEMENS, 2011) 148

Figura 9-1: Modelo com o eixo montado. 150

Figura 9-2: Modelo numérico com todos os eixos verticais representados na mesma figura.151 
Figura 9-3: Forças em função da distância do eixo vertical em relação ao bordo de fuga do veículo.

Figura 9-4: Esquema da montagem experimental (sem escala).

Figura 9-5: Estrutura de barras com a célula de carga e o eixo de suporte montados.

Figura 9-6: Detalhe da célula de carga com o eixo montado.

Figura 9-7: Detalhe do modelo no fundo do canal.

Figura 9-8: Esquema do efeito de blocagem no escoamento (REINO UNIDO, 1998)

Figura 10-1: Resultados experimentais de $C_{D}$ para as 4 séries de ensaios.

Figura 10-2: Resultados experimentais de $\mathrm{C}_{\mathrm{L}}$ para as 4 séries de ensaios.

Figura 10-3: Comparação dos resultados experimentais de $C_{D}$ com e sem a correção da blocagem

Figura 10-4: Comparação dos resultados experimentais de $C_{L}$ com e sem a correção da blocagem.

Figura 10-5: Resultados experimentais de $C_{D}$ considerando a margem de erro calculada. ... 166 Figura 10-6: Resultados experimentais de $\mathrm{C}_{\mathrm{L}}$ considerando a margen de erro calculada...... 167 Figura 10-7: Nuvem de tinta ao redor do modelo. 168

Figura 10-8: Vista lateral do escoamento.

Figura 10-9: Importante concentração de tinta entre a cobertura das rodas e o cockpit. 169

Figura 10-10: O escoamento sobre a cobertura das rodas desce para as laterais.

Figura 10-11: A separação num plano horizontal ocorre logo após as entradas de ar. 170

Figura 11-1: Esquema da primeira montagem experimental (sem escala).... 172

Figura 11-2: Primeira montagem experimental e detalhe do ponto fixo da alavanca e transmissão da força para a célula de carga. 173

Figura 11-3: Sistema de polias para a calibração do mecanismo de alavanca (sem escala). .174 Figura 11-4: Esquema (sem escala) da projeção das forças no mecanismo de alavanca 175 
Figura 11-5: Modelo da carenagem com o perfil NACA0030 extrudado............................. 176

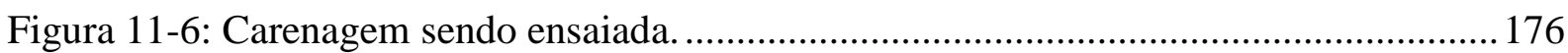

Figura 12-1: Comparação dos resultados experimentais e numéricos de $C_{D}$...................... 177

Figura 12-2: Comparação dos resultados experimentais e numéricos de $\mathrm{C}_{\mathrm{L}}$......................178

Figura 12-3: Comparação dos resultados de $C_{D}$ experimentais e numéricos com escala de

Reynolds reduzida e barras de erros experimentais........................................ 178

Figura 12-4: Comparação dos resultados de $C_{L}$ experimentais e numéricos com escala de Reynolds reduzida e barras de erros experimentais......................................... 179

Figura 12-5: Visualização dos resultados numéricos e experimentais do escoamento: vista

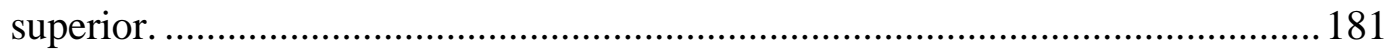

Figura 12-6: Visualização dos resultados numéricos e experimentais do escoamento: vista lateral.

Figura 12-7: Volkswagen "Sparmobil”, $\mathrm{C}_{\mathrm{D}}=0.15, \mathrm{~A}=0.32 \mathrm{~m}^{2}(\mathrm{HUCHO}, 1998$, p. 234)... 184 


\section{LISTA DE TABELAS}

Tabela 2-1: Compilação dos resultados obtidos por Korkischko (2006) para os coeficientes de arrasto do Corpo de Ahmed 15

Tabela 2-2: Decomposição do arrasto em parcelas devido à pressão e à viscosidade obtida por Korkischko (2006, p. 78)

Tabela 2-3: Resultados obtidos por Gagnon e Richard (2010) para as forças de arrasto e sustentação .16

Tabela 2-4: Variação do coeficiente de arrasto em função da altura do modelo do piso e da velocidade obtida por Burban, Hegna e Zvodney (2008).

Tabela 5-1: Intensidade de turbulência em função do número de Reynolds. 78

Tabela 6-1: Resultados dos coeficientes de arrasto obtidos em cada modelo de turbulência para cada número de Reynolds 89

Tabela 6-2: Resultados das forças de arrasto obtidas em cada modelo de turbulência para cada número de Reynolds .90

Tabela 6-3: Resultados dos coeficientes de sustentação obtidos em cada modelo de turbulência para cada número de Reynolds

Tabela 6-4: Resultados das forças de sustentação obtidas em cada modelo de turbulência para cada número de Reynolds .93

Tabela 6-5: Resultados dos coeficientes de sustentação no eixo dianteiro obtidos em cada modelo de turbulência para cada número de Reynolds.

Tabela 6-6: Resultados das forças de sustentação no eixo dianteiro obtidos em cada modelo de turbulência para cada número de Reynolds. 96

Tabela 6-7: Resultados dos coeficientes de sustentação na roda traseira obtidos em cada modelo de turbulência para cada número de Reynolds. 97 
Tabela 6-8: Resultados das forças de sustentação no eixo traseiro obtidos em cada modelo de turbulência para cada número de Reynolds 98

Tabela 6-9: Resultados dos momentos de arfagem (momento em y) em função do número de Reynolds para cada modelo de turbulência.. 99

Tabela 8-1: Cálculo das dimensões do modelo experimental 134

Tabela 8-2: Fundo de escala e resolução da célula de carga utilizada (ATI, 2011). 146

Tabela 12-1: Exemplos de $\mathrm{C}_{\mathrm{D}}$ de equipes de milhagem. 182 


\section{LISTA DE SIGLAS}

2D

$3 \mathrm{D}$

ABS

CAD

CAE

CFD

NACA

$\mathrm{NDF}$

RMS

RSM

SAE

USP

VIV
2 Dimensões

3 Dimensões

Acrilonitrila-butadieno-estireno

Computer Assisted Design

Computer-Aided Engineering

Computational Fluid Dynamic

National Advisory Committee for Aeronautics

Núcleo de Dinâmica e Fluidos

Root Mean Square

Reynolds Stress Model

Society of Automotive Engineers

Universidade de São Paulo

Vortex-Induced Vibration 


\section{LISTA DE SÍMBOLOS}

\section{Símbolos latinos}

\begin{tabular}{|c|c|}
\hline $\mathrm{F}_{\mathrm{D}}$ & Força de arrasto $[\mathrm{N}]$ \\
\hline $\mathrm{F}_{\mathrm{L}}$ & Força de sustentação [N] \\
\hline $\mathrm{C}_{\mathrm{D}}$ & Coeficiente de arrasto [-] \\
\hline $\mathrm{C}_{\mathrm{L}}$ & Coeficiente de sustentação [-] \\
\hline $\mathrm{C}_{\mathrm{LF}}$ & Coeficiente de sustentação no eixo frontal [-] \\
\hline $\mathrm{C}_{\mathrm{LR}}$ & Coeficiente de sustentação no eixo traseiro[-] \\
\hline A & Área projetada $\left[\mathrm{m}^{2}\right]$ \\
\hline $\mathrm{v}$ & Velocidade do escoamento ao longe $[\mathrm{m} / \mathrm{s}]$ \\
\hline $\operatorname{Re}$ & Número de Reynolds [-] \\
\hline $\mathrm{Ma}$ & Número de Mach [-] \\
\hline $\mathrm{Fr}$ & Número de Froude [-] \\
\hline $\mathrm{G}$ & Produção de determinada variável [mesma unidade da variável] \\
\hline $\mathrm{Y}$ & $\begin{array}{l}\text { Destruição de determinada variável [mesma unidade da } \\
\text { variável] }\end{array}$ \\
\hline $\mathrm{S}$ & $\begin{array}{l}\text { Termo fonte ou medida escalar um tensor [mesma unidade do } \\
\text { restante da equação ou do tensor] }\end{array}$ \\
\hline $\operatorname{Pr}$ & Número de Prandtl [-] \\
\hline$a$ & Velocidade do som $[\mathrm{m} / \mathrm{s}]$ \\
\hline M & Momento [N/m] \\
\hline $\overrightarrow{\mathrm{g}}$ & Vetor aceleração gravitacional $\left[\mathrm{m} / \mathrm{s}^{2}\right]$ \\
\hline $\overrightarrow{\mathrm{F}}$ & Vetor forças externas e de campo $[\mathrm{N}]$ \\
\hline $\overrightarrow{\mathrm{u}}$ & Vetor velocidade $[\mathrm{m} / \mathrm{s}]$ \\
\hline $\mathrm{u}_{\mathrm{i}}$ & Velocidade na direção i $[\mathrm{m} / \mathrm{s}]$ \\
\hline
\end{tabular}




$\begin{array}{ll}\mathrm{u}_{\mathrm{i}}^{\prime} & \text { Flutuação da velocidade na direção i }[\mathrm{m} / \mathrm{s}] \\ \mathrm{c}_{\mathrm{p}} & \text { Calor específico à pressão constante }[\mathrm{J} / \mathrm{KgK}] \\ \mathrm{Faq} & \text { Frequiência de aquisição }\left[\mathrm{s}^{-1}\right] \\ \mathrm{k} & \text { Energia cinética turbulenta }[\mathrm{J}] \\ \mathrm{p} & \text { Pressão }[\mathrm{Pa}] \\ \mathrm{T} & \text { Temperatura }[\mathrm{K}] \\ \mathrm{t} & \text { Tempo [s] } \\ \mathrm{x}, \mathrm{y}, \mathrm{z} & \text { Coordenadas cartesianas }[\mathrm{m}] \\ \mathrm{x}_{\mathrm{i}} & \text { Coordenada cartesiana na direção i }[\mathrm{m}]\end{array}$

\section{Símbolos gregos}

$\begin{array}{ll}\rho & \text { Densidade }\left[\mathrm{kg} / \mathrm{m}^{3}\right] \\ \mu & \text { Viscosidade dinâmica }\left[\mathrm{Ns} / \mathrm{m}^{2}\right] \\ \varepsilon & \begin{array}{l}\text { Taxa de dissipação da energia cinética turbulenta }\left[\mathrm{m}^{2} / \mathrm{s}^{3}\right] \text { ou } \\ \text { altura da rugosidade }[\mathrm{m}]\end{array} \\ \omega & \text { Taxa de dissipação específica }\left[\mathrm{s}^{-1}\right] \\ \Phi & \text { Função de dissipação [ ] } \\ \mu \mathrm{t} & \text { Viscosidade turbulenta }\left[\mathrm{Ns} / \mathrm{m}^{2}\right] \\ \nu & \text { Viscosidade cinemática }\left[\mathrm{m}^{2} / \mathrm{s}\right] \\ \tau_{0,} \tau_{\mathrm{p}} & \text { Tensão de cisalhamento junto à parede }[\mathrm{Pa}] \\ \beta & \text { Coeficiente de expansão térmica }\left[\mathrm{K}^{-1}\right] \\ \tau & \text { Tensão de cisalhamento [Pa] } \\ \Omega_{\mathrm{ij}} & \left.\text { Tensor taxa de rotação [s }{ }^{-1}\right]\end{array}$




\section{Operadores matemáticos}

$\begin{array}{ll}\partial & \text { Derivada parcial } \\ - & \text { Média } \\ \delta_{\mathrm{ij}} & \text { Delta de Kronecker } \\ \rightarrow & \text { Vetor } \\ \operatorname{div} & \text { Divergente } \\ \operatorname{grad} & \text { Gradiente }\end{array}$




\section{SUMÁRIO}

Lista de figuras

Lista de tabelas

Lista de Siglas

Lista de Símbolos

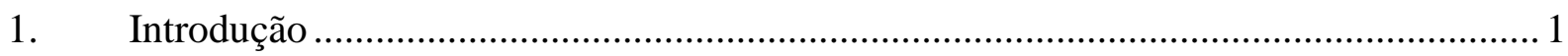

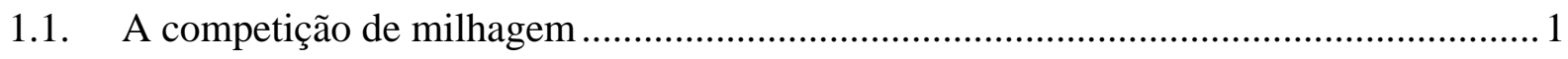

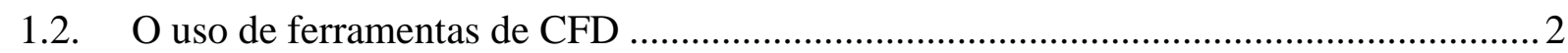

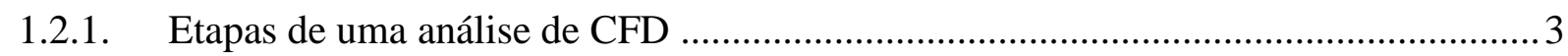

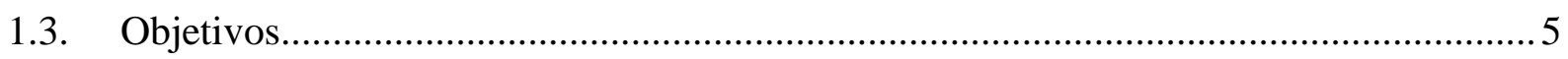

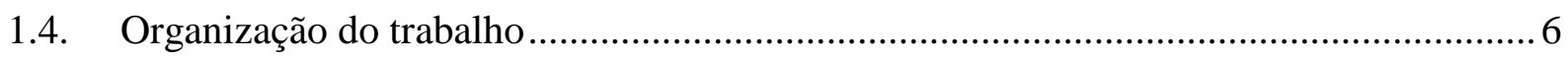

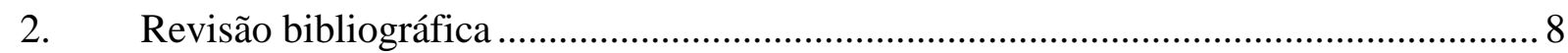

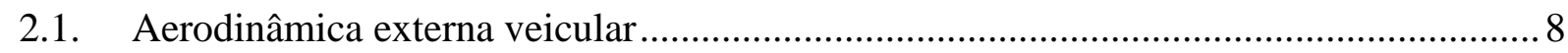

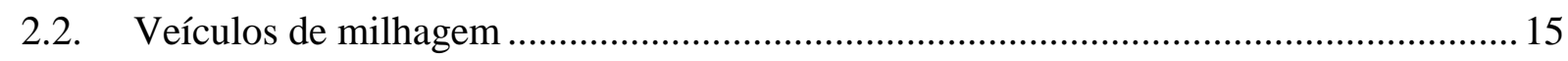

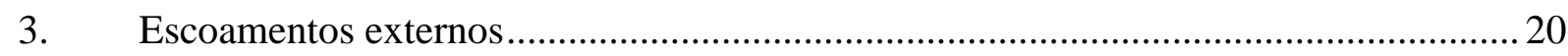

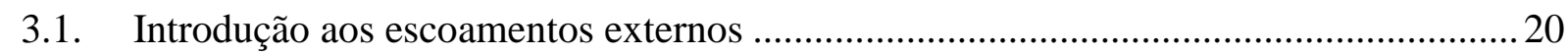

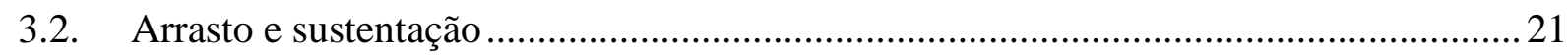

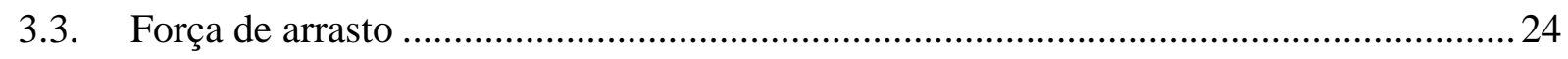

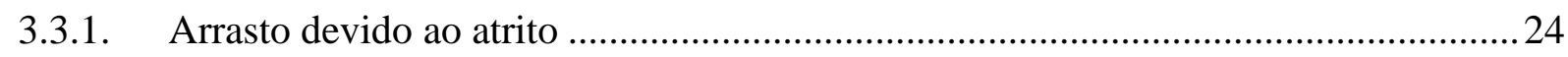

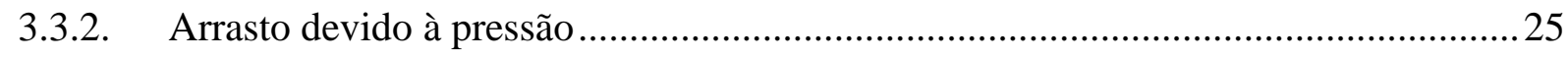

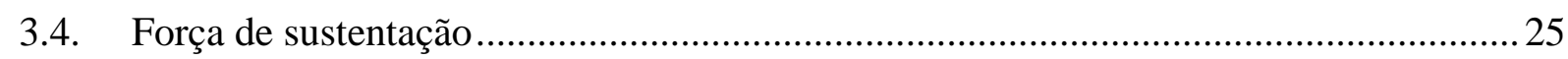




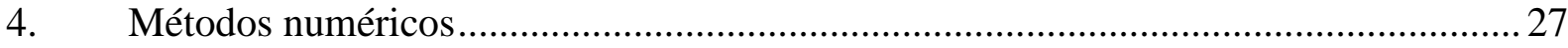

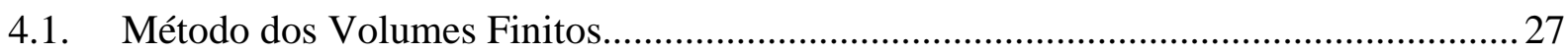

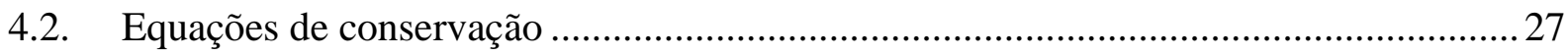

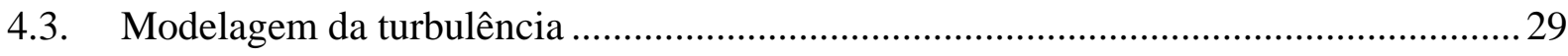

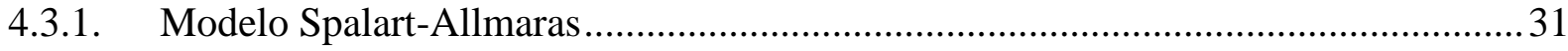

4.3.2. Introdução aos modelos de duas equações................................................................ 36

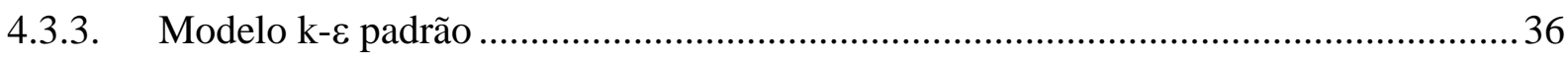

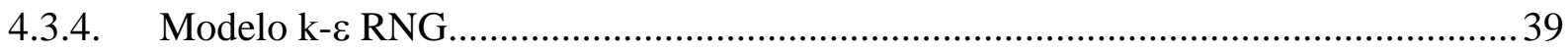

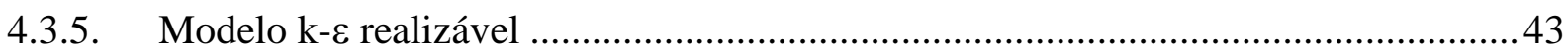

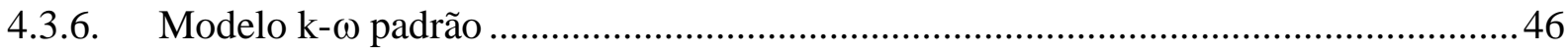

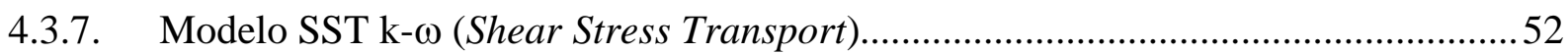

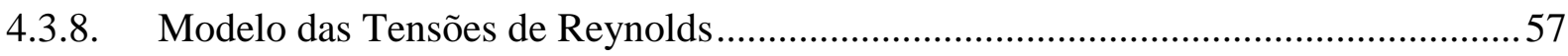

4.3.9. $\mathrm{O}$ tratamento da turbulência próximo às paredes...................................................... 66

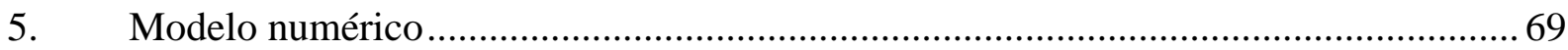

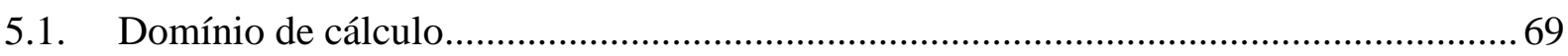

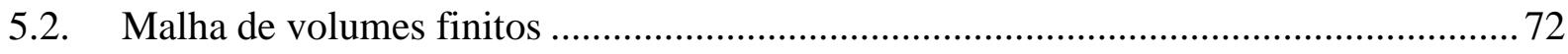

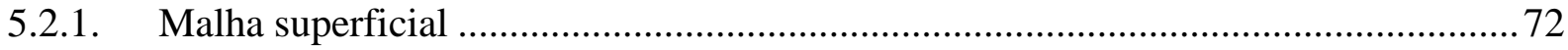

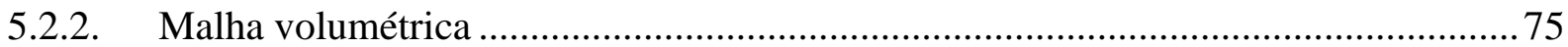

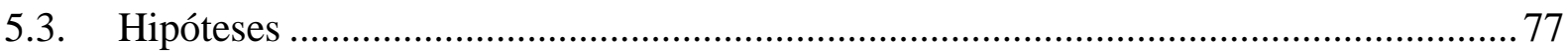

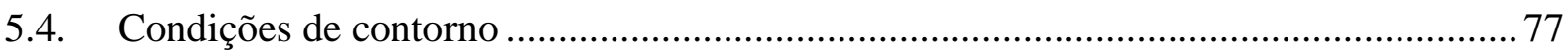

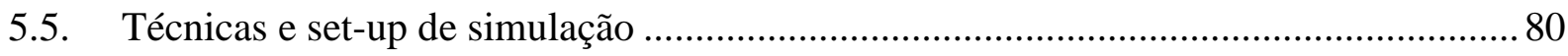

5.6. Cálculo dos coeficientes de arrasto e sustentação ........................................................ 83 


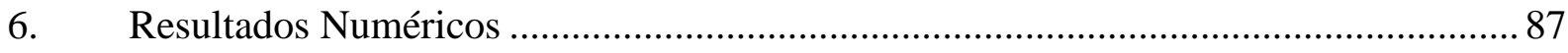

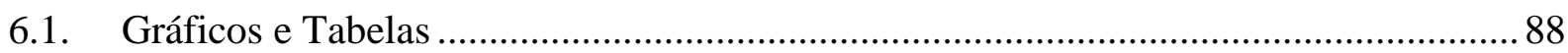

6.2. Contornos e visualização do escoamento ............................................................. 101

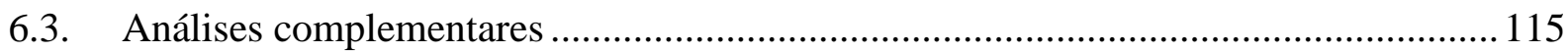

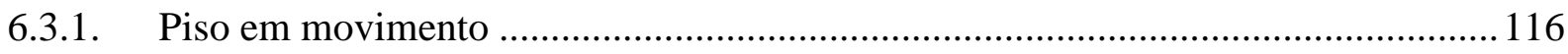

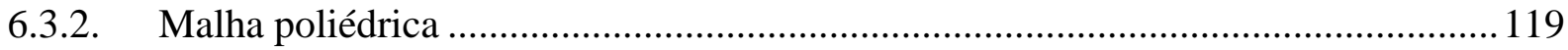

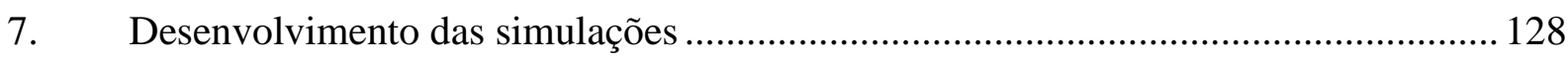

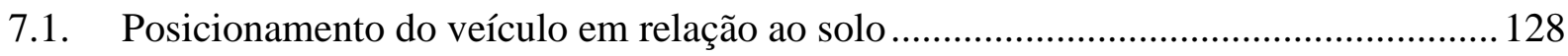

7.2. Variação dos resultados com o Hardware utilizado ................................................. 130

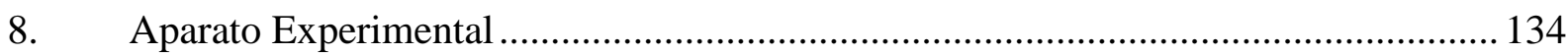

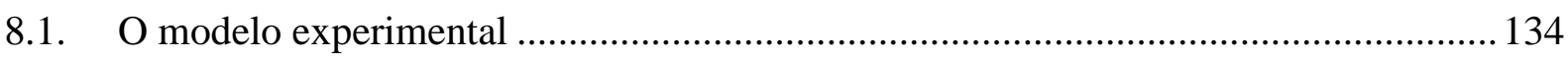

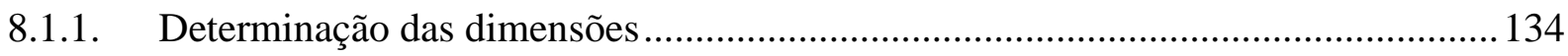

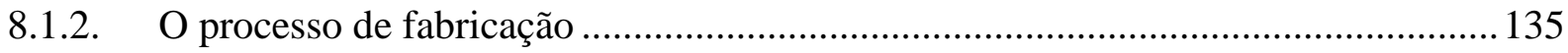

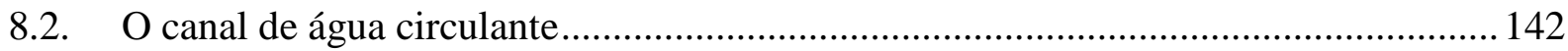

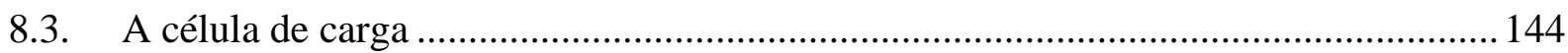

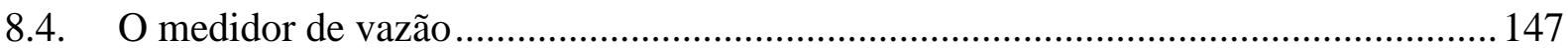

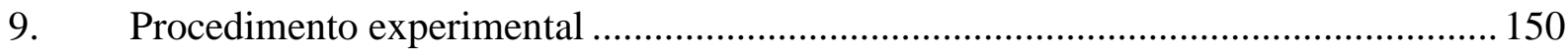

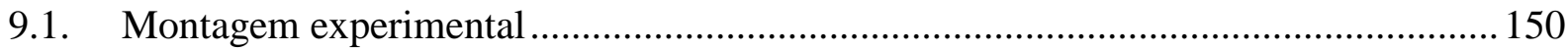

9.2. Procedimento de aquisição de dados .................................................................. 154

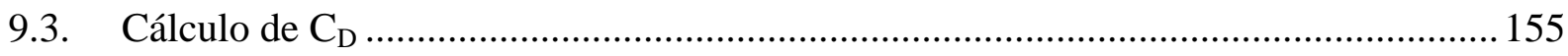

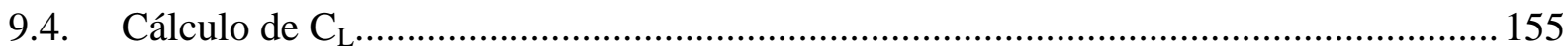

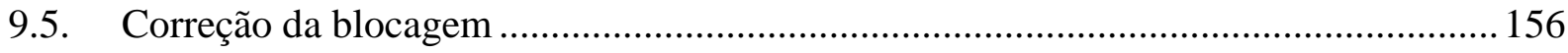




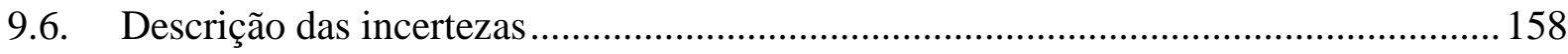

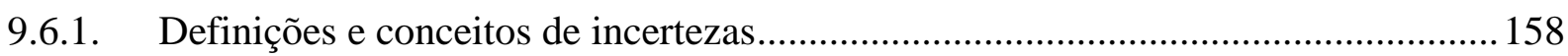

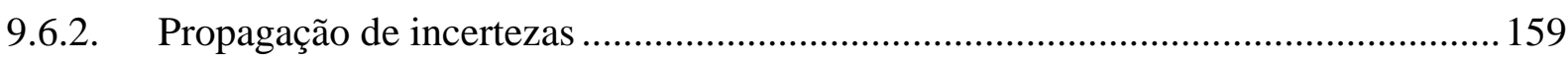

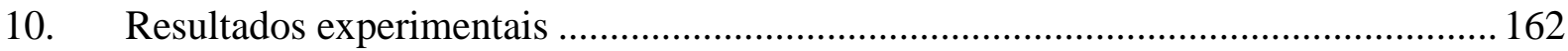

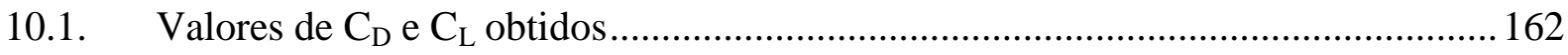

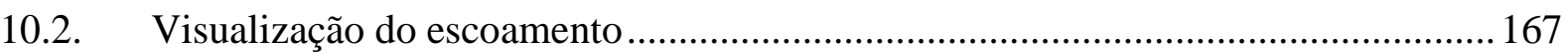

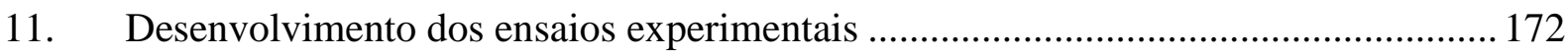

11.1. Desenvolvimento da montagem experimental..................................................... 172

11.2. Desenvolvimento de uma carenagem para o eixo de suporte ...................................175

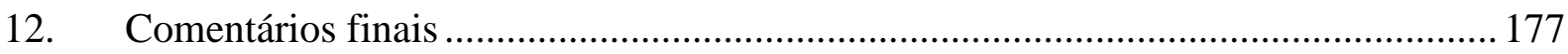

12.1. Comparação dos resultados numéricos e experimentais............................................ 177

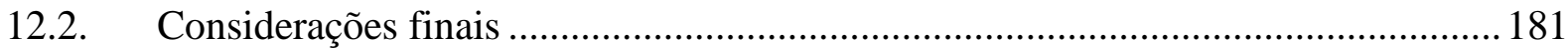

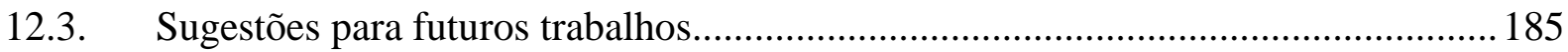

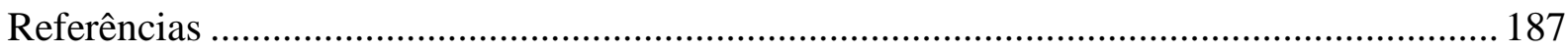

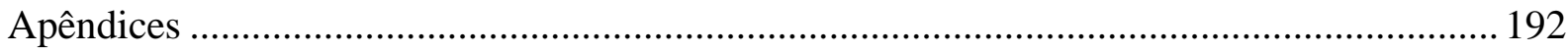

A. Códigos de MatLab para o tratamento dos sinais experimentais ................................ 193

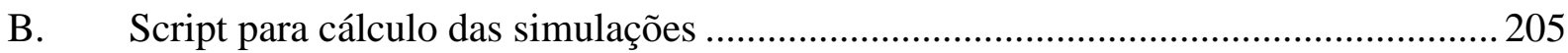




\section{INTRODUÇÃO}

\subsection{A competição de milhagem}

A primeira competição cujo objetivo é percorrer a maior distância possível com o menor consumo de combustível aconteceu em 1939, como uma aposta amigável entre cientistas do laboratório da Shell em Ilinois. Surgia assim a Shell Eco-Marathon atualmente a principal competição de autonomia do mundo. Nos moldes atuais o evento ocorre desde 1985, na França (SHELL, 2010). Em 1980 ocorreu a primeira competição de milhagem organizada pela SAE, dentro da série de disputas estudantis que inclui o Baja, Aerodesign, Fórmula SAE e Snowmobile (SAE, 2010). No Brasil essa competição é chamada de "Maratona de Eficiência Energética", teve seu início em 2004 e é realizada pela empresa Projeto de Comunicação.

É interessante notar como há diferentes organizadores desse tipo de competição ao redor do mundo, com diferentes regras e peculiaridades. No Brasil, por exemplo, há uma categoria cujo combustível é o etanol. A variedade de empresas interessadas em organizar esse tipo de competição reforça a importância dos conceitos envolvidos nela, e que são desenvolvidos por seus participantes como sustentabilidade, eficiência energética, trabalho em equipe e visão de vanguarda.

O nome da competição no Brasil é muito apropriado, pois a eficiência energética é a chave para a redução de consumo e conseqüente sucesso nesse tipo de prova. Com isso um dos principais objetivos de um projeto de um veículo de milhagem é a minimização das perdas de energia, na transmissão de potência entre o motor e as rodas e no arrasto aerodinâmico. A minimização da massa do veículo também é de grande importância para uma melhor relação peso/potência. 
Em veículos de competição de alto desempenho, como é o caso, cada detalhe que influencie no consumo deve ser cuidadosamente considerado. Nesse contexto o presente trabalho visa estudar maneiras de se avaliar através de simulação numérica e experimental as forças aerodinâmicas envolvidas, para melhor compreender como esse carregamento atua num veículo de milhagem e o que pode ser feito para minimizar seus efeitos.

\subsection{O uso de ferramentas de CFD}

O grande avanço da capacidade de processamento e armazenamento de dados que os computadores obtiveram nas últimas décadas permitiu uma grande difusão das técnicas de dinâmica dos fluidos computacional, mais conhecida por sua sigla do inglês CFD (Computational Fluid Dynamics) tanto nas universidades como nas indústrias. Em ambos os casos o objetivo é a pesquisa e o desenvolvimento de produtos ou processos em que o escoamento de um ou mais fluidos está envolvido.

Segundo Versteeg e Malalasekera (1995, p. 2), as principais vantagens da simulação numérica em relação à construção de protótipos são:

- Redução substancial de tempo e custo de novos projetos;

- Habilidade de estudar sistemas nos quais experimentos controlados são difíceis ou impossíveis de se realizar (por exemplo, sistemas de grande porte);

- Obter as condições de ótimo desempenho no projeto;

- Habilidade de estudar sistemas sob condições perigosas e além das condições limites de desempenho (por exemplo, acidentes e estudos de segurança);

- Nível de detalhes dos resultados praticamente ilimitado e;

- Como item de importância extremamente significativa, pode-se citar a inovação, ou seja, a geração de novas idéias que podem ser transpostas para outros desenvolvimentos. 
Porém, mesmo com todas essas vantagens, a simulação utilizando CFD não substitui os dados experimentais, pois são com eles que as simulações são validadas e somente a partir da validação que resultados de simulações de alterações em relação ao modelo original podem ser considerados consistentes.

Além disso, é necessária mão-de-obra especializada (engenheiros ou técnicos experientes) para operar os softwares de CFD. Isso porque geralmente esses softwares são de fácil domínio da interface gráfica, e de algoritmos bem robustos, o que pode levar o usuário despreparado a obter soluções falsas as quais não seja capaz de identificar.

\subsubsection{Etapas de uma análise de CFD}

Segundo Ferreira, (2006, p. 5) um estudo utilizando CFD consiste basicamente de quatro etapas detalhadas a seguir: construção da geometria, geração de malha, processamento e pósprocessamento.

- Construção das geometrias: etapa extremamente trabalhosa consiste em construir, em um software adequado, a geometria do domínio a ser simulado, no caso do presente trabalho a superfície externa do veículo. Vale ressaltar que já nessa etapa são empregadas algumas hipóteses simplificadoras, pois nem todos os componentes do domínio são desenhados exatamente como são, por exemplo, fecham-se as entradas de ar (FERREIRA, 2006, p. 5).

- Geração das malhas: uma das etapas mais importantes em uma análise CFD, a geração da malha consiste em discretizar a geometria construída na etapa anterior em vários elementos volumétricos para que a utilização do método dos volumes finitos pelo solver seja possível (FERREIRA, 2006, p. 5). 
- Processamento: etapa principal, a análise propriamente dita, é a resolução das equações de conservação das quantidades físicas por um software de CFD apropriado. É nessa etapa que são inseridas as condições de contorno no modelo e tem-se como resultado as variáveis desejadas (FERREIRA, 2006, p. 5).

- Pós-processamento: é a análise dos resultados provenientes do processamento. Nessa fase são identificados problemas relacionados a todas as etapas anteriores, como inconsistências na geometria, baixo nível de refinamento da malha em regiões de grandes gradientes, ou ainda erros na determinação das condições de contorno. Encontrados os problemas, volta-se ao passo referente, corrige-se e a análise é reiniciada. (FERREIRA, 2006, p. 5)

Dessa forma a espiral de projeto para as análises e conseqüentemente para o trabalho inteiro fica da seguinte forma: 


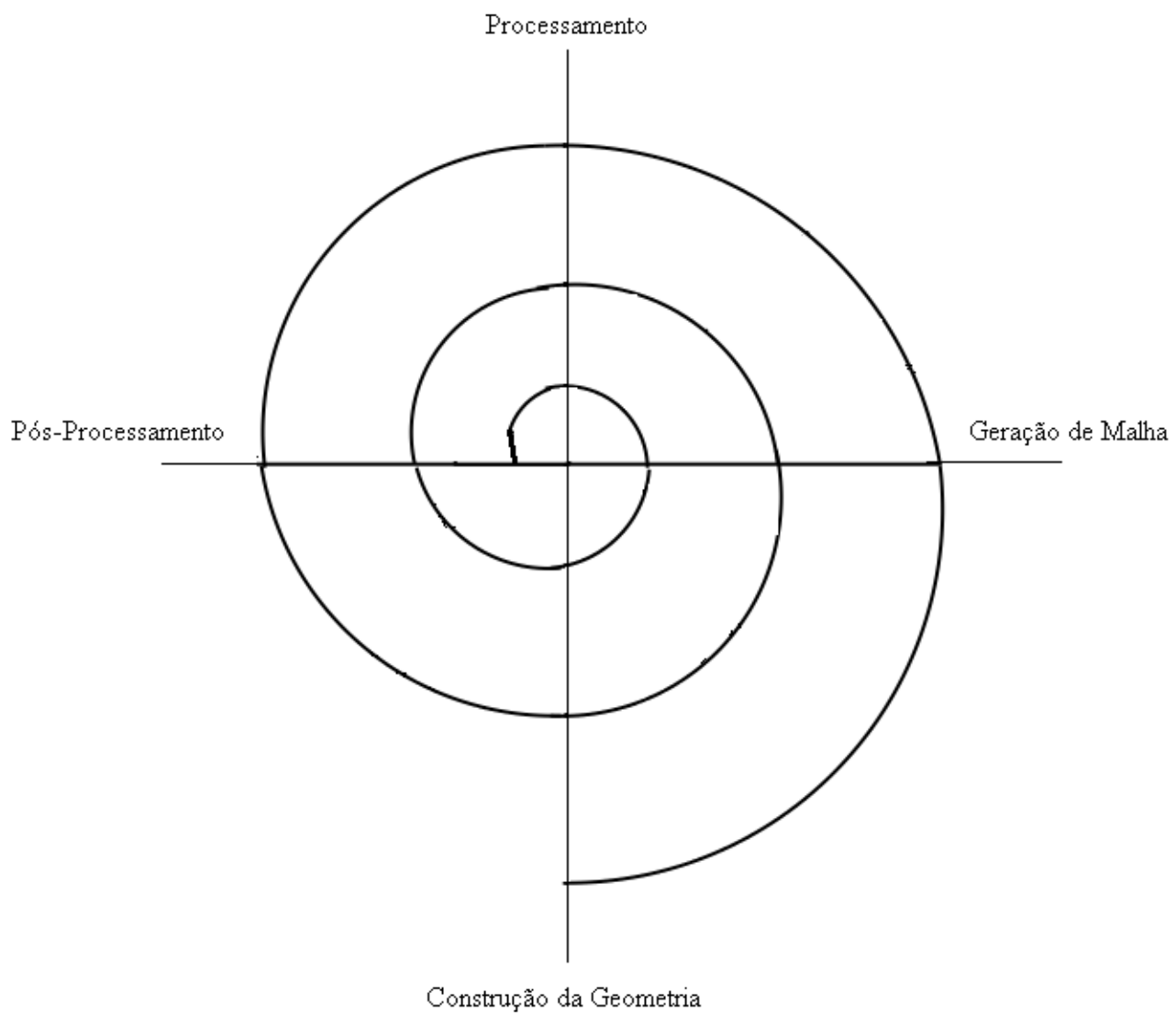

Figura 1-1: Espiral de projeto de uma análise de CFD (FERREIRA, 2006, p. 6).

\subsection{Objetivos}

Tendo em vista as potencialidades e limitações de uma análise utilizando CFD, e de uma investigação puramente experimental, ao juntar as duas ferramentas na avaliação aerodinâmica de um veículo de milhagem esse trabalho tem por objetivo:

- Compreender o escoamento ao redor do veículo citado, verificando quais as regiões na geometria de maior contribuição para o arrasto e sustentação;

- Obter os coeficientes de arrasto e sustentação do veículo de forma numérica e experimental;

- Avaliar a sensibilidade dos resultados dos coeficientes aerodinâmicos em relação aos modelos de turbulência e ao número de Reynolds. 


\subsection{Organização do trabalho}

O presente trabalho está dividido em 4 partes: visão e noções gerais, estudo numérico, estudo experimental e comentários finais.

A primeira parte, visão e noções gerais, compreende os capítulos 1 a 3. No capítulo 2, "Revisão bibliográfica", são apresentados os trabalhos encontrados mais relevantes relacionados diretamente com o tema dessa dissertação. Os estudos estão divididos em aerodinâmica externa veicular em geral, especialmente avaliações sobre o arrasto, e mais especificamente veículos de milhagem. O capítulo 3 "Escoamentos externos" fala sobre os aspectos teóricos das forças envolvidas no escoamento ao redor de corpos imersos.

A avaliação numérica constitui a segunda parte do texto, e engloba os capítulos 4 a 7 . A fundamentação teórica é mostrada no capítulo 4 "Métodos numéricos" onde os equacionamentos do Método dos Volumes Finitos e dos modelos de turbulência utilizados são expostos. O capítulo 5 "Modelo numérico" discorre sobre detalhes da malha utilizada, do domínio de cálculo, das hipóteses simplificadoras e do método de cálculo dos coeficientes de arrasto e sustentação. No capítulo 6 "Resultados numéricos" são apresentados os coeficientes de arrasto e sustentação obtidos nas simulações, além de figuras de visualização do escoamento ao redor do veículo. O capítulo 7 "Desenvolvimento das simulações" fala sobre as dificuldades e soluções encontradas durante o estudo numérico.

A terceira parte discorre sobre o estudo experimental realizado e abrange os capítulos 8 a 11. Os equipamentos utilizados assim como seus princípios de funcionamento são mostrados no capítulo 8, “Aparato experimental”. O capítulo 9, "Procedimento experimental”, explica como o ensaio foi montado, os sinais aquisitados tratados e o coeficiente de arrasto calculado. No capítulo 10, "Resultados experimentais" são mostrados os coeficientes de arrasto e susetantação obtidos no experimento assim como visualizações do escoamento. $\mathrm{O}$ 
capítulo 11 "Desenvolvimento dos ensaios experimentais" descreve as dificuldades encontradas e as soluções implementadas durante a preparação para os testes experimentais.

Finalmente, o capítulo 12, "Comentários finais", constitui a última parte do trabalho e expõe uma comparação entre os resultados numéricos e experimentais, considerações finais e sugestões para futuros trabalhos relacionados. 


\section{REVISÃO BIBLIOGRÁFICA}

Nesse capítulo procurou-se apresentar as pesquisas encontradas que são diretamente relacionadas com o presente trabalho. Os estudos estão divididos em aerodinâmica externa veicular em geral e publicações sobre veículos de milhagem.

\subsection{Aerodinâmica externa veicular}

Angelo et al. (2009) estudaram numericamente a influência dos elementos interiores à caixa de roda na aerodinâmica de um veículo de passeio. Para tal os autores utilizaram um modelo de um quarto da geometria do automóvel (apenas a região frontal próxima à roda dianteira esquerda) e um domínio de cálculo próximo a essa geometria. Eles concluíram que a maior parcela da força arrasto é proveniente da carroceria, como esperavam, e que pneu, roda e caixa de roda representaram juntos $16.3 \%$ dessa força. Entretanto os autores observaram que os elementos internos à caixa de roda representaram apenas $0.4 \%$ da resistência ao escoamento. Não fizeram um estudo sobre a influência da parte traseira da geometria do veículo nesses resultados.

Buscariolo (2009) realizou a simulação numérica para avaliar os efeitos de diferentes tipos de piso de tuneis de vento no coeficiente de arrasto de uma caminhonete pequena. $\mathrm{O}$ autor testou três tamanhos de elementos triangulares na superfície do veículo: 5, 10 e $20 \mathrm{~mm}$, obteve praticamente os mesmos resultados com os dois primeiros e por questão de velocidade de processamento decidiu usar $10 \mathrm{~mm}$. Buscariolo (2009, p. 69) utilizou 7 camadas de prismas na superfície da caminhonete, mas não especificou o tamanho ou método de geração. O modelo do veículo contempla detalhes da geometria do motor. A malha escolhida tem 8.3 milhões de elementos (tetraedros e prismas) e demorou aproximadamente $15.5 \mathrm{~h}$ para rodar 3300 iterações em 32 processadores. Os tipos de piso testados foram: estático (como o túnel 
de vento utilizado no teste experimental), plataforma elevada e esteira rolante. Uma diferença de apenas $0.25 \%$ entre o coeficiente de arrasto medido experimentalmente e a simulação com o piso estático foi obtida validando assim o modelo. Tanto com a plataforma elevada quanto com a esteira rolante o coeficiente de arrasto diminuiu em relação ao piso estático, sendo o decréscimo mais significativo para o segundo caso.

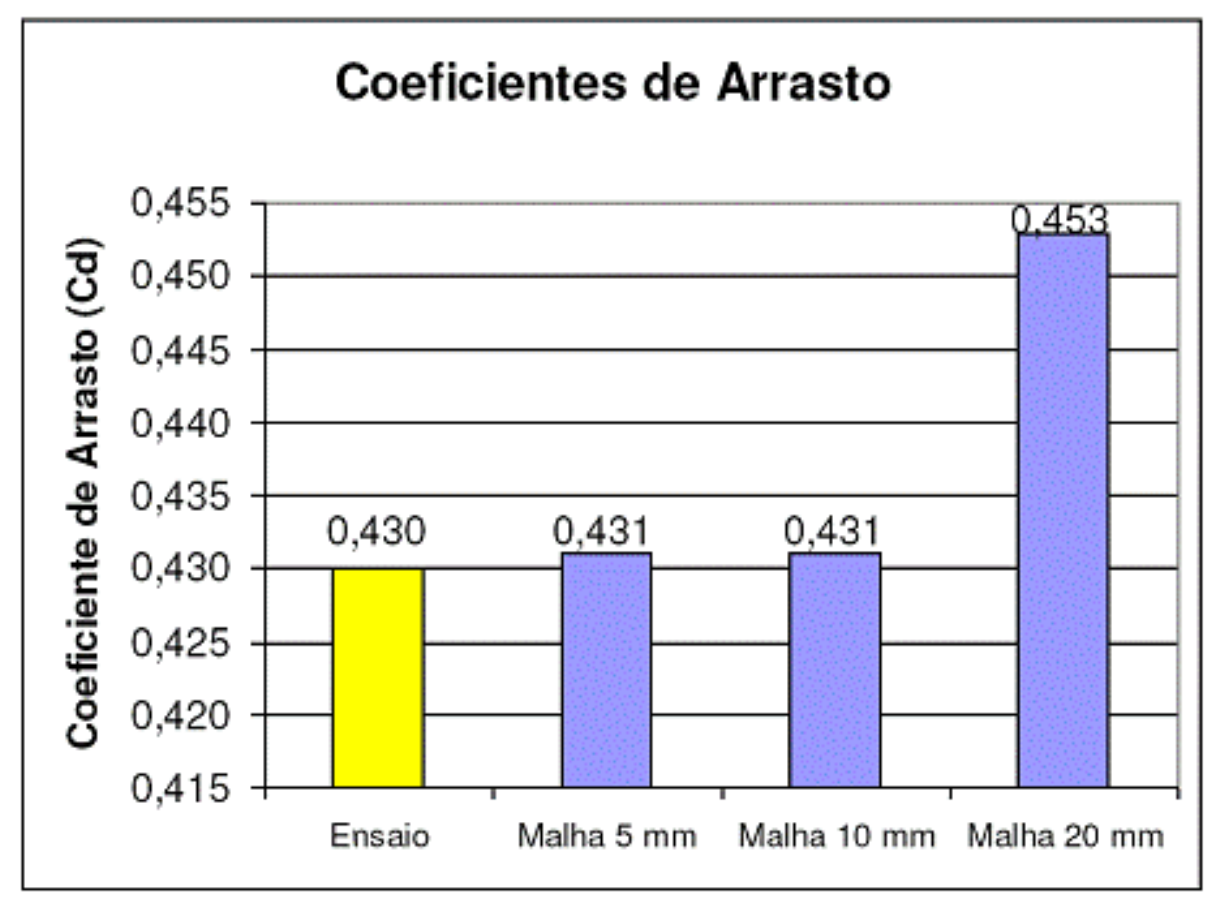

Figura 2-1: Resultados dos coeficientes de arrasto em função do tamanho da aresta dos triângulos na superfície do veículo obtidos por Buscariolo (2009, p. 78). 


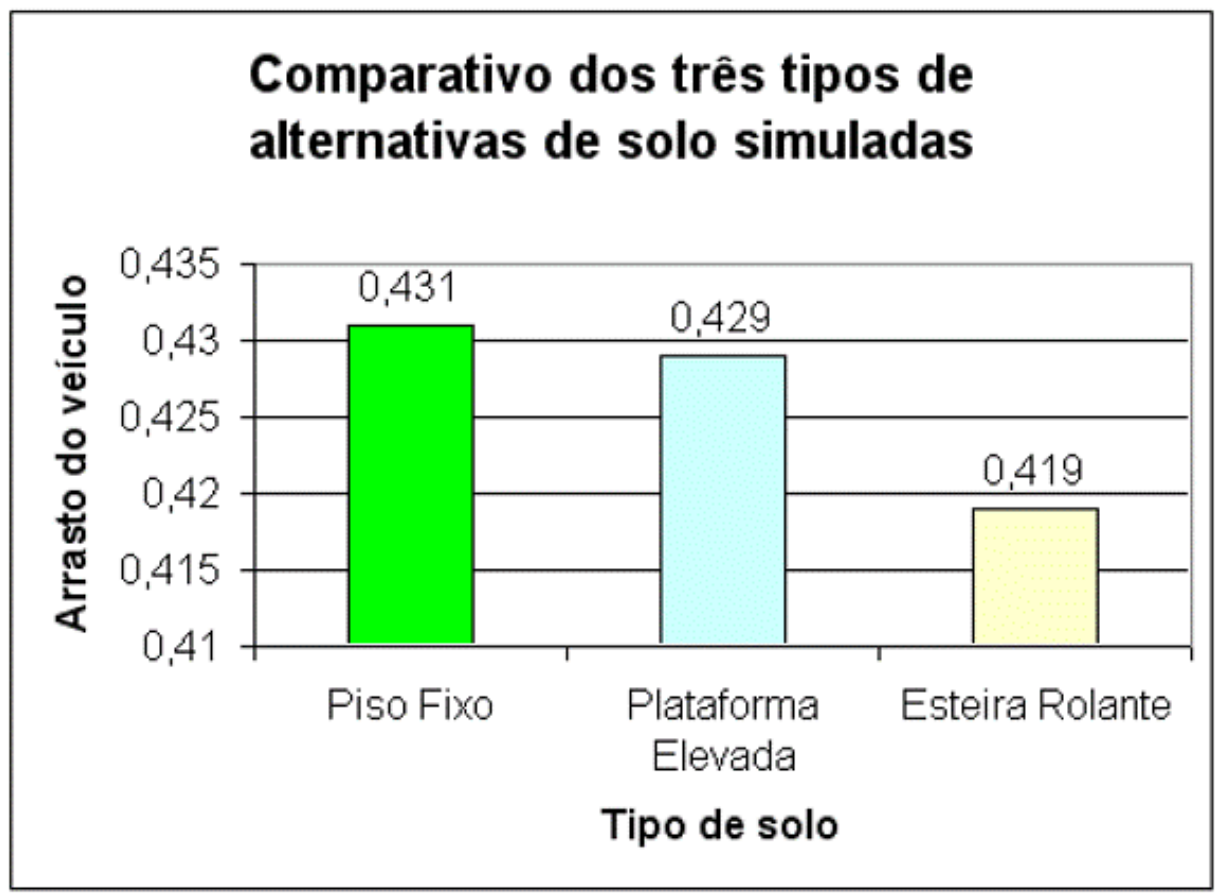

Figura 2-2: Resultados do coeficiente de arrasto em função do tipo de piso do túnel de vento utilizado nas simulações realizadas por Buscariolo (2009, p. 105).

Carregari (2006) fez simulações numéricas e estudos experimentais de um modelo de um ônibus de passageiro com o objetivo de investigar a variação do coeficiente de arrasto e da força lateral com o ângulo de guinada $\beta$, além do perfil de pressão na superfície do veículo. Os testes experimentais foram realizados num túnel de vento com o piso estático com um modelo em escala de 1:17.5 com dimensões de comprimento, altura e largura respectivamente de $755 \mathrm{~mm}, 208 \mathrm{~mm}$ e $155 \mathrm{~mm}$. O pesquisador estudou também o efeito da camada limite formada pelo piso estático do túnel de vento, calculou sua espessura com a equação de Blasius e obteve $2.53 \mathrm{~mm}$ como resultado. Para garantir que a camada limite não influenciaria o autor elevou o modelo $10 \mathrm{~mm}$ em relação ao piso. Carregari (2006, p. 63) não observou variação significativa nos resultados entre o modelo encostado no chão e elevado, contrariando referências que cita. Ele variou o ângulo $\beta$ entre $-10^{\circ}$ e $10^{\circ}$ com um passo de $2^{\circ}$, fez 5 séries de medições em cada ângulo e tirou a média delas, gerando as curvas representadas na Figura 2-3 e na Figura 2-4. As diferenças entre os resultados numéricos e experimentais obtidos nessas curvas foram atribuídas à discretização da malha, modelo de 
turbulência, ausência de perturbações externas e incertezas nas medições experimentais. No decorrer das análises Carregari (2006, p. 61) percebeu que o modelo não estava perfeitamente alinhado com o escoamento, o que explica a defasagem em $2^{\circ}$ entre a curva experimental e a computacional.

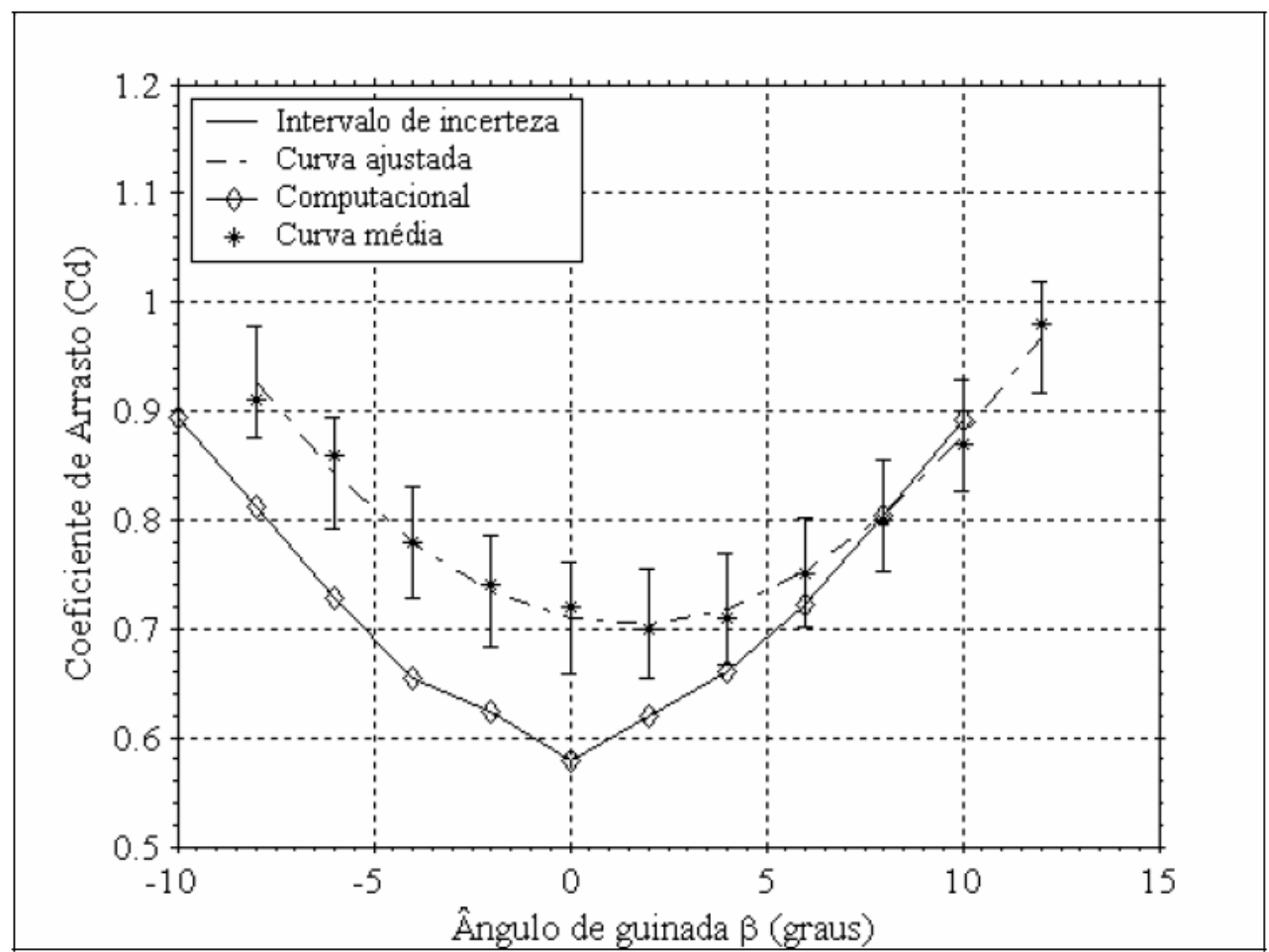

Figura 2-3: Resultados numéricos e experimentais dos coeficientes de arrasto em função do ângulo de guinada, com o veículo encostado no piso, obtidos por Carregari (2006, p. 62)

Entretanto, os resultados computacionais e experimentais do coeficiente de força lateral e do perfil de pressões na superfície do veículo concordaram melhor que os de coeficiente de arrasto. 


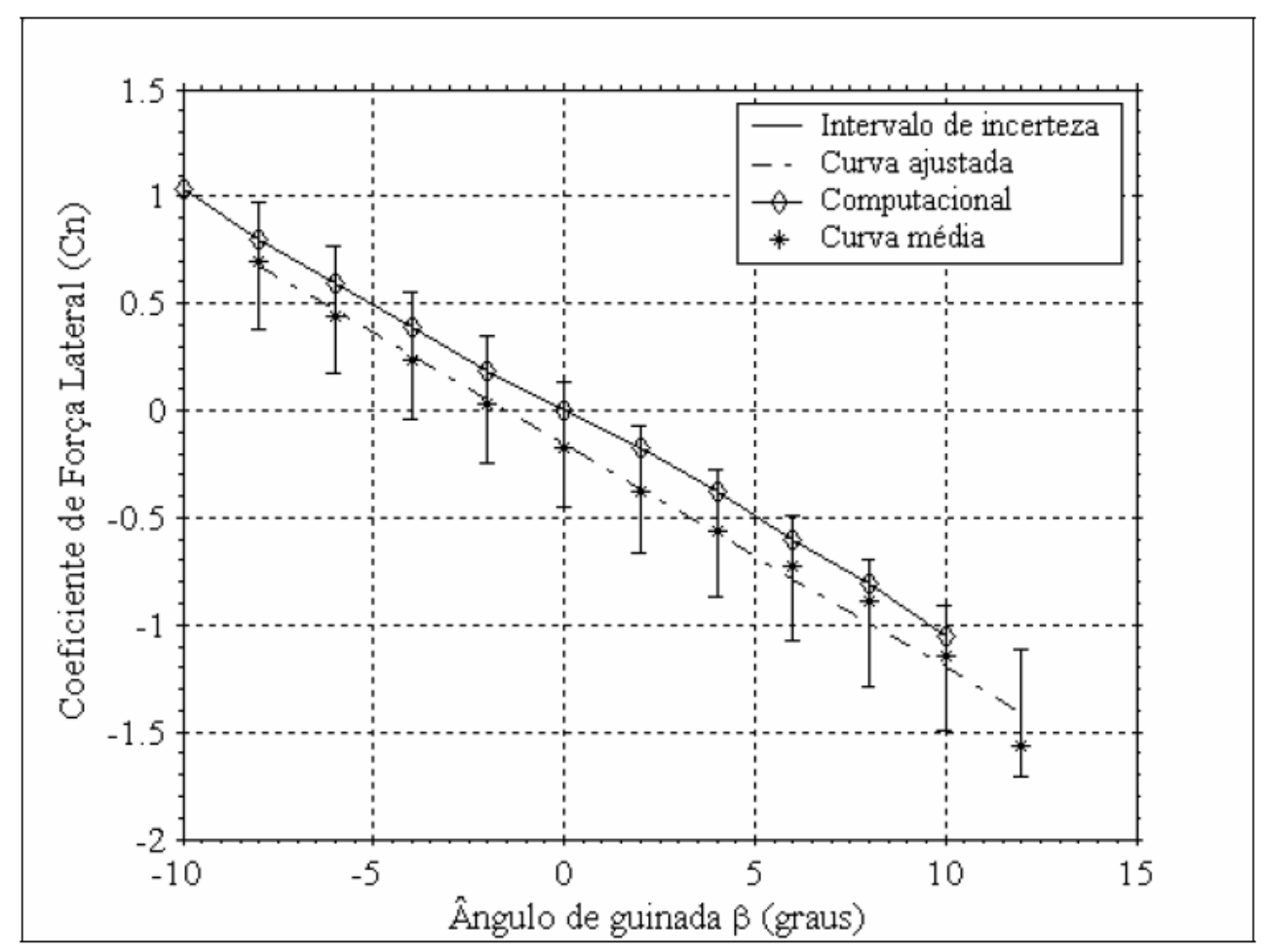

Figura 2-4: Resultados numéricos e experimentais dos coeficientes de força lateral em função do ângulo de guinada, com o veículo encostado no piso, obtidos por Carregari (2006, p. 65)

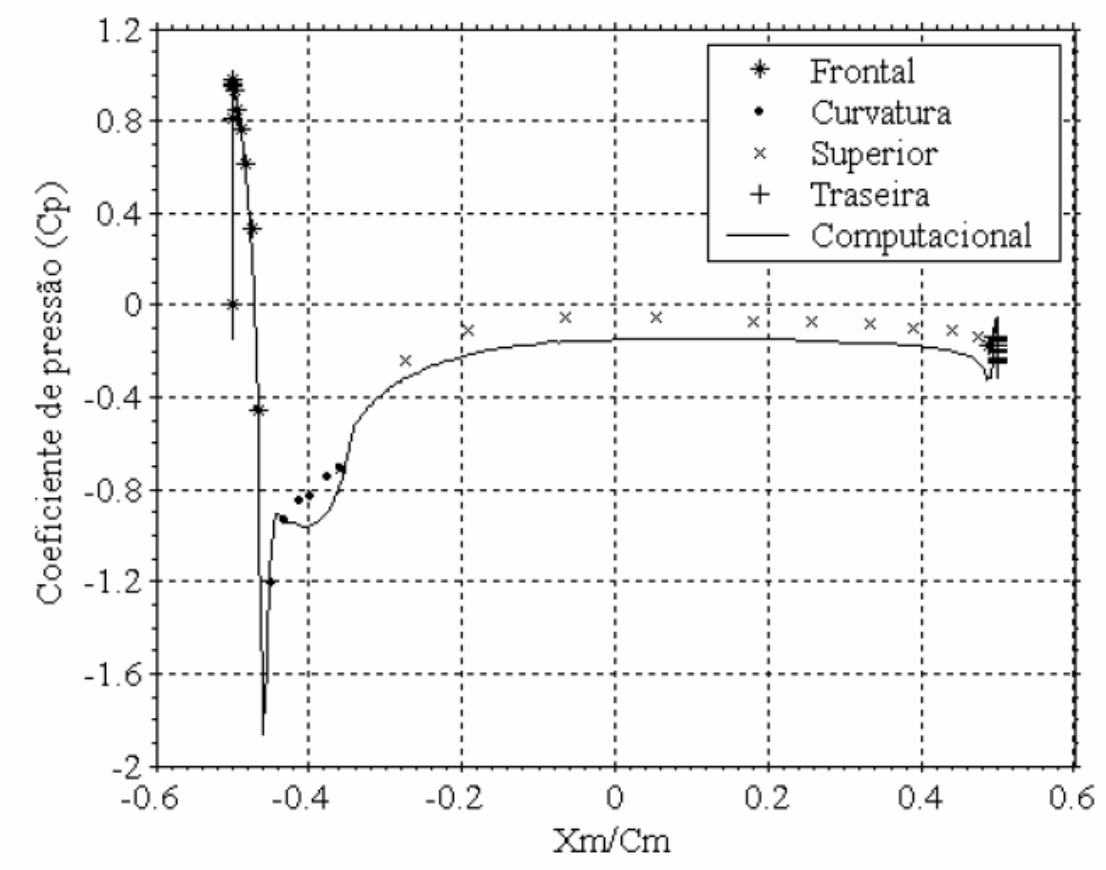

Figura 2-5: Resultados numéricos e experimentais dos coeficientes de pressão, com $\beta=0^{\circ}$, obtidos por Carregari (2006, p. 81) 
Além disso, Carregari (2006, p. 67) realizou testes experimentais de visualização do escoamento com o auxílio de fios de lã ("tufs") e de um composto de dióxido de titânio e pode identificar zonas de separação e recirculação.

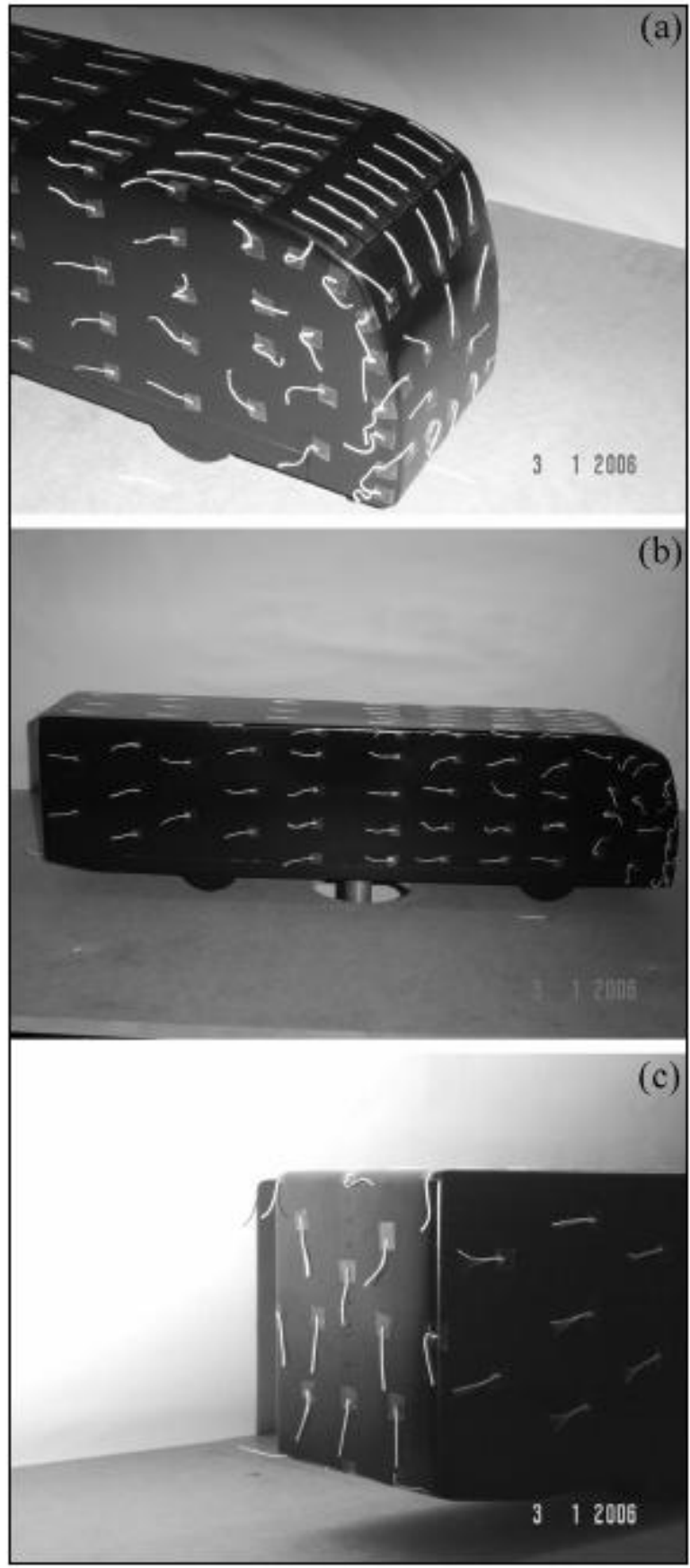

Figura 2-6: Visualização do escoamento obtida por fios de lã (“tufs") realizada por Carregari (2006, p. 69) para $\beta=0^{\circ}$. 


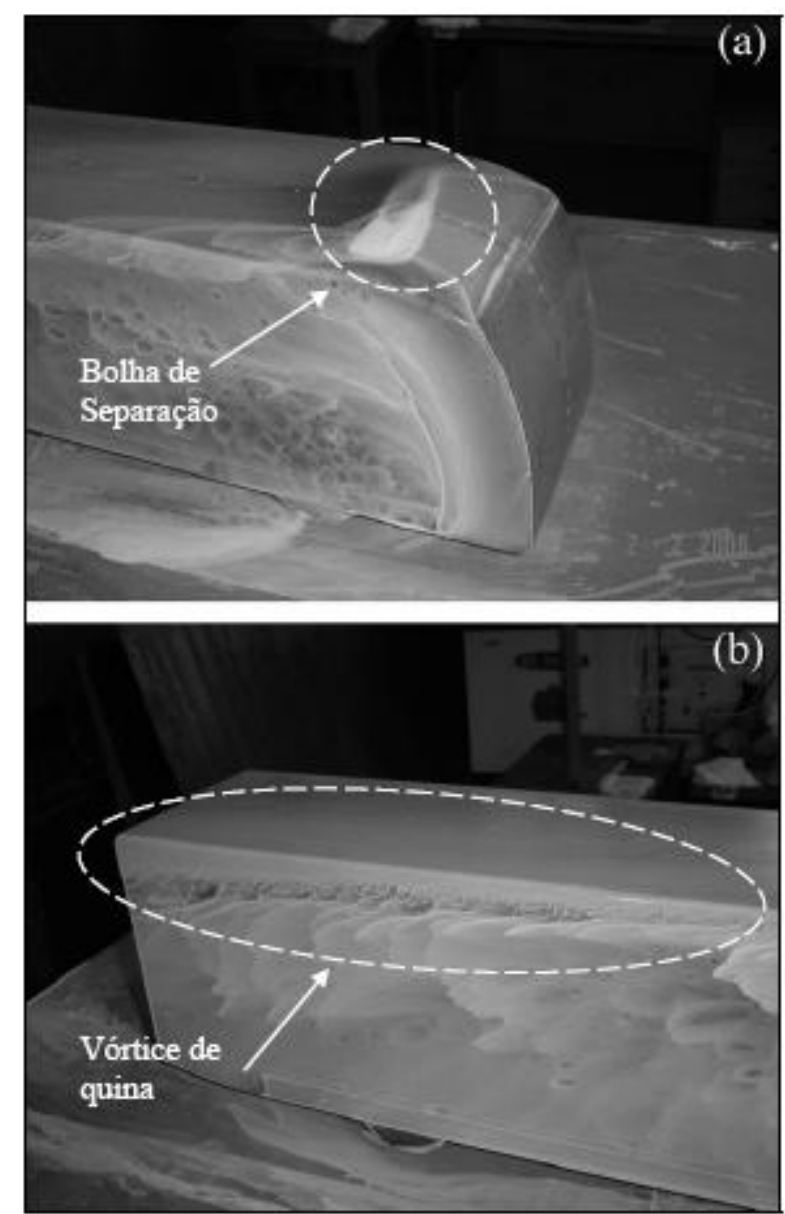

Figura 2-7: Visualização do escoamento obtida com um composto de dióxido de titânio, para $\beta=0^{\circ}$ realizada por Carregari (2006, p. 73).

Korkischko (2006) realizou testes experimentais e simulações numéricas do escoamento ao redor do modelo automobilístico corpo de Ahmed. Os testes foram realizados num canal de água circulante com um modelo numa escala de $36 \%$ do original. Desses testes foram obtidos o coeficiente de arrasto (corrigido para eliminar o efeito de blocagem do canal) e a visualização do escoamento através de velocimetria por imagens de partículas (conhecida também pela sigla em inglês PIV - Particle Image Velocimetry). Nas simulações numéricas o autor comparou os resultados quando empregados três diferentes modelos de turbulência: k- $\omega$ padrão, k- $\omega$ SST e Spalart-Allmaras no software Ansys Fluent. Um domínio de dimensões 12L x 4L x 3L (comprimento x largura $x$ altura) foi utilizado, com L sendo o comprimento do corpo de Ahmed igual a $1044 \mathrm{~mm}$, e o posicionou elevado a $50 \mathrm{~mm}$ do piso. O modelo numérico possuía somente elementos tetraédricos que totalizaram aproximadamente 1,5 
milhão. Também foram comparadas as parcelas do arrasto devido à pressão e à viscosidade obtidas por Ahmed com os modelos de turbulência. Os resultados do coeficiente de arrasto são apresentados na Tabela 2-1 e da decomposição dessa força na Tabela 2-2.

Tabela 2-1: Compilação dos resultados obtidos por Korkischko (2006) para os coeficientes de arrasto do Corpo de Ahmed

\begin{tabular}{c|c|c|c|c}
$\begin{array}{c}\text { Ahmed } \\
\text { (Referência) }\end{array}$ & Experimental & k-w padrão & k-w SST & $\begin{array}{c}\text { Spalart- } \\
\text { Allmaras }\end{array}$ \\
\hline 0.378 & 0.383 & 1.618 & 0.384 & 0.404
\end{tabular}

Tabela 2-2: Decomposição do arrasto em parcelas devido à pressão e à viscosidade obtida por Korkischko (2006,

\begin{tabular}{c|c|c|c|c} 
& Ahmed & k-w padrão & k-w SST & $\begin{array}{c}\text { Spalart- } \\
\text { Allmaras }\end{array}$ \\
\hline Pressão & 85 & 94.7 & 86.6 & 84.1 \\
\hline Viscosidade & 15 & 5.3 & 13.4 & 15.9
\end{tabular}

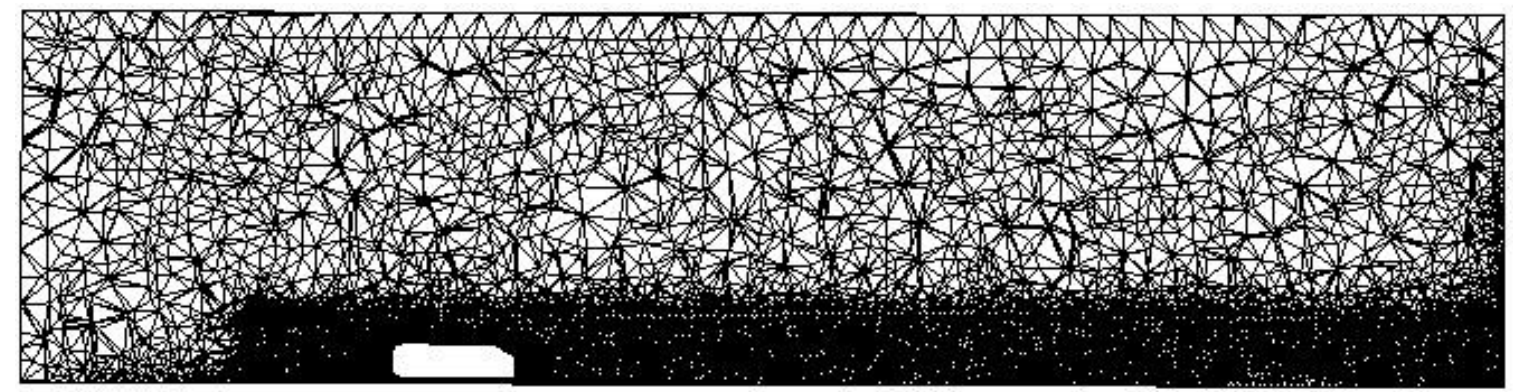

Figura 2-8: Domínio numérico utilizado por Korkischko (2006, p. 75)

\subsection{Veículos de milhagem}

Gagnon e Richard (2010) realizaram a simulação numérica do veículo de supermilhagem da Universidade de Laval, Canadá (equipe Alérion). Softwares do pacote OpenFOAM foram usados para a geração de malha e resolução das equações, e o ParaView para a visualização do escoamento. Foram testadas sete diferentes geometrias (uma de referência e seis variações) e a validação foi feita utilizando a simulação do corpo de Ahmed. O modelo foi elevado a 30 mm do solo (GAGNON, 2010). Como condição de contorno foi imposta uma velocidade de 9 
m/s na entrada do domínio e uma pressão relativa de 0 Pa na saída. Os autores concluíram que não há diferença em utilizar no piso uma condição de parede com escorregamento ou móvel com a mesma velocidade do fluido. O modelo de turbulência utilizado foi o k- $\omega$ SST e obtiveram forças de arrasto entre $1,2 \mathrm{~N}$ e $2,0 \mathrm{~N}$ para as diferentes geometrias. Foi feita também a simulação do veículo (geometria de referência) realizando uma curva, com um ângulo de guinada de $15^{\circ}$, e a força de arrasto obtida foi de $3,7 \mathrm{~N}$, o que demonstrou um aumento significativo frente ao 1,2 $\mathrm{N}$ obtidos anteriormente.

\begin{tabular}{c|cccc}
\multicolumn{5}{c}{ Tabela 2-3: Resultados obtidos por Gagnon e Richard (2010) } \\
Shape & $\begin{array}{c}\text { Pressure Drag } \\
{[\mathbf{N}]}\end{array}$ & $\begin{array}{c}\text { Friction Drag } \\
{[\mathbf{N}]}\end{array}$ & $\begin{array}{c}\text { Drag } \\
{[\mathbf{N}]}\end{array}$ & $\begin{array}{c}\text { Lift } \\
{[\mathbf{N}]}\end{array}$ \\
\hline $\mathbf{R e f}$. & 0.772 & 0.464 & 1.236 & -7.520 \\
$\mathbf{1}$ & 1.026 & 0.480 & 1.506 & -5.278 \\
$\mathbf{2}$ & 1.087 & 0.650 & 1.737 & -8.877 \\
$\mathbf{3}$ & 1.421 & 0.488 & 1.909 & -10.659 \\
$\mathbf{4}$ & 0.906 & 0.469 & 1.375 & -4.703 \\
$\mathbf{5}$ & 0.879 & 0.49 & 1.369 & -4.730 \\
$\mathbf{6}$ & 0.750 & 0.637 & 1.387 & -4.138
\end{tabular}




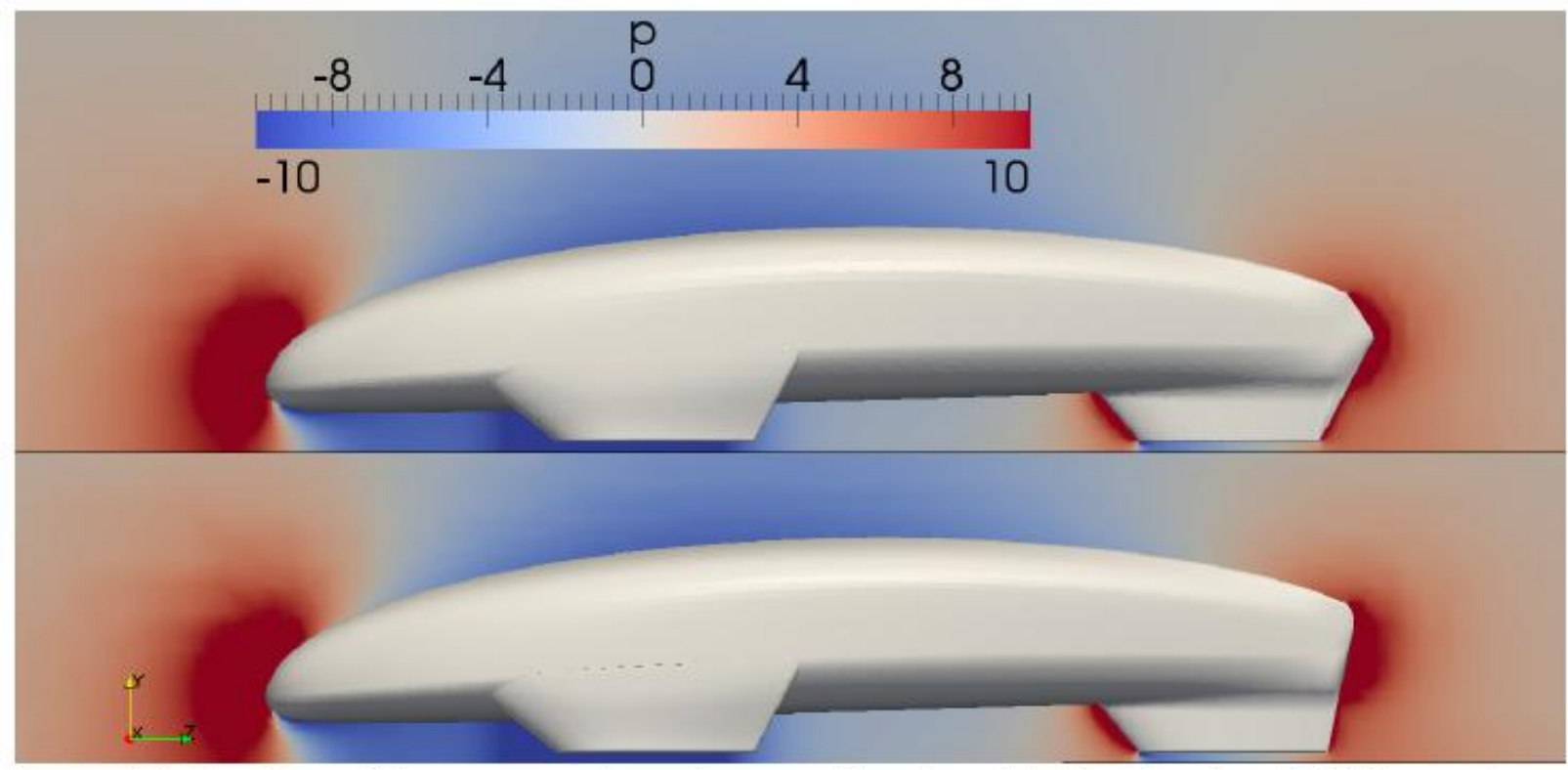

Figura 2-9: Resultados de pressão no plano central do modelo de Gagnon e Richard (2010) para as geometrias 6 (acima) e 5 (abaixo). Escoamento da esquerda para a direita.

Burban, Hegna e Zvodney (2008) falam sobre os benefícios de se adotar ferramentas de CFD num projeto de graduação de um veículo de supermilhagem. Descrevem que na Universidade de Cerderville, Ohio, os alunos participantes do projeto tem seu primeiro contato com CFD realizando a simulação do perfil de asa Clark Y 14 e validando com testes experimentais realizado no ano anterior do curso. Nesse processo utilizaram o Ansys Fluent e

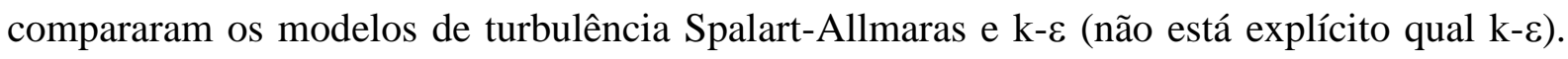
Com essa etapa concluída passaram à análise do veículo, e utilizaram o Solidworks para a construção da geometria e o Flowizard para a geração de malha e resolução das equações. Duas geometrias foram comparadas: uma com a região traseira do veículo convergindo para um ponto, como o formato de uma gota, e outra com a traseira em aresta. Os autores fizeram modelos em escala para testes em túnel de vento, mas não foi possível atingir o número de Reynolds das condições de competição, então realizaram análises de CFD. A correlação obtida foi melhor para a traseira em aresta, mas a equipe decidiu usar a forma de gota e que a decisão da forma do modelo seria baseada em outros fatores. Foi realizada também, somente através de simulação a comparação entre os projetos com as rodas dentro ou fora do veículo. 
Um melhor resultado foi obtido com as rodas fora, com um coeficiente de arrasto e uma área frontal menores. Todas as simulações foram realizadas com o modelo suspenso, sem ligação com o solo. Os alunos estudaram como essa altura de elevação afeta o arrasto e concluíram que quanto mais longe do solo menor a resistência do ar ao movimento, devido à simetria da região inferior do veículo.
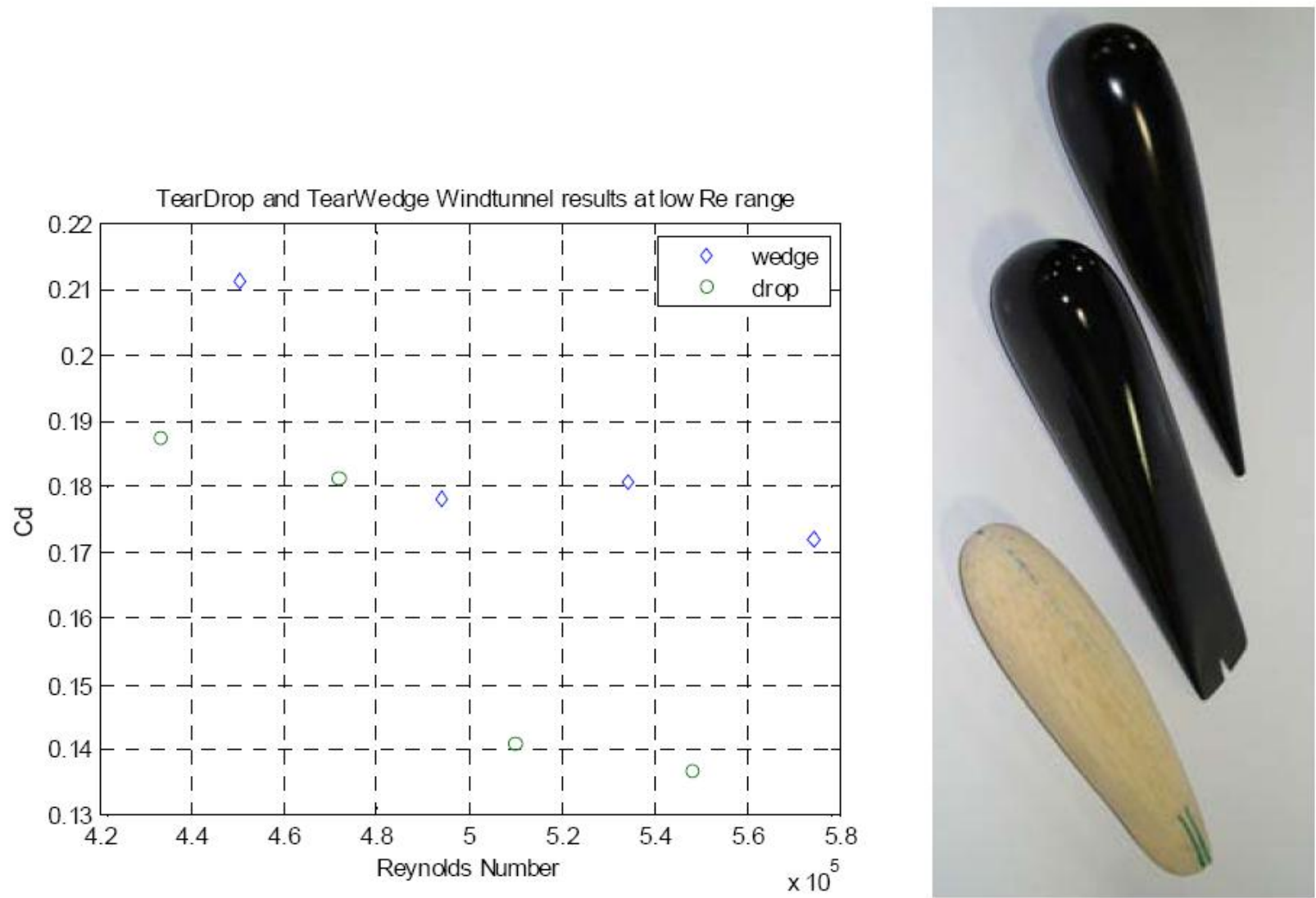

Figura 2-10: Coeficiente de arrasto em função do número de Reynolds e geometrias testadas experimentalmente por Burban, Hegna e Zvodney (2008), velocidades de 4 a $5 \mathrm{mph}$. 


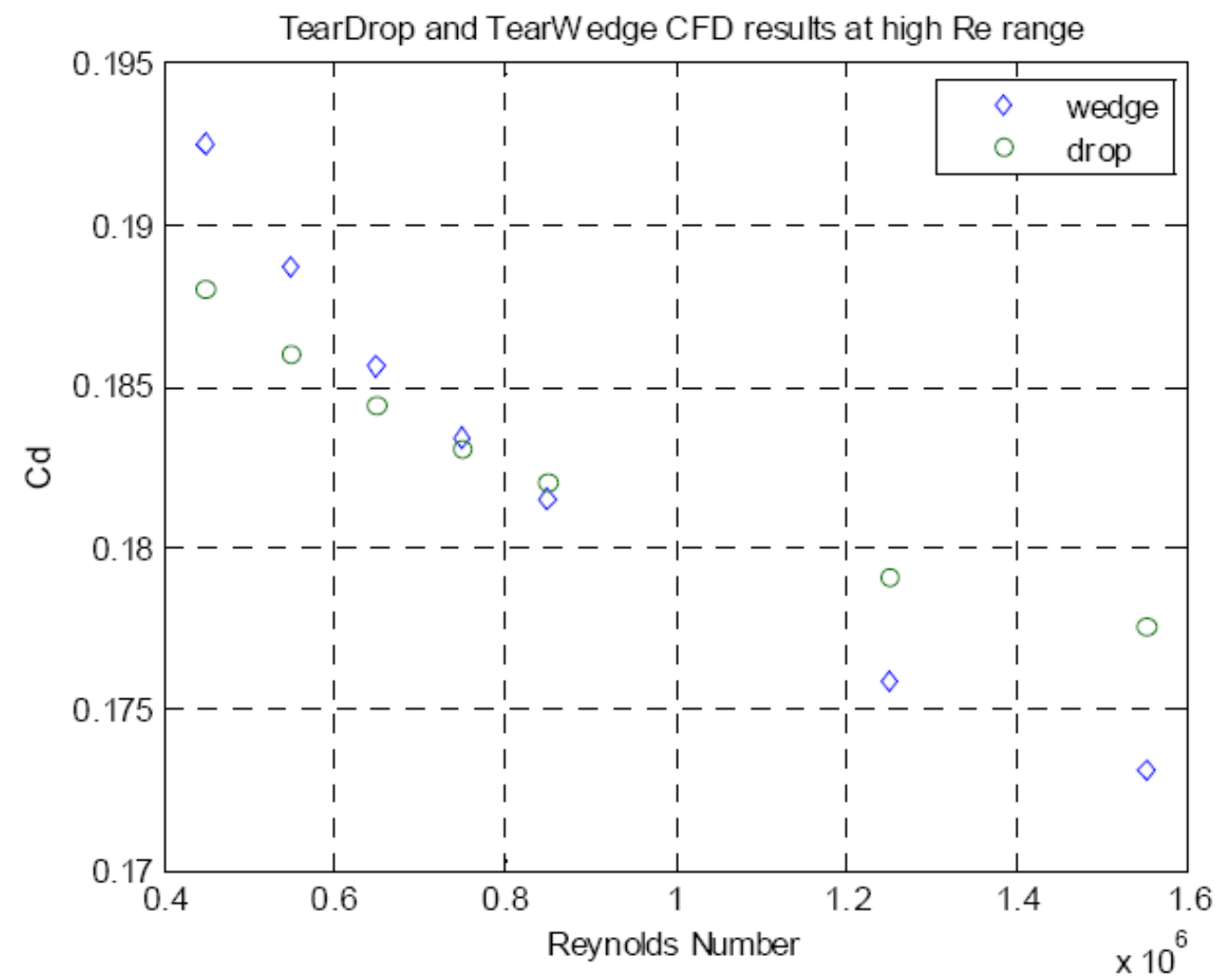

Figura 2-11: Coeficiente de arrasto em função do número de Reynolds obtidos através de simulação por Burban, Hegna e Zvodney (2008), velocidades de 5 a $15 \mathrm{mph}$.

Tabela 2-4: Variação do coeficiente de arrasto em função da altura do modelo do piso e da velocidade obtida por

\begin{tabular}{|c|c|c|}
\hline $\begin{array}{c}\text { Burban, He } \\
\text { Ground } \\
\text { Clearance } \\
\text { [in] }\end{array}$ & Cd & $\begin{array}{c}\text { y (2008). } \\
\text { Velocity } \\
\text { [mph] }\end{array}$ \\
\hline 0.855 & 0.234 & 15 \\
\hline 0.855 & 0.624 & 25 \\
\hline 4.970 & 0.223 & 15 \\
\hline 19.660 & 0.147 & 15 \\
\hline
\end{tabular}




\section{ESCOAMENTOS EXTERNOS}

\subsection{Introdução aos escoamentos externos}

Escoamentos externos são aqueles nos quais o corpo que é objeto de estudo está completamente imerso no fluido. A importância desse tipo de estudo envolve várias aplicações, desde o porquê dos vários "rebaixos" numa bola de golfe, da quilha de uma prancha de surf até o perfil de asa em aviões e formatos de carros de passeio. Mais especificamente tratando-se de veículos, as forças aerodinâmicas exercem um papel fundamental no consumo de combustível, e nas características de mobilidade, conseqüentemente obtendo um uso mais racional dos recursos naturais, além de garantir a segurança dos ocupantes quando se depararem com situações onde essas forças afetam significantemente a dirigibilidade.

Como em outras áreas da mecânica dos fluidos, as abordagens teórica e experimental são utilizadas para a obtenção das forças resultantes do escoamento do fluido ao redor do corpo imerso. As técnicas teóricas e analíticas fornecem muitas informações, mas devido à complexidade das equações que descrevem o fenômeno elas ainda são insuficientes para uma análise mais completa sendo ainda necessário o auxílio de técnicas computacionais. Uma grande fonte de informações sobre escoamentos externos são obtidas experimentalmente em túneis de vento, tanques de prova e canais de água como o utilizado nesse trabalho. (MUNSON et al., 2004, p. 481).

A interação entre um corpo imerso e o fluido em movimento resulta numa força atuante no corpo. O importante é o movimento relativo entre o fluido e o corpo, não importa qual dos dois está parado ou em movimento. Normalmente se considera um sistema de coordenadas fixo no objeto e o fluido escoando com velocidade ao longe U. Muitas vezes 
efeitos transientes e não-uniformidades no escoamento muitas vezes não são importantes em escoamentos externos (MUNSON et al., 2004, p. 481 - 482).

Como escoamentos externos são dependentes do formato do objeto imerso, uma classificação desse fenômeno se baseia na forma do modelo. Normalmente corpos esbeltos, como por exemplo uma gota ou perfis de asa, perturbam menos o fluxo na comparação com corpos rombudos, como cilindros e automóveis de passeio (MUNSON et al., 2004, p. 482). O projeto de um veículo de milhagem deve ter como premissa uma carenagem que perturbe menos possível o escoamento, aproximando-se de um corpo esbelto.

\subsection{Arrasto e sustentação}

Quando há movimento relativo entre um fluido e um corpo existem também forças que atuam na interface fluido-corpo. Essas forças são a tensão de cisalhamento na parede, $\tau_{\mathrm{p}}$, originada de efeitos viscosos, e a tensão normal, causada pela pressão, p, e em alguns casos por uma

parcela do cisalhamento. É de grande valor saber as distribuições de pressão e de tensão de cisalhamento, entretanto essas informação são extremamente difíceis de serem conseguidas na maioria dos problemas práticos, e nesses casos apenas os efeitos globais são necessários para sua resolução (MUNSON et al., 2004, p. 483).

Para um melhor entendimento da interação fluido-corpo o carregamento aerodinâmico é decomposto em duas principais forças: o arrasto, $\mathrm{F}_{\mathrm{D}}$ (drag, da tradução do inglês), que atua na direção paralela ao escoamento principal, e a sustentação, $\mathrm{F}_{\mathrm{L}}$ (lift, da tradução do inglês) que age na direção perpendicular ao fluxo. Em alguns corpos tridimensionais também é detectada uma força perpendicular ao plano onde $F_{D}$ e $F_{L}$ estão contidas (MUNSON et al., 2004, p. 483). Entretanto devido à simetria do veículo em estudo no presente trabalho essa força é desprezada e não será explicitada nessa teoria. 
A forma teórica de se obter as forças de arrasto e sustentação é com a integração das tensões de cisalhamento e normais na superfície do corpo em estudo. As componentes $\mathrm{x}$ (arrasto) e z (sustentação) da força que atua num elemento infinitesimal de área dA são (MUNSON et al., 2004, p. 483):

$$
\begin{gathered}
\mathrm{dF}_{\mathrm{x}}=(\mathrm{pdA}) \cos \varphi+\left(\tau_{\mathrm{p}} \mathrm{dA}\right) \sin \varphi \\
\mathrm{dF}_{\mathrm{z}}=-(\mathrm{pdA}) \sin \varphi+\left(\tau_{\mathrm{p}} \mathrm{dA}\right) \cos \varphi
\end{gathered}
$$

Deste modo, os módulos das forças $\mathrm{F}_{\mathrm{D}}$ e $\mathrm{F}_{\mathrm{L}}$ que atuam no corpo são:

$$
\begin{aligned}
& \mathrm{F}_{\mathrm{D}}=\int \mathrm{dF}_{\mathrm{x}}=\int \mathrm{p} \cos \varphi \cdot \mathrm{dA}+\int \tau_{\mathrm{p}} \sin \varphi \cdot \mathrm{dA} \\
& \mathrm{F}_{\mathrm{L}}=\int \mathrm{dF}_{\mathrm{z}}=-\int \mathrm{p} \sin \varphi \cdot \mathrm{dA}+\int \tau_{\mathrm{p}} \cos \varphi \cdot \mathrm{dA}
\end{aligned}
$$

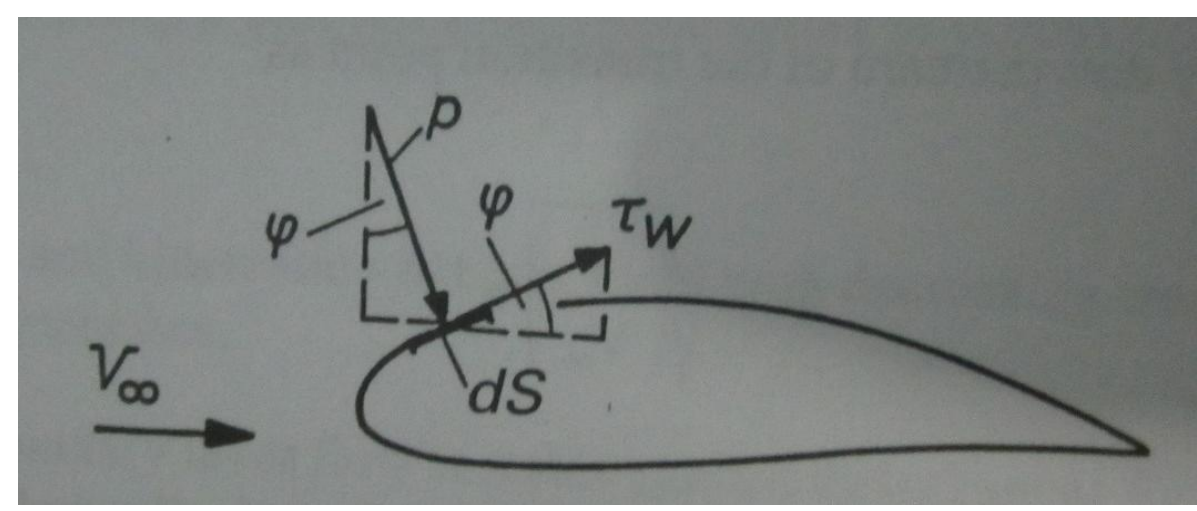

Figura 3-1: Forças de pressão $(\mathrm{p})$ e cisalhamento $\left(\tau_{\mathrm{W}}\right)$ num elemento de área infinitesimal (dS) localizado na superfície de um corpo imerso (HUCHO, 1998, p. 68).

Para calcular o arrasto e a sustentação de forma teórica é necessário resolver as integrais das Equações ( 3-3 ) e ( 3-4 ), onde é necessário o conhecimento do formato do 
modelo e também de $\tau_{\mathrm{p}}$ e p como função da geometria do corpo, o que é muito difícil de se conseguir tanto de forma experimental como teórica. Assim uma forma de se resolver esse problema é definir coeficientes adimensionais de arrasto e sustentação que englobam os efeitos das tensões normais e de cisalhamento, que podem ser obtidos de forma experimental ou numérica. Os coeficientes de arrasto, $\mathrm{C}_{\mathrm{D}}$, e de sustentação, $\mathrm{C}_{\mathrm{L}}$, são definidos por (MUNSON et al., 2004, p. 486):

$$
\begin{aligned}
& C_{D}=\frac{F_{D}}{\frac{1}{2} \cdot \rho \cdot A \cdot v^{2}} \\
& C_{L}=\frac{F_{L}}{\frac{1}{2} \cdot \rho \cdot A \cdot v^{2}}
\end{aligned}
$$

onde: $F_{D}$ - força de arrasto $[N], F_{L}$ - força de sustentação $[N], \rho$ - massa específica do fluido $\left[\mathrm{kg} / \mathrm{m}^{3}\right], \mathrm{v}$ - velocidade do escoamento $[\mathrm{m} / \mathrm{s}]$ e A - área frontal do objeto projetada num plano perpendicular ao escoamento $\left[\mathrm{m}^{2}\right]$.

A Figura 3-2 representa a definição de área frontal projetada para o caso de um veículo de passeio. 


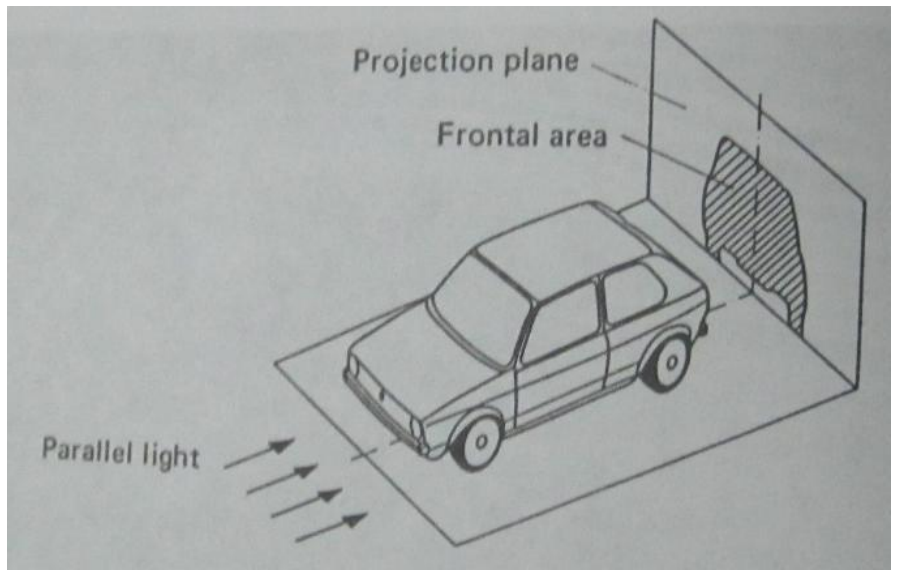

Figura 3-2: Definição de área frontal projetada (HUCHO, 1998, p. 4).

\subsection{Força de arrasto}

Nos raros casos como, por exemplo, de uma placa plana paralela ao escoamento, onde a distribuição de pressão, p, e a tensão de cisalhamento, $\tau_{\mathrm{p}}$, em função da geometria do corpo são conhecidas a força de arrasto pode ser obtida com a equação ( 3-3 ).

Atualmente, a mecânica dos fluidos computacional tem fornecido bons resultados para o arrasto em geometrias complexas (HUCHO, 1998, p. 132). Segundo Munson et al. (2004, p. 516) a maior parte das informações relacionadas ao arrasto em objetos é resultado de vários experimentos realizados em túneis de vento, canais de água, tanques de prova dentre outros equipamentos. Assim,

$$
\mathrm{C}_{\mathrm{D}}=(\text { forma, } \mathrm{Re}, \mathrm{Ma}, \mathrm{Fr}, \varepsilon / 1)
$$

\subsubsection{Arrasto devido ao atrito}

A porção da força de arrasto devido à tensão de cisalhamento $\left(\tau_{\mathrm{p}}\right)$ é o arrasto devido ao atrito, $\mathrm{F}_{\mathrm{Df}}$. Tomando a equação ( 3-3 ) nota-se que o arrasto por atrito depende da distribuição de $\tau_{\mathrm{p}}$, e também do formato do modelo. Geralmente a viscosidade dinâmica dos fluidos mais comuns é pequena, o que torna a força de arrasto devido ao atrito muitas vezes desprezível. 
Isso pode ser quantificado através do número de Reynolds, que usualmente é alto para escoamentos práticos (MUNSON et al., 2004, p. 516). No entanto, para corpos esbeltos ou para baixos números de Reynolds, onde há uma menor perturbação do campo de pressão na direção do escoamento, a maior parte do arrasto pode ser devida ao atrito

\subsubsection{Arrasto devido à pressão}

De acordo com Munson et al.( 2004, p. 518) o arrasto devido à pressão, F $\mathrm{D}_{\mathrm{Dp}}$, é a parcela dessa força provocada pela distribuição de pressão sobre o objeto. Por ser extremamente dependente da geometria do modelo, essa componente também é denominada arrasto de forma. $\mathrm{O}$ arrasto de pressão é definido pela primeira integral da equação ( 3-3 ) ( $\left.\int p \cos \varphi \cdot d A\right)$ e além da pressão, é função também da orientação da superfície.

\subsection{Força de sustentação}

A sustentação, $F_{L}$, é uma força normal à velocidade do fluido ao longe, provocada pela assimetria do escoamento. Essa assimetria pode ser devido à geometria do modelo imerso ou ao movimento do objeto como, por exemplo, uma esfera girando (MUNSON et al., 2004, p. 534).

No caso de automóveis, a sustentação tende a reduzir a força de contato entre os pneus e o solo, o que provaca redução de tração e capacidade de fazer curvas (MUNSON et al., 2004, p. 535). Nessa situação é desejável reduzir a sustentação, e em casos extremos, como veículos esportivos ou de competições de alta velocidade, o projeto do carro é tal que a sustentação é negativa.

De forma análoga à força de arrasto, se as distribuições de pressão e de tensão de cisalhamento na superfície do objeto em função da geometria do corpo são conhecidas, a 
sustentação pode ser calculada pela equação ( 3-4 ). Essa força é comumente representada pelo coeficiente de sustentação, $C_{L}$, equação ( 3-6 ). Da mesma forma que o coeficiente de arrasto, o coeficiente de sustentação depende de outros parâmetros adimensionais como os números de Reynolds (Re), Mach (Ma), Froude (Fr) e da rugosidade relativa da superfície, $\varepsilon / 1$ (MUNSON et al., 2004, p. 536)

$$
\mathrm{C}_{\mathrm{L}}=(\text { forma, } \mathrm{Re}, \mathrm{Ma}, \mathrm{Fr}, \varepsilon / 1)
$$

Segundo Munson et al. (2004, p. 536) o número de Froude, Fr, somente é relevante em casos com uma superfície livre. Ainda de acordo com esses autores a rugosidade superficial, $\varepsilon$, tem maior influência no arrasto do que na sustentação. Munson et al. (2004, p. 536) ainda dizem que o número de Mach, Ma, é relevante para escoamentos subsônicos $(\mathrm{Ma}>0.8)$ e supersônicos $(\mathrm{Ma}>1.0)$ e que o efeito do número de Reynolds, Re, geralmente não é tão decisivo. Os autores afirmam que parâmetro mais importante para o coeficiente de sustentação é a forma do objeto.

Para escoamentos com elevados número de Reynolds, onde os efeitos viscosos ficam confinados nas camadas limites e na esteira, a tensão de cisalhamento, $\tau_{\mathrm{p}}$, pouco influi na sustentação, que é em majoritariamente devido à distribuição de pressão na superfície. (MUNSON et al., 2004, p. 536). Em casos de escoamentos com número de Reynolds menores do que 1 as tensões viscosas se tornam tão importantes quanto a pressão para a sustentação (MUNSON et al., 2004, p. 536).

Entretanto a forma do objeto também influi na distribuição da sustentação entre pressão e forças cisalhantes, por exemplo, um guarda-chuva, aberto na posição vertical numa situação de vento de alta velocidade, vira devido à sustentação de origem viscosa, e não de pressão. 


\section{MÉTODOS NUMÉRICOS}

\subsection{Método dos Volumes Finitos}

Nesse capítulo são apresentados os conceitos teóricos envolvidos n na simulação com CFD e explicitadas as equações que são resolvidas pelo solver usado nessa dissertação, o Ansys Fluent versão 12.0.1. O programa utiliza o Método dos Volumes Finitos, que emprega diretamente a formulação integral das equações de conservação. O procedimento consiste em dividir o domínio de cálculo em volumes de controle, e calcular o balanço dos fluxos em cada uma de suas faces (BLAZEK, 2001, p. 37).

De acordo com Lomax et al. (1999, p. 71) o Método dos Volumes Finitos se popularizou como ferramenta de CFD por duas principais razões: a primeira é a garantia de que as quantidades, como massa, momento e energia se conservam de forma discreta. A segunda é o fato do método não necessitar de transformação de coordenadas para ser aplicado em malhas irregulares, e assim pode ser utilizado em malhas não estruturadas sem maiores dificuldades.

\subsection{Equações de conservação}

\section{Conservação de massa}

Aplicando-se o balanço de massa em um elemento fluido, representado na Figura 4-1, tem-se:

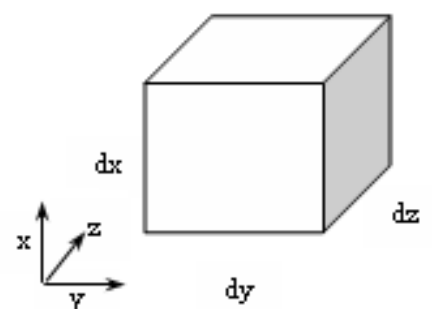

Figura 4-1: Exemplo de elemento fluido infinitesimal e suas coordenadas 


$$
\frac{\partial \rho}{\partial t}+\operatorname{div}(\rho \cdot \vec{u})=0
$$

Onde $\rho$ é a massa específica, t o tempo e $\overrightarrow{\mathrm{u}} \mathrm{o}$ vetor velocidade.

O primeiro termo representa a variação da densidade do fluido no tempo, enquanto o segundo termo é a massa que atravessa o contorno do elemento, é o termo convectivo.

\section{Conservação da Quantidade de Movimento}

A equação da quantidade de movimento é obtida com a aplicação da segunda lei de Newton num elemento infinitesimal:

$$
\frac{\partial}{\partial t}(\rho \vec{u})+\operatorname{div}(\rho \vec{u} \vec{u})=-\operatorname{grad} p+\operatorname{div}\left(\tau_{\text {eff }}\right)+\rho \vec{g}+\vec{F}
$$

Onde p é a pressão estática, $\tau_{\text {eff }}$ é o tensor das tensões devido à viscosidade efetiva (molecular e turbulenta), definido na equação ( $4-3$ ), $\overrightarrow{\mathrm{g}}$ é a aceleração gravitacional e $\overrightarrow{\mathrm{F}}$ representa as forças externas e quaisquer outros termos fontes como, por exemplo, meios porosos.

O primeiro termo é a variação quantidade de movimento no tempo. O segundo representa a variação da quantidade de movimento devido ao fluxo que atravessa o volume fluido (termo convectivo). $\mathrm{O}$ terceiro representa a força devido à pressão hidrostática. $\mathrm{O}$ quarto termo é o aumento da quantidade de movimento devido à transferência viscosa e o quinto termo representa as forças de campo e termos fontes. $\mathrm{O}$ tensor $\tau_{\text {eff }}$ é definido por: 


$$
\tau_{\text {eff }}=\left(\mu+\mu_{t}\right)\left(\frac{\partial u_{i}}{\partial x_{j}}+\frac{\partial u_{j}}{\partial x_{i}}\right)-\frac{2}{3} \rho k \delta_{i j}
$$

\subsection{Modelagem da turbulência}

Segundo Tennekes e Lumley (1972, p. 1) é muito difícil definir precisamente o que seja turbulência. Entretanto os autores dizem que é possível descrever algumas características comuns aos escoamentos turbulentos:

- Irregularidade: Os escoamentos turbulentos têm característica randômica, assim tratamentos estatísticos são realizados ao invés de determinísticos.

- Difusividade: A difusividade é responsável pela rápida mistura e aumento das taxas de transferência de quantidade de movimento, calor e massa nos fluxos turbulentos. Como conseqüência atrasa a separação do escoamento em fólios com um elevado ângulo de ataque, aumenta a troca de calor em vários tipos de equipamento e é uma fonte de resistência ao escoamento em dutos.

- Altos números de Reynolds: Turbulência sempre ocorre em elevados números de Reynolds, e está relacionada com a instabilidade do escoamento provocada pela interação dos termos viscosos e dos termos de inércia não lineares da equação de movimento.

- Flutuação tridimensional de vórtices: A turbulência é um fenômeno altamente rotacional e tridimensional, e caracterizado pela flutuação de vórtices.

- Dissipação: Escoamentos turbulentos são sempre dissipativos. A tensão viscosa cisalhante faz um trabalho de deformação, que aumenta a energia interna do fluido o que diminui a energia cinética da turbulência, que por sua vez necessita de uma contínua fonte de energia para manter suas características. 
- Contínuo: Turbulência é um fenômeno contínuo. Até mesmo as menores escalas são muito maiores do que um comprimento molecular.

- Escoamentos turbulentos são escoamentos: Turbulência é uma característica do escoamento e não do fluido.

A grande maioria dos escoamentos presentes na natureza e aplicações industriais é em regime turbulento. Segundo Ferreira (2006, p.13) por mais que a tecnologia computacional tenha avançado nos últimos anos, ainda não é possível discretizar os domínios dos modelos práticos de tal forma que o menor elemento da malha seja menor ou igual ao menor vórtice que dissipa sua energia de forma térmica, sem causar movimento nas partículas fluidas ao seu redor (escala de Kolmogorov) e dessa forma utilizar a simulação numérica direta (DNS Direct Numerical Simulation), detalhada em Wilcox (1994, p.318). Assim, são necessários modelos que tentem reproduzir a maneira randômica com a qual a turbulência influência nas propriedades do fluido, os chamados modelos de turbulência. Contudo ainda não existe um modelo geral, que produza bons resultados para as infinitas formas de um escoamento turbulento. Nesse contexto uma escolha equivocada do modelo utilizado para determinada aplicação pode resultar desde dificuldade na convergência, tempo de processamento extremamente elevado, ou mesmo resultados que não condizem com a realidade (FERREIRA, 2006 p.13).

De acordo com Wilcox (1994, p. 1) modelagem da turbulência, geração de malha e desenvolvimento de algoritmos de soluções de equações são os pilares da fluidodinâmica computacional. Ele destaca que, devido à complexidade do fenômeno, a modelagem da turbulência está menos desenvolvida em relação aos outros dois. O autor define que um modelo de turbulência ideal deve introduzir o mínimo possível de complexidade e ainda captar a essência relevante da física. 
Como citado anteriormente, o software utilizado para a resolução das equações foi o Ansys Fluent 12.0.1, então o equacionamento e a notação apresentados nos itens 4.3.1 a 4.3.8 foram retirados do guia teórico do programa, referenciado como Ansys Fluent, 2009. Nesses itens os modelos de turbulência utilizados no presente trabalho são definidos e suas equações apresentadas.

\subsubsection{Modelo Spalart-Allmaras}

O modelo Spalart-Allmaras faz parte da classe de modelos de uma equação: resolve a equação de transporte da viscosidade cinemática turbulenta. Esse tipo de equacionamento foi primeiramente proposto por Prandtl, que a época já tinha experiência o suficiente para generalizar aproximações do comprimento de escala turbulento (WILCOX, 1994, p. 77).

Spalart e Allmaras propuseram um modelo que resolve uma equação de transporte para uma viscosidade cinemática turbulenta modificada, $\tilde{v}$. Inicialmente essa formulação visava aplicações aeroespaciais, e foi pensada para escoamentos de camada limite com

$\mathrm{y}^{+} \approx 1$ (explicado melhor no item 4.3.9). Porém, no Ansys Fluent o modelo foi alterado para utilizar funções de parede nos locais onde a malha não capta a subcamada laminar (ANSYS FLUENT, 2009, p. 4-7).

Esse modelo, assim como os modelos k- $\varepsilon$ e k- $\omega$, emprega a aproximação de Boussinesq, que relaciona viscosidade cinemática turbulenta, gradientes de velocidade, tensões de Reynolds e energia cinética turbulenta. O Ansys Fluent (2009, p. 4-5) modela da seguinte maneira essa hipótese:

$$
-\rho \overline{u_{i}^{\prime} u_{j}^{\prime}}=\mu_{t}\left(\frac{\partial u_{i}}{\partial x_{j}}+\frac{\partial u_{j}}{\partial x_{i}}\right)-\frac{2}{3}\left(\rho k+\mu_{t} \frac{\partial u_{i}}{\partial x_{i}}\right) \delta_{i j}
$$


A equação de transporte da viscosidade cinemática turbulenta modificada, $\tilde{v}$, fica (ANSYS FLUENT, 2009, p. 4-7):

$$
\frac{\partial}{\partial \mathrm{t}}(\rho \tilde{v})+\frac{\partial}{\partial \mathrm{x}_{\mathrm{i}}}\left(\rho \tilde{v} u_{i}\right)=\frac{1}{\sigma_{\tilde{v}}}\left[\frac{\partial}{\partial \mathrm{x}_{\mathrm{j}}}\left\{(\mu+\rho \tilde{v}) \frac{\partial \tilde{v}}{\partial \mathrm{x}_{j}}\right\}+\mathrm{C}_{\mathrm{b} 2} \rho\left(\frac{\partial \tilde{v}}{\partial \mathrm{x}_{j}}\right)^{2}\right]+\mathrm{G}_{\mathrm{v}}-\mathrm{Y}_{\mathrm{v}}+\mathrm{S}_{\tilde{v}}
$$

Onde:

$\mathrm{G}_{v}$ : produção de viscosidade turbulenta;

$\mathrm{Y}_{v}$ :destruição da viscosidade turbulenta próxima à parede devido ao amortecimento viscoso;

$v$ : viscosidade cinética molecular;

$S_{v}$ : termo fonte definido pelo usuário:

$\sigma_{v}$ e $\mathrm{C}_{\mathrm{b} 2}$ : constantes.

A viscosidade turbulenta é dada por:

$$
\mu_{t}=\rho \tilde{v} f_{v 1}
$$

Onde:

$$
\mathrm{f}_{\mathrm{v} 1}=\frac{\chi^{3}}{\chi^{3}+\mathrm{C}_{\mathrm{v} 1}^{3}}
$$

Com $\mathrm{C}_{\mathrm{v} 1}$ constante $\mathrm{e}$

$$
\chi=\tilde{v} / v
$$

O termo de produção de viscosidade turbulenta, $G_{v}$, é dado por: 


$$
\mathrm{G}_{\mathrm{v}}=\mathrm{C}_{\mathrm{b} \rho} \rho \tilde{\mathrm{S}} \tilde{\mathrm{v}}
$$

No qual:

$$
\widetilde{S} \equiv S+\frac{\tilde{v}}{\kappa^{2} d^{2}} f_{v 2}
$$

e

$$
\mathrm{f}_{\mathrm{v} 2}=1-\frac{\chi}{1+\chi \mathrm{f}_{\mathrm{v} 1}}
$$

Onde:

$\mathrm{C}_{\mathrm{b} 1}$ e $\kappa:$ constantes;

d: distância da parede;

S: a medida escalar do tensor vorticidade:

$$
S=\sqrt{2 \Omega_{\mathrm{ij}} \Omega_{\mathrm{ij}}}
$$

E $\Omega_{\mathrm{ij}}$ é o tensor taxa de rotação:

$$
\Omega_{\mathrm{ij}}=\frac{1}{2}\left(\frac{\partial \mathrm{u}_{\mathrm{i}}}{\partial \mathrm{x}_{\mathrm{j}}}-\frac{\partial \mathrm{u}_{\mathrm{j}}}{\partial \mathrm{x}_{\mathrm{i}}}\right)
$$

A definição padrão de $\mathrm{S}$ considera apenas que a produção de turbulência acontece somente próximo às paredes, onde a vorticidade é maior (ANSYS FLUENT, 2009, p. 4-9). Entretanto, ao se levar em conta o efeito da deformação média, S fica:

$$
\mathrm{S} \equiv\left|\Omega_{\mathrm{ij}}\right|+\mathrm{C}_{\text {prod }} \min \left(0,\left|\mathrm{~S}_{\mathrm{ij}}\right|-\left|\Omega_{\mathrm{ij}}\right|\right)
$$

Onde:

$\mathrm{C}_{\text {prod }}:$ constante $=2.0 \mathrm{e}$ 


$$
\begin{array}{r}
\left|\Omega_{\mathrm{ij}}\right| \equiv \sqrt{2 \Omega_{\mathrm{ij}} \Omega_{\mathrm{ij}}} \text { e } \\
\left|\mathrm{S}_{\mathrm{ij}}\right| \equiv \sqrt{2 \mathrm{~S}_{\mathrm{ij}} \mathrm{S}_{\mathrm{ij}}} \\
\mathrm{S}_{\mathrm{ij}}=\frac{1}{2}\left(\frac{\partial \mathrm{u}_{\mathrm{i}}}{\partial \mathrm{x}_{\mathrm{j}}}+\frac{\partial \mathrm{u}_{\mathrm{j}}}{\partial \mathrm{x}_{\mathrm{i}}}\right)
\end{array}
$$

De acordo com Ansys Fluent (2009, p. 4-9) ao se incluir os tensores de rotação e deformação a produção de viscosidade turbulenta é reduzida e, obviamente, a própria viscosidade turbulenta diminui, especialmente nas regiões onde a vorticidade é maior do que a taxa de deformação. Por opção padrão o Ansys Fluent leva em conta apenas o tensor de rotação, equação ( 4-12 ), o que tende a superestimar a produção de viscosidade turbulenta e como conseqüência aumenta a viscosidade turbulenta (ANSYS FLUENT, 2009, p. 4-9).

O penúltimo termo da equação ( 4-5 ), de destruição de turbulência, é dado por:

$$
Y_{v}=C_{\omega 1} \rho f_{\omega}\left(\frac{\tilde{v}}{d}\right)^{2}
$$

Onde:

$$
\begin{gathered}
f_{\omega}=g\left(\frac{1+C_{\omega 3}^{6}}{g^{6}+C_{\omega 3}^{6}}\right)^{1 / 6} \\
g=r+C_{\omega 2}\left(r^{6}-r\right) \\
r \equiv \frac{\tilde{v}}{\widetilde{S} \kappa^{2} d^{2}}
\end{gathered}
$$

Com $\mathrm{C}_{\omega 1}, \mathrm{C}_{\omega 2}$ e $\mathrm{C}_{\omega 3}$ são constantes. 
As constantes utilizadas no modelo possuem os seguintes valores padrão no software Ansys Fluent:

$$
\begin{gathered}
\mathrm{C}_{\mathrm{b} 1}=0,1335 \quad \mathrm{C}_{\mathrm{b} 2}=0,622 \quad \mathrm{C}_{\mu}=0,09 \quad \sigma_{v}=2 / 3 \quad \mathrm{C}_{v} 1=7,1 \\
\mathrm{C}_{\omega 1}=\frac{\mathrm{C}_{\mathrm{b} 1}}{\kappa^{2}}+\frac{\left(1+\mathrm{C}_{\mathrm{b} 2}\right)}{\sigma_{\tilde{v}}} \quad \mathrm{C}_{\omega 2}=0,3 \quad \mathrm{C}_{\omega 3}=2,0 \quad \kappa=0,4187
\end{gathered}
$$

A viscosidade cinemática turbulenta modificada, $\widetilde{v}$, é nula nas paredes. Se a malha é refinada o suficiente para calcular a subcamada laminar, a tensão de cisalhamento na parede é obtida da relação tensão deformação laminar (ANSYS FLUENT, 2009, p. 4-10):

$$
\frac{\mathrm{u}}{\mathrm{u}_{\tau}}=\frac{\rho \mathrm{u}_{\tau} \mathrm{y}}{\mu}
$$

Entretanto em casos com número de Reynolds elevado, que são a maioria das aplicações industriais, os centróides dos primeiros elementos em relação à parede estão fora da subcamada laminar. Nessas situações, assumi-se que esses centróides estejam na região logarítmica da camada limite, e então a lei de parede da equação ( 4-24 ) é aplicada (ANSYS FLUENT, 2009, p. 4-10).

$$
\frac{\mathrm{u}}{\mathrm{u}_{\tau}}=\frac{1}{\kappa} \ln \mathrm{E}\left(\frac{\rho \mathrm{u}_{\tau} \mathrm{y}}{\mu}\right)
$$

Onde

u: velocidade paralela à parede;

$\mathrm{u}_{\tau}$ : velocidade de cisalhamento;

y: distância da parede, 
к: constante de von Kármán (0.4187);

$\mathrm{E}=9.793$.

\subsubsection{Introdução aos modelos de duas equações}

Os modelos k- $\varepsilon$, k- $\omega$ e suas variáveis fazem parte do grupo de modelos de duas equações. Essa categoria resolve uma equação de transporte para a energia cinética turbulenta e outra para o comprimento de escala turbulento ou equivalente. Por esse motivo pode-se dizer que esses modelos são completos, ou seja, podem ser usados para prever propriedades de um escoamento turbulento sem conhecer previamente a estrutura de turbulência. São os modelos de turbulência completos mais simples, e praticamente todos nessa categoria se baseiam na aproximação de Boussinesq (WILCOX, 1994, p. 83).

Wilcox (1994, p. 84) salienta que, assim como nos modelos de uma equação, não há razão física para a viscosidade turbulenta depender apenas de variáveis de turbulência. Em geral a razão entre as tensões de Reynolds e as tensões médias depende do escoamento médio além da turbulência. Assim os modelos de duas equações não são superiores ao de uma equação no sentido de generalidade de aplicações, podendo não ser precisos para escoamentos transitórios.

\subsubsection{Modelo k- $\varepsilon$ padrão}

Vários autores (WILCOX, 1994, POPE, 2000, ANSYS FLUENT, 2009), descrevem o k- $\varepsilon$ padrão como o mais popular modelo de turbulência. Como razões para isso Ansys Fluent (2009, p 4-12), diz que ele é robusto, econômico e possui razoável acurácia para muitas 
aplicações de engenharia. O trabalho que originou o modelo k-e padrão foi publicado por Jones e Launder ${ }^{1}$ (1972, apud WILCOX, 1994, p. 87 e apud POPE, 2000, p. 373).

O k- $\varepsilon$ padrão contempla as equações de transporte da energia cinética turbulenta, k, e sua taxa de dissipação, $\varepsilon$. A primeira equação é utilizada a partir de sua dedução exata, enquanto a de $\varepsilon$ é empírica. Isso porque, segundo Pope (2000, p. 375) $\varepsilon$ é mais bem compreendido como uma taxa de um fluxo de energia em cascata, que é determinada pelas largas escalas da turbulência, independentemente da viscosidade para elevados números de Reynolds. Wilcox (1994, p. 89) faz algumas considerações sobre a equação de $\varepsilon$, falando da dificuldade de sua validação experimental, e que ela na verdade representa a taxa de transferência de energia das largas escalas, e não a dissipação física. Por fim conclui que a diferença entre a equação modelada e a exata é insignificante.

De acordo com Ansys Fluent (2009, p. 4-12) na dedução do modelo k- $\varepsilon$ assumiu-se que o escoamento é completamente turbulento e que os efeitos da viscosidade molecular são desprezíveis. Assim, esse modelo é válido apenas para escoamentos plenamente turbulentos.

As equações de k e $\varepsilon$ são representadas no Ansys Fluent (2009, p. 4-13) por:

$$
\begin{gathered}
\frac{\partial}{\partial \mathrm{t}}(\rho \mathrm{k})+\frac{\partial}{\partial \mathrm{x}_{\mathrm{i}}}\left(\rho \mathrm{ku}_{\mathrm{i}}\right)=\frac{\partial}{\partial \mathrm{x}_{\mathrm{j}}}\left[\left(\mu+\frac{\mu_{\mathrm{t}}}{\sigma_{\mathrm{k}}}\right) \frac{\partial \mathrm{k}}{\partial \mathrm{x}_{\mathrm{j}}}\right]+\mathrm{G}_{\mathrm{k}}+\mathrm{G}_{\mathrm{b}}-\rho \varepsilon-\mathrm{Y}_{\mathrm{M}}+\mathrm{S}_{\mathrm{k}} \\
\frac{\partial}{\partial \mathrm{t}}(\rho \varepsilon)+\frac{\partial}{\partial \mathrm{x}_{\mathrm{i}}}\left(\rho \varepsilon \mathrm{u}_{\mathrm{i}}\right)=\frac{\partial}{\partial \mathrm{x}_{\mathrm{j}}}\left[\left(\mu+\frac{\mu_{\mathrm{t}}}{\sigma_{\mathrm{k}}}\right) \frac{\partial \varepsilon}{\partial \mathrm{x}_{\mathrm{j}}}\right]+\mathrm{C}_{1 \varepsilon} \frac{\varepsilon}{\mathrm{k}}\left(\mathrm{G}_{\mathrm{k}}+\mathrm{C}_{3 \varepsilon} \mathrm{G}_{\mathrm{b}}\right)-\mathrm{C}_{2 \varepsilon} \rho \frac{\varepsilon}{\mathrm{k}}+\mathrm{S}_{\varepsilon}
\end{gathered}
$$

\footnotetext{
${ }^{1}$ Jones, W. P.; Launder, B. E. The Prediction of Laminarization with a Two-Equation Model of Turbulence. International Journal of Heat and Mass Transfer, v. 15, pp. 301-314, 1972.
} 
Nas equações ( 4-25) e ( 4-26 ), $\mathrm{G}_{\mathrm{k}}$ representa a geração de energia cinética turbulenta devido ao gradiente de velocidade média e dado pela equação ( 4-27 ). $\mathrm{G}_{\mathrm{b}}$ é a geração de energia cinética devido ao empuxo, definido pela equação ( 4-30 ). O termo $\mathrm{Y}_{\mathrm{M}}$ representa a flutuação da dilatação em escoamentos compressíveis, descrito pela equação ( 432 ). $\mathrm{C}_{1 \varepsilon}$ e $\mathrm{C}_{2 \varepsilon}$ são constantes. $\mathrm{S}_{\varepsilon}$ e $\mathrm{S}_{\mathrm{k}}$ são as fontes de $\mathrm{k}$ e $\varepsilon$ definidas pelo usuário. Ainda é necessário definir $\sigma_{\varepsilon}$ e $\sigma_{\mathrm{k}}$, os números de Prandtl turbulento para k- $\varepsilon$, que nesse modelo são constantes (ANSYS FLUENT, 2009, p. 4-13).

$$
\mathrm{G}_{\mathrm{k}}=-\rho \overline{\mathrm{u}_{\mathrm{i}}^{\prime} \mathrm{u}_{\mathrm{j}}^{\prime}} \frac{\partial \mathrm{u}_{\mathrm{j}}}{\partial \mathrm{x}_{\mathrm{i}}}
$$

Para ficar coerente com a aproximação de Boussinesq (ANSYS FLUENT, 2009, p. 422):

$$
\mathrm{G}_{\mathrm{k}}=\mu_{\mathrm{t}} \mathrm{S}^{2}
$$

Onde S é média do módulo do tensor taxa de deformação, definida por:

$$
\begin{gathered}
S \equiv \sqrt{2 S_{i j} S_{i j}} \\
G_{b}=\beta g_{i} \frac{\mu_{t}}{\operatorname{Pr}_{t}} \frac{\partial T}{\partial x_{i}}
\end{gathered}
$$

com

$$
\beta=-\frac{1}{\rho}\left(\frac{\partial \rho}{\partial T}\right)_{p}
$$




$$
Y_{M}=2 \rho \varepsilon M_{t}^{2}
$$

A viscosidade turbulenta $\left(\mu_{\mathrm{t}}\right)$ édada pela seguinte relação entre k e $\varepsilon$ :

$$
\begin{aligned}
& \mu_{t}=\rho C_{\mu} \frac{\mathrm{k}^{2}}{\varepsilon} \\
& C_{3 \varepsilon}=\tanh \left|\frac{\mathrm{v}}{\mathrm{u}}\right|
\end{aligned}
$$

Onde v e u são, respectivamente, as componentes do vetor velocidade paralela e perpendicular ao vetor gravidade. Com isso $\mathrm{C}_{3 \varepsilon}$ é igual a 1 em flutuações nas camadas limites que o escoamento principal está alinhado com a gravidade, e será igual a 0 onde a flutuação for perpendicular ao vetor gravitacional (ANSYS FLUENT, 2009, p. 4-24).

As constantes do modelo (valores padrão do Ansys Fluent) foram obtidas experimentalmente.

$$
\mathrm{C}_{1 \varepsilon}=1,44 \quad \mathrm{C}_{2 \varepsilon}=1,92 \quad \mathrm{C}_{\mu}=0,09 \quad \sigma_{\varepsilon}=1,0 \quad \sigma_{\mathrm{k}}=1,3
$$

\subsubsection{Modelo k- $\varepsilon$ RNG}

De acordo com Pope (2000, p. 382) com o passar dos anos alterações no modelo k- $\varepsilon$ padrão foram sendo propostas com o objetivo de melhorar o desempenho para classes particulares de escoamentos. Dentre essas propostas está o modelo RNG (Renormalization Group), que aplica técnicas estatísticas de renormalização nas equações de Navier-Stokes para a obtenção de k e $\varepsilon$. 
Dentre as melhorias e diferenças entre esse modelo e o k- $\varepsilon$ padrão Ansys Fluent (2009, p. 4-14) cita o termo adicional na equação de $\varepsilon$, que é dito como a principal diferença entre esses modelos também por Pope (2000, p. 383). Além disso, é incluído o efeito da rotação da turbulência, os números de Prandtl turbulento são calculados de forma analítica (no modelo k$\varepsilon$ padrão são constantes) e ainda efeitos de baixos números de Reynolds são considerados, diferentemente do k- $\varepsilon$ padrão.

As equações de transporte são semelhantes à do modelo padrão (ANSYS FLUENT, 2009, p. 4-15)

$$
\begin{array}{r}
\frac{\partial}{\partial \mathrm{t}}(\rho \mathrm{k})+\frac{\partial}{\partial \mathrm{x}_{\mathrm{i}}}\left(\rho \mathrm{ku}_{\mathrm{i}}\right)=\frac{\partial}{\partial \mathrm{x}_{\mathrm{j}}}\left(\alpha_{\mathrm{k}} \mu_{\text {eff }} \frac{\partial \mathrm{k}}{\partial \mathrm{x}_{\mathrm{j}}}\right)+\mathrm{G}_{\mathrm{k}}+\mathrm{G}_{\mathrm{b}}-\rho \varepsilon-\mathrm{Y}_{\mathrm{M}}+\mathrm{S}_{k} \\
\frac{\partial}{\partial \mathrm{t}}(\rho \varepsilon)+\frac{\partial}{\partial \mathrm{x}_{\mathrm{i}}}\left(\rho \varepsilon \mathrm{u}_{\mathrm{i}}\right)=\frac{\partial}{\partial \mathrm{x}_{\mathrm{j}}}\left(\alpha_{\mathrm{k}} \mu_{\text {eff }} \frac{\partial \varepsilon}{\partial \mathrm{x}_{\mathrm{j}}}\right)+\mathrm{C}_{1 \varepsilon} \frac{\varepsilon}{\mathrm{k}}\left(\mathrm{G}_{\mathrm{k}}+\mathrm{C}_{3 \varepsilon} \mathrm{G}_{\mathrm{b}}\right)-\mathrm{C}_{2 \varepsilon} \rho \frac{\varepsilon}{\mathrm{k}}-\mathrm{R}_{\varepsilon}+\mathrm{S}_{\varepsilon}
\end{array}
$$

Onde $G_{k}$ é dado pela equação ( 4-27 ), $G_{b}$ pela equação ( 4-30 ), $Y_{M}$ pela ( 4-32 ) e $S_{k}$ e $S_{\varepsilon}$ são os termos fontes de k e $\varepsilon$.

Nota-se que em relação ao modelo k- $\varepsilon$ padrão existe um termo a mais, a viscosidade efetiva ( $\left.\mu_{\text {eff }}\right)$, que é calculada da seguinte forma:

$$
\mathrm{d}\left(\frac{\rho^{2} \mathrm{k}}{\sqrt{\varepsilon \mu}}\right)=1,72 \frac{\hat{v}}{\sqrt{\hat{v}^{3}-1+\mathrm{C}_{v}}} \mathrm{~d} \hat{v}
$$

$\operatorname{com} \mathrm{C}_{v} \approx 100 \mathrm{e}$ 


$$
\hat{v}=\frac{\mu_{\text {eff }}}{\mu}
$$

A integração da equação ( 4-38 ) permite descrever como o transporte turbulento efetivo varia com o número de Reynolds, assim é possível obter melhores resultados para escoamentos em baixo Reynolds e próximo às paredes. Fazendo o limite para Reynolds elevado, a equação ( 4-38 ) fica (ANSYS FLUENT, 2009, p. 5-15):

$$
\mu_{\mathrm{t}}=\rho \mathrm{C}_{\mu} \frac{\mathrm{k}^{2}}{\varepsilon}
$$

A opção padrão no Ansys Fluent, utilizada no presente trabalho, para cálculo da viscosidade efetiva é a equação ( 4-40 ). Entretanto, há a opção de se integrar a equação ( 438 ) para se levar em conta efeitos de baixo Reynolds (ANSYS FLUENT, 2009, p.5-16).

A equação analítica ( 4-41) é usada para calcular os números de Prandtl turbulento $\alpha_{k}$ e $\alpha_{\varepsilon}$ (ANSYS FLUENT, 2009, p.5-16):

$$
\left|\frac{\alpha-1,3929}{\alpha_{0}-1,3929}\right|^{0,6321}\left|\frac{\alpha+2,3929}{\alpha_{0}+2,3929}\right|^{0,3679}=\frac{\mu_{\mathrm{mol}}}{\mu_{\text {eff }}}
$$

No qual $\alpha_{0}=1,0$ e no limite, para número de Reynolds alto $\left(\mu_{\mathrm{mol}} / \mu_{\mathrm{eff}}<<1\right)$, tem-se $\alpha_{\mathrm{k}}=$ $\alpha_{\varepsilon} \approx 1,393$ (ANSYS FLUENT, 2009, p.5-16).

O termo $\mathrm{R}_{\varepsilon}$ representa a principal diferença do modelo RNG (ANSYS FLUENT, 2009, p.5-16: POPE, 2000, p. 383) em relação ao padrão. 


$$
\mathrm{R}_{\varepsilon}=\frac{\mathrm{C}_{\mu} \rho \eta^{3}\left(1-\eta / \eta_{0}\right) \varepsilon^{2}}{\left(1+\beta \eta^{3}\right) \mathrm{k}}
$$

No qual,

$$
\eta=\mathrm{Sk} / \varepsilon
$$

E $\eta_{0}$ e $\beta$ são constantes $\left(\eta_{0}=4,38\right.$ e $\left.\beta=0,012\right)$.

Para valores de $\eta<\eta_{0}, R_{\varepsilon}$ tem uma contribuição positiva na equação e os resultados se aproximam do modelo k- $\varepsilon$ padrão. Assim pode-se concluir que para escoamentos onde os efeitos cisalhantes não são dominantes os modelos k-E padrão e RNG são praticamente equivalentes (ANSYS FLUENT, 2009, p. 4-17).

Já se $\eta>\eta_{0}$, o termo $R_{\varepsilon}$ possui uma contribuição negativa. Na comparação com o modelo padrão $\mathrm{k}-\varepsilon$, a menor destruição de $\varepsilon$, reduz a produção de $\mathrm{k}$ e eventualmente a viscosidade efetiva. Conseqüentemente, o modelo RNG produz uma viscosidade turbulenta menor que o modelo padrão para escoamentos com elevados gradientes de tensão. Isso significa que o modelo responde melhor a efeitos cisalhantes e escoamentos curvos (ANSYS FLUENT, 2009, p. 4-17).

As constantes do modelo RNG são:

$$
\mathrm{C}_{1 \varepsilon}=1,42 \quad \mathrm{C}_{2 \varepsilon}=1,68
$$




\subsubsection{Modelo k- $\varepsilon$ realizável}

O modelo k- $\varepsilon$ realizável foi desenvolvido por Shih et al., 1995² (apud ANSYS FLUENT, 2009, p. 4-18) e difere do modelo padrão em dois aspectos: na formulação da viscosidade turbulenta e na equação de $\varepsilon$.

O termo "realizável" significa que o modelo satisfaz algumas restrições matemáticas nas tensões de Reynolds que estão de acordo com a física da turbulência. Os modelos padrão e RNG não são "realizáveis” (ANSYS FLUENT, 2009, p. 4-18).

Segundo Ansys Fluent, (2009, p. 4-18) o k-e realizável possui desempenho superior ao modelo padrão na modelagem de jatos, separação, camada limite com gradiente de pressão adverso, rotação e recirculação.

Uma tensão normal de Reynolds é obtida combinando-se a aproximação de Boussinesq (equação ( 4-4 )), com a definição de viscosidade turbulenta (equação ( 4-33 )) do modelo padrão (ANSYS FLUENT, 2009, p. 4-18):

$$
\overline{\mathrm{u}^{2}}=\frac{2}{3} \mathrm{k}-2 v_{\mathrm{t}} \frac{\partial \mathrm{U}}{\partial \mathrm{x}}
$$

Quando se substitui $v_{\mathrm{t}}=\mu_{\mathrm{t}} / \rho$ na equação ( 4-33 ) e a utiliza na equação ( 4-4 ) obtémse $\overline{u^{2}}$ negativo (o que contraria a definição de $\overline{u^{2}}$, que é positivo) tornando o modelo "não realizável”, quando a tensão é grande o suficiente para satisfazer (ANSYS FLUENT, 2009, p. 4-18):

\footnotetext{
${ }^{2}$ SHIH,T.-H.; LIOU, W. W.; SHABBIR, A.; YANG, Z.; ZHU, J. A New k- $\varepsilon$ Eddy- Viscosity Model for High Reynolds Number Turbulent Flows - Model Development and Validation. Computers Fluids, v. 24(3), p. 227238, 1995.
} 


$$
\frac{\mathrm{k}}{\varepsilon} \frac{\partial \mathrm{U}}{\partial \mathrm{x}}>\frac{1}{3 \mathrm{C}_{\mu}} \approx 3,7
$$

As equações de transporte do modelo k-e realizável são (ANSYS FLUENT, 2009, p. 4-20):

$$
\begin{gathered}
\frac{\partial}{\partial \mathrm{t}}(\rho \mathrm{k})+\frac{\partial}{\partial \mathrm{x}_{\mathrm{i}}}\left(\rho \mathrm{ku}_{\mathrm{j}}\right)=\frac{\partial}{\partial \mathrm{x}_{\mathrm{i}}}\left[\left(\mu+\frac{\mu_{\mathrm{t}}}{\sigma_{\mathrm{k}}}\right) \frac{\partial \mathrm{k}}{\partial \mathrm{x}_{\mathrm{j}}}\right]+\mathrm{G}_{\mathrm{k}}+\mathrm{G}_{\mathrm{b}}-\rho \varepsilon-\mathrm{Y}_{\mathrm{M}}+\mathrm{S}_{\mathrm{k}} \\
\frac{\partial}{\partial \mathrm{t}}(\rho \varepsilon)+\frac{\partial}{\partial \mathrm{x}_{\mathrm{j}}}\left(\rho \varepsilon \mathrm{u}_{\mathrm{j}}\right)=\frac{\partial}{\partial \mathrm{x}_{\mathrm{j}}}\left[\left(\mu+\frac{\mu_{\mathrm{t}}}{\sigma_{\mathrm{k}}}\right) \frac{\partial \varepsilon}{\partial \mathrm{x}_{\mathrm{j}}}\right]+\rho \mathrm{C}_{1} \mathrm{~S}_{\varepsilon}+\mathrm{C}_{1 \varepsilon} \frac{\varepsilon}{\mathrm{k}} \mathrm{C}_{3 \varepsilon} \mathrm{G}_{\mathrm{b}}-\mathrm{C}_{2 \varepsilon} \rho \frac{\varepsilon^{2}}{\mathrm{k}+\sqrt{\nu \varepsilon}}
\end{gathered}
$$

Onde:

$$
C_{1}=\max \left[0.43, \frac{\eta}{\eta+5}\right]
$$

E

$$
\eta=S \frac{\mathrm{k}}{\varepsilon}
$$

Onde $G_{k}$ é dado pela equação ( 4-27 ), $G_{b}$ pela equação ( 4-30 ), $Y_{M}$ pela ( 4-32 ) e $S_{k}$ e $S_{\varepsilon}$ são os termos fontes de k e $\varepsilon$.

Observa-se que as equações de $\mathrm{k}$ de todos os modelos $\mathrm{k}-\varepsilon$ são muito parecidas (equações ( 4-47 ), ( 4-36 ) e ( 4-25 )), o que não ocorre com as equações de $\varepsilon$ ( ( 4-48 ) ( 437 ) ( 4-26 )). A principal diferença está no termo da produção de $\varepsilon$ ( o segundo, do lado direito), que não envolve k, como no RNG e no modelo padrão. Além disso, nos dois 
primeiros modelos apresentados no termo de produção de $\varepsilon$ o k está no denominador o que pode levar a singularidades (ANSYS FLUENT, 2009, p 4-20).

A viscosidade turbulenta é modelada como (ANSYS FLUENT, 2009, p 4-21).

$$
\mu_{\mathrm{t}}=\rho \mathrm{C}_{\mu} \frac{\mathrm{k}^{2}}{\varepsilon}
$$

Diferentemente dos modelos padrão e RNG, no realizável o $C_{\mu}$ não é constante, mas sim função das taxas de deformação e rotação médias, da velocidade angular do sistema e os campos de turbulência (k e e). (ANSYS FLUENT, 2009, p 4-21-22).

$$
\mathrm{C}_{\mu}=\frac{1}{\mathrm{~A}_{0}+\mathrm{A}_{\mathrm{S}} \mathrm{k} \frac{\mathrm{U}^{*}}{\varepsilon}}
$$

Com:

$$
\begin{gathered}
\mathrm{U}^{*}=\sqrt{\mathrm{S}_{\mathrm{ij}} \mathrm{S}_{\mathrm{ij}}+\tilde{\Omega}_{\mathrm{ij}} \tilde{\Omega}_{\mathrm{ij}}} \\
\tilde{\Omega}_{\mathrm{ij}}=\Omega_{\mathrm{ij}}-2 \varepsilon_{\mathrm{ijk}} \omega_{\mathrm{k}} \\
\Omega_{\mathrm{ij}}=\overline{\Omega_{\mathrm{ij}}}-\varepsilon_{\mathrm{ijk}} \omega_{\mathrm{k}}
\end{gathered}
$$

No qual o termo $\overline{\Omega_{\mathrm{ij}}}$ é o tensor médio taxa de rotação visto num referencial com velocidade angular $\omega_{\mathrm{k}}$. As constantes $\mathrm{A}_{0}$ e $\mathrm{A}_{\mathrm{S}}$ são dadas por (ANSYS FLUENT, 2009, p 421):

$$
A_{0}=4.04 A_{S}=\sqrt{6} \cos \varphi
$$

Com 


$$
\begin{gathered}
\varphi=\frac{1}{3} \arccos (\sqrt{6} \mathrm{~W}) \\
\mathrm{W}=\frac{\mathrm{S}_{\mathrm{ij}} \mathrm{S}_{\mathrm{jk}} \mathrm{S}_{\mathrm{ik}}}{\overline{\mathrm{S}}^{3}} \\
\overline{\mathrm{S}}=\sqrt{\mathrm{S}_{\mathrm{ij}} \mathrm{S}_{\mathrm{ij}}}, \\
\mathrm{S}_{\mathrm{ij}}=\frac{1}{2}\left(\frac{\partial \mathrm{u}_{\mathrm{i}}}{\partial \mathrm{x}_{\mathrm{j}}}+\frac{\partial \mathrm{u}_{\mathrm{j}}}{\partial \mathrm{x}_{\mathrm{i}}}\right)
\end{gathered}
$$

As constantes do modelo são:

$$
\mathrm{C}_{1 \varepsilon}=1.44, \quad \mathrm{C}_{2}=1.9, \quad \sigma_{\mathrm{k}}=1.0, \quad \sigma_{\varepsilon}=1.9
$$

\subsubsection{Modelo k- $\omega$ padrão}

Segundo Pope (2000, p. 384) e Ansys Fluent (2009, p. 4-26) o modelo k- $\omega$ teve sua versão considerada padrão desenvolvida por Wilcox (1994), e é o segundo modelo de turbulência de duas equações mais utilizado.

O primeiro modelo de turbulência de duas equações foi proposto por Kolmogorov ${ }^{3}$ (1942, apud WILCOX, 1994, p. 83), onde além da energia cinética turbulenta (k) foi proposta uma equação de transporte para a dissipação por unidade de energia cinética turbulenta, $\omega$. Segundo Wilcox (1994, p. 85) Kolmogorov definiu $\omega$ como a taxa de dissipação de energia por unidade de volume e tempo. Wilcox $(1994$, p. 86) diz ainda que a interpretação física de $\omega$ dada pelos pesquisadores do assunto tem um comportamento similar ao das flutuações da

\footnotetext{
${ }^{3}$ KOLMOGOROV, A. N, Equations of Turbulent Motion of an Incompressible Fluid. Izvestia Academy of Sciences, USSR; Physics, Vol. 6, Nos. 1 and 2. 1942. pp. 56-58.
} 
turbulência, ou seja, varia muito. Dentre essas definições $\operatorname{Saffman}^{4}$ (1970, apud WILCOX ,1994, p. 86) interpreta como “a frequiência característica do processo de decaimento da turbulência sobre sua própria interação”. Wilcox e Alber ${ }^{5}$ (1972, apud WILCOX 1994, p. 86) definem $\omega$ como a média quadrática (RMS - Root Mean Square) da flutuação da vorticidade, conhecido também por enstropia. Já Wilcox (1994 p. 86) citando vários de seus trabalhos prévios, e ainda citado por Ansys Fluent (2009 p. 4-26) define $\omega$ como a razão entre $\varepsilon$ e k, ou seja, a taxa de dissipação por unidade de energia cinética turbulenta..

Dentre as alterações propostas por Wilcox $(1994$, p. 87) em relação ao modelo de Kolmogorov (1942, apud WILCOX,1994 p. 83) está a inclusão de termos de produção, e de constantes de fechamento.

As equações de transporte utilizadas no Ansys Fluent (2009, p. 4-27) são:

$$
\begin{aligned}
& \frac{\partial}{\partial \mathrm{t}}(\rho \mathrm{k})+\frac{\partial}{\partial \mathrm{x}_{\mathrm{i}}}\left(\rho \mathrm{ku} \mathrm{u}_{\mathrm{i}}\right)=\frac{\partial}{\partial \mathrm{x}_{\mathrm{j}}}\left(\Gamma_{\mathrm{k}} \frac{\partial \mathrm{k}}{\partial \mathrm{x}_{\mathrm{j}}}\right)+\mathrm{G}_{\mathrm{k}}-\mathrm{Y}_{\mathrm{k}}+\mathrm{S}_{k} \\
& \frac{\partial}{\partial \mathrm{t}}(\rho \omega)+\frac{\partial}{\partial \mathrm{x}_{\mathrm{i}}}\left(\rho \omega \mathrm{u}_{\mathrm{i}}\right)=\frac{\partial}{\partial \mathrm{x}_{\mathrm{j}}}\left(\Gamma_{\omega} \frac{\partial \omega}{\partial \mathrm{x}_{\mathrm{j}}}\right)+\mathrm{G}_{\omega}-\mathrm{Y}_{\omega}+\mathrm{S}_{\omega}
\end{aligned}
$$

$\Gamma_{\mathrm{k}}$ e $\Gamma_{\omega}$ representam a difusividade efetiva de k e $\omega . S_{\mathrm{k}}$ e $S_{\omega}$ são termos fonte.

$$
\begin{gathered}
\Gamma_{\mathrm{k}}=\mu+\frac{\mu_{\mathrm{t}}}{\sigma_{\mathrm{k}}} \\
\Gamma_{\omega}=\mu+\frac{\mu_{\mathrm{t}}}{\sigma_{\omega}}
\end{gathered}
$$

\footnotetext{
${ }^{4}$ SAFFMAN, P. G. A Model for Inhomogeneous Turbulent Flow. Proc. Roy. Soc, Lond., Vol. A317. 1970. pp. 417-433.

5 WILCOX, D. C.; ALBER, I. E. A Turbulence Model for High Speed Flows. Proc. of the 1972 Heat Trans. \& Fluid Mech. Inst, Stanford Univ. Press, 1972. pp. 231-252.
} 
Na qual $\sigma_{\omega}$ e $\sigma_{\mathrm{k}}$ são os números de Prandtl turbulento para $\omega$ e k. A viscosidade turbulenta é modelada por:

$$
\mu_{\mathrm{t}}=\alpha^{*} \frac{\rho \mathrm{k}}{\omega}
$$

A viscosidade turbulenta é amortecida pelo coeficiente $\alpha^{*}$, que funciona como uma correção para baixos números de Reynolds (ANSYS FLUENT, 2009, p.4-28):

$$
\alpha^{*}=\alpha_{\infty}^{*}\left(\frac{\alpha_{0}^{*}+\operatorname{Re}_{\mathrm{t}} / \operatorname{Re}_{\mathrm{k}}}{1+\operatorname{Re}_{\mathrm{t}} / \operatorname{Re}_{\mathrm{k}}}\right)
$$

Com:

$$
\operatorname{Re}_{\mathrm{t}}=\frac{\rho \mathrm{k}}{\mu \omega}, \operatorname{Re}_{\mathrm{k}}=6, \alpha_{0}^{*}=\frac{\beta_{\mathrm{i}}}{3} \text { e } \beta_{\mathrm{i}}=0.072
$$

Observa-se que para elevados números de Reynolds $\alpha_{0}^{*}=\alpha_{\infty}^{*}=1$.

$\mathrm{G}_{\mathrm{k}}$ é a produção de energia cinética turbulenta devido ao gradiente da velocidade média, definido pela equação ( 4-28 ).

$\mathrm{G}_{\omega}$ representa a produção de $\omega$ :

$$
\mathrm{G}_{\omega}=\alpha \frac{\omega}{\mathrm{k}} \mathrm{G}_{\mathrm{k}}
$$

E o coeficiente $\alpha$ é dado por:

$$
\alpha=\frac{\alpha_{\infty}}{\alpha^{*}}\left(\frac{\alpha_{0}+\operatorname{Re}_{\mathrm{t}} / \operatorname{Re}_{\omega}}{1+\operatorname{Re}_{\mathrm{t}} / \operatorname{Re}_{\omega}}\right)
$$


Ccom $\mathrm{R}_{\omega}=2.95$.

Analogamente, para elevados números de Reynolds $\alpha=\alpha_{\infty}=1$

$\mathrm{Y}_{\mathrm{k}}$ e $\mathrm{Y}_{\omega}$ representam a dissipação de $\mathrm{k}$ e $\omega$ devido à turbulência (ANSYS FLUENT, 2009, p. 4-29).

$$
Y_{k}=\rho \beta^{*} f_{\beta^{*}} k \omega
$$

Onde:

$$
\mathrm{f}_{\beta^{*}}=\left\{\begin{array}{cc}
1 & \chi_{\mathrm{k}} \leq 0 \\
\frac{1+680 \chi_{\mathrm{k}}^{2}}{1+400 \chi_{\mathrm{k}}^{2}} & \chi_{\mathrm{k}}>0
\end{array}\right.
$$

Com:

$$
\chi_{\mathrm{k}} \equiv \frac{1}{\omega^{3}} \frac{\partial \mathrm{k}}{\partial \mathrm{x}_{\mathrm{j}}} \frac{\partial \omega}{\partial \mathrm{x}_{\mathrm{j}}}
$$

E

$$
\begin{gathered}
\beta^{*}=\beta_{\mathrm{i}}^{*}\left[1+\zeta^{*} \mathrm{~F}\left(\mathrm{M}_{\mathrm{t}}\right)\right] \\
\beta_{\mathrm{i}}^{*}=\beta_{\infty}^{*}\left(\frac{4 / 15+\left(\mathrm{Re}_{\mathrm{t}} / \mathrm{R}_{\beta}\right)^{4}}{1+\left(\mathrm{Re}_{\mathrm{t}} / \mathrm{R}_{\beta}\right)^{4}}\right) \\
\zeta^{*}=1.5 \quad \mathrm{R}_{\beta}=8 \quad \beta_{\infty}^{*}=0.09
\end{gathered}
$$

A dissipação de $\omega$ é calculada por 


$$
Y_{\omega}=\rho \beta f_{\beta} \omega^{2}
$$

com

$$
\begin{gathered}
\mathrm{f}_{\beta}=\frac{1+70 \chi_{\omega}}{1+80 \chi_{\omega}} \\
\chi_{\omega}=\left|\frac{\Omega_{\mathrm{ij}} \Omega_{\mathrm{ik}} \mathrm{S}_{\mathrm{ki}}}{\left(\beta_{\infty}^{*} \omega\right)^{3}}\right| \\
\Omega_{\mathrm{ij}}=\frac{1}{2}\left(\frac{\partial \mathrm{u}_{\mathrm{i}}}{\partial \mathrm{x}_{\mathrm{j}}}-\frac{\partial \mathrm{u}_{\mathrm{j}}}{\partial \mathrm{x}_{\mathrm{i}}}\right) \\
\beta=\beta_{\mathrm{i}}\left[1+\frac{\beta_{\mathrm{i}}^{*}}{\beta_{\mathrm{i}}} \zeta^{*} \mathrm{~F}\left(\mathrm{M}_{\mathrm{t}}\right)\right]
\end{gathered}
$$

A função de compressibilidade é calculada por:

$$
F\left(M_{t}\right)= \begin{cases}0 & M_{t} \leq M_{t 0} \\ M_{t}^{2}-M_{t 0}^{2} & M_{t}>M_{t 0}\end{cases}
$$

Onde

$$
\mathrm{M}_{\mathrm{t}}^{2} \equiv \frac{2 \mathrm{k}}{\mathrm{a}^{2}} \quad \mathrm{M}_{\mathrm{t} 0}=0.25 \quad \mathrm{a}=\sqrt{\gamma \mathrm{RT}}
$$

As constantes do modelo são:

$$
\begin{aligned}
& \alpha_{\infty}^{*}=1, \quad \alpha_{\infty}=0.52, \quad \alpha_{0}=1 / 9, \quad \beta_{\infty}^{*}=0.09, \quad \beta_{\mathrm{i}}=0.072, \quad \mathrm{R}_{\beta}=8, \\
& \mathrm{R}_{\mathrm{k}}=6, \quad \mathrm{R}_{\omega}=2.95, \quad \zeta^{*}=1.5, \quad \mathrm{M}_{\mathrm{t} 0}=0.25, \quad \sigma_{\mathrm{k}}=2.0, \quad \sigma_{\omega}=2.0
\end{aligned}
$$


Maiores detalhes sobre a dedução dos coeficientes de fechamento podem ser encontradas em Wilcox (1994, p. 92-95).

Nas paredes os modelos k- $\omega$ (padrão e SST) se comportam como se fossem utilizadas as funções de parede aprimoradas dos modelos k-E. Ou seja, se a malha for refinada o suficiente, calcula-se a subcamada laminar, caso o contrário são empregadas funções de parede (ANSYS FLUENT, 2009, p. 4-35). O valor de $\omega$ na parede é definido por:

$$
\omega_{\omega}=\frac{\rho\left(\mathrm{u}^{*}\right)^{2}}{\mu} \omega^{+}
$$

O valor assintótico de $\omega^{+}$na subcamada laminar é dado por:

$$
\begin{gathered}
\omega^{+}=\min \left(\omega_{\omega}^{+}, \frac{6}{\beta_{\infty}^{*}\left(\mathrm{y}^{+}\right)^{2}}\right) \\
\omega_{\omega}^{+}= \begin{cases}\left(\frac{50}{\mathrm{k}_{\mathrm{s}}^{+}}\right)^{2} & \mathrm{k}_{\mathrm{s}}^{+}<25 \\
\frac{100}{\mathrm{k}_{\mathrm{s}}^{+}} & \mathrm{k}_{\mathrm{s}}^{+} \geq 25\end{cases} \\
\mathrm{k}_{\mathrm{s}}^{+}=\max \left(1, \frac{\rho \mathrm{k}_{\mathrm{s}} \mathrm{u}^{*}}{\mu}\right)
\end{gathered}
$$

E $\mathrm{k}_{\mathrm{s}}$ é a altura da rugosidade.

Na região turbulenta da camada limite o valor de $\omega^{+}$é: 


$$
\omega^{+}=\frac{1}{\sqrt{\beta_{\infty}^{*}}} \frac{\mathrm{du}_{\mathrm{turb}}^{+}}{\mathrm{dy}^{+}}
$$

O que leva ao valor de $\omega$ nas células das paredes como:

$$
\omega=\frac{u^{*}}{\sqrt{\beta_{\infty}^{*}} \kappa y}
$$

Caso o primeiro elemento esteja na região de transição entre a subcamada limite laminar e a turbulenta, o Ansys Fluent misturará $\omega^{+}$entre os valores dessas duas regiões (ANSYS FLUENT, 2009, p. 4-36).

\subsubsection{Modelo SST k- $\omega$ (Shear Stress Transport)}

Segundo Pope (2000, p. 384) o modelo k- $\omega$ padrão necessita de uma condição de contorno diferente de zero (sem significado físico) em fronteiras com o fluxo livre, e o resultado do restante do escoamento é dependente desse valor. Dessa forma Menter ${ }^{6}$ (1994, apud POPE, 2000, p. 384 e apud ANSYS FLUENT, 2009, p. 4-31) criou um modelo de turbulência que teve por objetivo juntar o melhor dos modelos k- $\varepsilon$ e k- $\omega$ : a independência das condições de contorno no escoamento livre do primeiro e a acurácia do segundo próximo às paredes.

O SST k- $\omega$ é escrito na forma do modelo k- $\omega$, mas com "funções de mistura" que transforma o modelo num k- $\omega$ padrão próximo às paredes e num k- $\varepsilon$ no escoamento ao longe (POPE, 2000, p. 384; ANSYS FLUENT, 2009, p. 4-31).

De acordo com Hoffman e Chiang (2000, p. 61) Menter inicialmente desenvolveu um modelo base (BSL - baseline) que depois evoluiu para a versão SST (Shear Stress

\footnotetext{
${ }^{6}$ MENTER, F. R. Two-Equation Eddy-Viscosity Turbulence Models for Engineering Applications. AIAA Journal. 32(8): p.1598-1605, 1994.
} 
Transport). A diferença entre eles é o cálculo da viscosidade turbulenta, que no SST há a hipótese de que as tensões de cisalhamento turbulentas são proporcionais à energia cinética turbulenta na região logarítmica da camada limite. Assim a viscosidade turbulenta é limitada para satisfazer essa proporcionalidade (HOFFMAN; CHIANG, 2000, p. 65).

Ansys Fluent (2009, p. 4-31) afirma que essas características fazem o modelo ser mais preciso para uma classe mais ampla de escoamentos como, por exemplo, aqueles com gradientes de pressão adversos, fólios e ondas de choque (que aparecem em regiões supersônicas de um escoamento em regime transônico) que o modelo k- $\omega$ padrão.

As equações de transporte no modelo SST k- $\omega$ são:

$$
\begin{gathered}
\frac{\partial}{\partial \mathrm{t}}(\rho \mathrm{k})+\frac{\partial}{\partial \mathrm{x}_{\mathrm{i}}}\left(\rho \mathrm{ku}_{\mathrm{i}}\right)=\frac{\partial}{\partial \mathrm{x}_{\mathrm{j}}}\left(\Gamma_{\mathrm{k}} \frac{\partial \mathrm{k}}{\partial \mathrm{x}_{\mathrm{j}}}\right)+\overline{\mathrm{G}}_{\mathrm{k}}-\mathrm{Y}_{\mathrm{k}}+\mathrm{S}_{k} \\
\frac{\partial}{\partial \mathrm{t}}(\rho \omega)+\frac{\partial}{\partial \mathrm{x}_{\mathrm{i}}}\left(\rho \omega \mathrm{u}_{\mathrm{i}}\right)=\frac{\partial}{\partial \mathrm{x}_{\mathrm{j}}}\left(\Gamma_{\omega} \frac{\partial \omega}{\partial \mathrm{x}_{\mathrm{j}}}\right)+\mathrm{G}_{\omega}-\mathrm{Y}_{\omega}+\mathrm{D}_{\omega}+\mathrm{S}_{\omega}
\end{gathered}
$$

$\overline{\mathrm{G}}_{\mathrm{k}}$ é a produção de energia cinética turbulenta devido ao gradiente da velocidade média, definido por:

$$
\overline{\mathrm{G}}_{\mathrm{k}}=\max \left(\mathrm{G}_{\mathrm{k}}, 10 \rho \beta^{*} \mathrm{k} \omega\right)
$$

Onde $\mathrm{G}_{\mathrm{k}}$ é definido pela equação ( 4-28 ) e $\beta^{*}$ na equação ( 4-73 )

$\mathrm{G}_{\omega}$ representa a produção de $\omega$, definido por: 


$$
\mathrm{G}_{\omega}=\frac{\alpha}{v_{\mathrm{t}}} \mathrm{G}_{\mathrm{k}}
$$

Com $\alpha$ dado pela equação ( 4-69 ) e $\mathrm{G}_{\mathrm{k}}$ pela ( 4-28 ). Entretanto $\alpha_{\infty}$ na equação ( 469 ) é constante igual a 0.52 no modelo k- $\omega$ padrão e no SST é calculado por (ANSYS FLUENT, 2009, p. 4-33):

$$
\alpha_{\infty}=\mathrm{F}_{1} \alpha_{\infty, 1}+\left(1-\mathrm{F}_{1}\right) \alpha_{\infty, 2}
$$

Onde:

$$
\begin{gathered}
\alpha_{\infty, 1}=\frac{\beta_{i, 1}}{\beta_{\infty}^{*}}-\frac{\kappa^{2}}{\sigma_{\omega, 1} \sqrt{\beta_{\infty}^{*}}} \\
\alpha_{\infty, 2}=\frac{\beta_{i, 2}}{\beta_{\infty}^{*}}-\frac{\kappa^{2}}{\sigma_{\omega, 2} \sqrt{\beta_{\infty}^{*}}}
\end{gathered}
$$

Com $\kappa, \beta_{\mathrm{i}, 1} \beta_{\mathrm{i}, 2}, \beta_{\infty}^{*}, \sigma_{\omega, 1}, \sigma_{\omega, 2}$ constantes. $\mathrm{F}_{1}$ é definido por:

$$
\begin{gathered}
\mathrm{F}_{1}=\tanh \left(\Phi_{1}^{4}\right) \\
\Phi_{1}=\min \left[\max \left(\frac{\sqrt{\mathrm{k}}}{0.09 \omega .}, \frac{500 \mu}{\rho \mathrm{y}^{2} \omega}\right), \frac{4 \rho \mathrm{k}}{\sigma_{\omega, 2} \mathrm{D}_{\omega}^{+} \mathrm{y}^{2}}\right] \\
\mathrm{D}_{\omega}^{+}=\max \left[2 \rho \frac{1}{\sigma_{\omega, 2}} \frac{1}{\omega} \frac{\partial \mathrm{k}}{\partial \mathrm{x}_{\mathrm{j}}} \frac{\partial \omega}{\partial \mathrm{x}_{\mathrm{j}}}, 10^{-20}\right]
\end{gathered}
$$


Com y sendo a distância até a parede mais próxima e $\mathrm{D}_{\omega}^{+}$é a parte positiva do termo de difusão cruzada definido na equação ( 4-107 ) (ANSYS FLUENT, 2009, p. 4-33).

$\Gamma_{\mathrm{k}}$ e $\Gamma_{\omega}$ são as difusividades efetivas de $\mathrm{k}$ e $\omega$, mostrados respectivamente nas equações ( 4-63 ) e ( 4-64 ). Entretanto os números de Prandtl turbulento para k e $\omega$ são definidos por:

$$
\begin{aligned}
& \sigma_{\mathrm{k}}=\frac{1}{\mathrm{~F}_{1} / \sigma_{\mathrm{k}, 1}+\left(1-\mathrm{F}_{1}\right) / \sigma_{\mathrm{k}, 2}} \\
& \sigma_{\omega}=\frac{1}{\mathrm{~F}_{1} / \sigma_{\omega, 1}+\left(1-\mathrm{F}_{1}\right) / \sigma_{\omega, 2}}
\end{aligned}
$$

Onde $\sigma_{\mathrm{k}, 1}, \sigma_{\mathrm{k}, 2}, \sigma_{\omega, 1}, \sigma_{\omega, 2}$ constantes.

Além disso, a viscosidade turbulenta também é alterada em relação ao modelo k- $\omega$ padrão, e passa a ser definida por (ANSYS FLUENT, 2009, p. 4-32):

$$
\mu_{\mathrm{t}}=\frac{\rho \mathrm{k}}{\omega} \frac{1}{\max \left[\frac{1}{\alpha^{*}}, \frac{\mathrm{S} \cdot \mathrm{F}_{2}}{\mathrm{a}_{1} \omega}\right]}
$$

Onde S é média do módulo do tensor taxa de deformação, mostrado na equação ( 4-29 ). O amortecimento da viscosidade turbulenta, $\alpha^{*}$, é definido pela equação ( 4-66 ), a é constante e $\mathrm{F}_{2}$ é uma função de mistura que é dada por: 


$$
\begin{gathered}
\mathrm{F}_{2}=\tanh \left(\Phi_{2}^{2}\right) \\
\Phi_{2}=\max \left[\frac{2 \sqrt{\mathrm{k}}}{0.09 \omega .}, \frac{500 \mu}{\rho y^{2} \omega}\right]
\end{gathered}
$$

$\mathrm{Y}_{\mathrm{k}}$ e $\mathrm{Y}_{\omega}$ são as dissipações de $\mathrm{k}$ e $\omega$ devido à turbulência, definidos fazendo $\mathrm{f}_{\beta}$ e e $\mathrm{f}_{\beta}$ igual a 1 nas equações ( 4-70) (4-76):

$$
\begin{aligned}
& Y_{\mathrm{k}}=\rho \beta^{*} k \omega \\
& Y_{\omega}=\rho \beta \omega^{2}
\end{aligned}
$$

$S_{\mathrm{k}}$ e $S_{\omega}$ são termos fonte. $D_{\omega}$ representa o termo de difusão cruzada, que aparece devido à mistura entre os modelos k- $\varepsilon$ e k- $\omega$, e é definido por (ANSYS FLUENT, 2009, p 435):

$$
\mathrm{D}_{\omega}=2\left(1-\mathrm{F}_{1}\right) \rho \sigma_{\omega, 2} \frac{1}{\omega} \frac{\partial \mathrm{k}}{\partial \mathrm{x}_{\mathrm{j}}} \frac{\partial \omega}{\partial \mathrm{x}_{\mathrm{j}}}
$$

As constantes utilizadas no modelo são:

$$
\sigma_{\mathrm{k}, 1}=1.176, \sigma_{\omega, 1}=2, \sigma_{\omega, 2}=1.168, \mathrm{a}_{1}=0.31, \beta_{\mathrm{i}, 1}=0.075 \text { e } \beta_{\mathrm{i}, 2}=0.0828
$$




\subsubsection{Modelo das Tensões de Reynolds}

O modelo das tensões de Reynolds (RSM - Reynolds Stress Model), também conhecido por modelo de fechamento de segunda ordem, é o mais complexo dos modelos clássicos. De acordo com vários autores (CHUNG, 2002, p. 690, TANNEHIL; ANDERSON; PLETCHER, 1997, p. 317, VERSTEEG; MALALASEKERA, 1995, p. 75) efeitos de curvatura nas linhas de corrente, mudanças bruscas nas taxas de deformação e escoamentos secundários induzidos por tensões são difíceis de serem bem captados pelos modelos de duas equações, pelo fato de utilizarem a aproximação de Boussinesq (equação ( 4-4 )) .Wilcox (1994, p. 223) afirma que essas situações são naturalmente incluídas no equacionamento nos modelos de fechamento de segunda ordem.

Esse tipo de equacionamento teve início com o trabalho de Launder, Reece e Rodi., $1975^{7}$ (apud VERSTEEG; MALALASEKERA, 1995, p. 75), onde as tensões de Reynolds são deduzidas multiplicando-se a equação de Navier-Stokes por flutuações das velocidades e depois feita a média. Maiores detalhes podem ser encontrados em Tannehil, Anderson e Pletcher (1997, p. 317) e Wilcox (1994, p.223).

Assim o modelo utiliza, para uma simulação 3D, seis equações de transporte para as tensões de Reynolds $\left(\overline{u_{\mathrm{i}}^{\prime} \mathrm{u}_{\mathrm{j}}^{\prime}}\right)$, devido à simetria do tensor, e uma para a taxa de dissipação, $\varepsilon$, no caso do Ansys Fluent, ou outra que forneça uma escala de tempo ou comprimento para a turbulência, como por exemplo, $\omega$.

Ansys Fluent (2009, p. 4-49) cita como exemplos de aplicações desse modelo o cálculo de ciclones, combustores, rotações em passagens e escoamentos secundários. O elevado custo computacional do modelo devido às 7 equações de transporte que ele calcula é comentado por Versteeg e Malalasekera (1995, p. 78) e por Wilcox (1994, p. 223). Apesar de

\footnotetext{
${ }^{7}$ LAUNDER, B. E.; REECE, G. J.; RODI, W. Progress in Development of a Reynolds-Stress Turbulence Closure. Journal of Fluid Mechanic, vol. 68, pt. 3, p. 537-566, 1975
} 


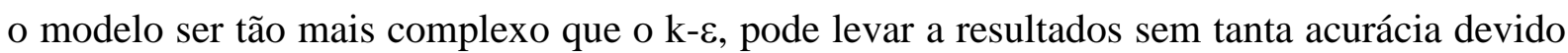
à dificuldade de modelagem de $\varepsilon$, em alguns casos, como por exemplo, de jatos axissimétricos (VERSTEEG; MALALASEKERA, 1995, p. 78)

A equação de transporte para as tensões de Reynolds são (ANSYS FLUENT, 2009, p. 4-49):

$$
\begin{aligned}
& \left.\frac{\partial}{\partial t}\left(\rho \overline{u_{i}^{\prime} u_{j}^{\prime}}\right)+\frac{\partial}{\partial x_{k}}\left(\rho u_{k} \overline{u_{i}^{\prime} u_{j}^{\prime}}\right)=-\frac{\partial}{\partial x_{k}}\left[\rho \overline{u_{i}^{\prime} u_{j}^{\prime} u_{k}^{\prime}}+\overline{p\left(\delta_{k j} u_{i}^{\prime}+\delta_{i k} u_{j}^{\prime}\right.}\right)\right] \\
& +\frac{\partial}{\partial x_{k}}\left[\mu \frac{\partial}{\partial x_{k}}\left(\overline{u_{i}^{\prime} u_{j}^{\prime}}\right)\right]-\rho\left(\overline{u_{i}^{\prime} u_{k}^{\prime}} \frac{\partial u_{j}}{\partial x_{k}}+\overline{u_{j}^{\prime} u_{k}^{\prime}} \frac{\partial u_{i}}{\partial x_{k}}\right)-\rho \beta\left(g_{i} \overline{u_{j}^{\prime} \theta}+g_{j} \overline{u_{i}^{\prime} \theta}\right) \\
& +\overline{\left(\frac{\partial u_{i}^{\prime}}{\partial x_{j}}+\frac{\partial u_{j}^{\prime}}{\partial x_{i}}\right)}-2 \mu \overline{\frac{\partial u_{i}^{\prime}}{\partial x_{k}} \frac{\partial u_{j}^{\prime}}{\partial x_{k}}}-2 \rho \Omega_{k}\left(\overline{u_{i}^{\prime} u_{m}^{\prime}} \varepsilon_{j k m}+\overline{u_{j}^{\prime} u_{m}^{\prime}} \varepsilon_{i k m}\right)+S
\end{aligned}
$$

O primeiro termo, da esquerda para a direita, representa a derivada temporal local.

O segundo termo é o convectivo $\left(\mathrm{C}_{\mathrm{ij}}\right)$.

O terceiro termo representa a difusão da turbulência $\left(D_{T, i j}\right)$.

O quarto termo mostra a difusão molecular $\left(\mathrm{D}_{\mathrm{L}, \mathrm{ij}}\right)$.

O quinto termo é o de produção de tensão $\left(\mathrm{P}_{\mathrm{ij}}\right)$.

O sexto termo representa a produção de flutuação $\left(\mathrm{G}_{\mathrm{ij}}\right)$.

O sétimo termo é o de pressão deformação $\left(\phi_{\mathrm{ij}}\right)$.

O oitavo termo é a dissipação $\left(\varepsilon_{\mathrm{ij}}\right)$.

O nono termo mostra a produção pelo sistema de rotação $\left(\mathrm{F}_{\mathrm{ij}}\right)$.

E por fim, o décimo termo é uma fonte definida pelo usuário.

Como as tensões de Reynolds são deduzidas a partir de equações exatas de NavierStokes, os termos $C_{\mathrm{ij}}, \mathrm{D}_{\mathrm{L}, \mathrm{ij}}, \mathrm{P}_{\mathrm{ij}}$ e $\mathrm{F}_{\mathrm{ij}}$ não precisam ser modelados. Entretanto os demais, $\mathrm{D}_{\mathrm{T}, \mathrm{ij}}$, 
$\mathrm{G}_{\mathrm{ij}}, \phi_{\mathrm{ij}}$ e $\varepsilon_{\mathrm{ij}}$ necessitam de modelagem para o fechamento das equações (ANSYS FLUENT, 2009 , p. 4-49).

\section{Modelagem do tensor pressão deformação $-\phi_{\mathrm{ij}}$}

Vários autores (CHUNG, 2002, p. 691, POPE, 2000, p. 387, e WILCOX, 1994, p. 226) consideram que o tensor pressão deformação $\left(\phi_{\mathrm{ij}}\right)$ é o mais importante a ser modelado. Wilcox (1994, p. 226) fala que isso se dá porque esse tensor é da mesma ordem de grandeza da produção e tem um papel importante em muitos escoamentos de interesse, além de envolver correlações que não são possíveis de serem medidas.

O Ansys Fluent possui três maneiras de modelar o tensor pressão deformação: linear, quadrática e tensão-omega. A modelagem linear é a padrão do software e foi a utilizada no presente trabalho, e por isso a única aqui equacionada:

$$
\varphi_{\mathrm{ij}}=\varphi_{\mathrm{ij}, 1}+\varphi_{\mathrm{ij}, 2}+\varphi_{\mathrm{ij}, \mathrm{w}}
$$

Onde:

$\varphi_{\mathrm{ij}, 1}$ é a deformação pressão lenta, também chamado de termo de retorno à isotropia,

$\varphi_{\mathrm{ij}, 2}$ é o de termo de deformação pressão rápida

$\varphi_{\mathrm{ij}, \mathrm{w}}$ representa o termo de reflexão de parede.

O termo de deformação pressão lenta é:

$$
\varphi_{\mathrm{ij}, 1} \equiv-\mathrm{C}_{1} \rho \frac{\varepsilon}{\mathrm{k}}\left[\overline{\mathrm{u}_{\mathrm{i}}^{\prime} \mathrm{u}_{\mathrm{j}}^{\prime}}-\frac{2}{3} \delta_{\mathrm{ij}} \mathrm{k}\right]
$$


Com $\mathrm{C}_{1}=1.8$, $\varepsilon$ dado pela equação ( 4-132 ) e a energia cinética turbulenta, $\mathrm{k}$, é modelada no escoamento livre utilizando-se o traço do tensor das tensões de Reynolds:

$$
\mathrm{k}=\frac{1}{2} \overline{\mathrm{u}_{\mathrm{i}}^{\prime} \mathrm{u}_{\mathrm{i}}^{\prime}}
$$

O termo de deformação pressão rápido $\varphi_{\mathrm{ij}, 2}$ é dado por:

$$
\varphi_{\mathrm{ij}, 2} \equiv-\mathrm{C}_{2}\left[\left(\mathrm{P}_{\mathrm{ij}}+\mathrm{F}_{\mathrm{ij}}+\frac{5}{6} \mathrm{G}_{\mathrm{ij}}-\mathrm{C}_{\mathrm{ij}}\right)-\frac{2}{3} \delta_{\mathrm{ij}}\left(\mathrm{P}+\frac{5}{6} \mathrm{G}-\mathrm{C}\right)\right] \mathrm{t}
$$

Onde $C_{2}=0.60$, e $P_{i j}, F_{i j}$ e $C_{i j}$ são definidos pela equação ( 4-109 ). A produção da flutuação, $G_{i j}$, será definida na equação ( 4-128 ), e ainda:

$$
\mathrm{P}=\frac{1}{2} \mathrm{P}_{\mathrm{kk}} \mathrm{G}=\frac{1}{2} \mathrm{G}_{\mathrm{kk}} \mathrm{C}=\frac{1}{2} \mathrm{C}_{\mathrm{kk}}
$$

O termo de reflexão da parede $\varphi_{\mathrm{ij}, \mathrm{w}}$ (um opcional ativado na forma padrão do modelo no Ansys Fluent) redistribui as tensões normais próximo à parede. Ele amortece as tensões normais e intensifica as tensões tangenciais à parede (ANSYS FLUENT, 2009, p. 4-51):

$$
\begin{aligned}
& \varphi_{\mathrm{ij}, \mathrm{w}} \equiv \mathrm{C}_{1}^{\prime} \frac{\varepsilon}{\mathrm{k}}\left(\overline{\mathrm{u}_{\mathrm{k}}^{\prime} \mathrm{u}_{\mathrm{m}}^{\prime}} \mathrm{n}_{\mathrm{k}} \mathrm{n}_{\mathrm{m}} \delta_{\mathrm{ij}}-\frac{3}{2} \overline{\mathrm{u}_{\mathrm{i}}^{\prime} \mathrm{u}_{\mathrm{k}}^{\prime}} \mathrm{n}_{\mathrm{j}} \mathrm{n}_{\mathrm{k}}-\frac{3}{2} \overline{\mathrm{u}_{\mathrm{j}}^{\prime} \mathrm{u}_{\mathrm{k}}^{\prime}} \mathrm{n}_{\mathrm{i}} \mathrm{n}_{\mathrm{k}}\right) \frac{\mathrm{k}^{3 / 2}}{\mathrm{C}_{\mathrm{l}} \varepsilon \mathrm{d}} \\
& +\mathrm{C}_{2}^{\prime}\left(\varphi_{\mathrm{km}, 2} \mathrm{n}_{\mathrm{k}} \mathrm{n}_{\mathrm{m}} \delta_{\mathrm{ij}}-\frac{3}{2} \varphi_{\mathrm{ik}, 2} \mathrm{n}_{\mathrm{j}} \mathrm{n}_{\mathrm{k}}-\frac{3}{2} \varphi_{\mathrm{jk}, 2} \mathrm{n}_{\mathrm{i}} \mathrm{n}_{\mathrm{k}}\right) \frac{\mathrm{k}^{3 / 2}}{\mathrm{C}_{\mathrm{l}} \varepsilon \mathrm{d}}
\end{aligned}
$$


Onde:

$\mathrm{C}_{1}^{\prime}=0.5$ e $\mathrm{C}_{2}^{\prime}=0.3$

$\mathrm{n}_{\mathrm{k}}$ são as componentes da normal unitária da parede.

d é a distância normal à parede

$\mathrm{C}_{1}$ é definido por

$$
\mathrm{C}_{1}=\frac{\mathrm{C}_{\mu}^{3 / 4}}{\kappa}
$$

Com :

$\mathrm{C}_{\mu}=0.09$

$\kappa=0.4187$ (constante de von Kármán)

Se a função de parede melhorada (Enhanced wall function) é empregada, que foi o caso do presente estudo, o modelo do tensor pressão deformação é alterado, e os valores de $\mathrm{C}_{1}^{\prime}, \mathrm{C}_{2}^{\prime}$ e $\mathrm{C}_{1}$ utilizados na equação ( 4-115 ) e $\mathrm{C}_{2}$ da equação ( 4-113 ) passam a ser funções dos invariantes do tensor das tensões de Reynolds (ANSYS FLUENT, 2009, p. 4-51).

$$
\begin{gathered}
\mathrm{C}_{1}=1+2.58 \mathrm{~A} \sqrt{\mathrm{A}_{2}}\left\{1-\exp \left[-\left(0.0067 \mathrm{Re}_{\mathrm{t}}\right)^{2}\right]\right\} \\
\mathrm{C}_{2}=0.75 \sqrt{\mathrm{A}} \\
\mathrm{C}_{1}^{\prime}=-\frac{2}{3} \mathrm{C}_{1}+1.67
\end{gathered}
$$




$$
\mathrm{C}_{2}^{\prime}=\max \left[\frac{\frac{2}{3} \mathrm{C}_{2}-\frac{1}{6}}{\mathrm{C}_{2}}, 0\right]
$$

O número de Reynolds turbulento definido como:

$$
\operatorname{Re}_{\mathrm{t}}=\frac{\rho \mathrm{k}^{2}}{\mu \varepsilon}
$$

O parâmetro de nivelamento A e as invariantes do tensor anisotrópico das tensões de Reynolds $\mathrm{A}_{2}$ e $\mathrm{A}_{3}$ são definidos por:

$$
\mathrm{A} \equiv\left[1-\frac{9}{8}\left(\mathrm{~A}_{2}-\mathrm{A}_{3}\right)\right]
$$

$$
\mathrm{A}_{2} \equiv \mathrm{a}_{\mathrm{ik}} \mathrm{a}_{\mathrm{ki}}
$$

$$
A_{3} \equiv a_{i k} a_{k j} a_{j i}
$$

Onde $\mathrm{a}_{\mathrm{ij}}$ é o tensor anisotrópico das tensões de Reynolds, dado como:

$$
a_{i j}=-\left(\frac{-\rho \overline{u_{i}^{\prime} u_{j}^{\prime}}+\frac{2}{3} \rho k \delta_{i j}}{\rho k}\right)
$$




\section{Modelagem do transporte difusivo turbulento $-\mathbf{D}_{\mathrm{T}, \mathrm{j}}$}

A modelagem do transporte difusivo turbulento $\left(\mathrm{D}_{\mathrm{T}, \mathrm{ij}}\right)$ adotado pelo Ansys Fluent é dada por (ANSYS FLUENT, 2009, p. 4-51):

$$
\mathrm{D}_{\mathrm{T}, \mathrm{ij}}=\frac{\partial}{\partial \mathrm{x}_{\mathrm{k}}}\left(\frac{\mu_{\mathrm{t}}}{\sigma_{\mathrm{k}}} \frac{\partial \overline{\mathrm{u}_{\mathrm{i}}^{\prime} \mathrm{u}_{\mathrm{j}}^{\prime}}}{\partial \mathrm{x}_{\mathrm{k}}}\right)
$$

Com $\sigma_{\mathrm{k}}=0.82$ (diferente do modelo $\mathrm{k}-\varepsilon$, onde valia 1) e a viscosidade turbulenta modelada da seguinte maneira:

$$
\mu_{\mathrm{t}}=\rho \mathrm{C}_{\mu} \frac{\mathrm{k}^{2}}{\varepsilon}
$$

$$
\mathrm{C}_{\mu}=0.09
$$

\section{Modelagem da produção de flutuação $-\mathbf{G}_{\mathrm{ij}}$}

O termo de produção devido à flutuação é modelado por (ANSYS FLUENT, 2009, p. 4-55):

$$
G_{i j}=-\frac{\mu_{t}}{\rho P r_{t}}\left(g_{i} \frac{\partial \rho}{\partial x_{j}}+g_{j} \frac{\partial \rho}{\partial x_{i}}\right)
$$

$\mathrm{Pr}_{\mathrm{t}}$ é o número de Prandtl turbulento igual a 0.85 


\section{Modelagem do tensor dissipação $-\varepsilon_{\mathrm{ij}}$}

O tensor dissipação é dado por (ANSYS FLUENT, 2009, p. 4-56):

$$
\varepsilon_{\mathrm{ij}}=\frac{2}{3} \delta_{\mathrm{ij}}\left(\rho \varepsilon+\mathrm{Y}_{\mathrm{M}}\right)
$$

Onde

$$
\mathrm{Y}_{\mathrm{M}}=2 \rho \varepsilon \mathrm{M}_{\mathrm{t}}^{2}
$$

Que é um termo adicional da dilatação da dissipação.

O número de Mach turbulento é dado por:

$$
M_{t}=\sqrt{\frac{k}{a^{2}}}
$$

Onde $a$ é a velocidade do som. Esta modificação de compressibilidade é sempre considerada quando a forma compressível da lei de gás ideal ${ }^{8}$ é usada (ANSYS FLUENT, 2009, p. 4-56).

A taxa de dissipação escalar $\varepsilon$ é calculada com uma equação de transporte semelhante à empregada pelo modelo k- $\varepsilon$ padrão:

\footnotetext{
${ }^{8}$ No Ansys Fluent há a opção de gás ideal incompressível, onde a densidade depende apenas da pressão de operação e não da pressão local relativa no domínio, como no modelo de gás ideal
} 


$$
\begin{aligned}
& \frac{\partial}{\partial t}(\rho \varepsilon)+\frac{\partial}{\partial x_{j}}\left(\rho \varepsilon u_{j}\right)=\frac{\partial}{\partial x_{j}}\left[\left(\mu+\frac{\mu_{t}}{\sigma_{k}}\right) \frac{\partial \varepsilon}{\partial x_{j}}\right]+C_{\varepsilon 1} \frac{1}{2}\left[P_{i i}+C_{3 \varepsilon} G_{i i}\right] \frac{\varepsilon}{k} \\
& -C_{\varepsilon 2} \rho \frac{\varepsilon^{2}}{k}+S_{\varepsilon}
\end{aligned}
$$

onde $\sigma_{\varepsilon}=1.0, \mathrm{C}_{\varepsilon 1}=1.44, \mathrm{C}_{\varepsilon 2}=1.92$ e $\mathrm{S}_{\varepsilon}$ é termo fonte.

\section{Modelagem das tensões de Reynolds próximo às paredes}

Nas células adjacentes às paredes o Ansys Fluent calcula as tensões de Reynolds e $\varepsilon$ com funções de parede. O software assume que o primeiro elemento está na zona logarítmica da camada limite (melhor explicada no item 4.3.9), que há equilíbrio, e desconsidera os termos convectivos e difusivos da equação ( 4-109 ). Assim, usando um sistema de coordenadas locais, onde $\tau$ é uma coordenada tangencial, $\eta$ é a normal e $\lambda$ é a binormal, as tensões de Reynolds nas células adjacentes às paredes são dadas por (ANSYS FLUENT, 2009, p. 4-57):

$$
\frac{\overline{\mathrm{u}_{\tau}^{\prime 2}}}{\mathrm{k}}=1.098, \frac{\overline{\mathrm{u}_{\eta}^{\prime 2}}}{\mathrm{k}}=0.247, \frac{\overline{\mathrm{u}_{\lambda}^{\prime 2}}}{\mathrm{k}}=0.655 \mathrm{e}-\frac{\overline{\mathrm{u}_{\tau}^{\prime} \mathrm{u}_{\eta}^{\prime}}}{\mathrm{k}}=0.255
$$

O k utilizado nas equações ( 4-133 ) é obtido com a equação de transporte ( 4-134 ):

$$
\frac{\partial}{\partial \mathrm{t}}(\rho \mathrm{k})+\frac{\partial}{\partial \mathrm{x}_{\mathrm{i}}}\left(\rho \mathrm{ku} \mathrm{j}_{\mathrm{j}}\right)=\frac{\partial}{\partial \mathrm{x}_{\mathrm{i}}}\left[\left(\mu+\frac{\mu_{\mathrm{t}}}{\sigma_{\mathrm{k}}}\right) \frac{\partial \mathrm{k}}{\partial \mathrm{x}_{\mathrm{j}}}\right]+\frac{1}{2}\left(\mathrm{P}_{\mathrm{ii}}+\mathrm{G}_{\mathrm{ii}}\right)-\rho \varepsilon\left(1+2 \mathrm{M}_{\mathrm{t}}^{2}\right)+\mathrm{S}_{k}
$$

Onde:

$\sigma_{\mathrm{k}}=0.82$. 
$\mathrm{S}_{\mathrm{k}}$ é o termo fonte definido pelo usuário.

$\mu_{\mathrm{t}}$ é definido pela equação ( 4-127 ).

$\mathrm{M}_{\mathrm{t}}$ é dado pela equação ( 4-131)

$\mathrm{P}_{\mathrm{ii}}$ é a diagonal principal do tensor produção de tensão definido na equação ( 4-109 ).

$\mathrm{G}_{\mathrm{ii}}$ é a diagonal principal do tensor produção de flutuação dado na equação ( 4-128 ).

Por motivos de conveniência computacional a equação ( 4-134 ) é resolvida em todo o domínio, embora os valores de $\mathrm{k}$ resultantes dela sejam utilizados apenas próximo às paredes. Para as outras regiões o valor de k é calculado pela equação ( 4-112 ) (ANSYS FLUENT, 2009, p. 4-57).

\subsubsection{O tratamento da turbulência próximo às paredes}

A presença de paredes sem escorregamento impõe a restrição de velocidade nula na interface entre a superfície e o fluido. Essa condição faz com que os efeitos viscosos sejam preponderantes nessa região. Entretanto, para elevados números de Reynolds a espessura da camada limite tem uma escala maior do que a região citada anteriormente, assim é preciso lidar com ordens de grandeza e regimes de escoamento diferentes simultaneamente (TENNEKES; LUMLEY, 1972, p. 146). Nesses casos a camada limite pode ser dividida em 3 regiões: a subcamada laminar, a camada amortecedora ou de transição e a zona turbulenta, ilustradas na

Figura 4-2. 


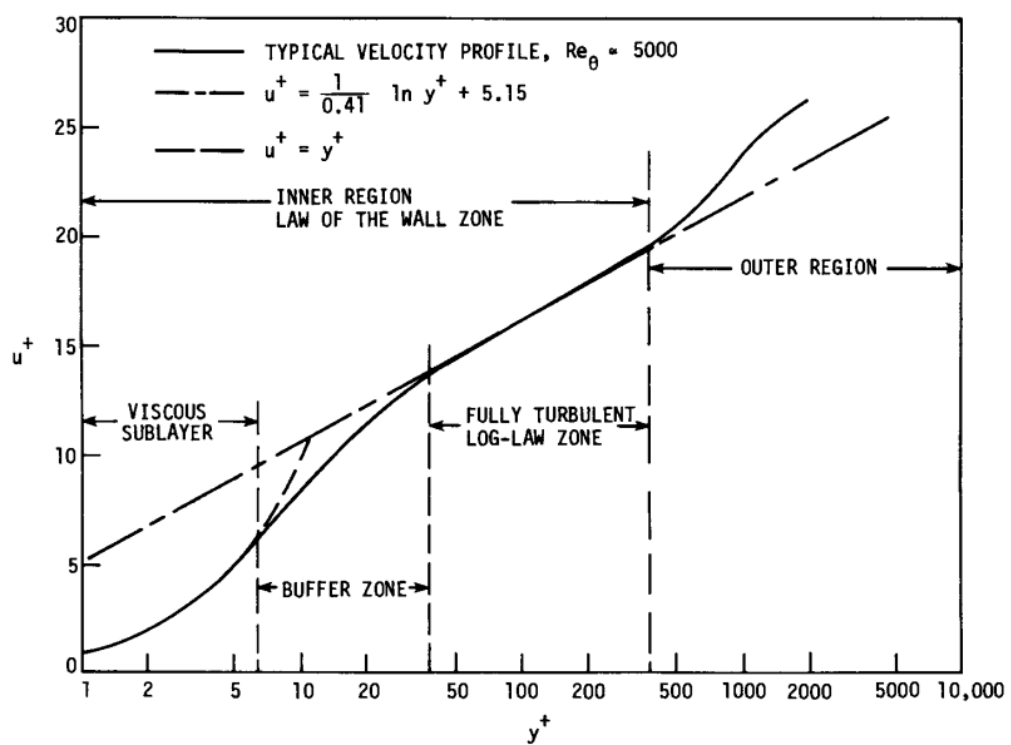

Figura 4-2: Divisões da camada limite em um escoamento turbulento (TANNEHIL; ANDERSON; PLETCHER, 1997, p. 302).

Para determinar se uma coordenada perpendicular à parede está em uma das 3 regiões da camada limite ou ainda fora dela é utilizado o adimensional y+, definido na equação ( 4$135)$

$$
\mathrm{y}^{+}=\frac{\mathrm{y} \sqrt{\tau_{0} / \rho}}{v}
$$

Com y sendo uma distância a partir da parede, $\rho$ representa a densidade, $v$ a viscosidade cinemática e $\tau_{0}$ a tensão de cisalhamento na parede.

Existem duas maneiras de se resolver o escoamento da camada limite: o refinamento da malha de forma suficiente que o centróide do primeiro elemento esteja na subcamada laminar, $\mathrm{y}^{+} \approx 1$ (BLAZEK, 2001, p. 245), ou através de funções de parede.

Funções de parede representam o comportamento do escoamento da subcamada viscosa e da zona intermediária quando a malha não for suficientemente refinada para calcular 
o fluxo nessa região. As leis de parede, como também são conhecidas, podem ser pensadas, aproximadamente, como uma solução de camada limite turbulenta utilizando o comprimento de mistura de Prandtl (TANNEHIL; ANDERSON; PLETCHER, 1997, p. 471), que apresenta uma função logarítmica. Foram encontradas pequenas variações para a validade dessas funções: $30<\mathrm{y}+<300$ (ANSYS FLUENT, 2009, p. 4-75) ou $30<\mathrm{y}+<200$ (TANNEHIL; ANDERSON; PLETCHER, 1997, p. 471).

Wilcox (1997, p. 127) comenta que as funções de parede nem sempre são a melhor escolha, pois, numericamente, a solução é sensível ao ponto onde essas funções são aplicadas e, além disso, são limitadas para predizer separação do escoamento.

No presente foi utilizada a "função de parede melhorada" (Enhanced wall function) que de acordo com Ansys Fluent (2009, p. 4-82) é aplicável tanto para malhas de baixo Reynolds $\left(\mathrm{y}^{+} \approx 1\right)$, como para malhas menos refinadas (malhas de funções de parede). Nessa mesma referência podem ser encontrados detalhes sobre o equacionamento desse modelo. 


\section{MODELO NUMÉRICO}

\subsection{Domínio de cálculo}

O tamanho do túnel de vento virtual e assim como os parâmetros de malha foram baseados no guia elaborado por Lanfrit (2005) para simulação de aerodinâmica automotiva externa utilizando o Ansys Fluent.

A geometria do veículo foi recebida através de correio eletrônico (TOLEDO, 2010) em formato stl. O modelo possui uma inclinação em relação ao plano horizontal de $0,07^{\circ}$, que é perceptível em vistas frontais do túnel virtual completo. Por questão de convergência o carro foi posicionado $30 \mathrm{~mm}$ acima do solo, como é possível observar na Figura 5-11, mesmo procedimento adotado por Gagnon e Richard (2010). A Figura 5-1, assim como a Figura 5-2 e a Figura 5-3, mostra o domínio de cálculo e os sub-domínios utilizados para refinamento da malha. Observa-se nelas que a hipótese de simetria longitudinal do escoamento foi empregada.

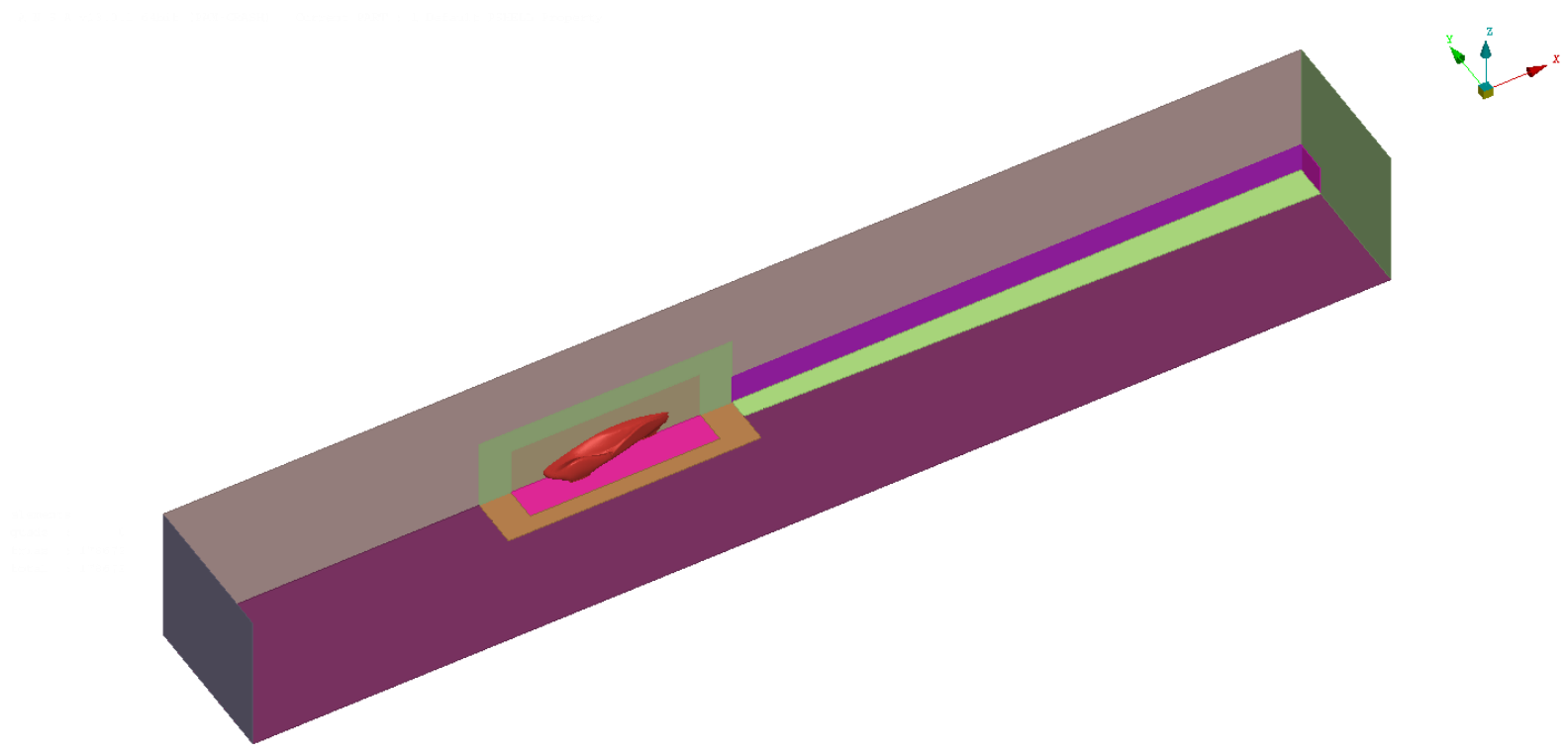

Figura 5-1: Vista isométrica do domínio de cálculo utilizado, sem os subdomínios de refinamento. 


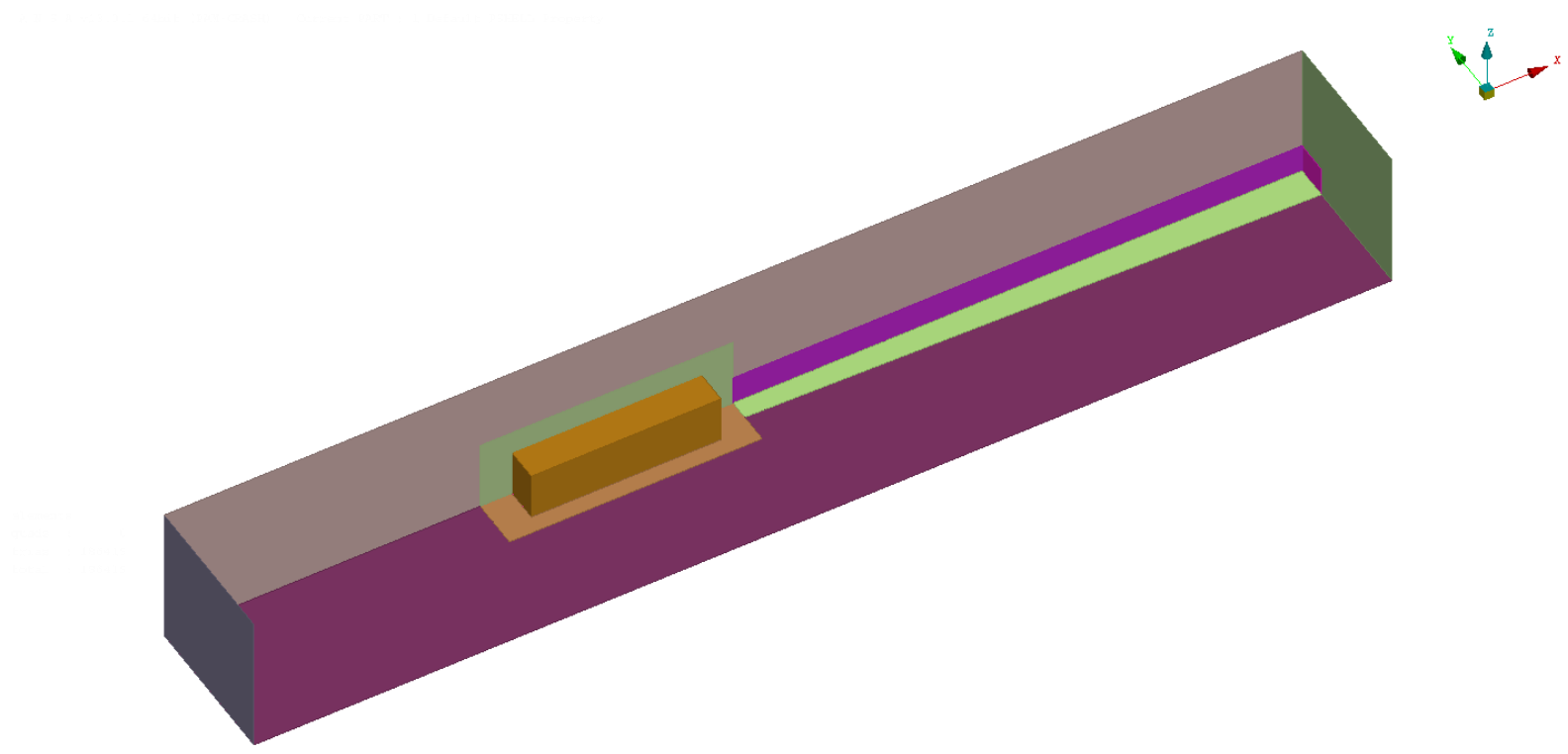

Figura 5-2: Vista isométrica do domínio de cálculo utilizado, com o volume de refinamento 1.

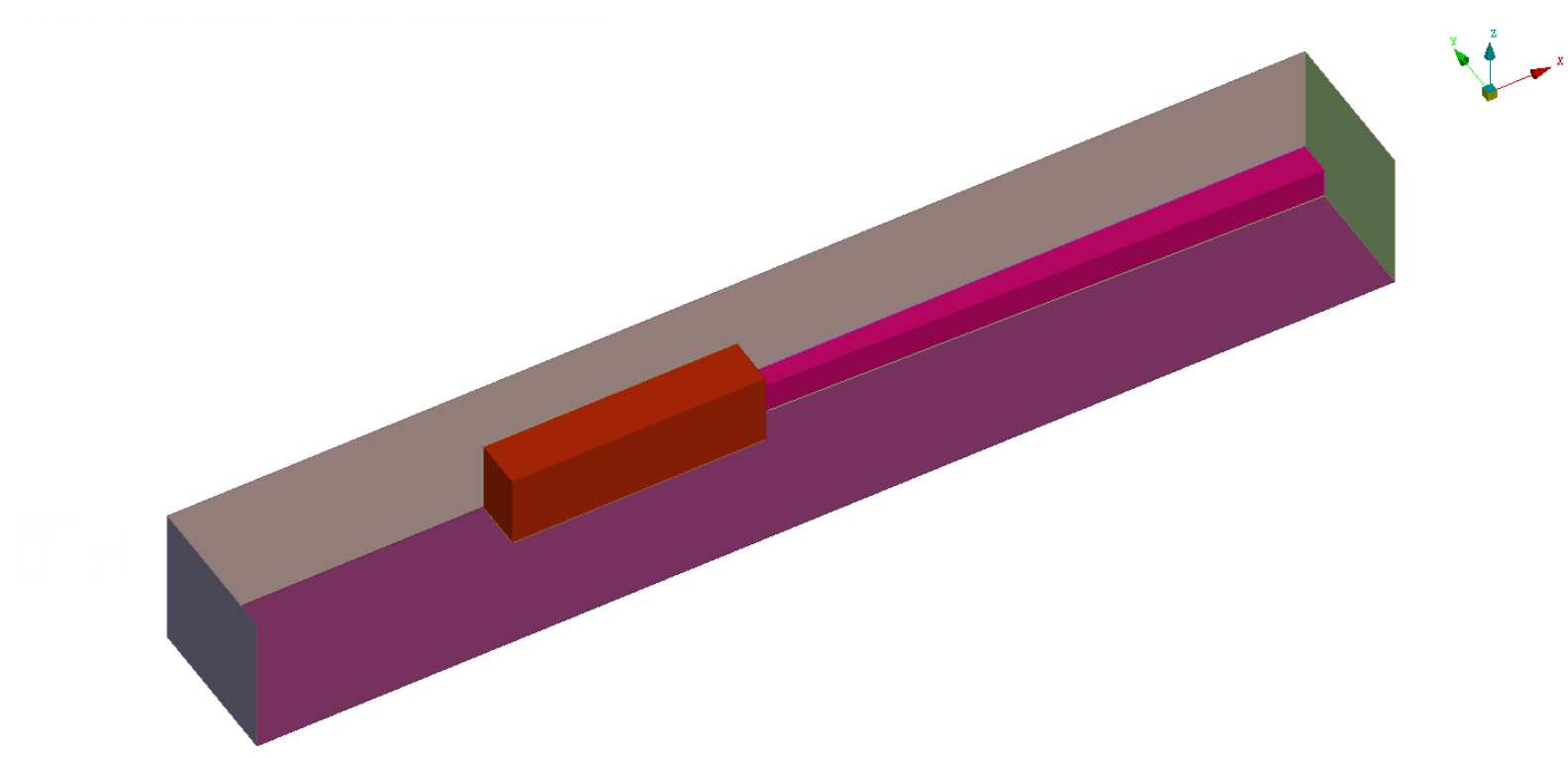

Figura 5-3: Vista isométrica do domínio de cálculo utilizado, com os volumes de refinamento 2 e na esteira.

Sendo L, H, e W o comprimento, a altura e a largura do veículo de milhagem o domínio de cálculo tem dimensões 9L x 23/3W x 5H, onde $\mathrm{L}=2503 \mathrm{~mm}, \mathrm{H}=575 \mathrm{~mm}$ e W = 400 mm. Há também outros três subdomínios para refino da malha, dois na região mais próxima ao carro e outro na zona da esteira. 


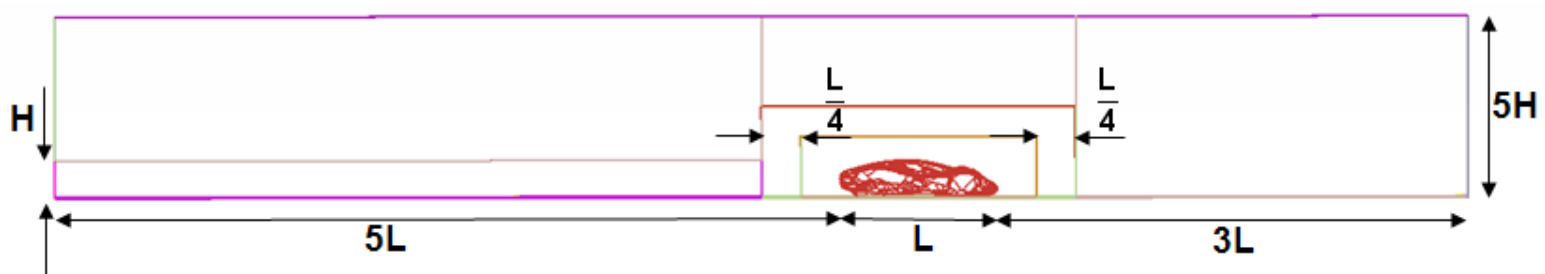

Figura 5-4: Vista lateral do domínio utilizado, com as dimensões explicitadas.

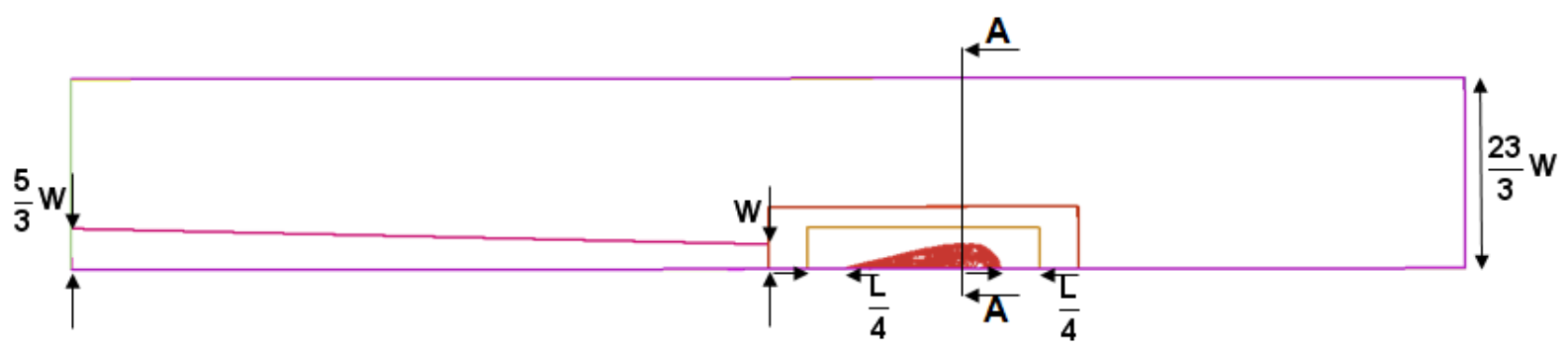

Figura 5-5: Vista lateral do domínio utilizado, com as dimensões explicitadas.

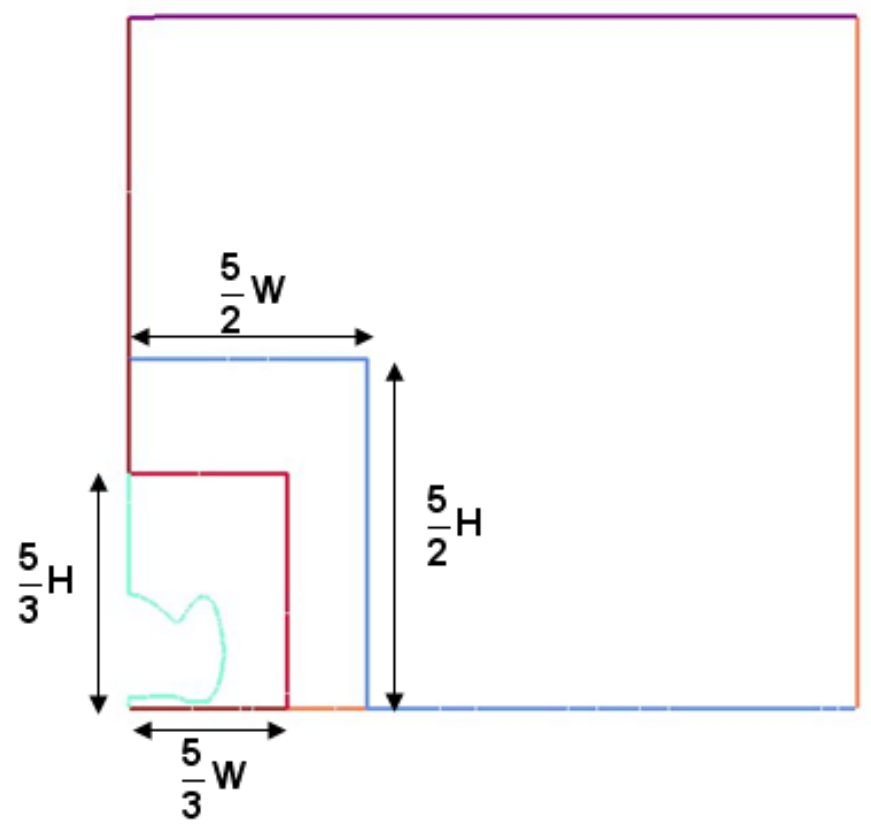

Figura 5-6: Corte AA referenciado na Figura 5-5.

Vale ressaltar que as dimensões dos subdomínios de cálculo, inclusive o ângulo de abertura do subdomínio da esteira, foram baseadas na experiência do autor com esse tipo de 
simulação. Um estudo mais detalhado sobre a dimensão do domínio de cálculo e dos subdomínios de refinamento da malha é uma sugestão de aprofundamento desse trabalho.

\subsection{Malha de volumes finitos}

\subsubsection{Malha superficial}

A malha superficial assim como o domínio de cálculo foram gerados no software Ansa v.13.0.1 e é composta exclusivamente por triângulos. Na superfície do veículo a aresta dos elementos têm $10 \mathrm{~mm}$ de comprimento nas regiões superior e lateral, e 5 nas partes mais próximas do solo.

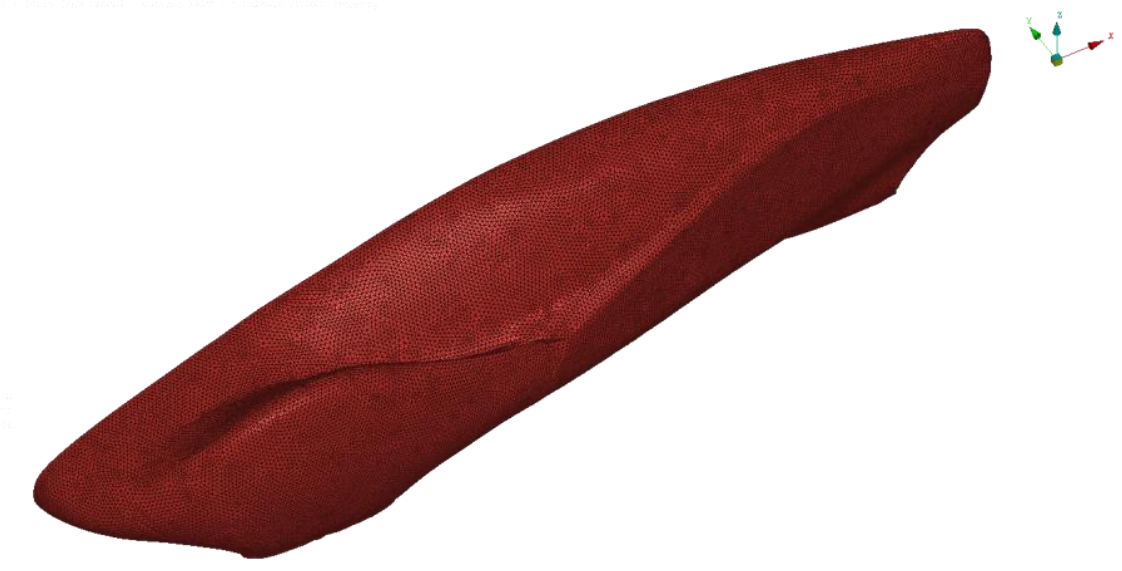

Figura 5-7: Vista isométrica da malha superficial no veículo. 

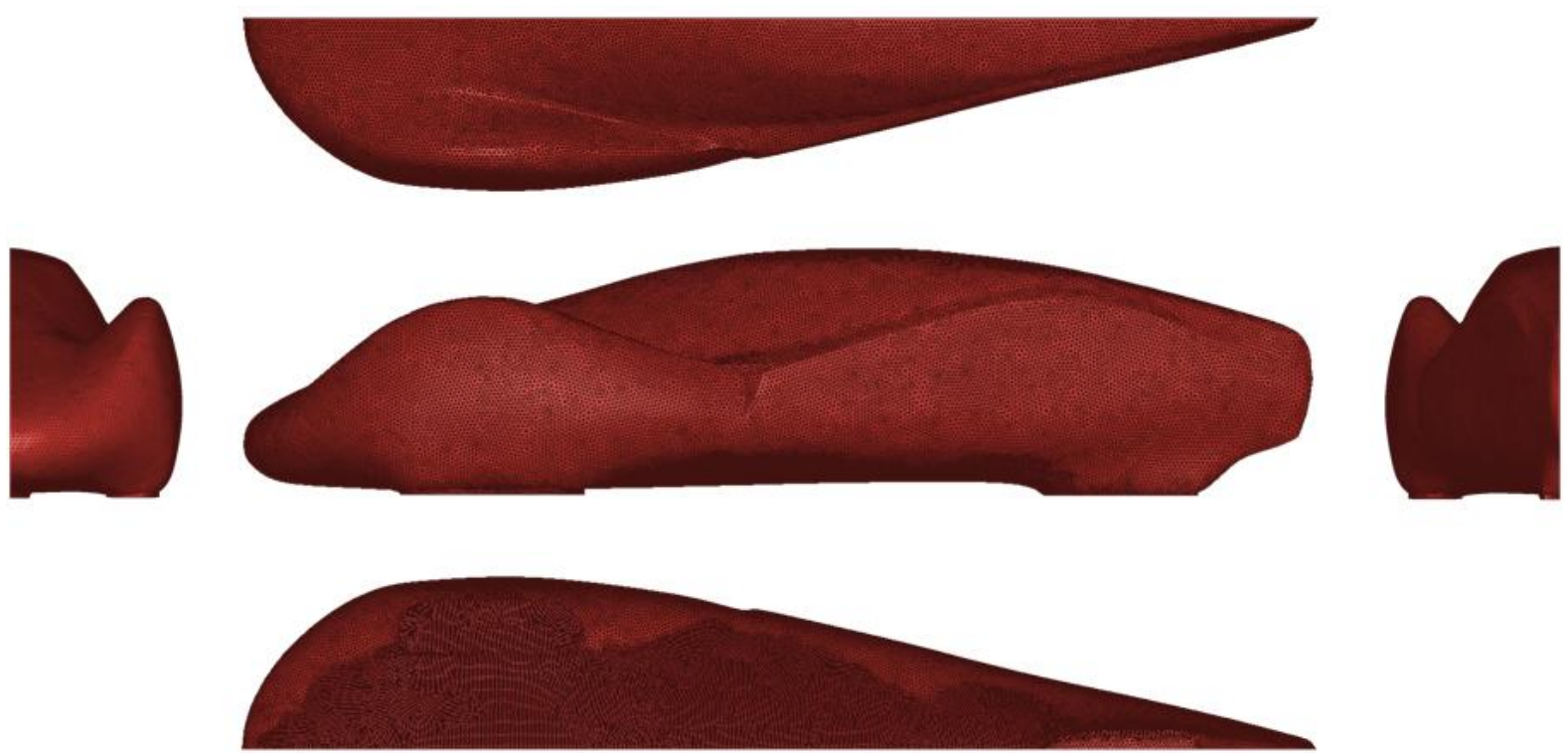

Figura 5-8: Vistas em planta da malha superficial no veículo. Na vista inferior pode-se ver a diferença das regiões com elementos de 5 e $10 \mathrm{~mm}$.

O piso possui triângulos com $40 \mathrm{~mm}$ de aresta nos dois os subdomínios próximos ao veículo e no de refinamento da esteira, e com $70 \mathrm{~mm}$ no subdomínio mais ao longe. Na região próxima a parte inferior do carro, o plano de simetria longitudinal possui espaçamento de 7 mm, e uma área próxima a parte inferior da caixa de roda, possui aresta de elemento de 10 mm. 


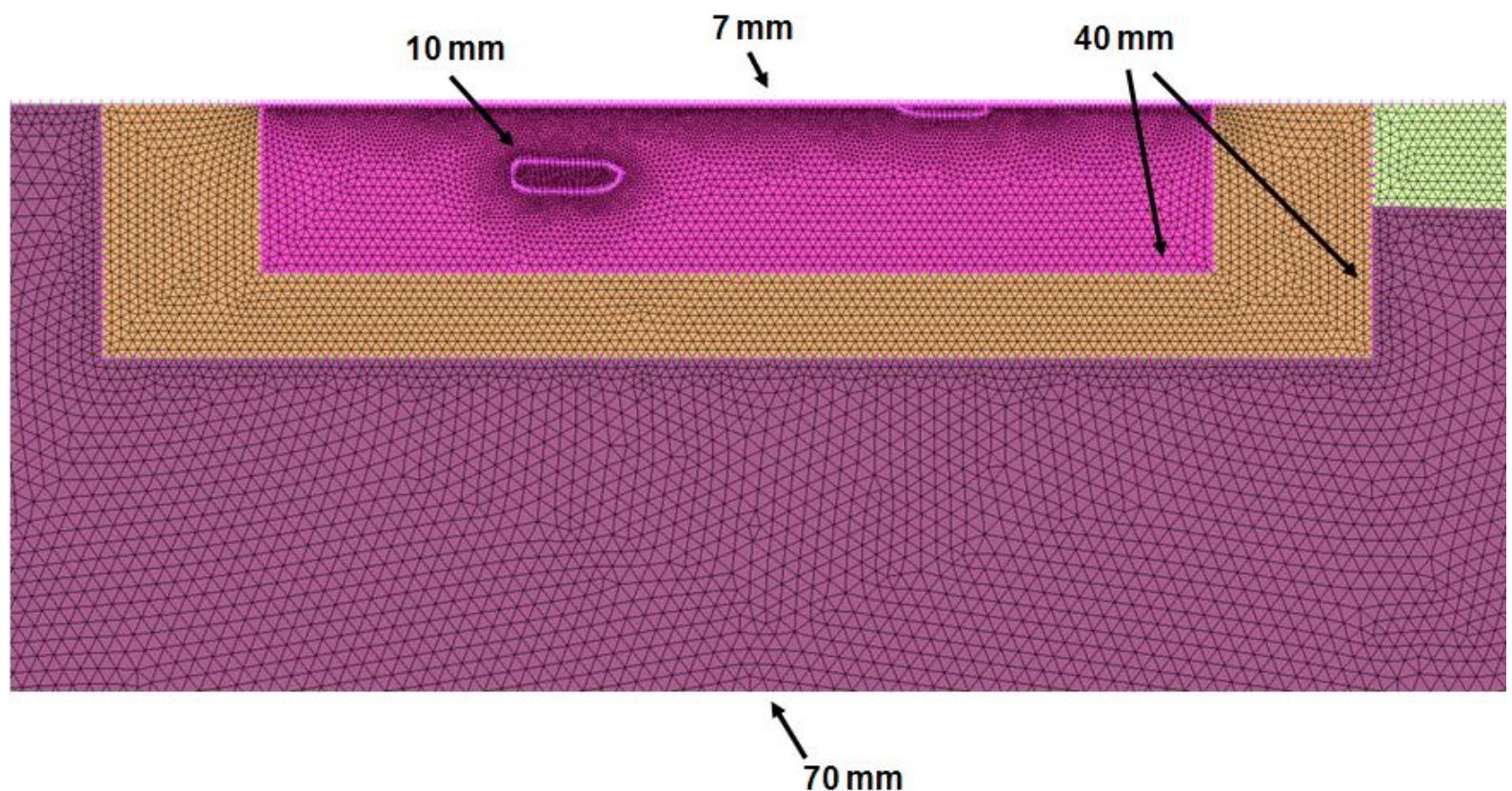

Figura 5-9: Valores do tamanho da aresta dos elementos no piso.

O primeiro volume de refinamento, mais próximo ao veículo, tem $50 \mathrm{~mm}$ de tamanho de aresta dos triângulos na parede, o segundo volume $100 \mathrm{~mm}$, a região para maior refinamento da esteira $70 \mathrm{~mm}$ e as paredes do túnel $300 \mathrm{~mm}$. Nas laterais da entrada e da saída os elementos possuem $200 \mathrm{~mm}$. A malha das paredes desses volumes na região próxima ao piso cresce de 40 até atingir o tamanho definido anteriormente com um fator de 1.1. 


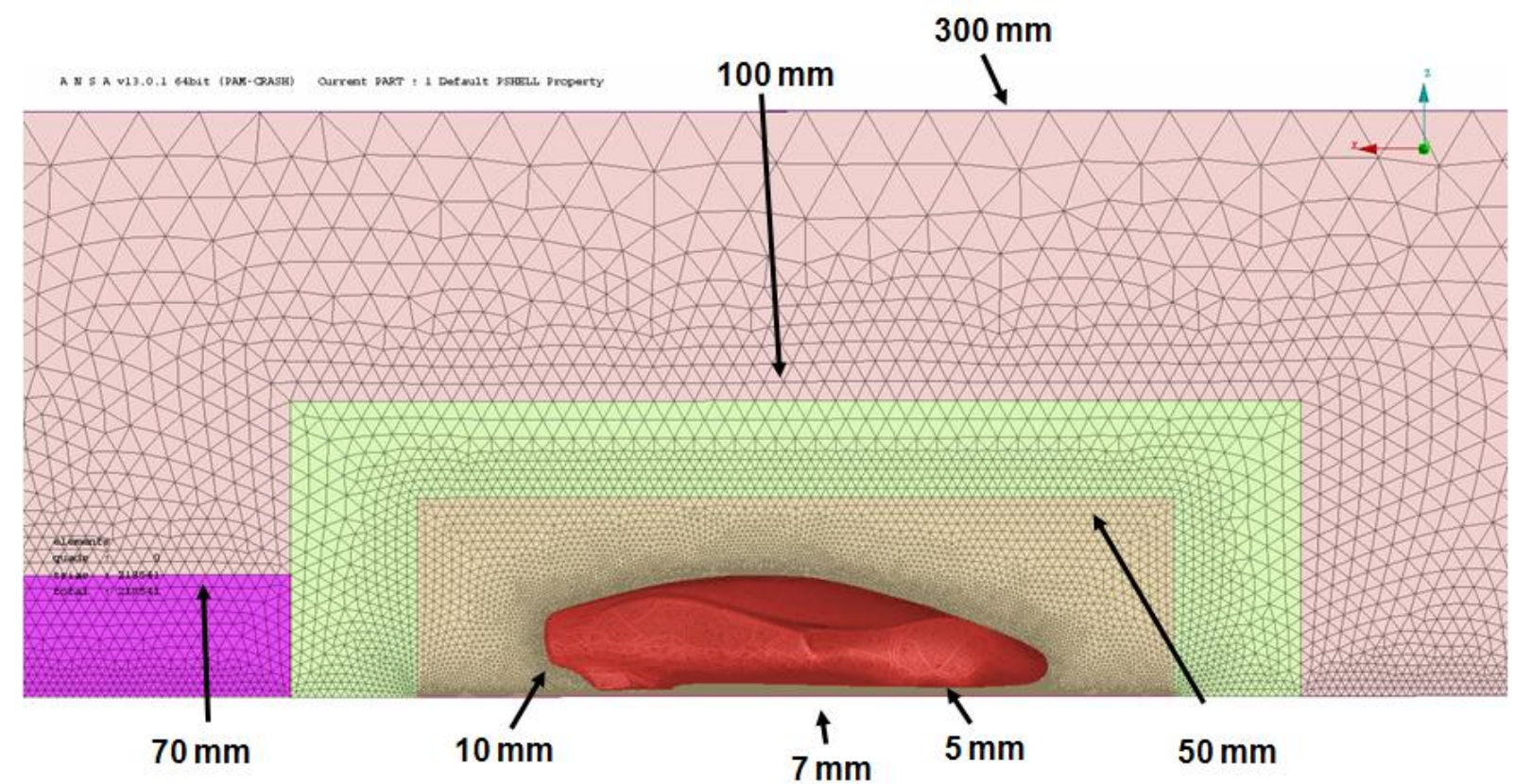

Figura 5-10: Dimensões dos elementos superficiais no veículo e nos volumes de refinamento.
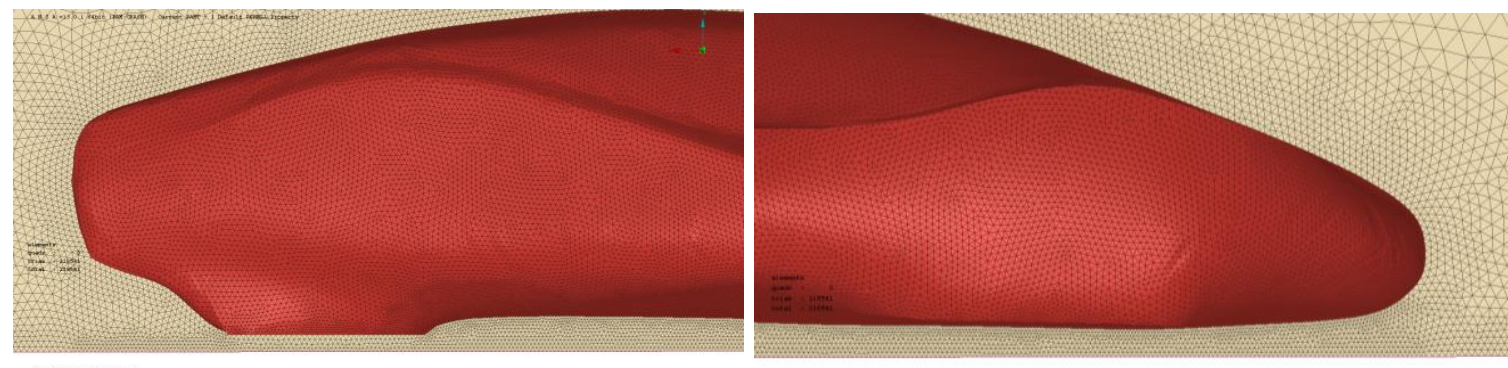

Figura 5-11: Detalhes dianteiro e traseiro da malha do veículo e da simetria.

\subsubsection{Malha volumétrica}

A malha volumétrica é composta de prismas nas regiões de paredes e tetraedros preenchendo o restante do domínio. Foi utilizado o software Tgrid 5.0.6 nesse procedimento.

$\mathrm{Na}$ superfície do veículo foram criadas 5 camadas de prismas, com a primeira tendo razão de aspecto 10 e com uma taxa de crescimento de 1.2. No piso 4 camadas de prismas foram geradas, com a primeira de tamanho constante $5.5 \mathrm{~mm}$ e taxa de crescimento de 1.2 também. Os tetraedros crescem a uma taxa de 1.3 e o tamanho máximo é o calculado automaticamente pelo software em cada sub-volume. 


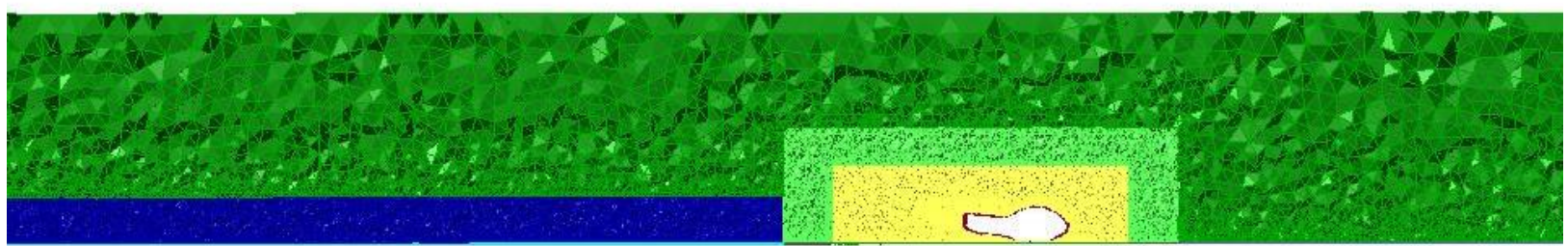

Figura 5-12: Visão geral da malha volumétrica. Plano y = -270 mm.

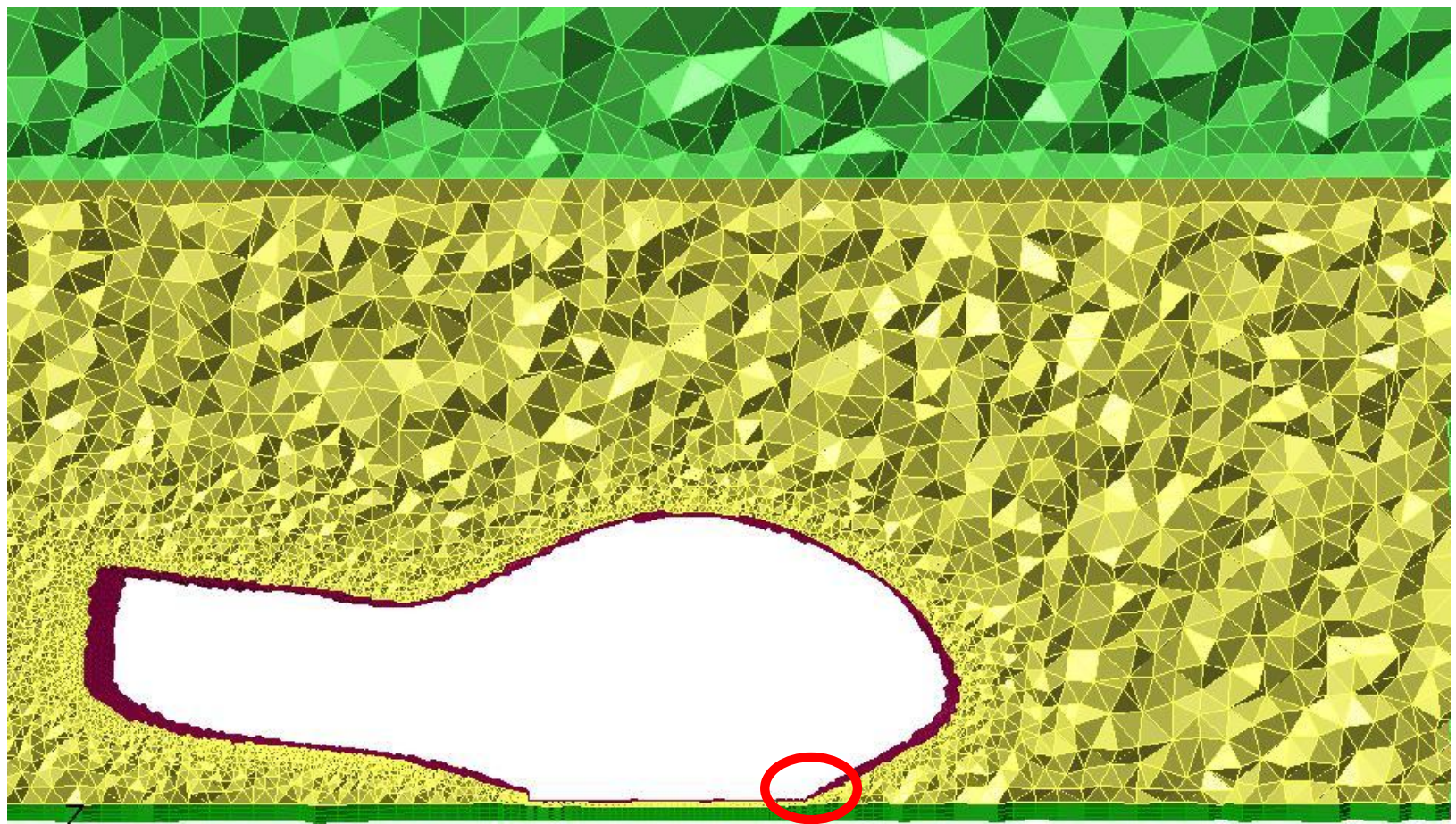

Figura 5-13: Visão mais próxima da malha volumétrica no plano y = -270 $\mathrm{mm}$. Detalhe do círculo vermelho ampliado na próxima figura. 


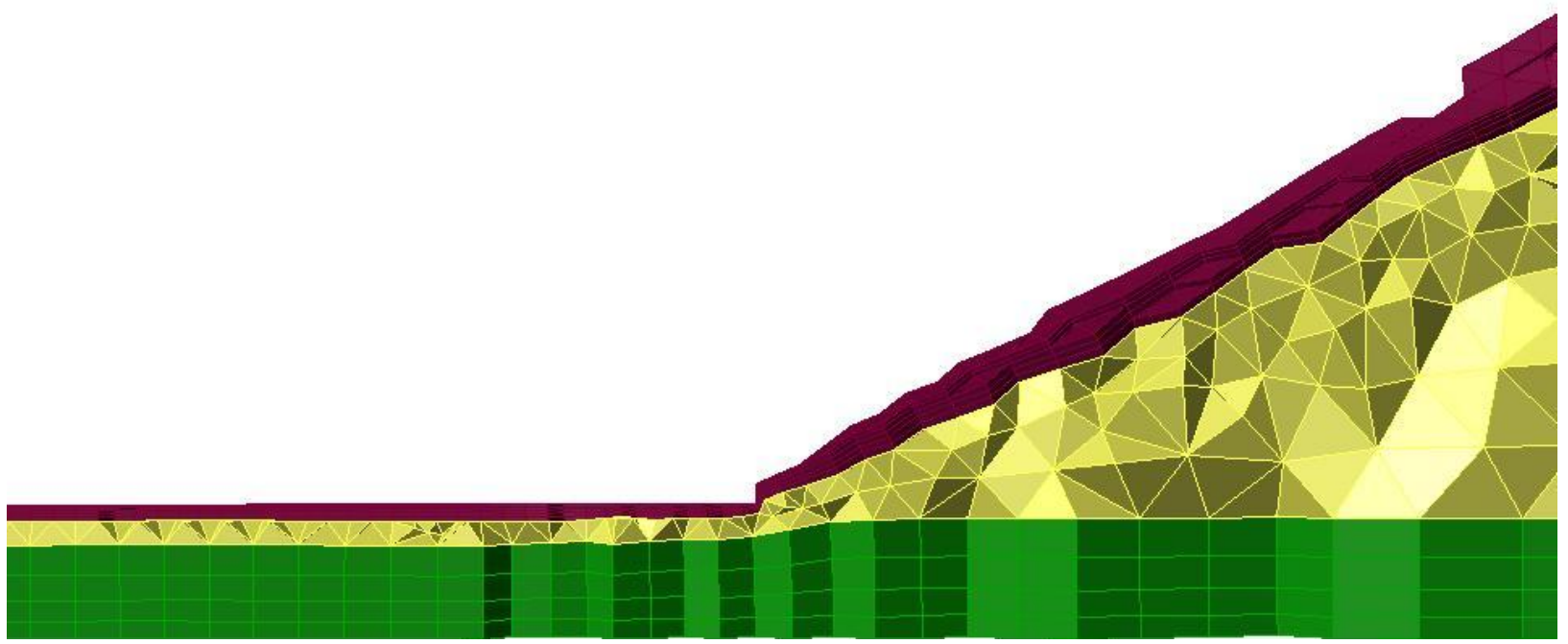

Figura 5-14: Aproximação do destaque na figura 4-2, onde se pode observar a diferença entre a camada de prismas do veiculo e do piso.

A contagem final de elementos da malha, composta de prismas e tetraedros, ficou em 2341389 células.

\subsection{Hipóteses}

As hipóteses simplificadoras utilizadas na resolução do problema numérico foram:

- Escoamento em regime permanente;

- Propriedades do fluido (ar) constantes;

- Escoamento adiabático;

- Simetria no eixo longitudinal do modelo;

- Veículo elevado em relação ao solo;

- Piso parado;

- Entradas de ar fechadas.

\subsection{Condições de contorno}

Para a resolução das equações utilizou-se o software comercial Ansys Fluent v.12.0.1. Nele foram empregadas as seguintes condições de contorno: 
- Entrada de ar: velocidade constante no plano de entrada. Foram utilizadas velocidades de $0.25,0.5,1.0,1.8,3.6,5.4,7.2,9.0$ e $10.8 \mathrm{~m} / \mathrm{s}$ para obter números de Reynolds, tomando o comprimento do veículo como medida característica, de 0.4, 0.9, 1.7, 3.1, 6.2, 9.3, 12.3, 15.4 e 18.5 todos multiplicados por $10^{5}$. Foi utilizada a intensidade de turbulência e o diâmetro hidráulico como chute inicial da turbulência. O diâmetro hidráulico foi de $0.1 \mathrm{~m}$, baseado nas dimensões do canal de água circulante empregado nos ensaios experimentais e descrito na seqüência do texto. A intensidade de turbulência foi calculada a partir da equação ( 5-1 ), retirada de Ansys Fluent (2009a,).

$$
\mathrm{I}=0.16 \cdot \mathrm{Re}^{-\frac{1}{8}}
$$

Obteve-se então a seguinte tabela para a intensidade de turbulência em função do número de Reynolds.

Tabela 5-1: Intensidade de turbulência em função do nú
\begin{tabular}{c|c}
$\boldsymbol{\operatorname { R e }}\left[\mathbf{x 1 0}^{-5}\right]$ & $\mathbf{I}$ \\
\hline 0.4 & $4.22 \%$ \\
0.9 & $3.87 \%$ \\
1.7 & $3.55 \%$ \\
3.1 & $3.30 \%$ \\
6.2 & $3.02 \%$ \\
9.3 & $2.87 \%$ \\
12.3 & $2.77 \%$ \\
15.4 & $2.70 \%$ \\
18.5 & $2.63 \%$
\end{tabular}


- Saída de ar: pressão constante relativa de $0 \mathrm{~Pa}$ (atmosférica). Em caso de fluxo reverso foram utilizadas as mesmas condições para a turbulência da entrada:

- Laterais e teto do túnel: Simetria. A condição de simetria, ou seja, gradiente nulo, possui duas interpretações nesse caso: na superfície que corta longitudinalmente o veículo o gradiente nulo indica que todas as grandezas estão espelhadas do outro lado; no teto do túnel e na lateral afastada do veículo o gradiente zero indica que a partir dessas superfícies não há mais alterações nos valores das grandezas relativas ao escoamento.

- Veículo e piso do túnel: Paredes, sem escorregamento e velocidade nula.

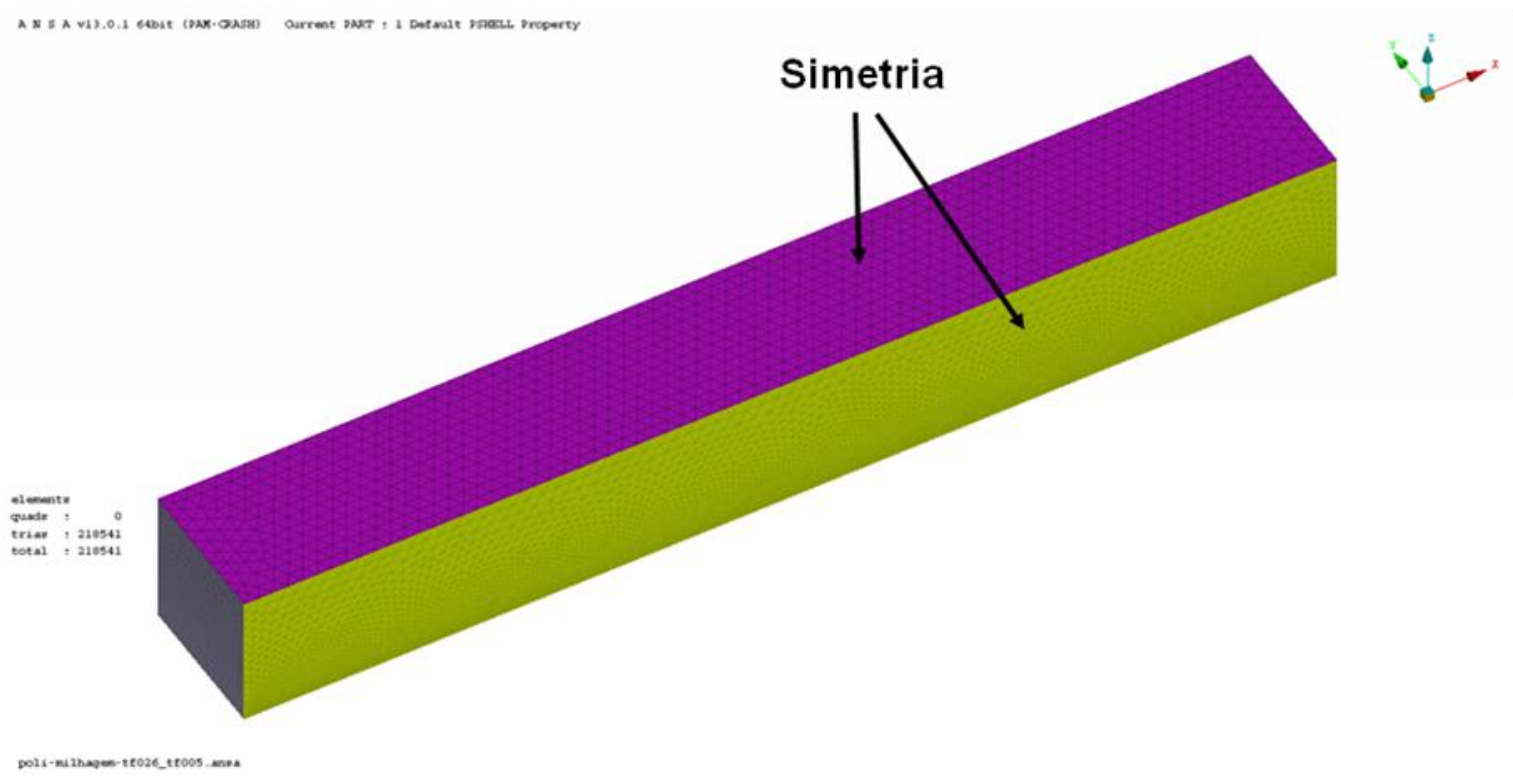

Figura 5-15: Condição de contorno de simetria no teto e na lateral do túnel. 


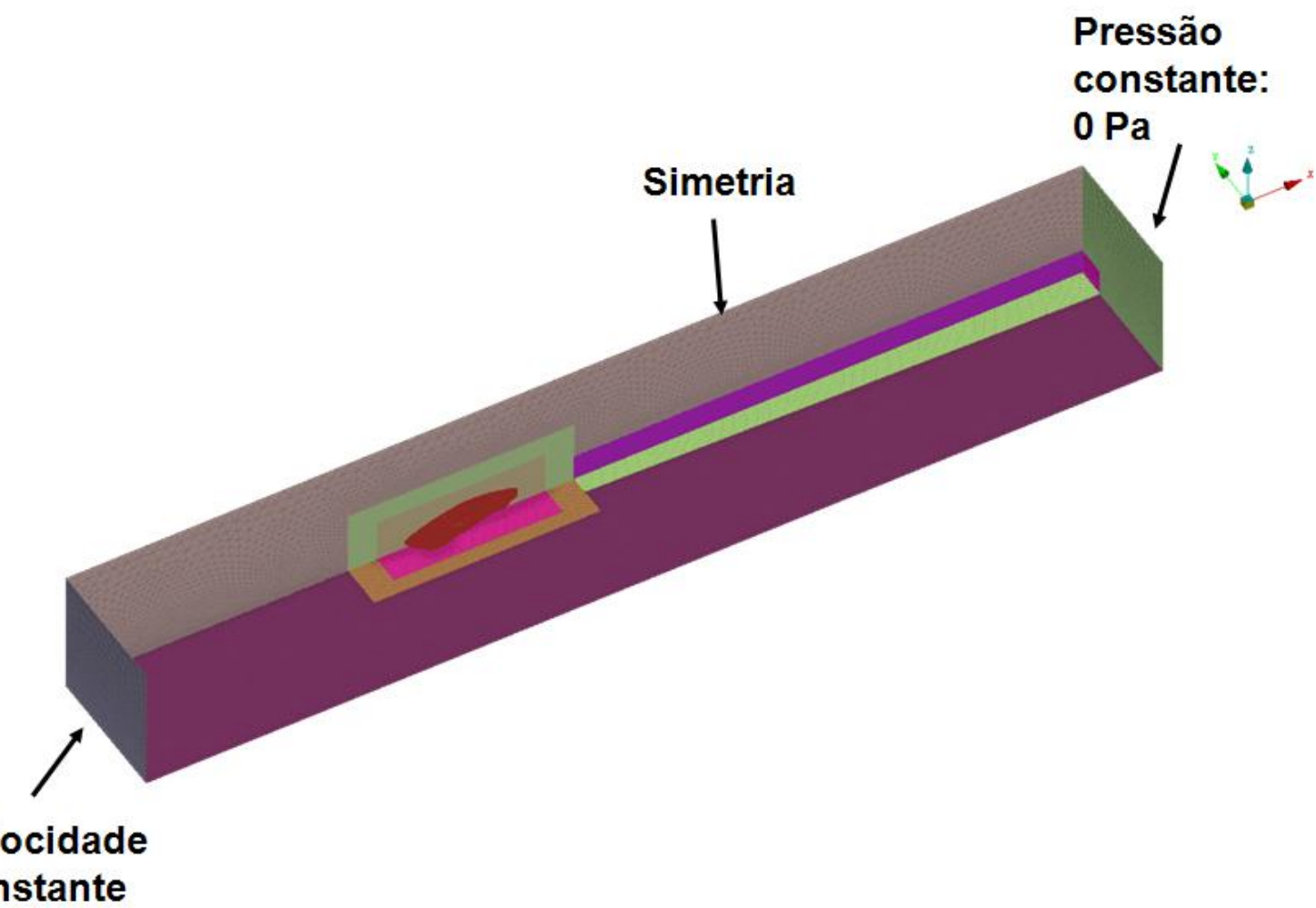

Figura 5-16: Condições de contorno de simetria no eixo longitudinal do veículo, e de velocidade constante e pressão constante na entrada e saída do túnel respectivamente.

\subsection{Técnicas e set-up de simulação}

Todas as simulações foram efetuadas com a mesma malha, apresentada no item 5.2, e obedeceram ao seguinte procedimento durante as iterações:

- Chute inicial com os dados da entrada do domínio;

- Inicialização do escoamento com o método Full Multigrid (FMG);

- As 100 primeiras iterações foram calculadas com esquemas de interpolação de $1^{\text {a }}$. ordem up-wind para todas as variáveis envolvidas. Então as equações de nut (viscosidade cinemática turbulenta modificada - $\tilde{v}$ ), no caso do modelo SpalartAllmaras, k e $\varepsilon$, para os modelos k- $\varepsilon$ e Tensões de Reynolds, k e $\omega$, para os modelos k$\omega$, e de quantidade de movimento, para todos os modelos, são alteradas para o esquema de interpolação up-wind $2^{\mathrm{a}}$. ordem; 
- A partir de 110 iterações as componentes da força resultante nos eixos x e $\mathrm{z}$ do veículo (forças de arrasto e sustentação, respectivamente), além do momento no eixo y (momento de arfagem) passam a ser monitorados;

- Em 400 iterações a pressão, em todos os modelos de turbulência, passa a ser interpolada com o esquema de $2^{\mathrm{a}}$. ordem. No modelo das Tensões de Reynolds, essas tensões começam a ser interpoladas com up-wind de $2^{\mathrm{a}}$. ordem;

- Em 2000 iterações a simulação é interrompida.

Os gráficos representados nas Figura 5-17, Figura 5-18 e Figura 5-19 mostram a convergência das forças de arrasto e sustentação, além do momento de arfagem, para todos os modelos de turbulência estudados, na velocidade de $7.2 \mathrm{~m} / \mathrm{s}\left(\operatorname{Re}=12.3 \times 10^{5}\right)$. Nota-se que esses monitores já estão estabilizados com aproximadamente 1500 iterações. Vale ressaltar que esses são os valores obtidos diretamente do software, e como somente metade do veículo faz parte do modelo os gráficos apresentam os valores das forças pela metade.

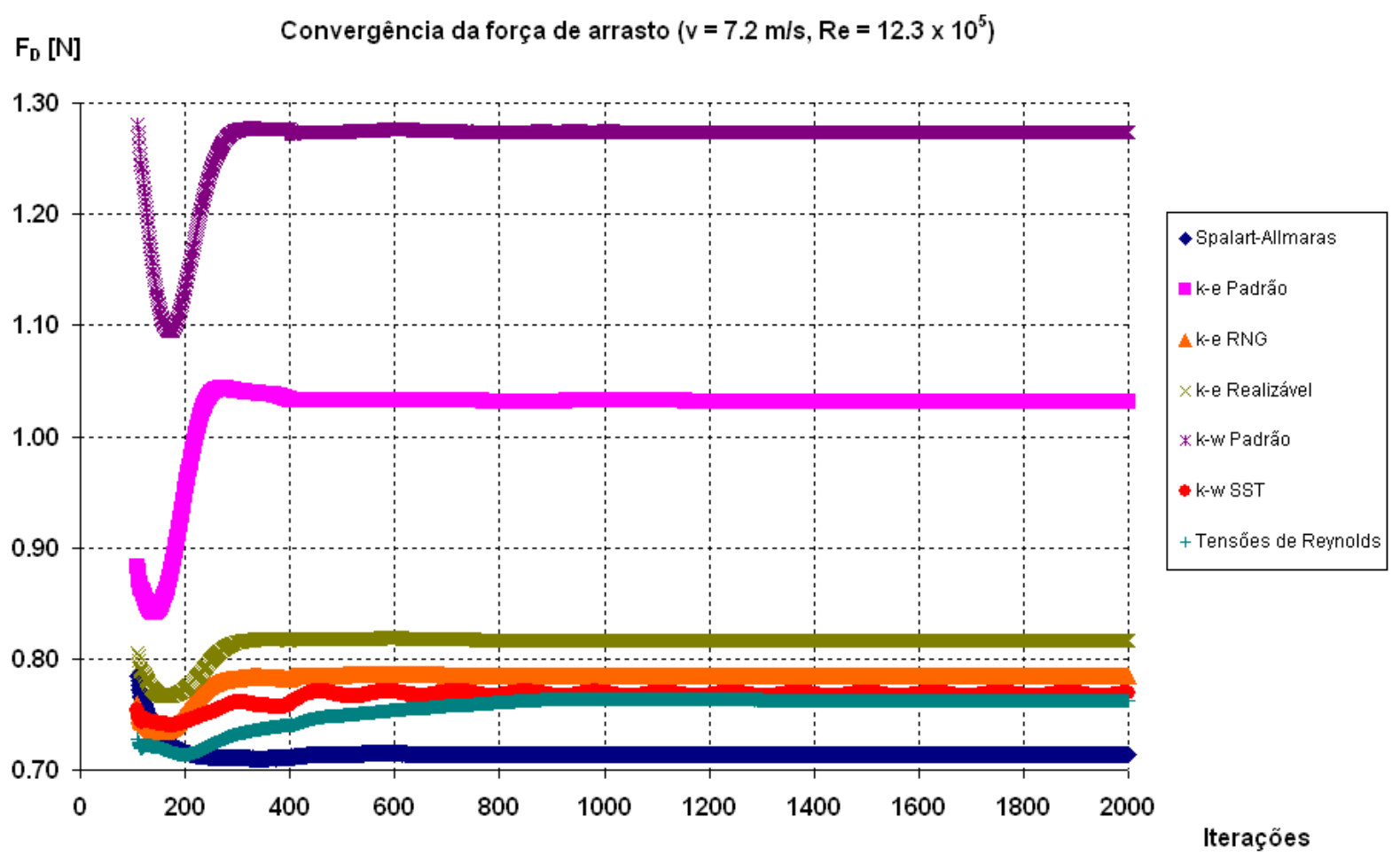

Figura 5-17: Gráfico de convergência da força de arrasto na velocidade de $7.2 \mathrm{~m} / \mathrm{s}\left(\operatorname{Re}=12.3 \times 10^{5}\right)$. 


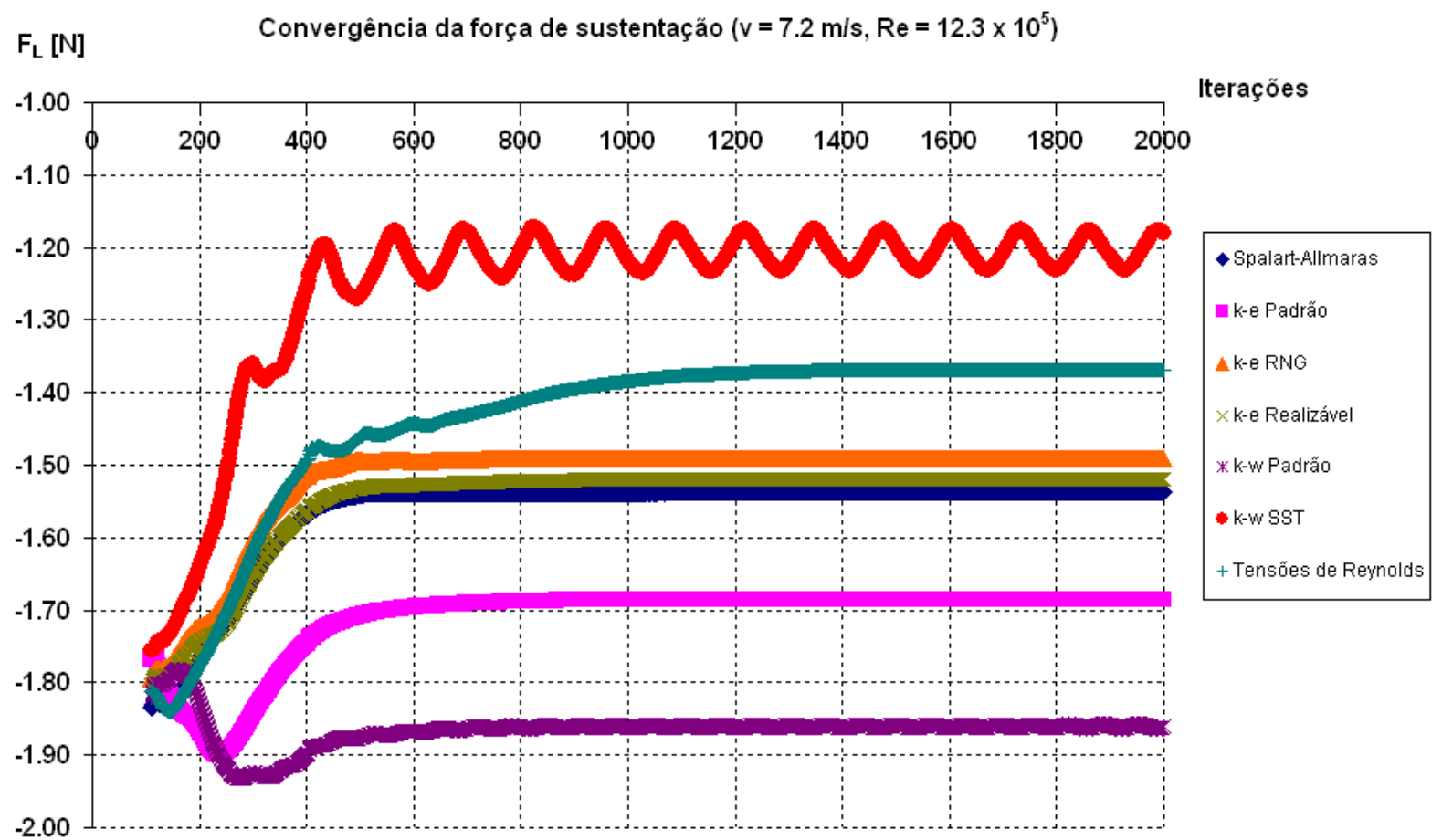

Figura 5-18: Gráfico de convergência da força de sustentação na velocidade de $7.2 \mathrm{~m} / \mathrm{s}\left(\operatorname{Re}=12.3 \times 10^{5}\right)$.

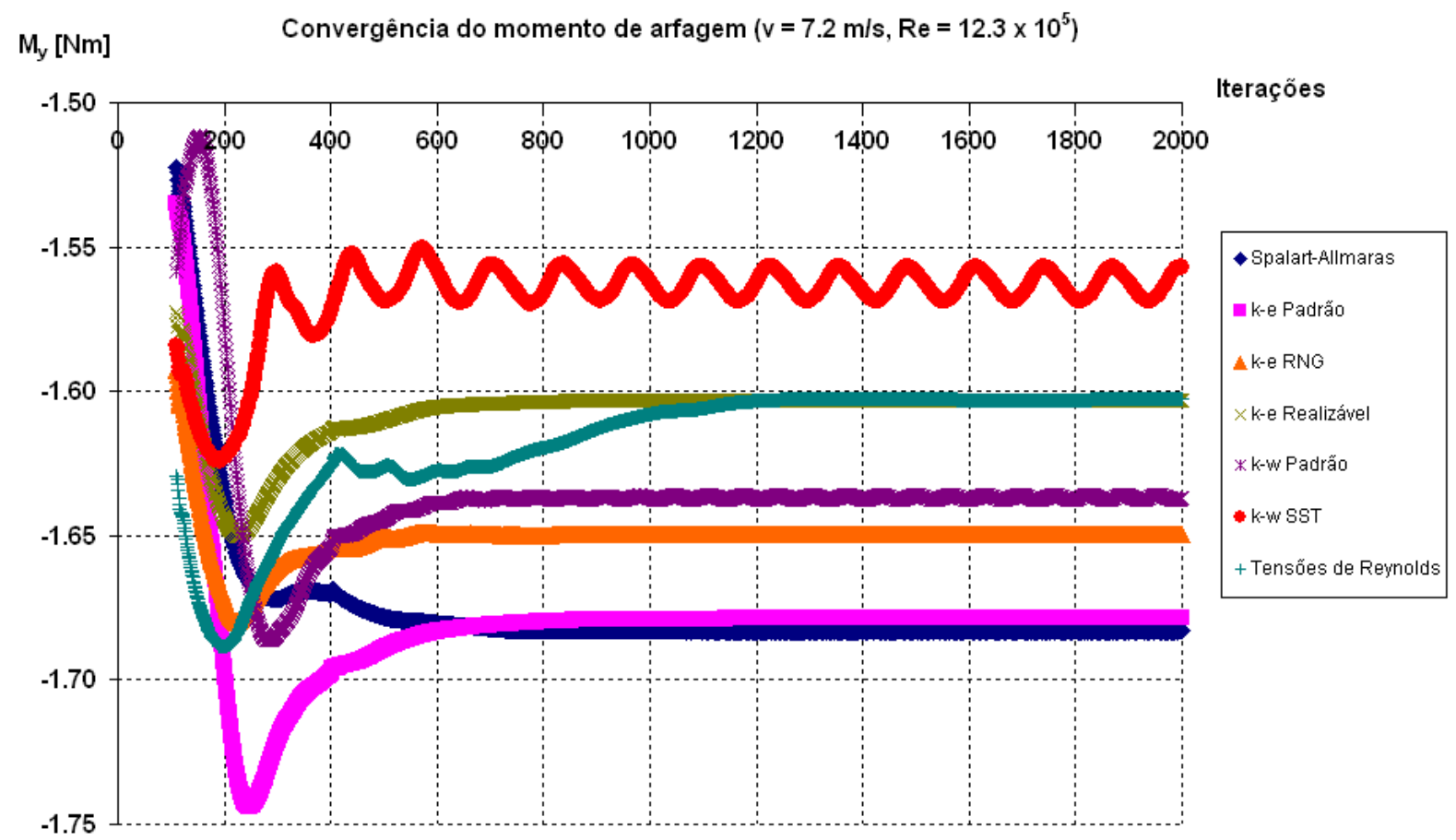

Figura 5-19: Gráfico de convergência do momento de arfagem na velocidade de $7.2 \mathrm{~m} / \mathrm{s}\left(\operatorname{Re}=12.3 \times 10^{5}\right)$.

Em todas as simulações o solver utilizado é o pressure-based, o esquema de acoplamento pressão velocidade é o SIMPLE e os fatores de sub-relaxação são os padrões do 
software. O fluido utilizado é o ar com as propriedades padrão do Ansys Fluent: densidade $\rho$ $=1.225 \mathrm{~kg} / \mathrm{m}^{3}$ e viscosidade dinâmica de $\mu=1.7894 \times 10^{-5} \mathrm{~kg} / \mathrm{ms}$.

Os casos eram considerados convergidos quando os resíduos ficavam menores do que $10^{-3}$ (especificação padrão do software) e quando as forças e momento monitorados se estabilizavam ou variavam em torno de uma média. É importante ressaltar que as simulações não eram interrompidas quando todos os resíduos atingiam $10^{-3}$, mas com 2000 iterações. Todos os casos aqui mostrados respeitaram esses critérios.

\subsection{Cálculo dos coeficientes de arrasto e sustentação}

Para o cálculo dos coeficientes de arrasto e sustentação é utilizada a média das últimas 500 iterações de cada força ou momento. Esses resultados são multiplicados por 2 se obter o valor total no veículo e então são inserido nas equações ( 3-5 ) e ( 3-6 ).

Foram calculados também os coeficientes de sustentação nos eixos dianteiro e traseiro separadamente, dessa forma uma melhor percepção de como a força de sustentação está distribuída pelo veículo é obtida.

Corpos imersos estão sujeitos a um carregamento de forças distribuídas, conforme o item 3.2, do capítulo 3. Esse sistema pode ser reduzido para uma força e um momento resultantes, calculado no pólo O (origem do sistema de coordenadas). 


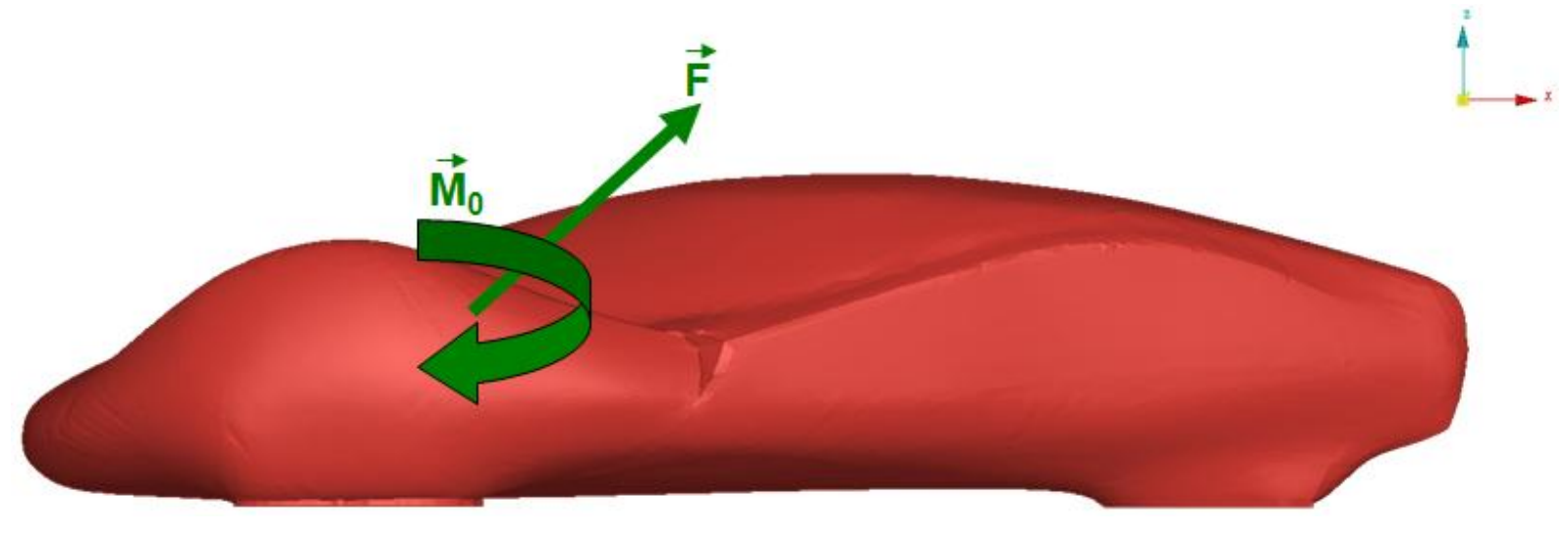

Figura 5-20: Força e momento resultantes calculados no pólo O.

Essa força e momento são então transferidos para o ponto de contato, no caso do modelo real, entre o piso e o solo, e no caso desse estudo para a superfície da caixa de roda mais próxima do solo, ponto $\mathrm{V}$, através da fórmula de mudança de pólo:

$$
\overrightarrow{\mathrm{M}}_{\mathrm{V}}=\overrightarrow{\mathrm{M}}_{\mathrm{O}}+(\mathrm{O}-\mathrm{V}) \wedge \overrightarrow{\mathrm{F}}
$$
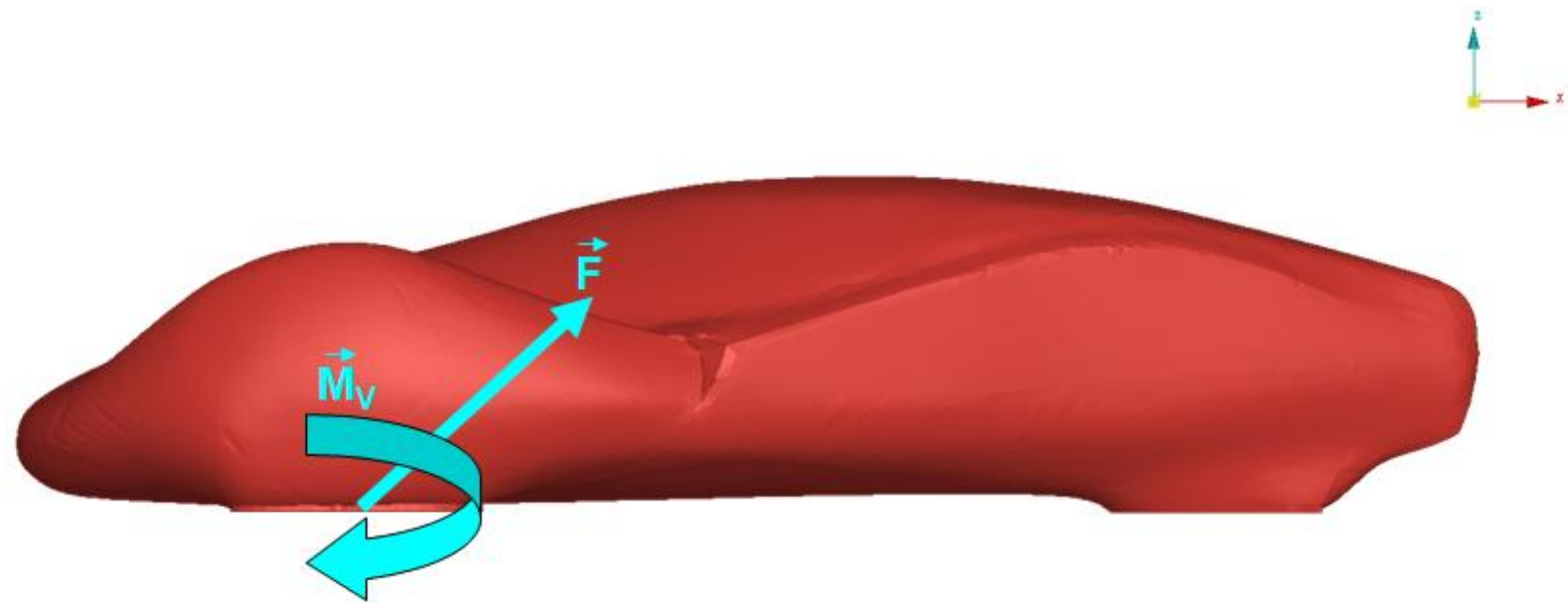

Figura 5-21: Força e momento resultantes transportados do pólo O para o pólo V.

Entretanto devido à simetria longitudinal do modelo a força e o momento resultante $\overrightarrow{\mathrm{F}}$ e $\overrightarrow{\mathrm{M}}_{0}$ ficam: 


$$
\begin{gathered}
\vec{F}=(F x ; 0 ; F z) \\
\vec{M}_{0}=(0 ; M y ; 0)
\end{gathered}
$$

Então esse sistema pode ser simplificado por uma força horizontal, e duas verticais, uma em cada roda:

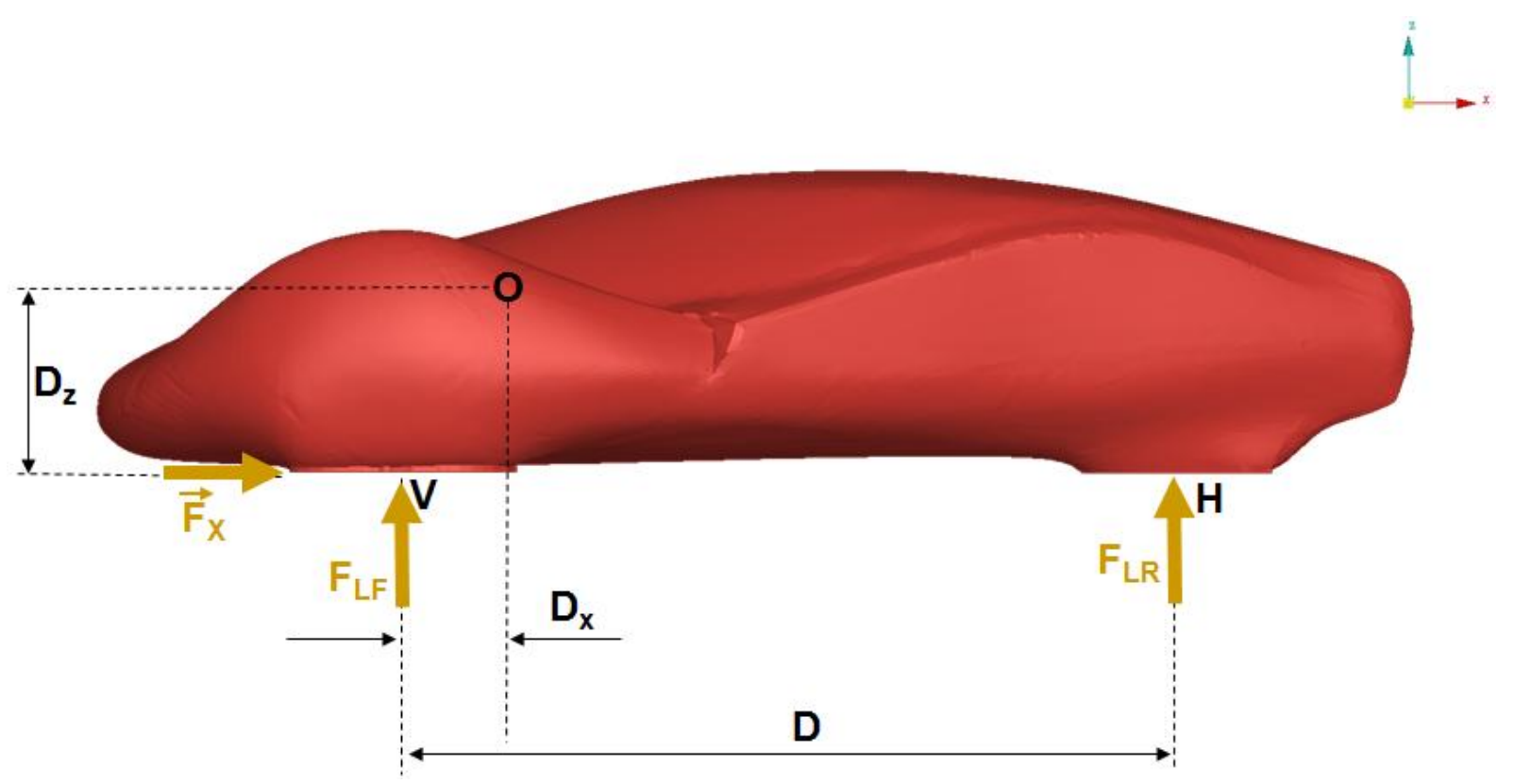

Figura 5-22: Forças de arrasto e sustentação em cada eixo.

Substituindo os valores de $\overrightarrow{\mathrm{F}}$ e $\overrightarrow{\mathrm{M}}$ na equação ( 5-2 ), apenas a componente y de $\overrightarrow{\mathrm{M}}_{\mathrm{v}}$ não é nula e vale:

$$
\mathrm{M}_{\mathrm{Vy}}=\mathrm{M}_{0 \mathrm{y}}+\mathrm{D}_{\mathrm{x}} \cdot \mathrm{F}_{\mathrm{z}}-\mathrm{D}_{\mathrm{z}} \mathrm{F}_{\mathrm{x}}
$$

Assim, as forças de sustentação nos eixos dianteiro e traseiro podem ser calculadas por: 


$$
\begin{gathered}
\mathrm{F}_{\mathrm{Z}} \equiv \mathrm{F}_{\mathrm{LF}}+\mathrm{F}_{\mathrm{LR}} \\
\mathrm{M}_{\mathrm{Vy}}=-\mathrm{F}_{\mathrm{LR}} \cdot \mathrm{D} \\
\mathrm{F}_{\mathrm{LR}}=-\frac{\mathrm{M}_{\mathrm{Vy}}}{\mathrm{D}} \\
\mathrm{F}_{\mathrm{LF}}=\mathrm{F}_{\mathrm{Z}}-\frac{\mathrm{M}_{\mathrm{Vy}}}{\mathrm{D}}
\end{gathered}
$$

No caso estudado $\mathrm{D}=1468 \mathrm{~mm}, \mathrm{Dx}=323 \mathrm{~mm}$ e $\mathrm{Dz}=-327 \mathrm{~mm}$. Os coeficientes de sustentação nos eixos dianteiro $\left(\mathrm{C}_{\mathrm{LF}}\right)$ e traseiro $\left(\mathrm{C}_{\mathrm{LR}}\right)$ são dados por:

$$
\begin{gathered}
C_{L F}=\frac{F_{L F}}{\frac{1}{2} \cdot \rho \cdot v^{2} \cdot A} \\
C_{L R}=\frac{F_{L R}}{\frac{1}{2} \cdot \rho \cdot v^{2} \cdot A}
\end{gathered}
$$




\section{RESULTADOS NUMÉRICOS}

Nesse capítulo são apresentados os resultados obtidos nas simulações numéricas. É exposto um total de 63 simulações: 7 modelos de turbulência e 9 velocidades na entrada. Primeiro são mostrados os resultados dos coeficientes aerodinâmicos e de suas respectivas forças em forma de gráficos e tabelas. Então são exibidas figuras de alguns contornos para um melhor entendimento do escoamento ao redor do veículo, e do porquê dos resultados obtidos nos gráficos. Para esse fim foi escolhido o modelo Spalart-Allmaras com a velocidade de $7.2 \mathrm{~m} / \mathrm{s}$ $\left(\operatorname{Re}=12.3 \times 10^{5}\right)$

São expostos também resultados de análises complementares, com o solo na mesma velocidade do ar e de modelos com a malha convertida em poliedros pelo software Ansys Fluent. 


\subsection{Gráficos e Tabelas}

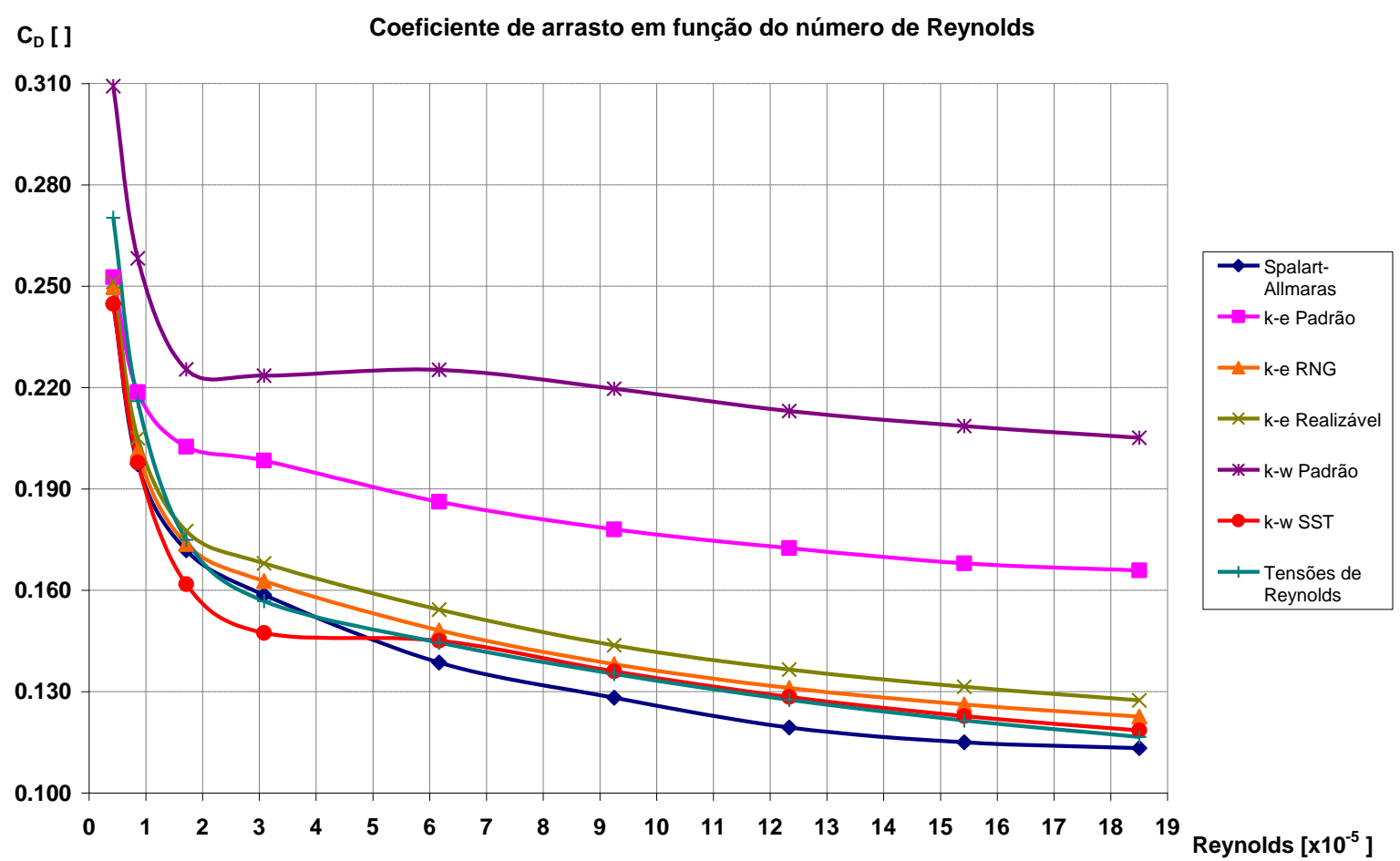

Figura 6-1: Gráfico dos coeficientes de arrasto em função do número de Reynolds para cada modelo de turbulência

Nota-se na Figura 6-1 que quanto menor o valor do número de Reynolds menor a influência do modelo de turbulência, como esperado. Observa-se também que os valores dos coeficientes de arrasto aumentam para baixos Reynolds. Para números de Reynolds mais elevados o gráfico mostra que os modelos k- $\omega$ padrão e k- $\varepsilon$ padrão são os que mais se distanciam dos demais, apresentando coeficientes de arrasto maiores. Os outros modelos apresentam resultados bem próximos, com o Spalart-Allmaras resultando em coeficientes ligeiramente menores, e o k- $\varepsilon$ realizável números ligeiramente maiores. Vale ressaltar a semelhança dos resultados dos modelos Tensões de Reynolds e k- $\omega$ SST para valores de Reynolds acima de $6 \times 10^{5}$. 
Tabela 6-1: Resultados dos coeficientes de arrasto obtidos em cada modelo de turbulência para cada número de Reynolds

\begin{tabular}{|c|c|c|c|c|c|c|c|c|c|}
\hline \multicolumn{10}{|c|}{$C_{D}$ - Coeficiente de Arrasto [ ] } \\
\hline $\operatorname{Re}\left[{\left.\mathrm{x} 10^{-5}\right]}^{-5}\right.$ & 0.4 & 0.9 & 1.7 & 3.1 & 6.2 & 9.3 & 12.3 & 15.4 & 18.5 \\
\hline $\begin{array}{l}\text { Spalart- } \\
\text { Allmaras }\end{array}$ & 0.245 & 0.197 & 0.172 & 0.159 & 0.139 & 0.128 & 0.119 & 0.115 & 0.113 \\
\hline k-e Padrão & 0.253 & 0.219 & 0.202 & 0.198 & 0.186 & 0.178 & 0.173 & 0.168 & 0.166 \\
\hline k-e RNG & 0.250 & 0.201 & 0.174 & 0.163 & 0.148 & 0.138 & 0.131 & 0.126 & 0.123 \\
\hline k-e Realizável & 0.251 & 0.205 & 0.178 & 0.168 & 0.154 & 0.144 & 0.137 & 0.131 & 0.127 \\
\hline k-w Padrão & 0.309 & 0.258 & 0.225 & 0.224 & 0.225 & 0.220 & 0.213 & 0.209 & 0.205 \\
\hline k-w SST & 0.245 & 0.198 & 0.162 & 0.147 & 0.145 & 0.136 & 0.128 & 0.123 & 0.118 \\
\hline $\begin{array}{l}\text { Tensões de } \\
\text { Reynolds }\end{array}$ & 0.270 & 0.216 & 0.175 & 0.157 & 0.145 & 0.135 & 0.128 & 0.121 & 0.117 \\
\hline
\end{tabular}

No gráfico seguinte observa-se, como esperado, que a influência do modelo de turbulência na força de arrasto aumenta com o número de Reynolds. Para baixos valores desse adimensional, o coeficiente de arrasto mostra melhor a diferença entre os modelos do que a força de arrasto, que tem a escala do gráfico aumentada rapidamente por ser calculada pelo quadrado da velocidade, tornando as diferenças para baixo Reynolds desprezível se comparada a maiores valores. 


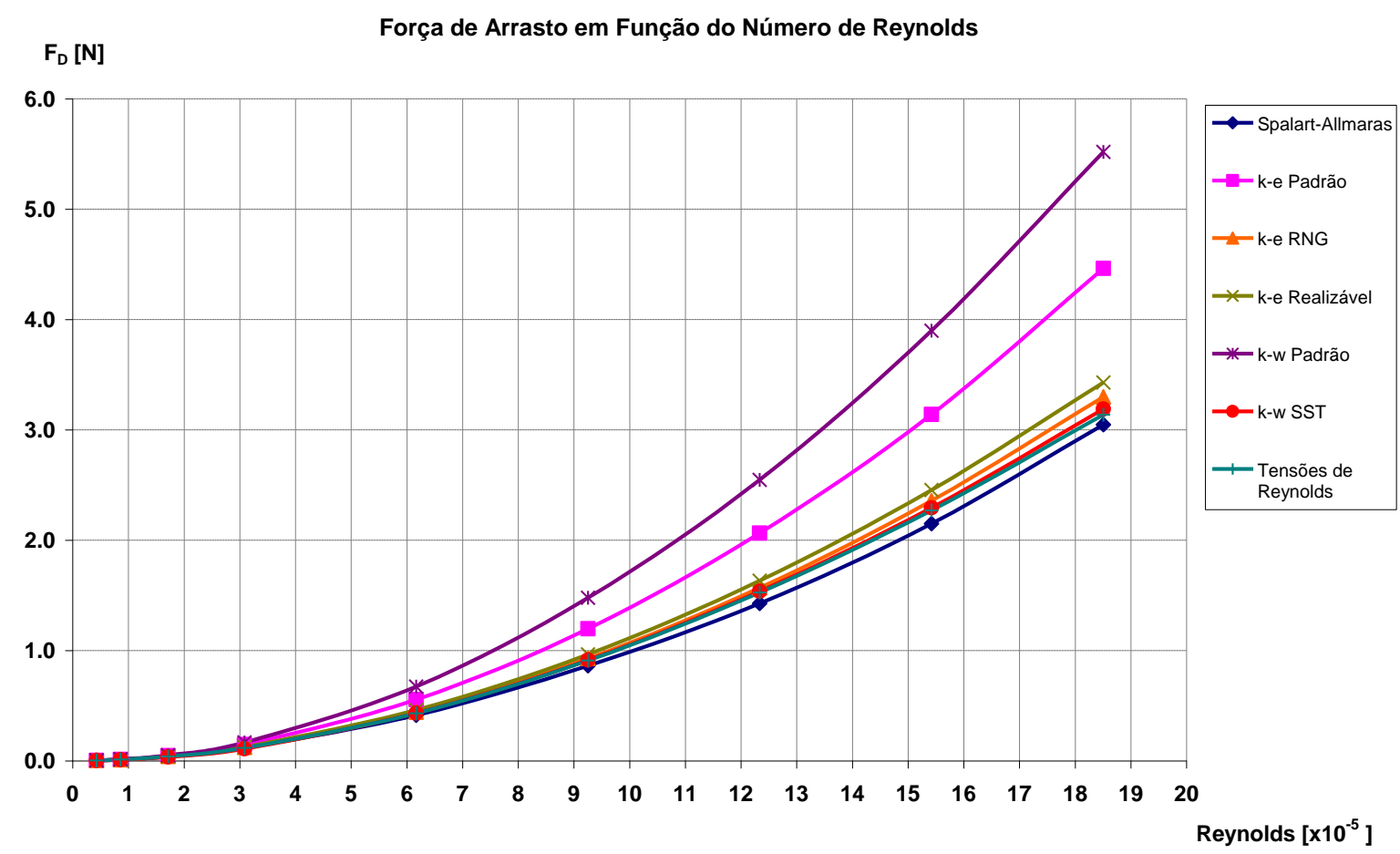

Figura 6-2: Gráfico das forças de arrasto em função do número de Reynolds para cada modelo de turbulência

Tabela 6-2: Resultados das forças de arrasto obtidas em cada modelo de turbulência para cada número de Reynolds

$F_{D}$ - Força de Arrasto [N]

\begin{tabular}{l|c|c|c|c|c|c|c|c|c}
\hline Re $\left[\mathbf{x 1 0}{ }^{-5}\right]$ & $\mathbf{0 . 4}$ & $\mathbf{0 . 9}$ & $\mathbf{1 . 7}$ & $\mathbf{3 . 1}$ & $\mathbf{6 . 2}$ & $\mathbf{9 . 3}$ & $\mathbf{1 2 . 3}$ & $\mathbf{1 5 . 4}$ & $\mathbf{1 8 . 5}$ \\
\hline $\begin{array}{l}\text { Spalart- } \\
\text { Allmaras }\end{array}$ & 0.004 & 0.011 & 0.040 & 0.119 & 0.415 & 0.863 & 1.427 & 2.150 & 3.048 \\
k-e Padrão & 0.004 & 0.013 & 0.047 & 0.148 & 0.557 & 1.198 & 2.063 & 3.139 & 4.464 \\
k-e RNG & 0.004 & 0.012 & 0.040 & 0.122 & 0.443 & 0.929 & 1.568 & 2.359 & 3.299 \\
k-e Realizável & 0.004 & 0.012 & 0.041 & 0.126 & 0.461 & 0.967 & 1.633 & 2.456 & 3.429 \\
k-w Padrão & 0.004 & 0.015 & 0.052 & 0.167 & 0.673 & 1.478 & 2.548 & 3.898 & 5.520 \\
k-w SST & 0.004 & 0.011 & 0.037 & 0.110 & 0.434 & 0.915 & 1.536 & 2.294 & 3.189 \\
$\begin{array}{l}\text { Tensões de } \\
\text { Reynolds }\end{array}$ & 0.004 & 0.012 & 0.040 & 0.117 & 0.432 & 0.910 & 1.525 & 2.270 & 3.136
\end{tabular}

Os resultados dos coeficientes de sustentação apresentam uma tendência diferente dos de arrasto. Os modelos Spalart-Allmaras, k- $\varepsilon$ RNG $\varepsilon$ k-e realizável mostram resultados semelhantes, enquanto k- $\omega$ e k- $\varepsilon$ em suas formas padrão levaram a coeficientes de sustentação 
menores e os modelos Tensões de Reynolds e k-w SST resultaram em valores maiores, em relação aos três primeiros citados.

Com exceção de um valor de Reynolds igual a 0.4 x $10^{5}$ do modelo Tensões de Reynolds, todos os valores são negativos. Essa força negativa pode ser explicada pela alta velocidade do escoamento entre o veículo e o piso, especialmente entre as rodas dianteiras, o que gera baixa pressão, como pode ser observado nas figuras de contornos de velocidade e pressão na seqüência desse capítulo. Gagnon e Richard (2010) chegaram à mesma conclusão.

Esse efeito é indesejado no caso da competição de milhagem, pois o objetivo não é fazer o percurso mais rápido, mas de forma mais econômica, assim as velocidades são baixas e a influência da sustentação na estabilidade do veículo em curvas é desprezível. Porém esse efeito faz com que a resistência a rolagem aumente, por aumentar a normal com o piso, além de produzir um maior arrasto induzido. Esse fenômeno é provocado pelo aumento da energia dos vórtices na esteira devido à diferença de pressão entre a região inferior e superior do veículo. 


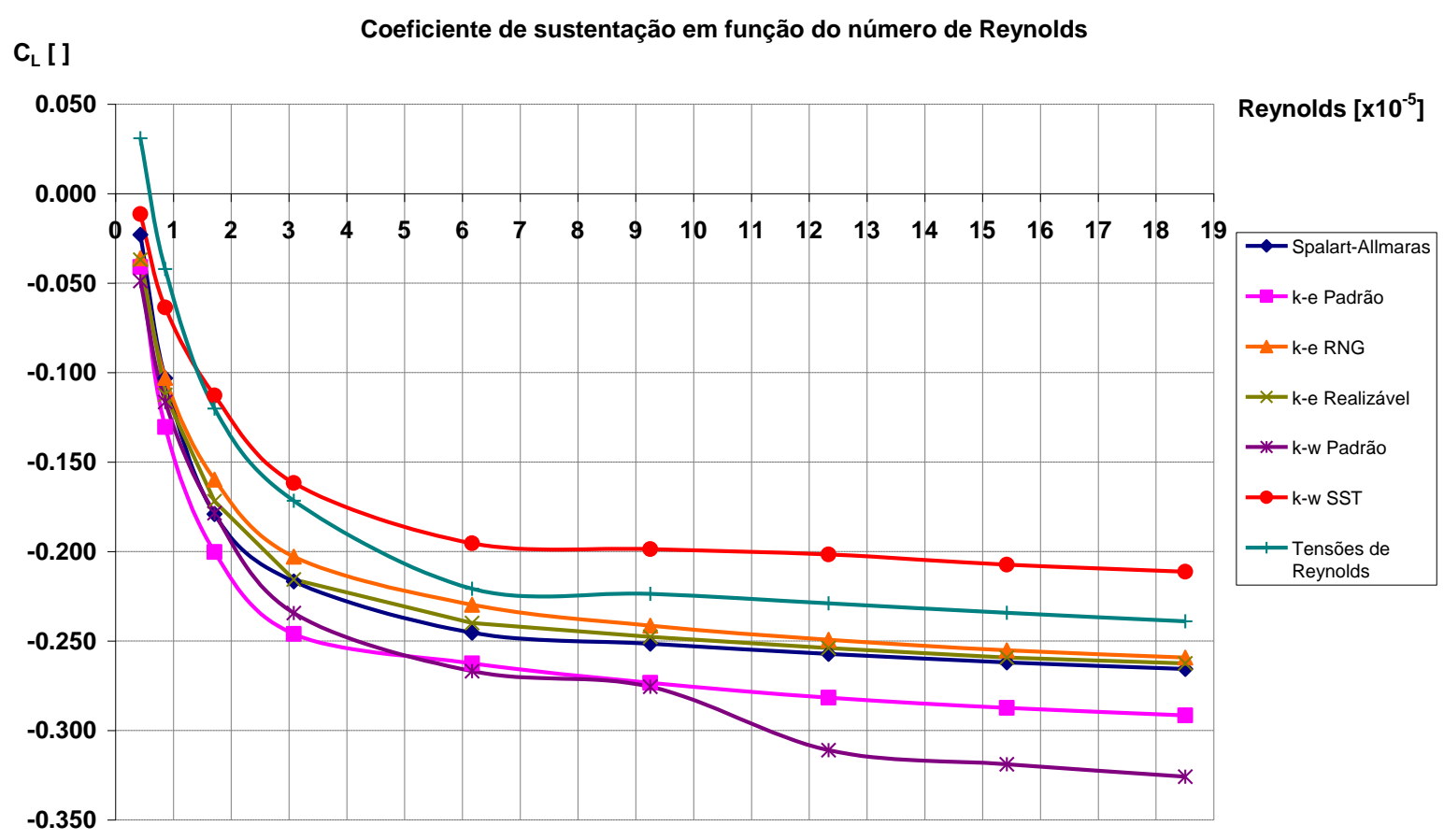

Figura 6-3: Gráfico dos coeficientes de sustentação em função do número de Reynolds para cada modelo de turbulência

Tabela 6-3: Resultados dos coeficientes de sustentação obtidos em cada modelo de turbulência para cada número de Reynolds

$\mathrm{C}_{\mathrm{L}}$ - Coeficiente de Sustentação [ ]

\begin{tabular}{l|c|c|c|c|c|c|c|c|c}
\hline Re $\left[\mathbf{x 1 0} \mathbf{5}^{-5}\right]$ & $\mathbf{0 . 4}$ & $\mathbf{0 . 9}$ & $\mathbf{1 . 7}$ & $\mathbf{3 . 1}$ & $\mathbf{6 . 2}$ & $\mathbf{9 . 3}$ & $\mathbf{1 2 . 3}$ & $\mathbf{1 5 . 4}$ & $\mathbf{1 8 . 5}$ \\
\hline $\begin{array}{l}\text { Spalart- } \\
\text { Allmaras }\end{array}$ & -0.023 & -0.103 & -0.179 & -0.217 & -0.245 & -0.252 & -0.257 & -0.262 & -0.266 \\
k-e Padrão & -0.041 & -0.130 & -0.200 & -0.246 & -0.262 & -0.273 & -0.282 & -0.287 & -0.292 \\
k-e RNG & -0.036 & -0.103 & -0.160 & -0.203 & -0.230 & -0.241 & -0.249 & -0.255 & -0.259 \\
k-e Realizável & -0.037 & -0.112 & -0.172 & -0.216 & -0.240 & -0.248 & -0.254 & -0.259 & -0.263 \\
k-w Padrão & -0.049 & -0.116 & -0.179 & -0.234 & -0.267 & -0.276 & -0.311 & -0.319 & -0.326 \\
k-w SST & -0.011 & -0.064 & -0.113 & -0.162 & -0.195 & -0.199 & -0.202 & -0.207 & -0.211 \\
$\begin{array}{l}\text { Tensões de } \\
\text { Reynolds }\end{array}$ & 0.031 & -0.042 & -0.120 & -0.172 & -0.221 & -0.224 & -0.229 & -0.234 & -0.239
\end{tabular}

Os valores máximos, em módulo, das forças de sustentação são ainda maiores do que os de arrasto, assim como os coeficientes, o que torna a diferença entre os modelos menos perceptíveis no gráfico seguinte para baixos números de Reynolds. 
Na precisão escolhida de 3 casas decimais para representar os valores na tabela, a força de sustentação é nula, ou praticamente, em todos os modelos de turbulência para Reynolds de 0.4 x $10^{5}$, o que explica os valores próximos de zero dos coeficientes de sustentação.

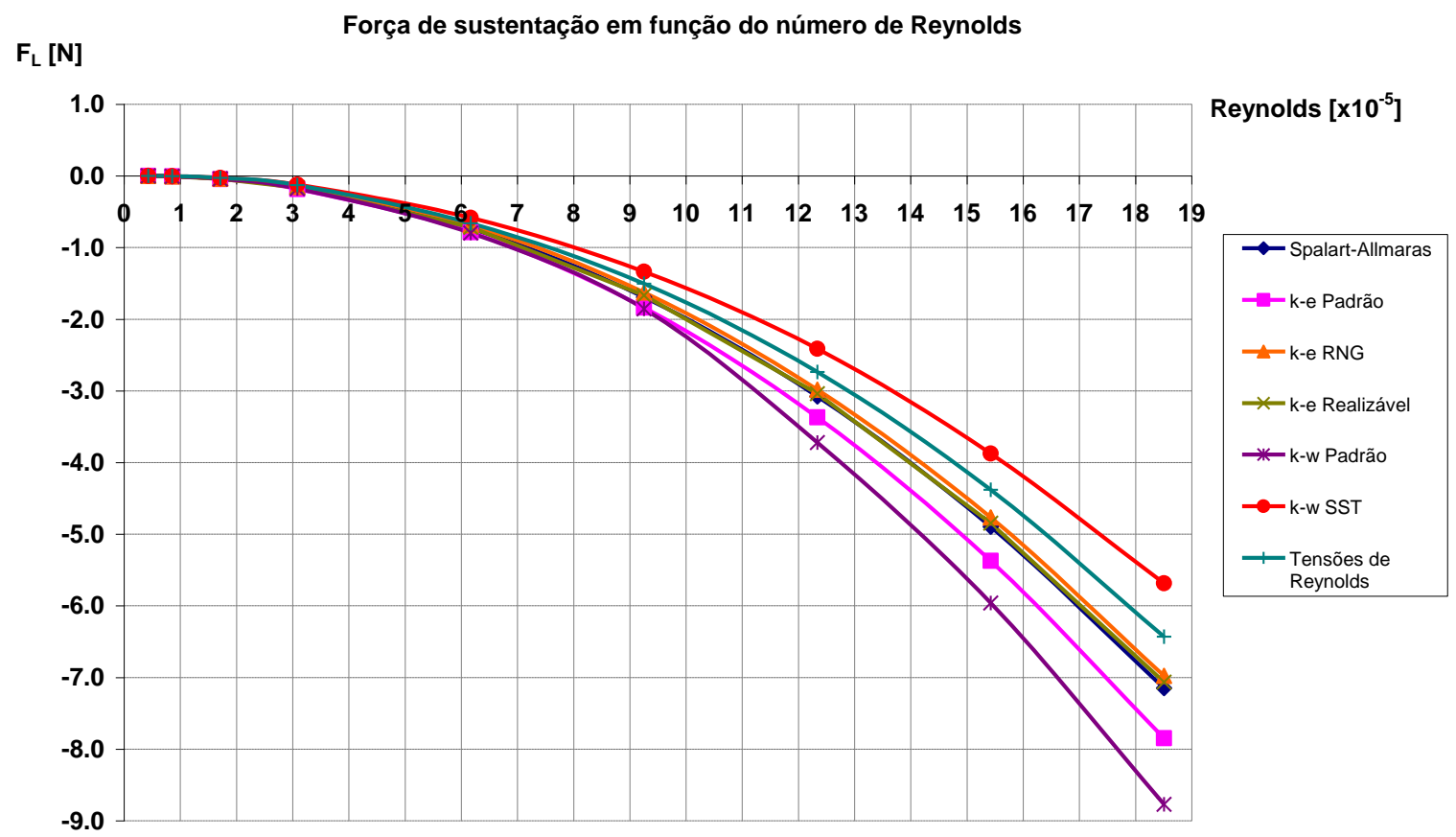

Figura 6-4: Gráfico das forças de sustentação em função do número de Reynolds para cada modelo de turbulência

Tabela 6-4: Resultados das forças de sustentação obtidas em cada modelo de turbulência para cada número de Reynolds

$F_{L}$ - Força de Sustentação [N]

\begin{tabular}{l|c|c|c|c|c|c|c|c|c}
\hline Re $\left[\mathbf{x 1 0} \mathbf{5}^{-5}\right]$ & $\mathbf{0 . 4}$ & $\mathbf{0 . 9}$ & $\mathbf{1 . 7}$ & $\mathbf{3 . 1}$ & $\mathbf{6 . 2}$ & $\mathbf{9 . 3}$ & $\mathbf{1 2 . 3}$ & $\mathbf{1 5 . 4}$ & $\mathbf{1 8 . 5}$ \\
\hline $\begin{array}{l}\text { Spalart- } \\
\text { Allmaras }\end{array}$ & 0.000 & -0.006 & -0.041 & -0.162 & -0.734 & -1.692 & -3.076 & -4.895 & -7.147 \\
k-e Padrão & -0.001 & -0.008 & -0.046 & -0.184 & -0.785 & -1.839 & -3.369 & -5.371 & -7.847 \\
k-e RNG & -0.001 & -0.006 & -0.037 & -0.152 & -0.687 & -1.624 & -2.982 & -4.767 & -6.978 \\
k-e Realizável & -0.001 & -0.006 & -0.040 & -0.161 & -0.718 & -1.666 & -3.038 & -4.845 & -7.066 \\
k-w Padrão & -0.001 & -0.007 & -0.041 & -0.175 & -0.798 & -1.854 & -3.721 & -5.961 & -8.769 \\
k-w SST & 0.000 & -0.004 & -0.026 & -0.121 & -0.584 & -1.337 & -2.411 & -3.874 & -5.684 \\
$\begin{array}{l}\text { Tensões de } \\
\text { Reynolds }\end{array}$ & 0.000 & -0.002 & -0.028 & -0.128 & -0.660 & -1.504 & -2.738 & -4.378 & -6.431
\end{tabular}


Separando o coeficiente e a força de sustentação por eixo, onde $\mathrm{C}_{\mathrm{LF}}$ é o coeficiente de sustentação no eixo frontal e $C_{L R}$ o coeficiente de sustentação na roda traseira, percebe-se que o primeiro possui valores negativos enquanto o segundo positivos. Nota-se também que as curvas de $C_{L F}$, têm tendências semelhantes às curvas de $C_{L}$, que é, obviamente, a soma das curvas de $C_{L F}$ e $C_{L R}$. Dessa forma é possível concluir que a região frontal do veículo é a determinante no valor de $C_{L}$. Esse fato vem confirmar que as altas velocidades na parte inferior do carro, entre as rodas dianteiras, exercem um papel fundamental na sustentação total.

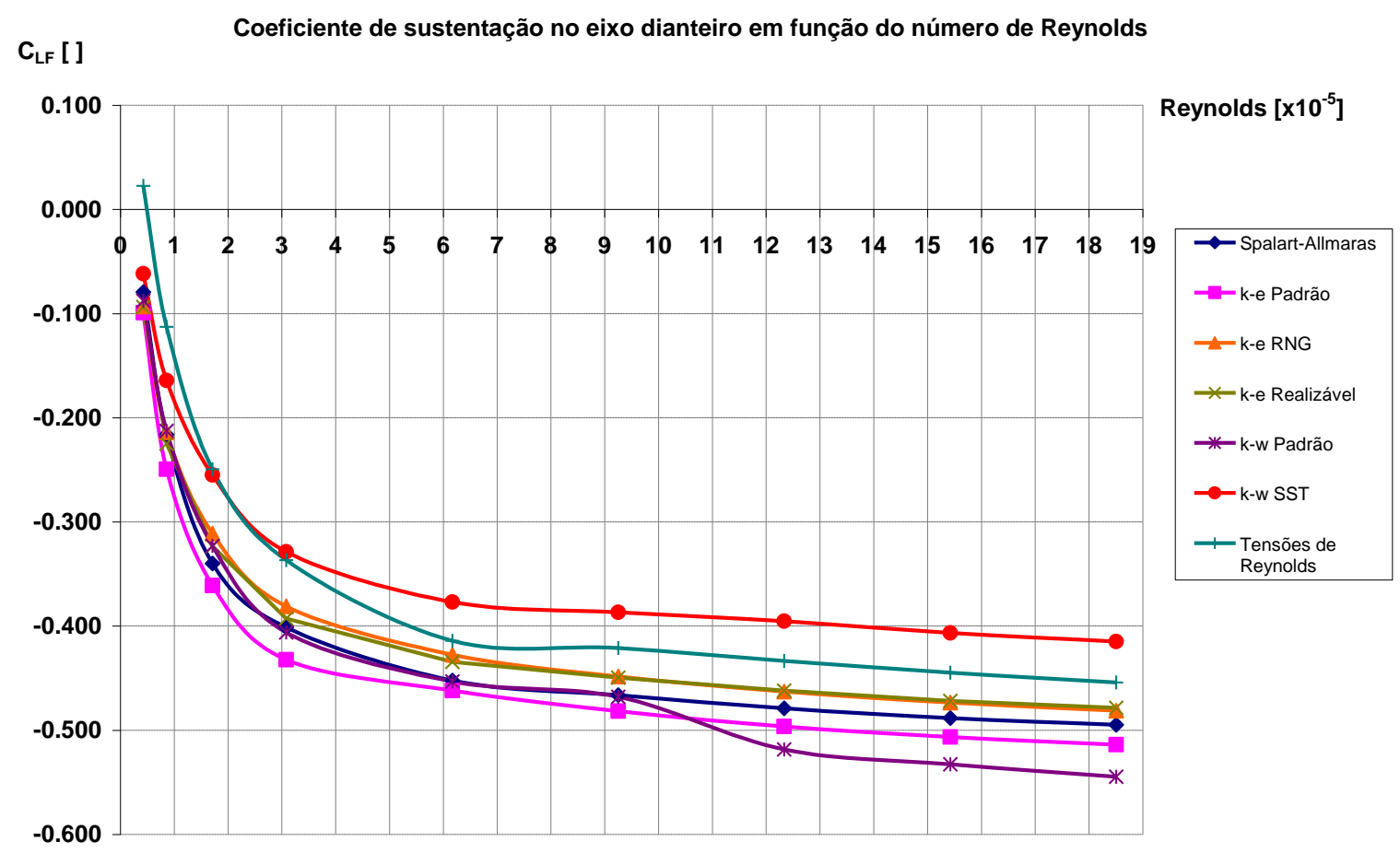

Figura 6-5: Gráfico dos coeficientes de sustentação no eixo dianteiro em função do número de Reynolds para cada modelo de turbulência 
Tabela 6-5: Resultados dos coeficientes de sustentação no eixo dianteiro obtidos em cada modelo de turbulência para cada número de Reynolds.

$C_{L F}$ - Coeficiente de Sustentação no Eixo Dianteiro [ ]

\begin{tabular}{l|c|c|c|c|c|c|c|c|c}
\hline Re $\left[\mathbf{x 1 0} \mathbf{- n}^{-5}\right]$ & $\mathbf{0 . 4}$ & $\mathbf{0 . 9}$ & $\mathbf{1 . 7}$ & $\mathbf{3 . 1}$ & $\mathbf{6 . 2}$ & $\mathbf{9 . 3}$ & $\mathbf{1 2 . 3}$ & $\mathbf{1 5 . 4}$ & $\mathbf{1 8 . 5}$ \\
\hline $\begin{array}{l}\text { Spalart- } \\
\text { Allmaras }\end{array}$ & -0.079 & -0.216 & -0.340 & -0.401 & -0.452 & -0.466 & -0.479 & -0.488 & -0.495 \\
k-e Padrão & -0.099 & -0.250 & -0.361 & -0.432 & -0.462 & -0.482 & -0.496 & -0.507 & -0.514 \\
k-e RNG & -0.093 & -0.214 & -0.311 & -0.381 & -0.427 & -0.448 & -0.463 & -0.473 & -0.481 \\
k-e Realizável & -0.094 & -0.225 & -0.323 & -0.393 & -0.434 & -0.450 & -0.462 & -0.472 & -0.478 \\
k-w Padrão & -0.088 & -0.213 & -0.323 & -0.406 & -0.453 & -0.468 & -0.518 & -0.533 & -0.545 \\
k-w SST & -0.062 & -0.164 & -0.255 & -0.329 & -0.377 & -0.387 & -0.395 & -0.407 & -0.415 \\
$\begin{array}{l}\text { Tensões de } \\
\text { Reynolds }\end{array}$ & 0.023 & -0.113 & -0.250 & -0.337 & -0.414 & -0.421 & -0.433 & -0.445 & -0.454
\end{tabular}

Assim como os coeficientes, as forças de sustentação no eixo dianteiro também apresentam comportamento semelhante à sustentação total.

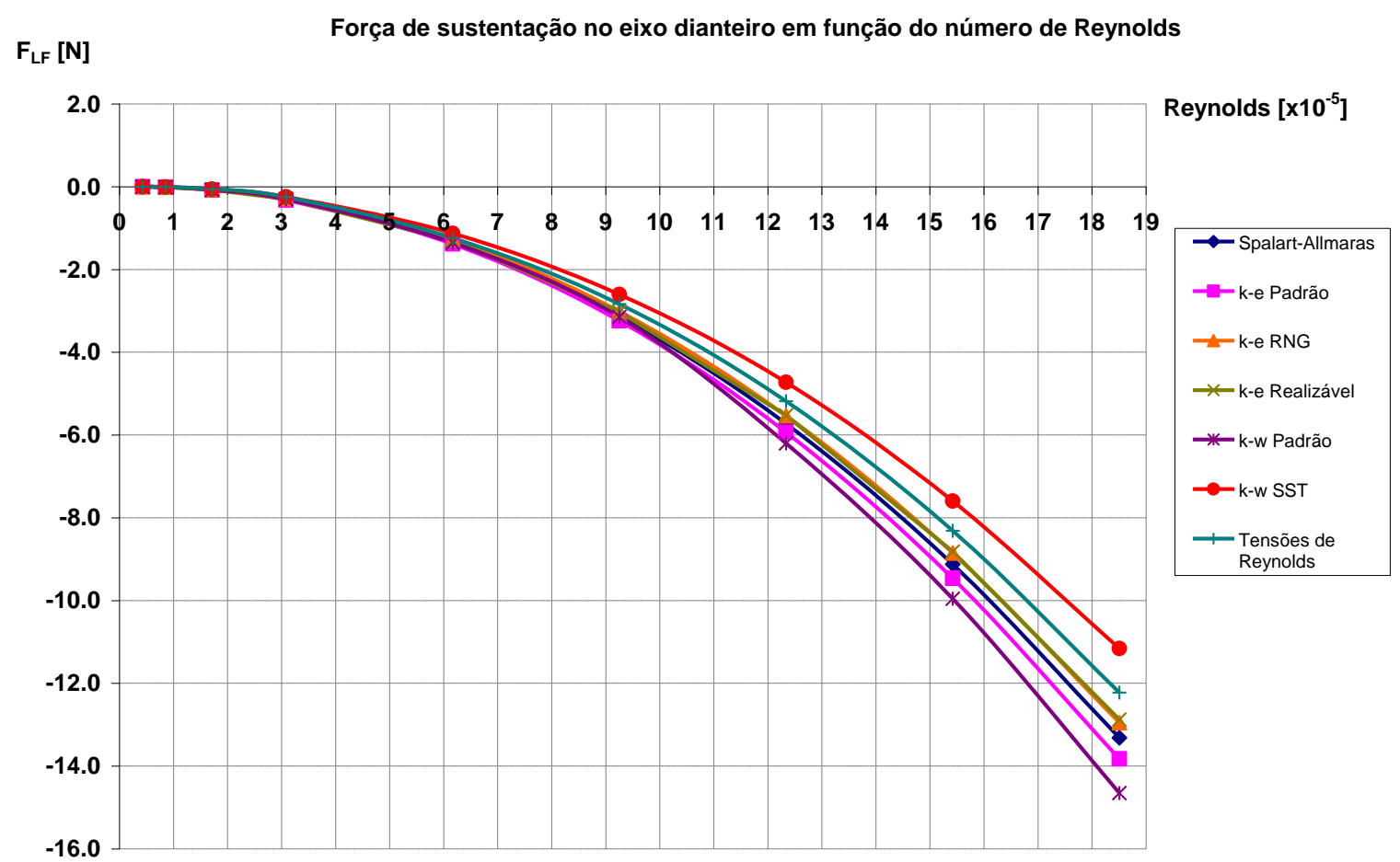

Figura 6-6: Gráfico das forças de sustentação no eixo dianteiro em função do número de Reynolds para cada modelo de turbulência 
Tabela 6-6: Resultados das forças de sustentação no eixo dianteiro obtidos em cada modelo de turbulência para cada número de Reynolds.

\begin{tabular}{|c|c|c|c|c|c|c|c|c|c|}
\hline \multicolumn{10}{|c|}{$\mathbf{F}_{\mathrm{LF}}$ - Força de Sustentação no Eixo Dianteiro [N] } \\
\hline $\operatorname{Re}\left[\times 10^{-5}\right]$ & 0.4 & 0.9 & 1.7 & 3.1 & 6.2 & 9.3 & 12.3 & 15.4 & 18.5 \\
\hline $\begin{array}{l}\text { Spalart- } \\
\text { Allmaras }\end{array}$ & -0.001 & -0.012 & -0.078 & -0.300 & -1.352 & -3.137 & -5.728 & -9.126 & -13.314 \\
\hline k-e Padrão & -0.001 & -0.014 & -0.083 & -0.323 & -1.381 & -3.240 & -5.938 & -9.466 & -13.826 \\
\hline k-e RNG & -0.001 & -0.012 & -0.072 & -0.285 & -1.278 & -3.016 & -5.536 & -8.848 & -12.953 \\
\hline k-e Realizável & -0.001 & -0.013 & -0.075 & -0.294 & -1.299 & -3.025 & -5.526 & -8.817 & -12.877 \\
\hline k-w Padrão & -0.001 & -0.012 & -0.075 & -0.304 & -1.355 & -3.148 & -6.202 & -9.955 & -14.654 \\
\hline k-w SST & -0.001 & -0.009 & -0.059 & -0.246 & -1.127 & -2.602 & -4.729 & -7.597 & -11.161 \\
\hline $\begin{array}{l}\text { Tensões de } \\
\text { Reynolds }\end{array}$ & 0.000 & -0.007 & -0.058 & -0.252 & -1.239 & -2.833 & -5.184 & -8.311 & -12.222 \\
\hline
\end{tabular}

Já para a roda traseira tanto os coeficientes quanto as forças de sustentação apresentam resultados positivos, completamente diferentes da sustentação global.

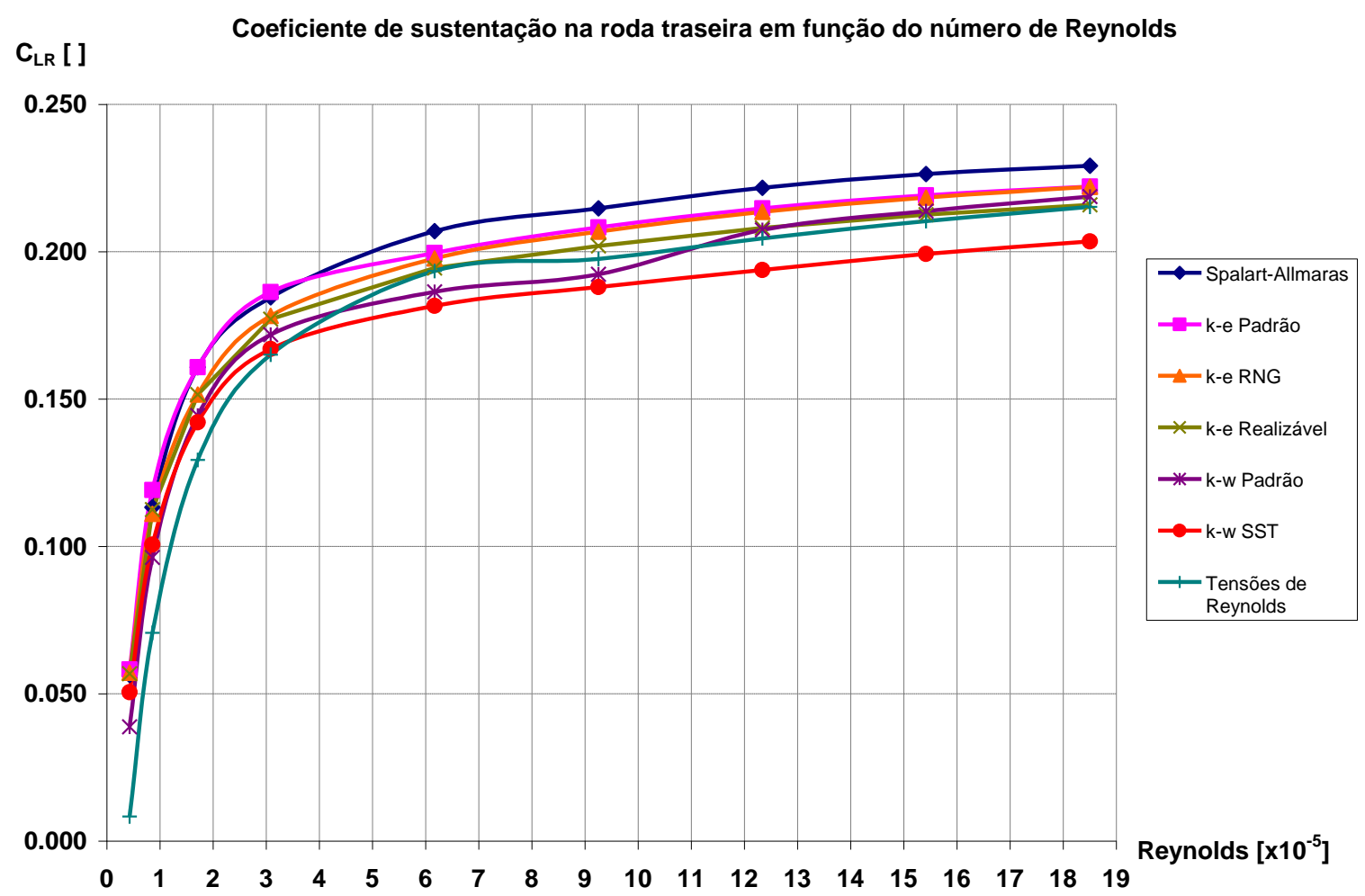

Figura 6-7: Gráfico dos coeficientes de sustentação na roda traseira em função do número de Reynolds para cada modelo de turbulência. 
Tabela 6-7: Resultados dos coeficientes de sustentação na roda traseira obtidos em cada modelo de turbulência para cada número de Reynolds.

$C_{L R}$ - Coeficiente de Sustentação na Roda Traseira [ ]

\begin{tabular}{l|c|c|c|c|c|c|c|c|c}
\hline Re $\left[\mathbf{x 1 0} \mathbf{5}^{-5}\right]$ & $\mathbf{0 . 4}$ & $\mathbf{0 . 9}$ & $\mathbf{1 . 7}$ & $\mathbf{3 . 1}$ & $\mathbf{6 . 2}$ & $\mathbf{9 . 3}$ & $\mathbf{1 2 . 3}$ & $\mathbf{1 5 . 4}$ & $\mathbf{1 8 . 5}$ \\
\hline $\begin{array}{l}\text { Spalart- } \\
\text { Allmaras }\end{array}$ & 0.056 & 0.113 & 0.161 & 0.185 & 0.207 & 0.215 & 0.222 & 0.226 & 0.229 \\
k-e Padrão & 0.058 & 0.119 & 0.161 & 0.186 & 0.200 & 0.208 & 0.215 & 0.219 & 0.222 \\
k-e RNG & 0.057 & 0.111 & 0.152 & 0.178 & 0.198 & 0.207 & 0.214 & 0.218 & 0.222 \\
k-e Realizável & 0.057 & 0.112 & 0.152 & 0.177 & 0.194 & 0.202 & 0.208 & 0.213 & 0.216 \\
k-w Padrão & 0.039 & 0.096 & 0.144 & 0.172 & 0.186 & 0.192 & 0.207 & 0.214 & 0.219 \\
k-w SST & 0.050 & 0.101 & 0.142 & 0.167 & 0.182 & 0.188 & 0.194 & 0.199 & 0.204 \\
$\begin{array}{l}\text { Tensões de } \\
\text { Reynolds }\end{array}$ & 0.008 & 0.071 & 0.129 & 0.165 & 0.193 & 0.198 & 0.205 & 0.210 & 0.215
\end{tabular}

A força de sustentação na roda traseira é representada pelo Figura 6-8 e pela Tabela

6-8.

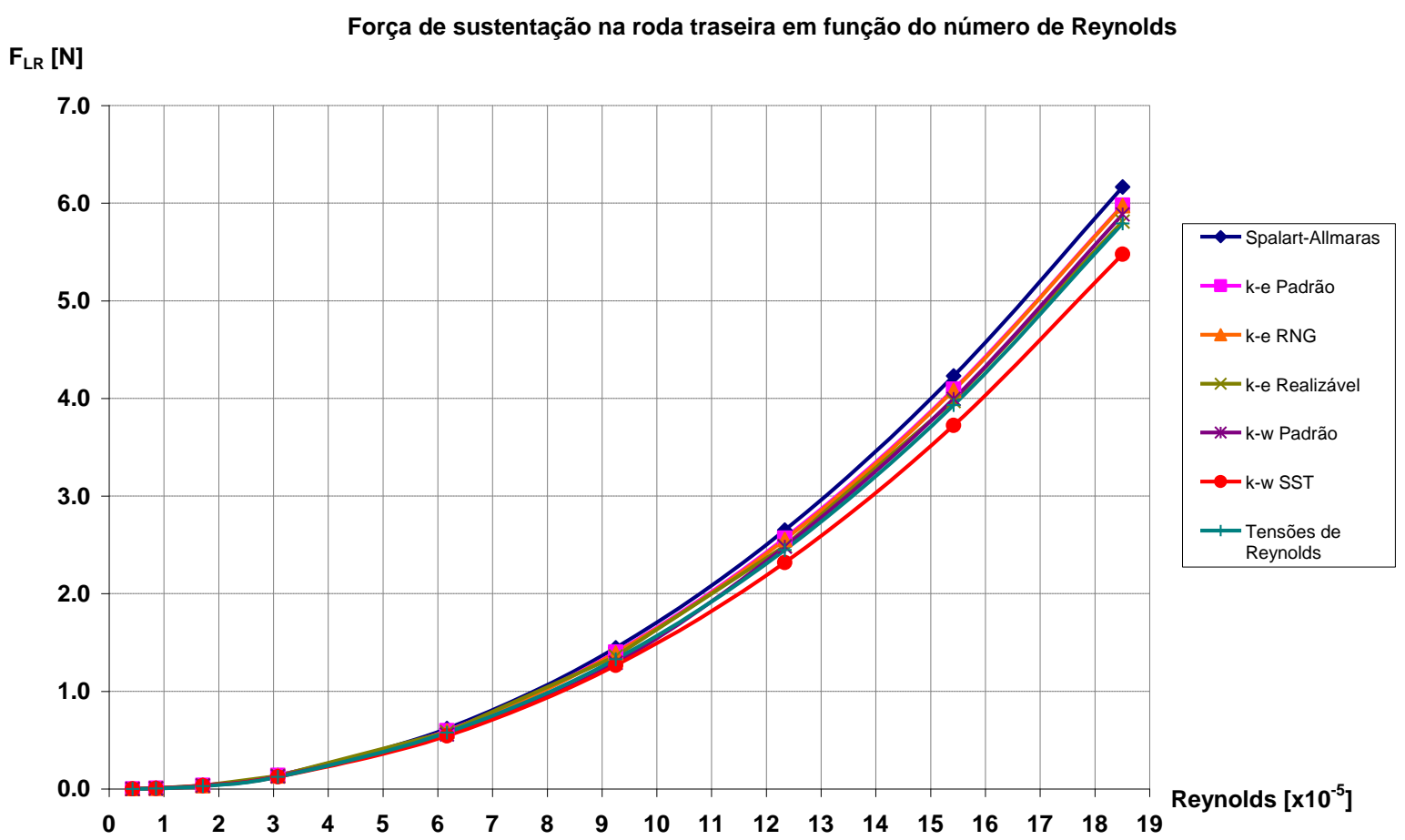

Figura 6-8: Gráfico das forças de sustentação no eixo traseiro em função do número de Reynolds para cada modelo de turbulência. 
Tabela 6-8: Resultados das forças de sustentação no eixo traseiro obtidos em cada modelo de turbulência para cada número de Reynolds.

\begin{tabular}{|c|c|c|c|c|c|c|c|c|c|}
\hline \multicolumn{10}{|c|}{$F_{L_{R}}$ Força de Sustentação na Roda Traseira [N] } \\
\hline $\operatorname{Re}\left[\times 10^{-5}\right]$ & 0.4 & 0.9 & 1.7 & 3.1 & 6.2 & 9.3 & 12.3 & 15.4 & 18.5 \\
\hline $\begin{array}{l}\text { Spalart- } \\
\text { Allmaras }\end{array}$ & 0.001 & 0.007 & 0.037 & 0.138 & 0.619 & 1.445 & 2.652 & 4.230 & 6.167 \\
\hline k-e Padrão & 0.001 & 0.007 & 0.037 & 0.139 & 0.597 & 1.401 & 2.569 & 4.095 & 5.978 \\
\hline k-e RNG & 0.001 & 0.006 & 0.035 & 0.133 & 0.591 & 1.391 & 2.554 & 4.081 & 5.974 \\
\hline k-e Realizável & 0.001 & 0.006 & 0.035 & 0.132 & 0.582 & 1.359 & 2.488 & 3.973 & 5.811 \\
\hline k-w Padrão & 0.001 & 0.006 & 0.033 & 0.128 & 0.557 & 1.294 & 2.481 & 3.995 & 5.885 \\
\hline k-w SST & 0.001 & 0.006 & 0.033 & 0.125 & 0.543 & 1.265 & 2.318 & 3.723 & 5.477 \\
\hline $\begin{array}{l}\text { Tensões de } \\
\text { Reynolds }\end{array}$ & 0.000 & 0.004 & 0.030 & 0.123 & 0.578 & 1.329 & 2.446 & 3.932 & 5.792 \\
\hline
\end{tabular}

Essa diferença entre as forças no eixo dianteiro e traseiro obviamente gera um momento de arfagem no veículo, que no caso é negativo, com a região frontal sendo forçada para baixo e a parte traseira para cima. Na escala da Figura 6-9 a diferença entre os momentos dos modelos não é muito perceptível. 


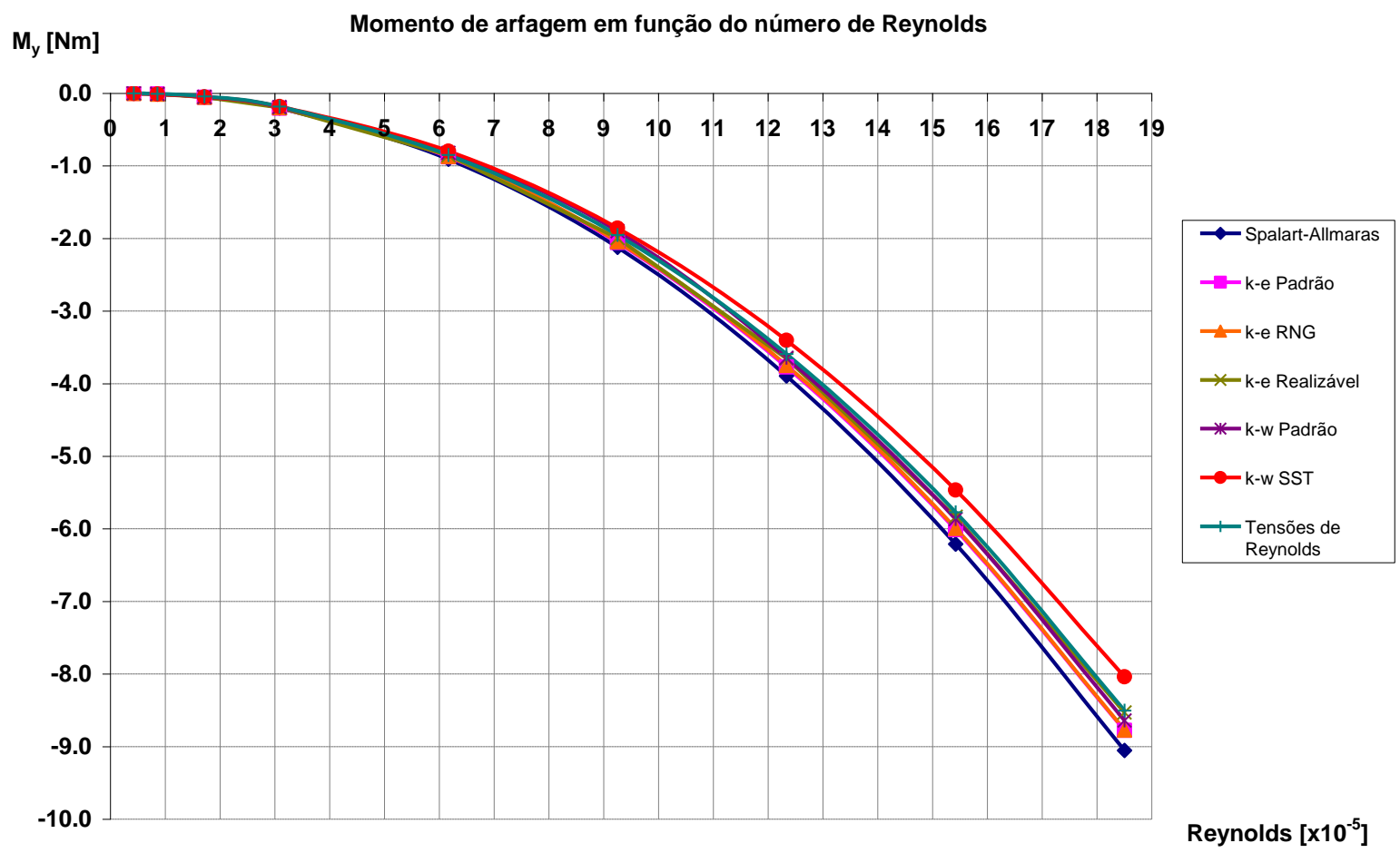

Figura 6-9: Gráfico dos momentos de arfagem (momento em y) em função do número de Reynolds para cada modelo de turbulência.

Tabela 6-9: Resultados dos momentos de arfagem (momento em y) em função do número de Reynolds para cada modelo de turbulência.

$\mathrm{M}_{\mathrm{y}}$ - Momento de arfagem $[\mathrm{Nm}]$

\begin{tabular}{l|c|c|c|c|c|c|c|c|c}
\hline Re $\left[\mathbf{x 1 0} \mathbf{5}^{-5}\right]$ & $\mathbf{0 . 4}$ & $\mathbf{0 . 9}$ & $\mathbf{1 . 7}$ & $\mathbf{3 . 1}$ & $\mathbf{6 . 2}$ & $\mathbf{9 . 3}$ & $\mathbf{1 2 . 3}$ & $\mathbf{1 5 . 4}$ & $\mathbf{1 8 . 5}$ \\
\hline $\begin{array}{l}\text { Spalart- } \\
\text { Allmaras }\end{array}$ & -0.001 & -0.010 & -0.054 & -0.202 & -0.908 & -2.121 & -3.893 & -6.210 & -9.053 \\
k-e Padrão & -0.001 & -0.010 & -0.054 & -0.204 & -0.876 & -2.057 & -3.771 & -6.012 & -8.776 \\
k-e RNG & -0.001 & -0.009 & -0.051 & -0.196 & -0.868 & -2.043 & -3.749 & -5.991 & -8.770 \\
k-e Realizável & -0.001 & -0.010 & -0.051 & -0.194 & -0.854 & -1.994 & -3.653 & -5.832 & -8.530 \\
k-w Padrão & -0.001 & -0.008 & -0.049 & -0.189 & -0.818 & -1.899 & -3.642 & -5.864 & -8.639 \\
k-w SST & -0.001 & -0.009 & -0.048 & -0.183 & -0.797 & -1.857 & -3.403 & -5.466 & -8.040 \\
$\begin{array}{l}\text { Tensões de } \\
\text { Reynolds }\end{array}$ & 0.000 & -0.006 & -0.044 & -0.181 & -0.849 & -1.951 & -3.591 & -5.773 & -8.502
\end{tabular}


Todos os cenários apresentados foram obtidos através de processamento paralelo em 8 CPU’s em um cluster. Esse equipamento possui as seguintes características:

- Sistema Operacional: Linux Red Hat.

- Kernel: 2.6.16.60-0.21-smp.

- Arquitetura: x86_64 bits.

- Processadores: Intel Xeon E5520 2.26GHz.

- Memória: $37 \mathrm{~Gb}$.

A Figura 6-10 mostra o tempo de processamento efetivo (tempo de parede) para cada modelo de turbulência no caso de $\operatorname{Re}=12.3 \times 10^{5}$. Como esperado, o modelo das Tensões de Reynolds é o que demanda mais tempo, por resolver o maior número de equações de transporte, enquanto o modelo Spalart-Allmaras é o que consome o menor tempo, por resolver menos equações. Os modelos k- $\varepsilon$ na forma padrão e realizável apresentaram o mesmo tempo de simulação o que demonstra que a condição de "realizável" não demanda um custo computacional significativo, diferentemente do k- $\varepsilon$ RNG que aumentou, mesmo que pouco, o tempo de cálculo. Também era esperado que o modelo k- $\omega$ SST levasse um maior tempo que o modelo k- $\omega$ padrão. É interessante ressaltar a diferença entre o modelo k- $\varepsilon$ padrão e suas variantes e o k- $\omega$ padrão e sua outra forma. 


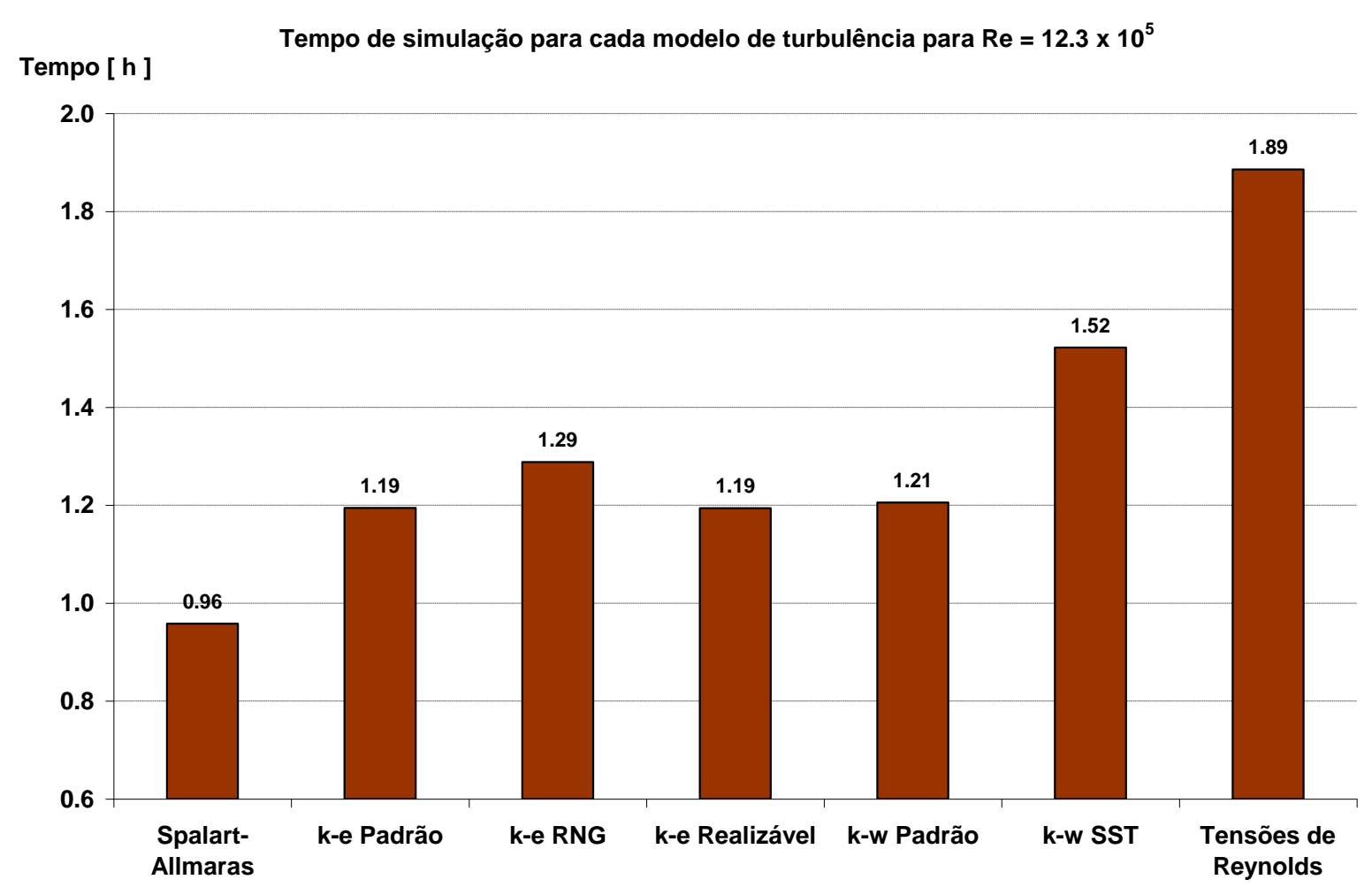

Figura 6-10: Tempo de simulação para cada modelo de turbulência com $\operatorname{Re}=12.3 \times 10^{5}$.

\subsection{Contornos e visualização do escoamento}

Nessa seção são apresentados os resultados de contornos obtidos com o modelo SpalartAllmaras com velocidade de entrada $7.2 \mathrm{~m} / \mathrm{s}\left(\operatorname{Re}=12.3 \times 10^{5}\right)$. Esse modelo foi escolhido para representar os contornos por ter sido concebido para aplicações aerodinâmicas (ANSYS FLUENT, 2009, p. 4-6) e essa velocidade foi a média dos participantes da edição de 2010 da Maratona de Eficiência Energética (MARATONA, 2010).

São divididos dois grupos de resultados: as primeiras figuras apresentam campos de variáveis na superfície do veículo, e então visualização das propriedades do escoamento ao redor. Essas ilustrações foram feitas com o software Ensight 8.2.6k.

No Ansys Fluent a lei logarítmica para a função de parede é empregada para $y^{*}$, definido na equação ( 6-1 ), maior que 11.225. Para camadas limites turbulentas em equilíbrio, que é o caso dessa simulação, y+ é aproximadamente igual a y* (ANSYS FLUENT, 2009, p. 4-75). 


$$
\mathrm{y}^{*}=\frac{\rho \cdot \mathrm{C}_{\mu}^{1 / 4} \cdot \mathrm{k}_{\mathrm{p}}^{1 / 2} \cdot \mathrm{y}_{\mathrm{p}}}{\mu}
$$

Onde:

$\rho=$ densidade do fluido; $\mathrm{C} \mu=0.09$ (constante), $\mathrm{k}_{\mathrm{p}}=$ energia cinética turbulenta no ponto $\mathrm{P}$ próximo à parede; $\mathrm{y}_{\mathrm{p}}=$ distância do centróide do ponto $\mathrm{P}$ à parede: $\mu=$ viscosidade dinâmica do fluido.

Na Figura 6-11 nota-se que a maior parte do veículo está com y+ maior que 11.225, o que torna o emprego de função de parede padrão válido.

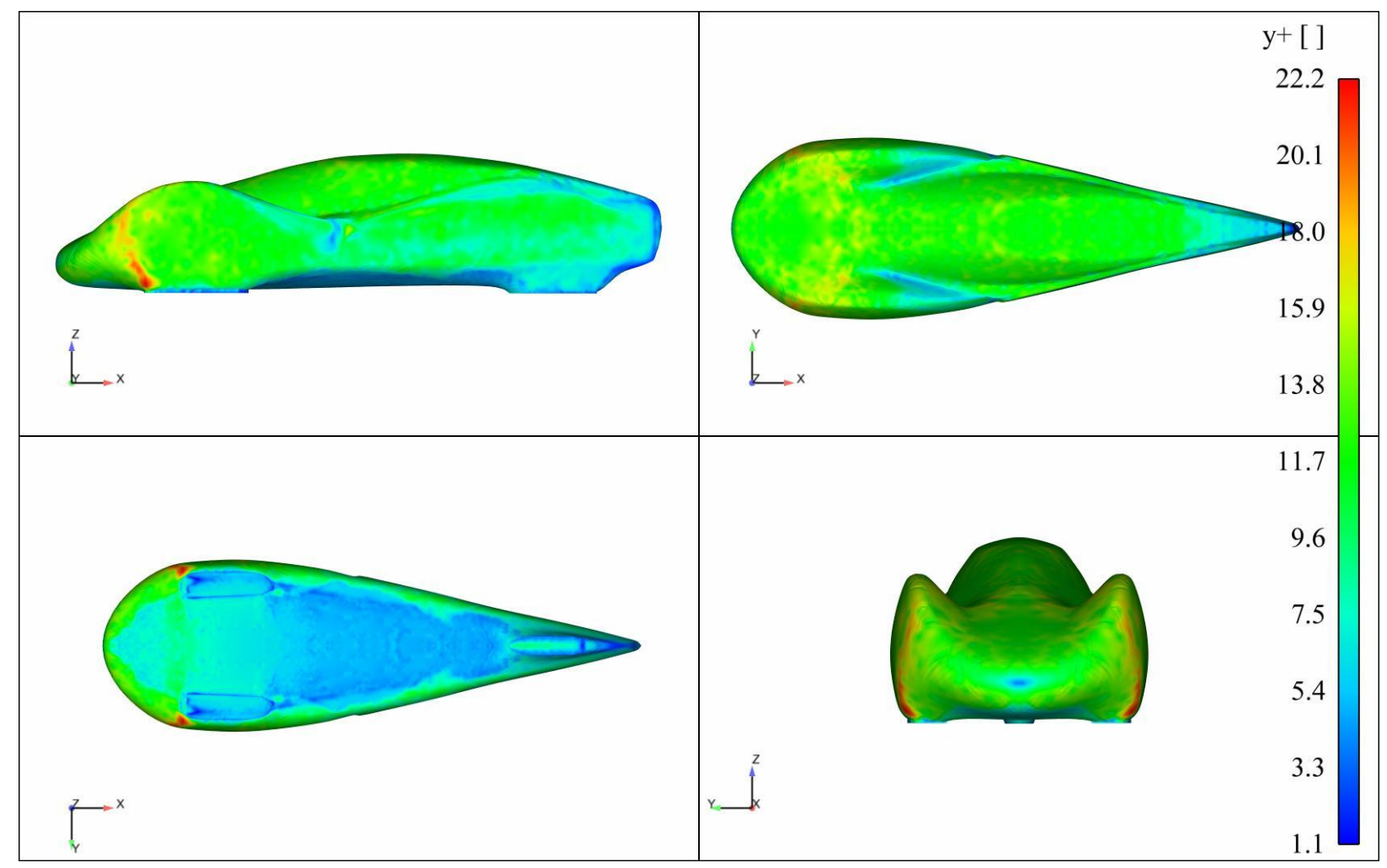

Figura 6-11: Contornos de y+ na superfície do veículo.

O coeficiente de pressão é um adimensional que descreve onde há uma pressão maior (valores positivos) ou menor (valores negativos) do que aquela encontrada no escoamento livre. É definido pela seguinte equação ( 6-2 ): 


$$
\mathrm{Cp}=\frac{\mathrm{p}-\mathrm{p}_{\infty}}{\frac{1}{2} \rho \mathrm{u}_{\infty}^{2}}
$$

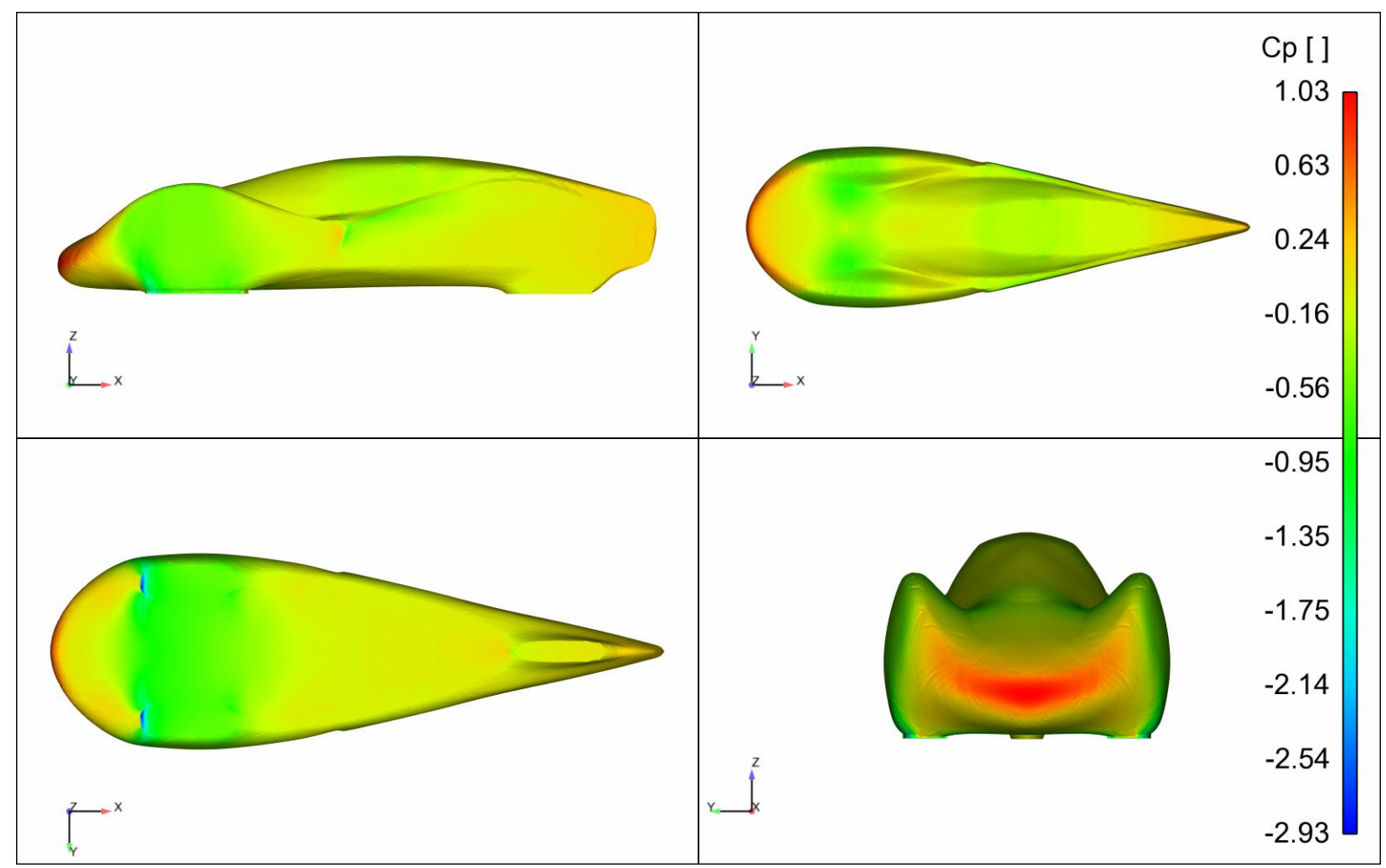

Figura 6-12: Contornos de Cp na superfície do veículo.

A Figura 6-12 mostra que a maior parte do veículo sofre uma pressão negativa na superfície. Essa pressão é menor na região lateral das caixas de roda dianteiras e nas superfícies superior e inferior da região frontal.

Uma maneira de verificar quais partes do veículo contribuem mais para o arrasto e a sustentação é "projetar" a pressão nos eixos x e z. Sendo a área de cada elemento da superfície representada por um vetor $\overrightarrow{\mathrm{A}}$, com origem no centróide, apontando para dentro do veículo, normal à face e de magnitude igual à área do elemento e de componentes Ax, Ay e Az, a pressão pode ser "projetada" na direção x utilizando-se a equação ( 6-3 ): 


$$
p_{x}=p \cdot \frac{A x}{|\vec{A}|}
$$

Com essa fórmula valores positivos de $\mathrm{p}_{\mathrm{x}}$ indicam as regiões pressionadas contra $\mathrm{o}$ escoamento e os valores negativos as que são "puxadas" no mesmo sentido do escoamento.

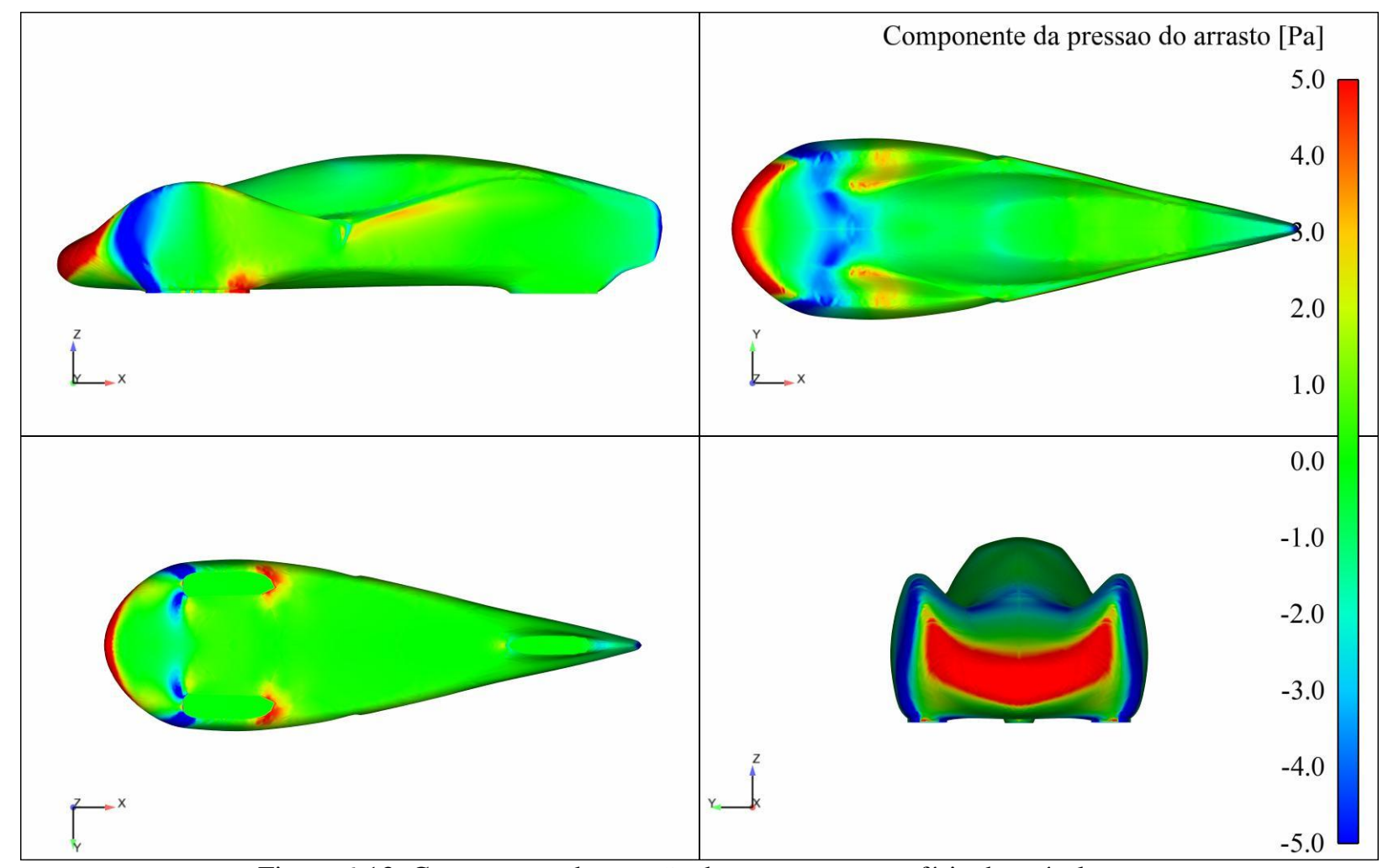

Figura 6-13: Componente da pressão do arrasto na superfície do veículo.

Da Figura 6-13 se conclui que a região frontal do veículo é a de maior contribuição para a força de arrasto, como esperado. Entretanto a baixa pressão na região superior e nas laterais da caixa de roda faz com que essas partes exerçam uma força na direção do movimento do veículo (contrária ao escoamento).

Da mesma forma pode-se "projetar" a pressão no eixo z e verificar quais regiões do veículo contribuem para a sustentação e como se dá essa contribuição. Assim a fórmula fica: 


$$
p_{z}=p \cdot \frac{A z}{|\vec{A}|}
$$

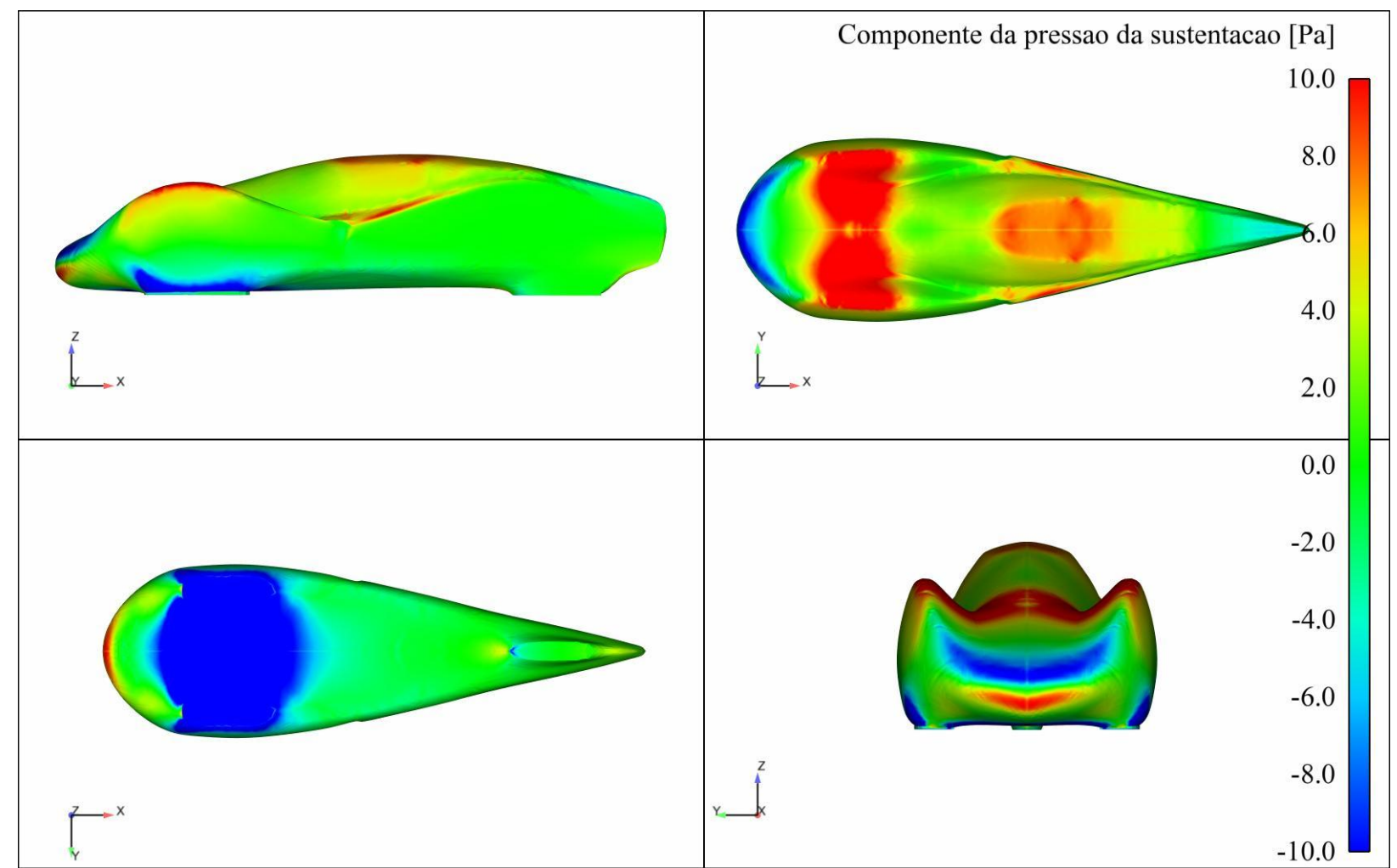

Figura 6-14: Componente da pressão da sustentação na superfície do veículo.

A Figura 6-14 complementa os gráficos de sustentação no eixo dianteiro e traseiro. Observando-a fica claro que a região frontal é a que tem maior influência nessa força. Nota-se também que a pressão negativa na parte dianteira inferior é maior do que a pressão positiva na parte superior, fazendo com que a força total no eixo dianteiro seja negativa. Por outro lado, na região traseira a pressão positiva na parte superior é maior do que a negativa na inferior, o que faz com que a força total de sustentação seja positiva. 
A alta velocidade entre as caixas de roda dianteira na região inferior, causadora da pressão negativa, e conseqüentemente da sustentação negativa nessa parte do veículo, pode ser visualizada na Figura 6-15, através das linhas de corrente criadas a $5 \mathrm{~mm}$ da superfície do veículo.

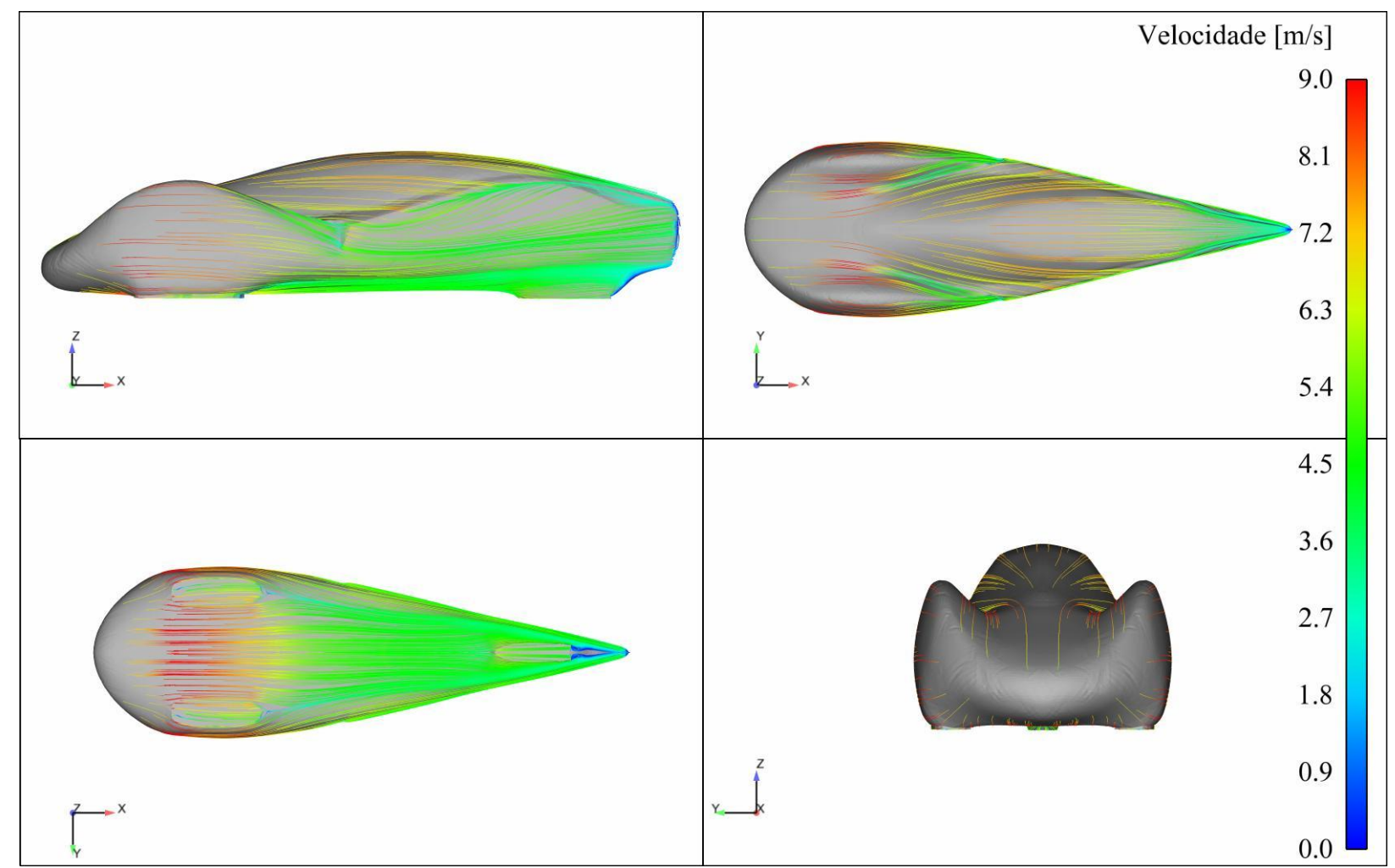

Figura 6-15: Linhas de corrente a $5 \mathrm{~mm}$ da superfície do veículo coloridas por velocidade. 
Pelas linhas de corrente ao redor do veículo percebe-se que o modelo pouco perturba o escoamento, como esperado devido aos baixos valores de coeficiente de arrasto

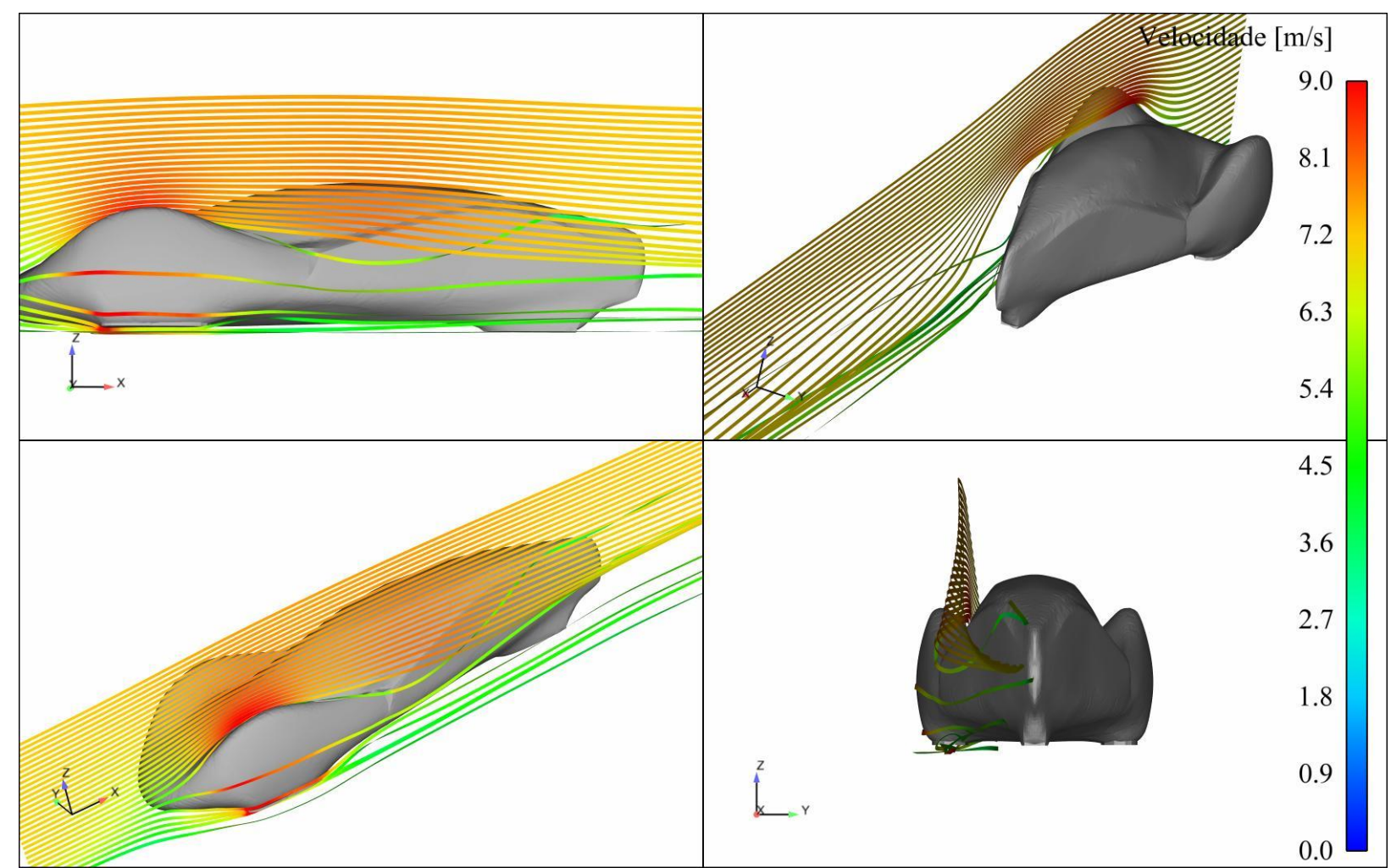

Figura 6-16: Linhas de corrente coloridas por velocidade ao redor do veículo.

As próximas figuras mostram o comportamento das variáveis ao redor do veículo, num plano de simetria longitudinal e num plano em $\mathrm{z}=-0.11 \mathrm{~m}$. 
No detalhe do campo de velocidades no plano de simetria é possível observar que a região onde o escoamento está mais rápido é entre as caixas de roda dianteira. Nota-se também baixas velocidades na região traseira e conseqüente a alta pressão observada na Figura 6-18.

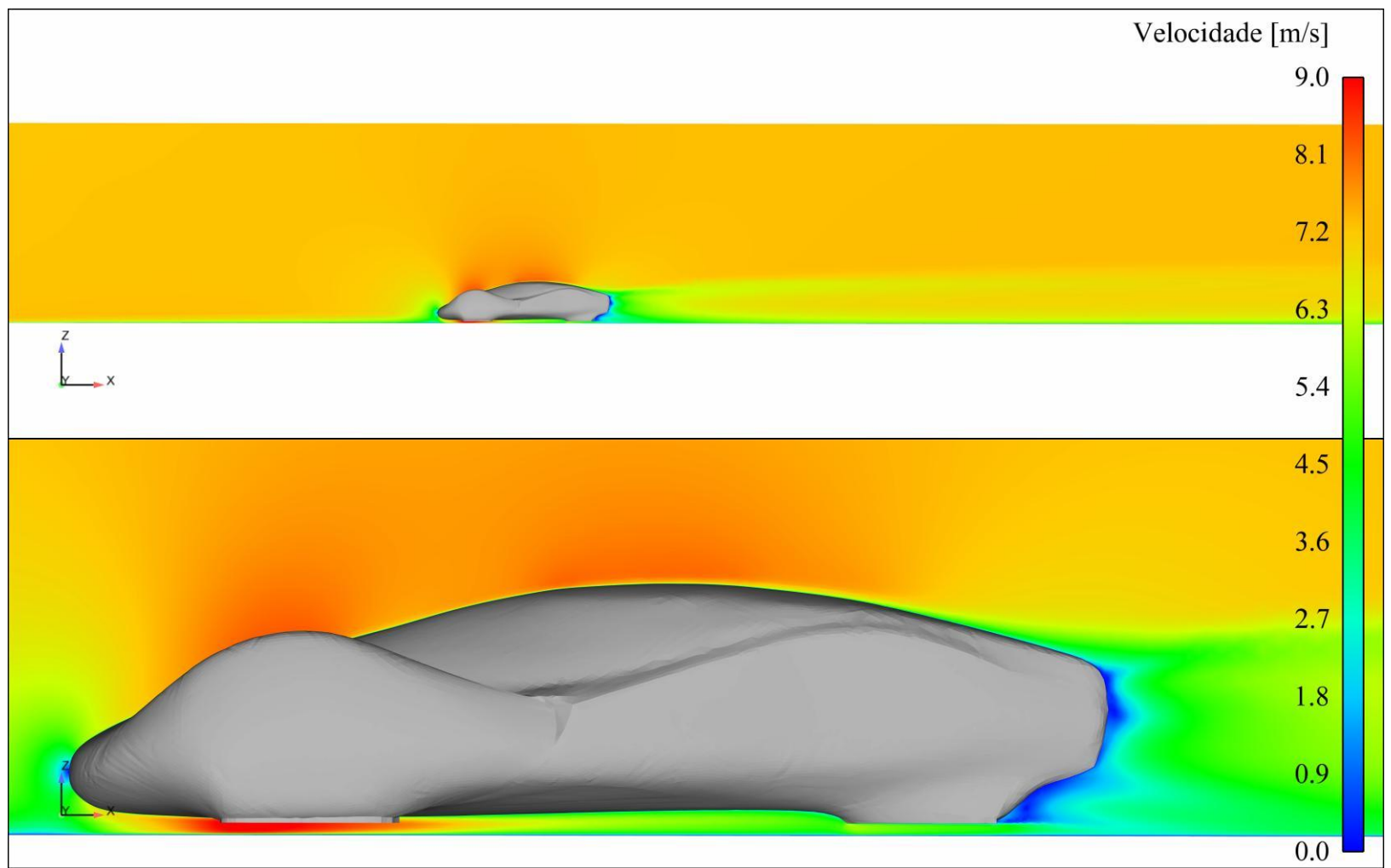

Figura 6-17: Campo de velocidades no plano de simetria longitudinal. 
O campo de pressões é análogo ao campo de velocidades, e complementa as informações observadas nas figuras das componentes da pressão do arrasto e da sustentação.

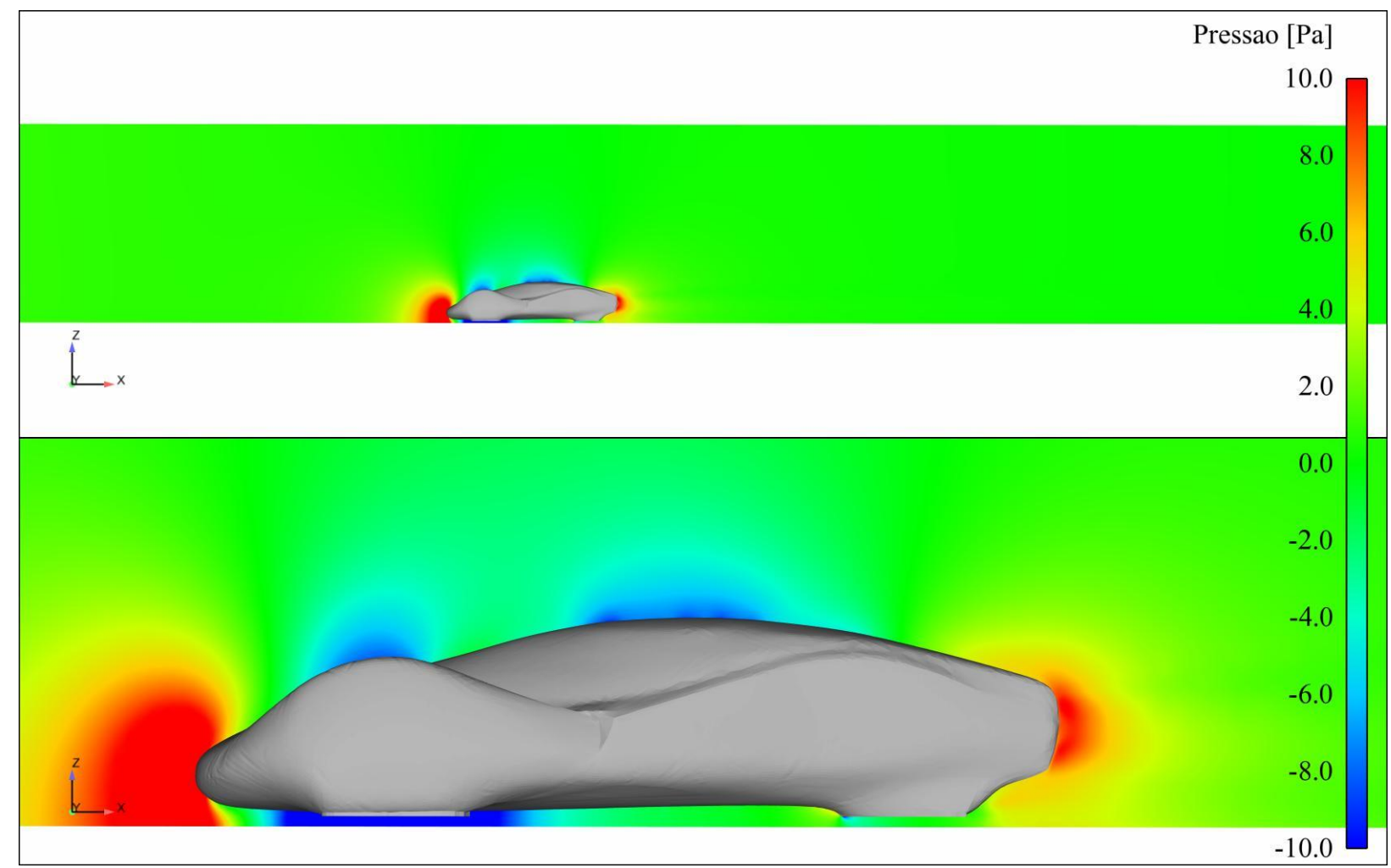

Figura 6-18: Campo de pressões no plano de simetria longitudinal. 
A figura do contorno da razão entre as viscosidades turbulenta e laminar mostra um escoamento ao longe plenamente turbulento, com uma espécie de camada limite se formando desde o início do túnel. Próximo à superfície do veículo o escoamento também perde um pouco de turbulência, e a esteira de vórtices é menos turbulenta que o escoamento livre.

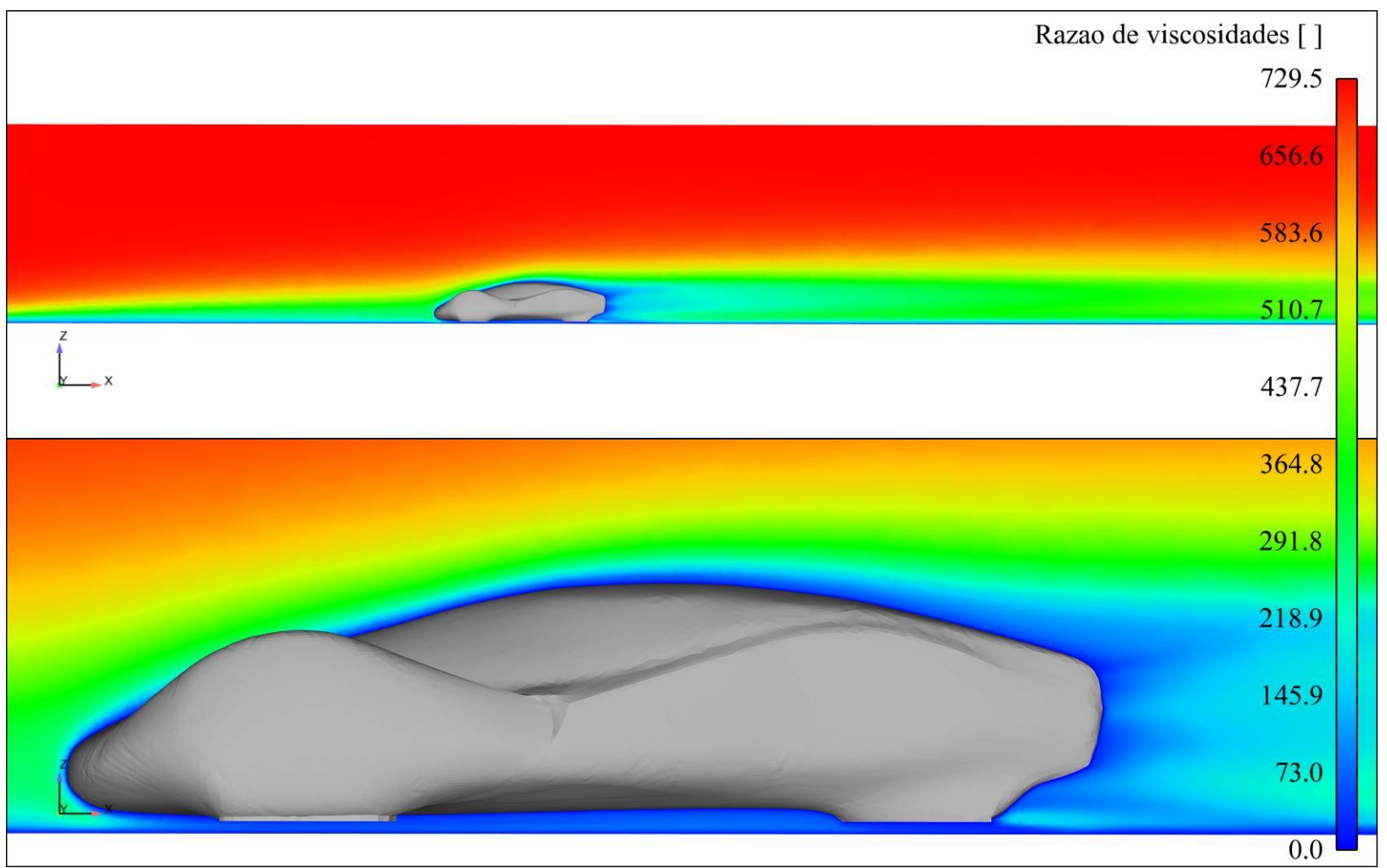

Figura 6-19 Campo de razão de viscosidades no plano de simetria longitudinal. 
Vorticidade é a medida de rotação de um elemento de fluido enquanto se move num escoamento. É definido pelo rotacional do vetor velocidade:

$$
\xi=\nabla \times \overrightarrow{\mathrm{V}}
$$

Na Figura 6-20 está representada a magnitude do vetor vorticidade.

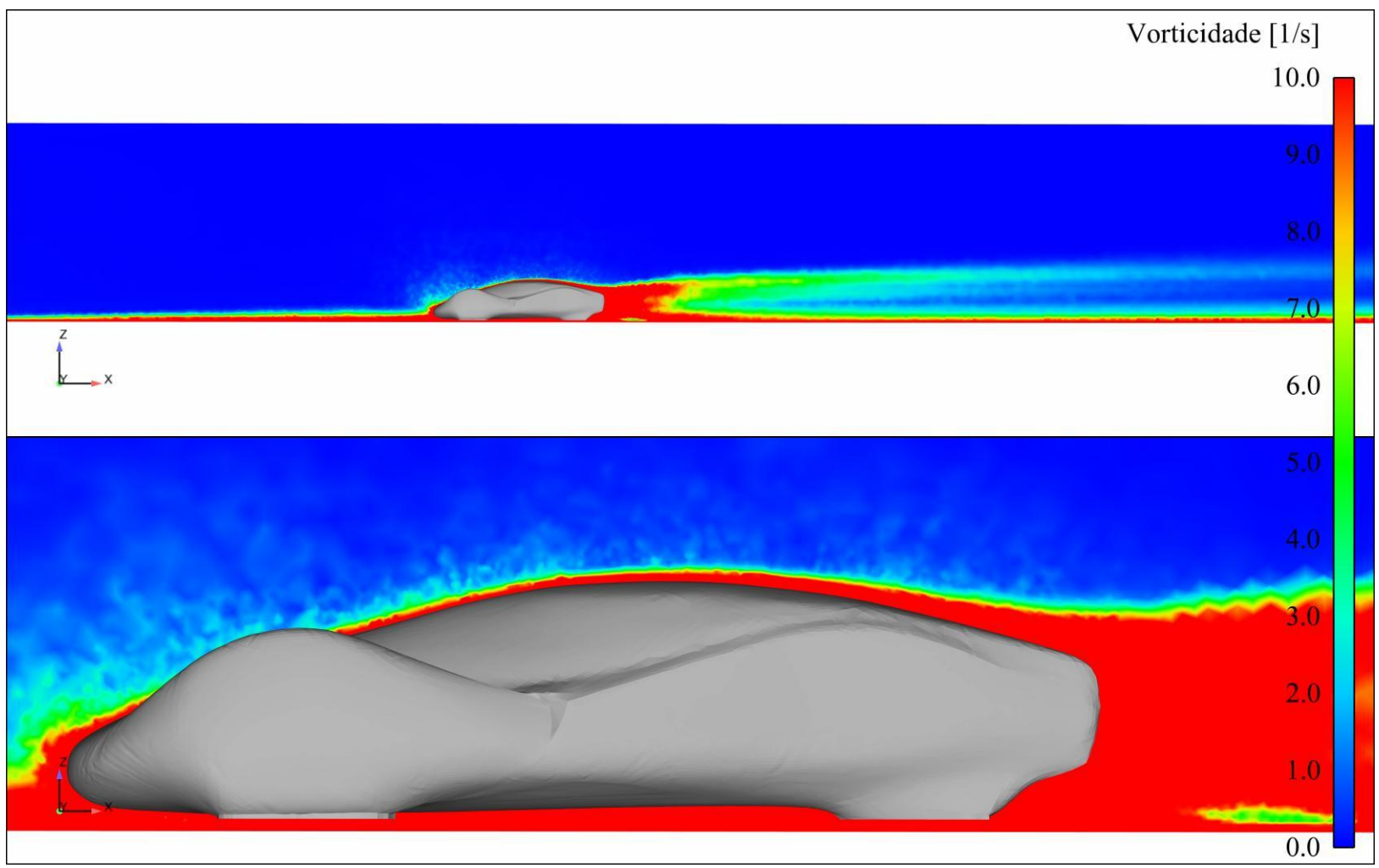

Figura 6-20: Campo de magnitude da vorticidade no plano de simetria longitudinal.

Observa-se que as maiores perturbações ocorrem próximas às paredes: superfície do veículo e do piso. É interessante notar uma variação abrupta da vorticidade na esteira de vórtices, que também é observada na Figura 6-25. 
As figuras seguintes são num plano em $z=-0.11$ m, visualizado na Figura 6-21:

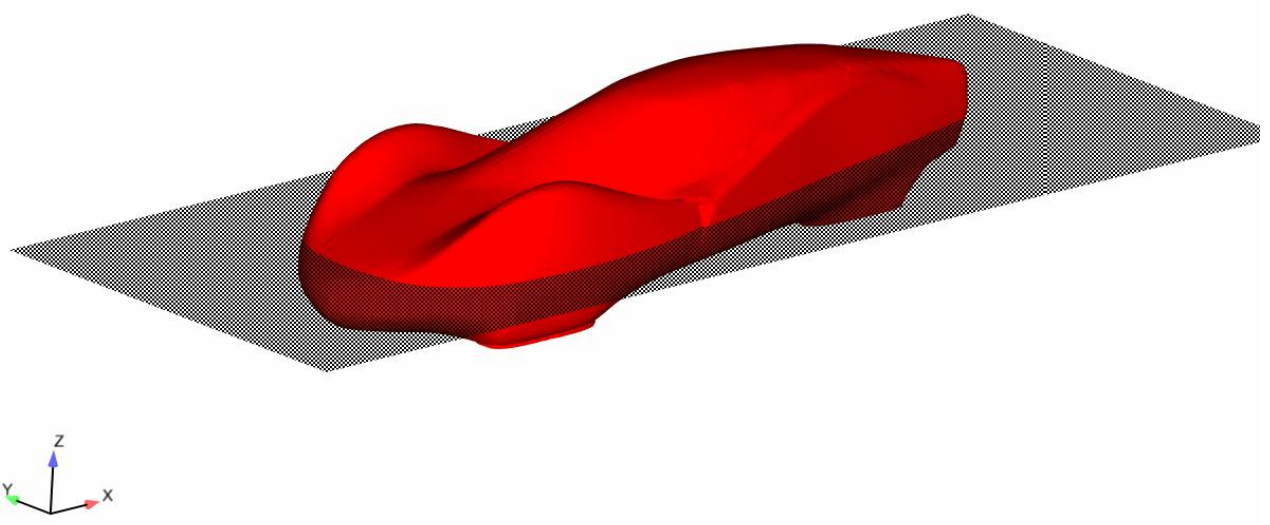

Figura 6-21: Ilustração da posição do plano horizontal z $=-0.11 \mathrm{~m}$.

Os contornos de velocidade na Figura 6-22 mostram aceleração do escoamento nas proximidades das caixas de rodas dianteiras.

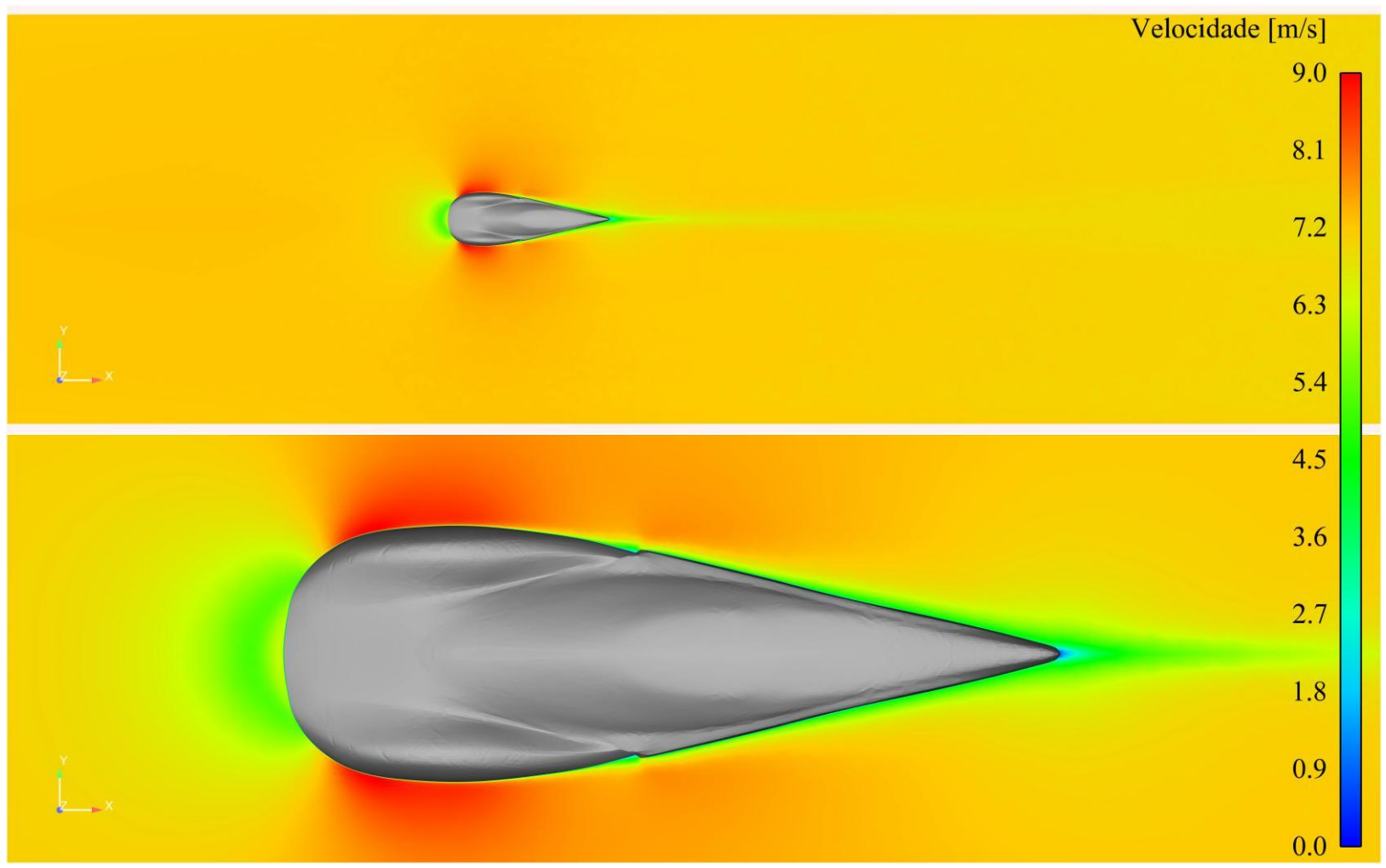

Figura 6-22: Campo de velocidades no plano $\mathrm{z}=-0.11 \mathrm{~m}$. 
Na figura do campo de pressões nota-se as baixos valores no mesmo lugar das altas velocidades, obviamente, e também um região de baixa pressão logo após a tomada de ar, aproximadamente no meio do veículo. A alta pressão na parte de trás é benéfica, pois compensa um pouco os efeitos da região de estagnação.

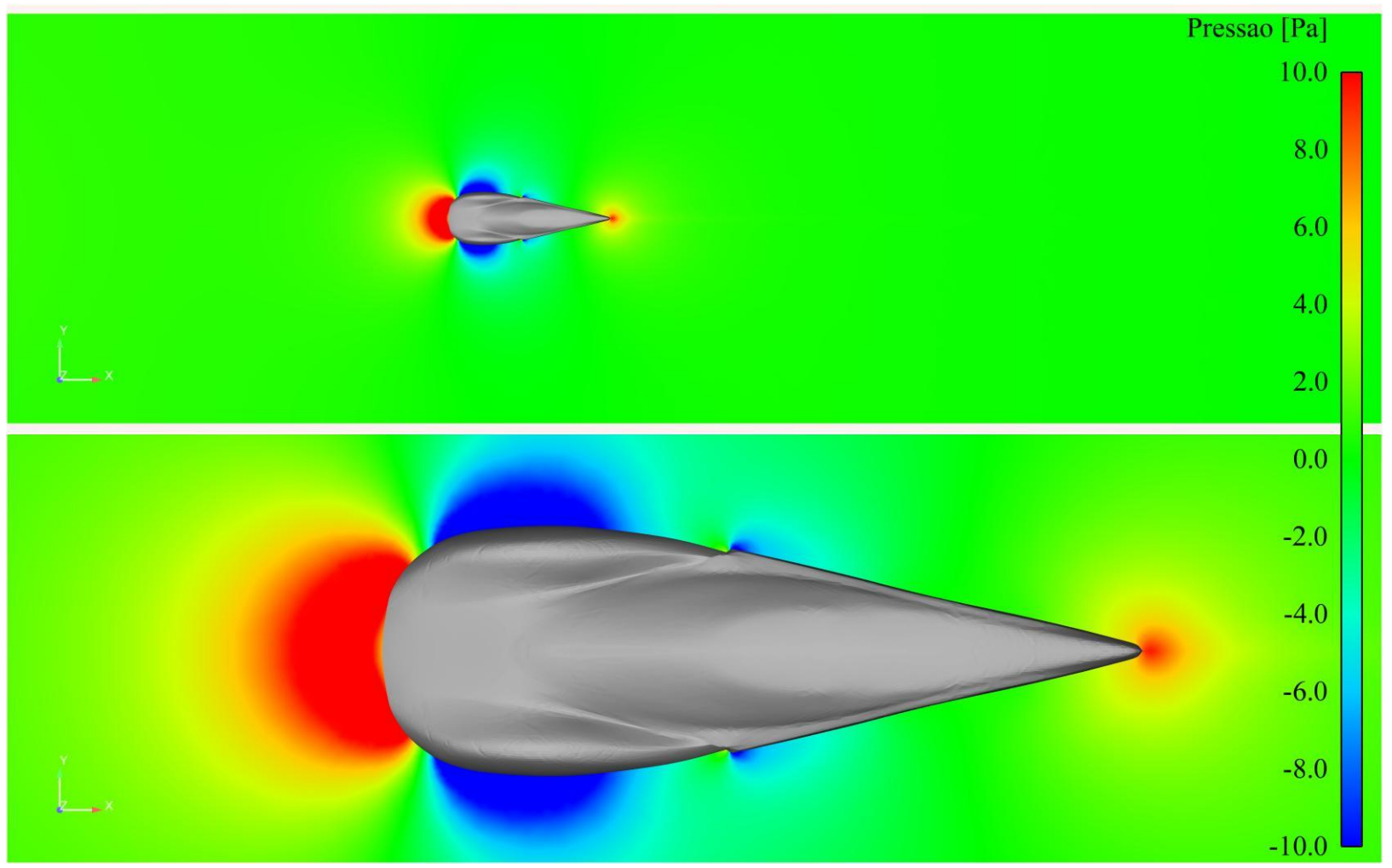

Figura 6-23: Campo de pressões no plano $\mathrm{z}=-0.11 \mathrm{~m}$. 
O campo de viscosidades num plano horizontal mostra um escoamento mais turbulento na entrada do domínio, provável efeito da condição de contorno, e mais laminar nas proximidades do veículo. Nota-se também um aumento da turbulência próximo à saída do túnel, e não se tem claro um motivo para isso.

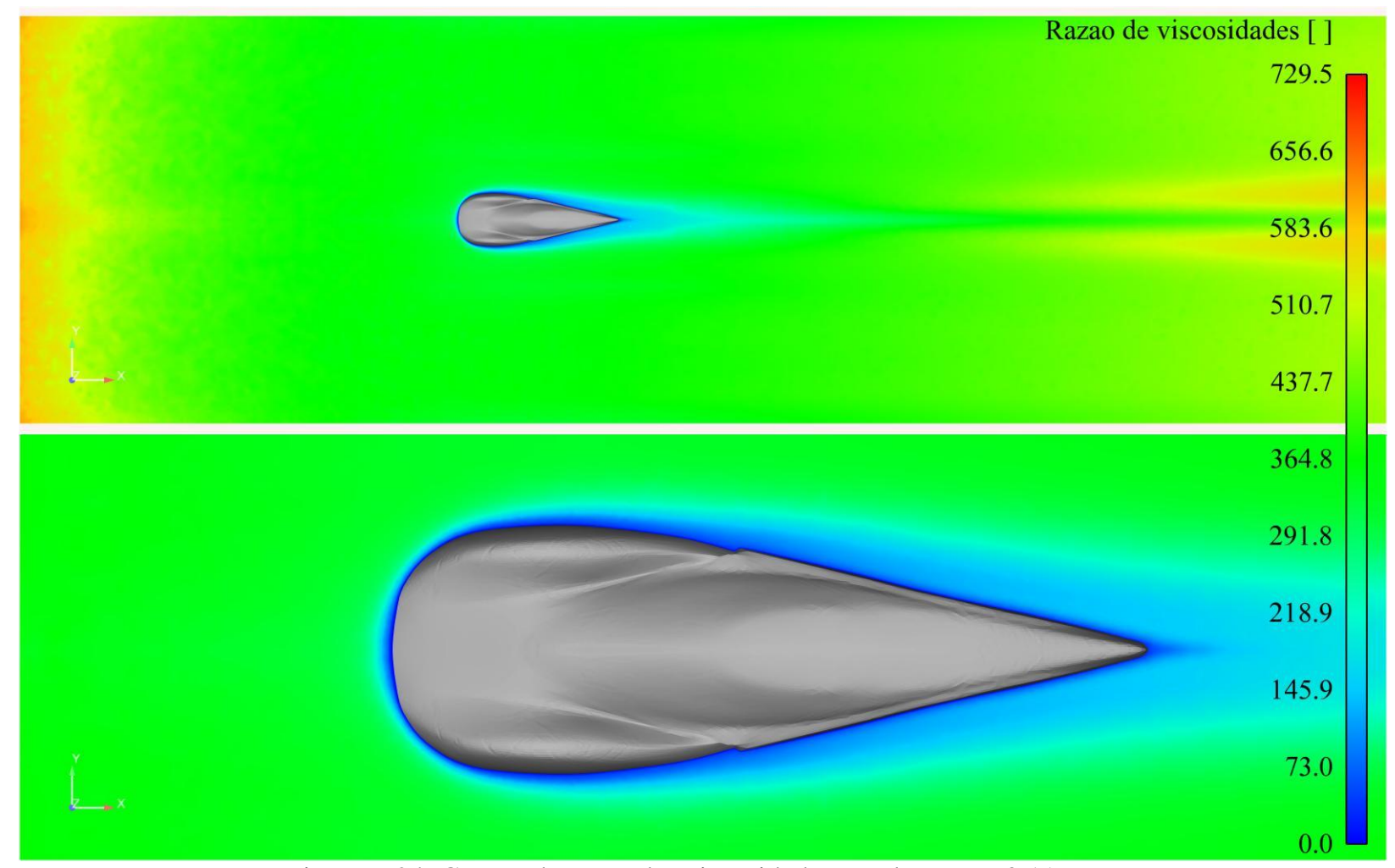

Figura 6-24: Campo de razão das viscosidades no plano $\mathrm{z}=-0.11 \mathrm{~m}$ 
A magnitude da vorticidade no plano $\mathrm{z}=-0.11 \mathrm{~m}$ mostra, assim como no plano longitudinal de simetria, que os maiores valores estão nas proximidades do veículo. Nota-se também, como já comentado, uma variação abrupta observada tanto na Figura 6-20 como na Figura 6-25.

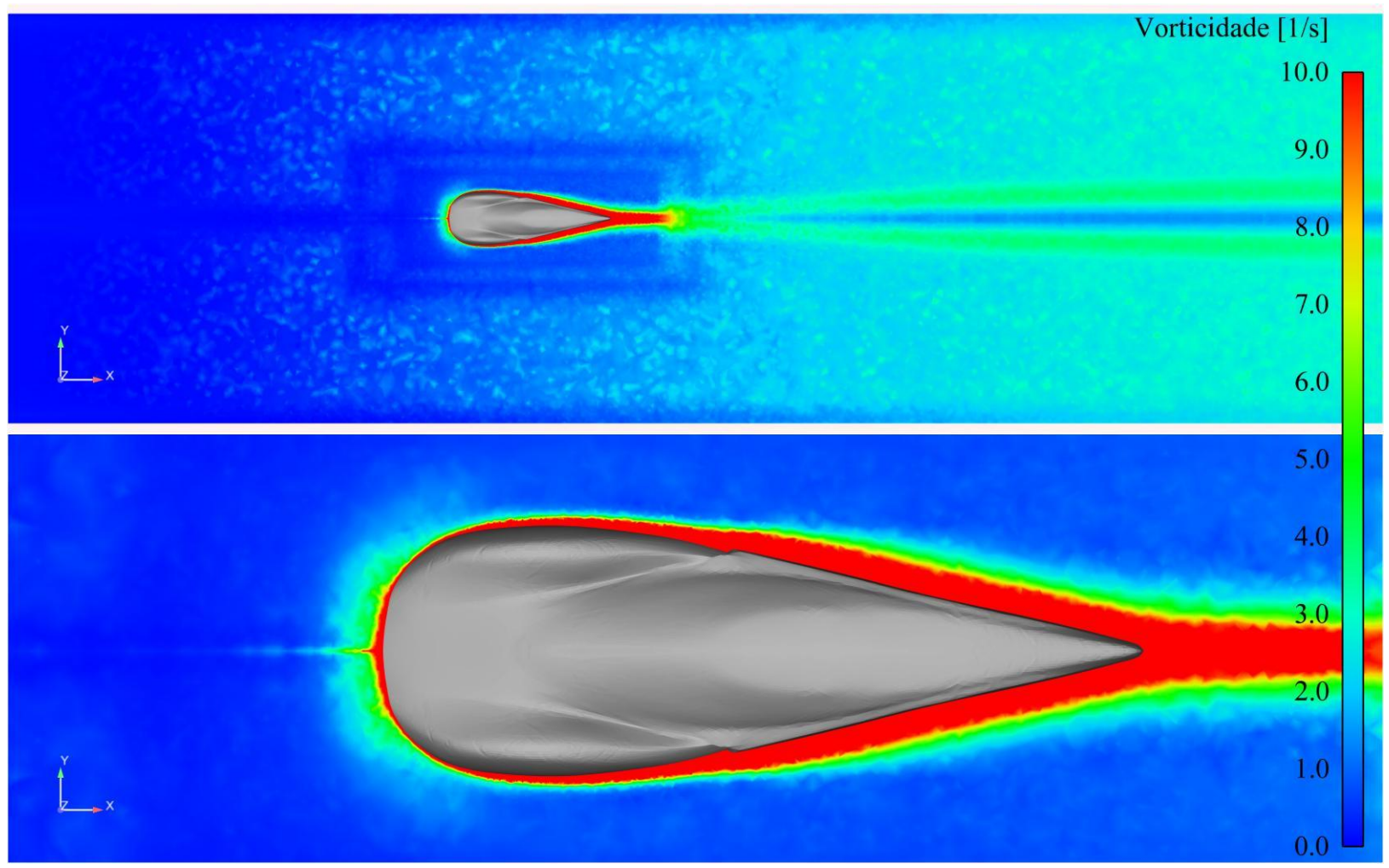

Figura 6-25: Campo de magnitude da vorticidade no plano $\mathrm{z}=-0.11 \mathrm{~m}$.

\subsection{Análises complementares}

Como uma forma de complementar as análises já realizadas foram efetuadas mais 3 simulações tomando como base o modelo de turbulência Spallart-Allmaras e velocidade na entrada de $7.2 \mathrm{~m} / \mathrm{s}\left(\operatorname{Re}=12.3 \times 10^{5}\right)$. 


\subsubsection{Piso em movimento}

A primeira alteração foi a da condição de contorno do piso, que passou a ter a mesma velocidade do escoamento. Os resultados dos coeficientes obtidos com essa nova configuração, comparados com o solo parado, podem ser observados na Figura 6-26.

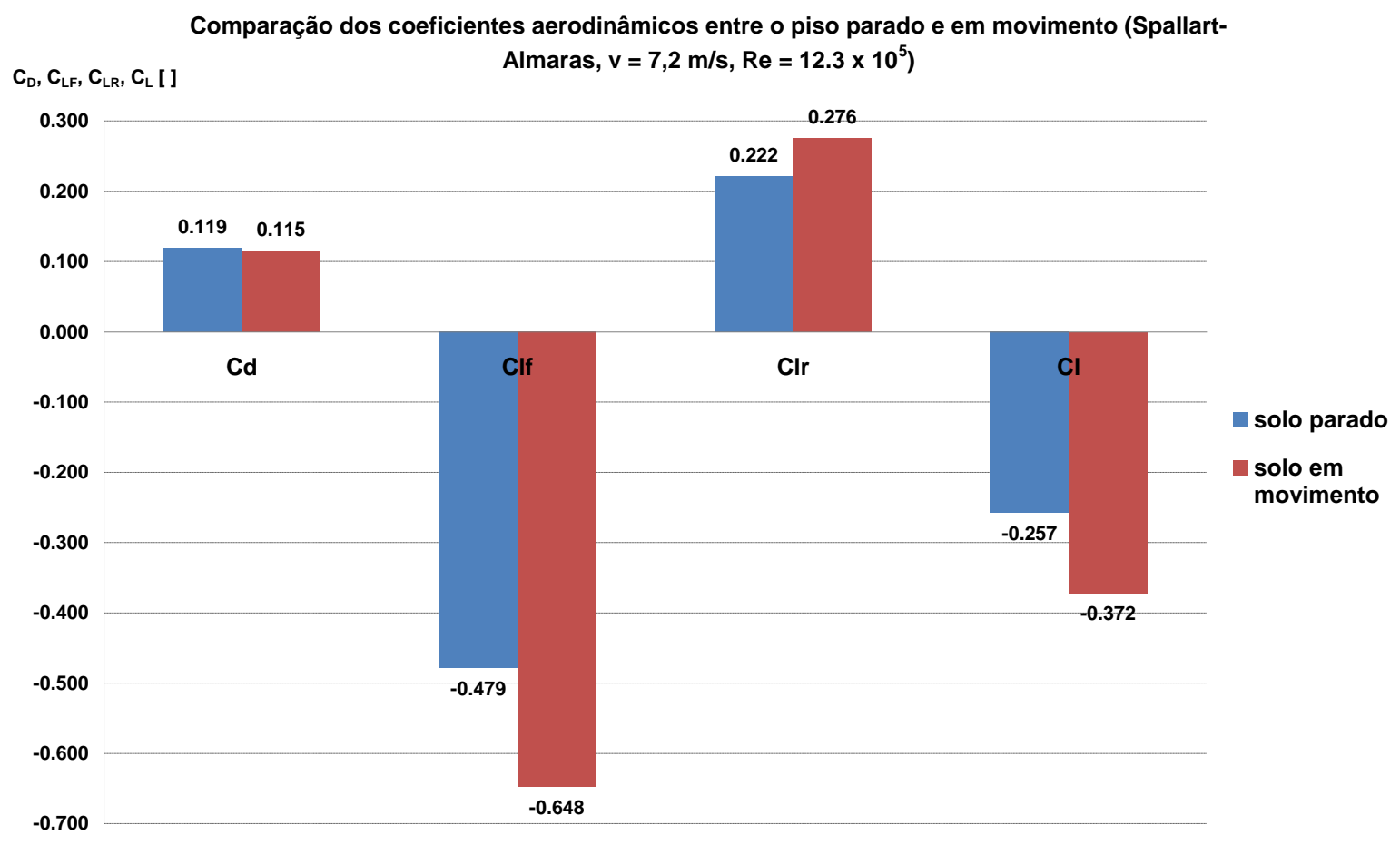

Figura 6-26: Comparação dos coeficientes aerodinâmicos entre o piso parado e em movimento (SpallartAlmaras, $\mathrm{v}=7.2 \mathrm{~m} / \mathrm{s}$ e $\mathrm{Re}=12.3 \times 10^{5}$ ).

O coeficiente de arrasto diminuiu um pouco, resultado que concorda com o apresentado por Buscariolo (2009). O coeficiente de sustentação no eixo dianteiro $\left(\mathrm{C}_{\mathrm{LF}}\right)$ apresentou uma redução significativa, resultado esperado, pois como já discutido anteriormente seu valor é ligado às altas velocidades na região entre as duas rodas dianteiras e com o piso em movimento essas velocidades aumentam ainda mais. Soma-se a isso o fato da sustentação no eixo traseiro ter aumentado, ou seja, houve um aumento no momento de arfagem. Mesmo assim a sustentação global diminuiu. Essas diferenças podem ser mais bem esclarecidas nas figuras seguintes. 


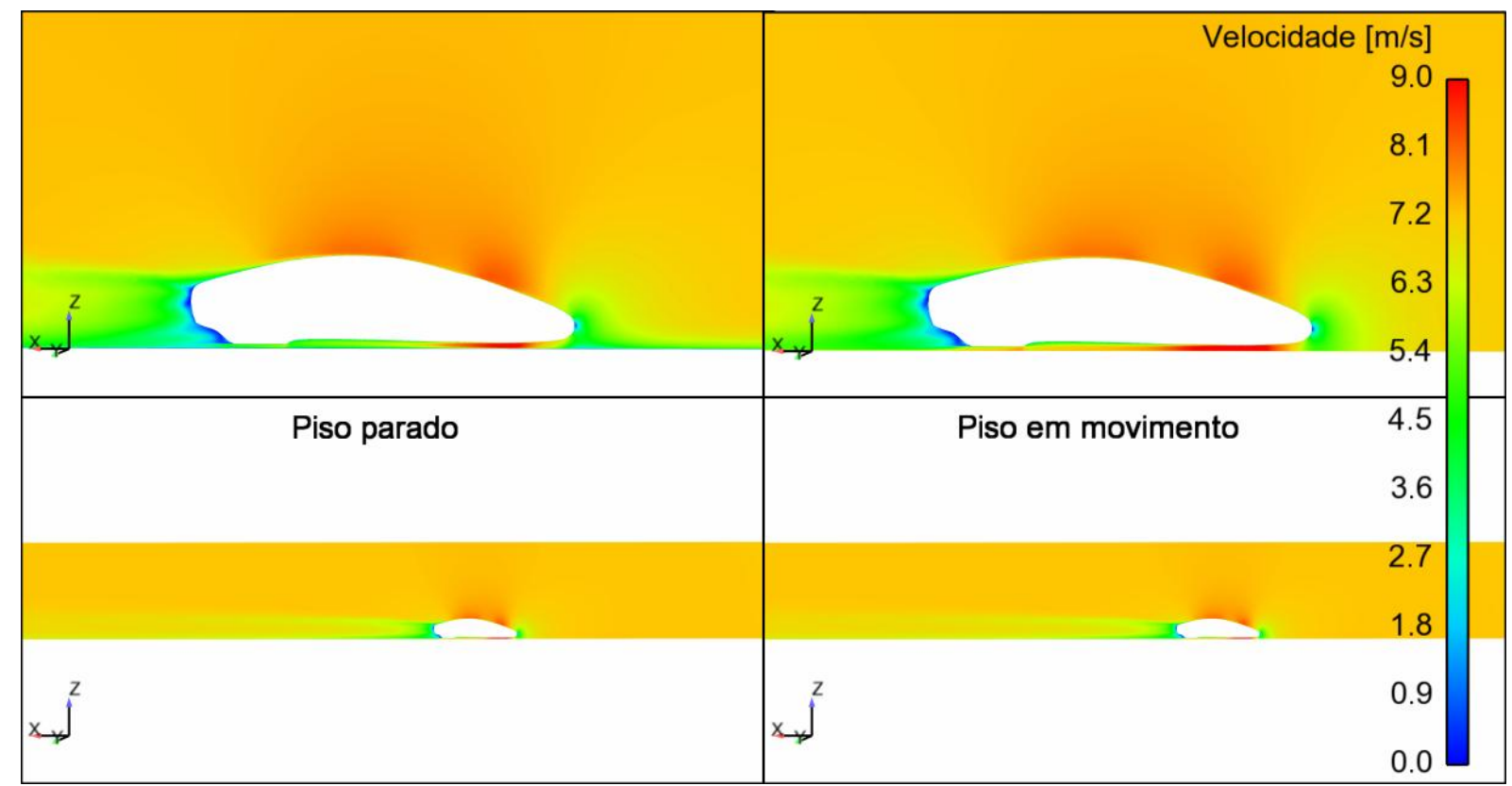

Figura 6-27: Velocidade no plano de simetria para o piso parado e em movimento. (Spallart-Almaras, $\mathrm{v}=7.2$ $\mathrm{m} / \mathrm{s}$ e $\left.\operatorname{Re}=12.3 \times 10^{5}\right)$.

Na Figura 6-27 pode ser observado o aumento da velocidade na região frontal abaixo do veículo, com a condição do solo em movimento. Nota-se também que o restante do escoamento tem um comportamento muito similar em relação ao solo parado.

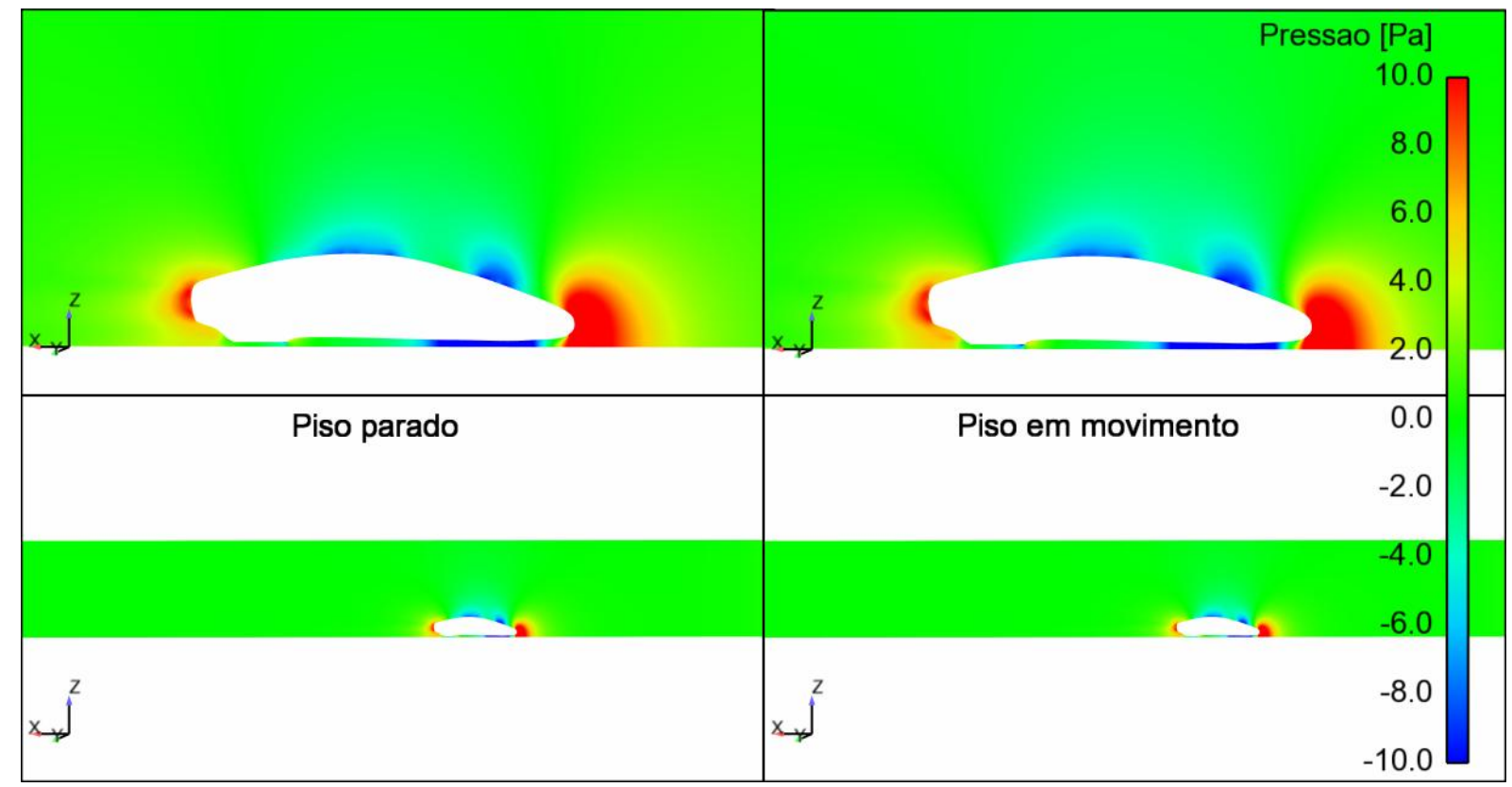

Figura 6-28: Pressão no plano de simetria para o piso parado e em movimento. (Spallart-Almaras, $\mathrm{v}=7.2 \mathrm{~m} / \mathrm{s}$ e $\left.\operatorname{Re}=12.3 \times 10^{5}\right)$ 


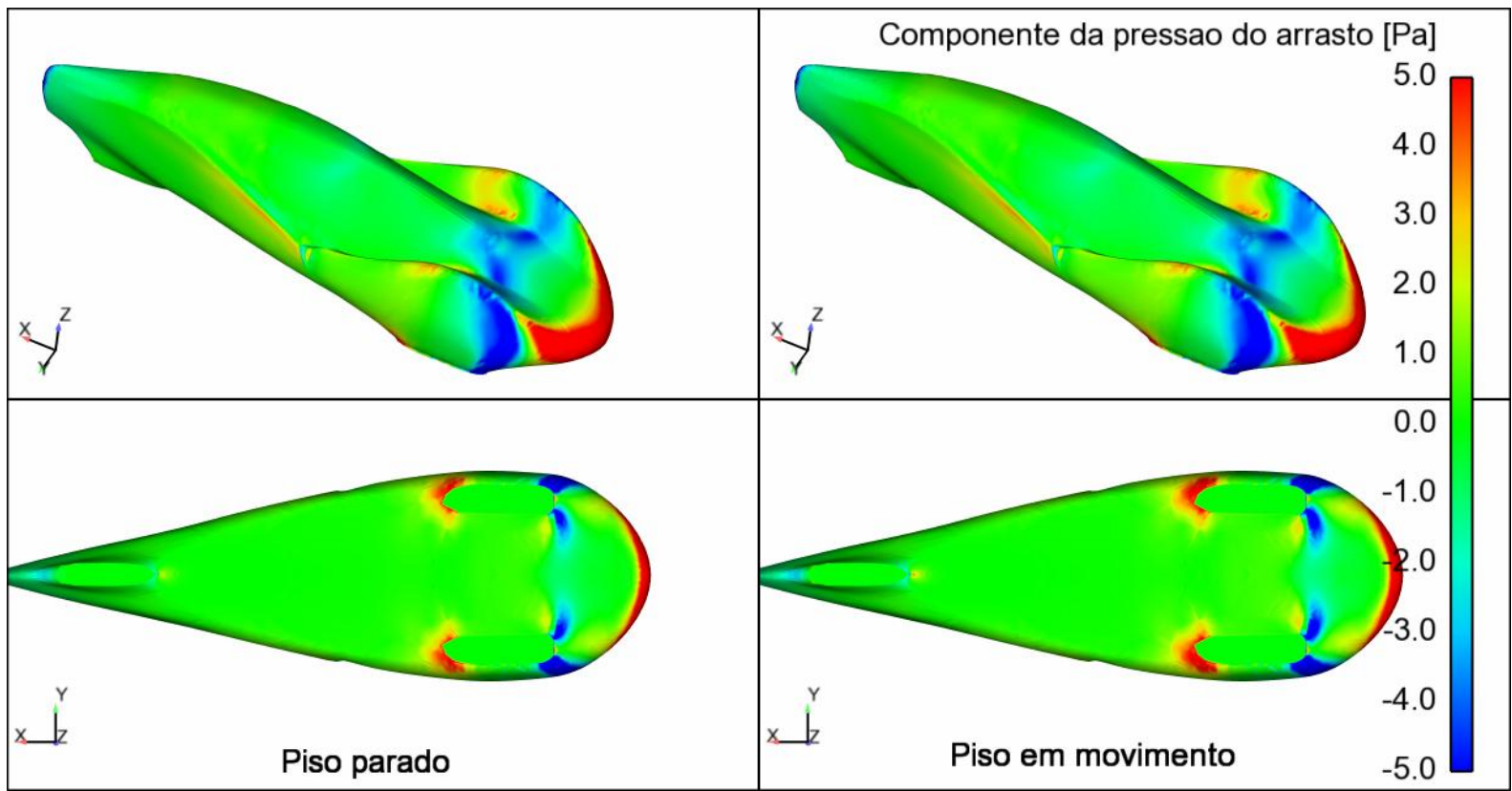

Figura 6-29: Componente da pressão do arrasto para o piso parado e em movimento (Spallart-Almaras, v = 7.2 $\mathrm{m} / \mathrm{s}$ e $\operatorname{Re}=12.3 \times 10^{5}$ ).

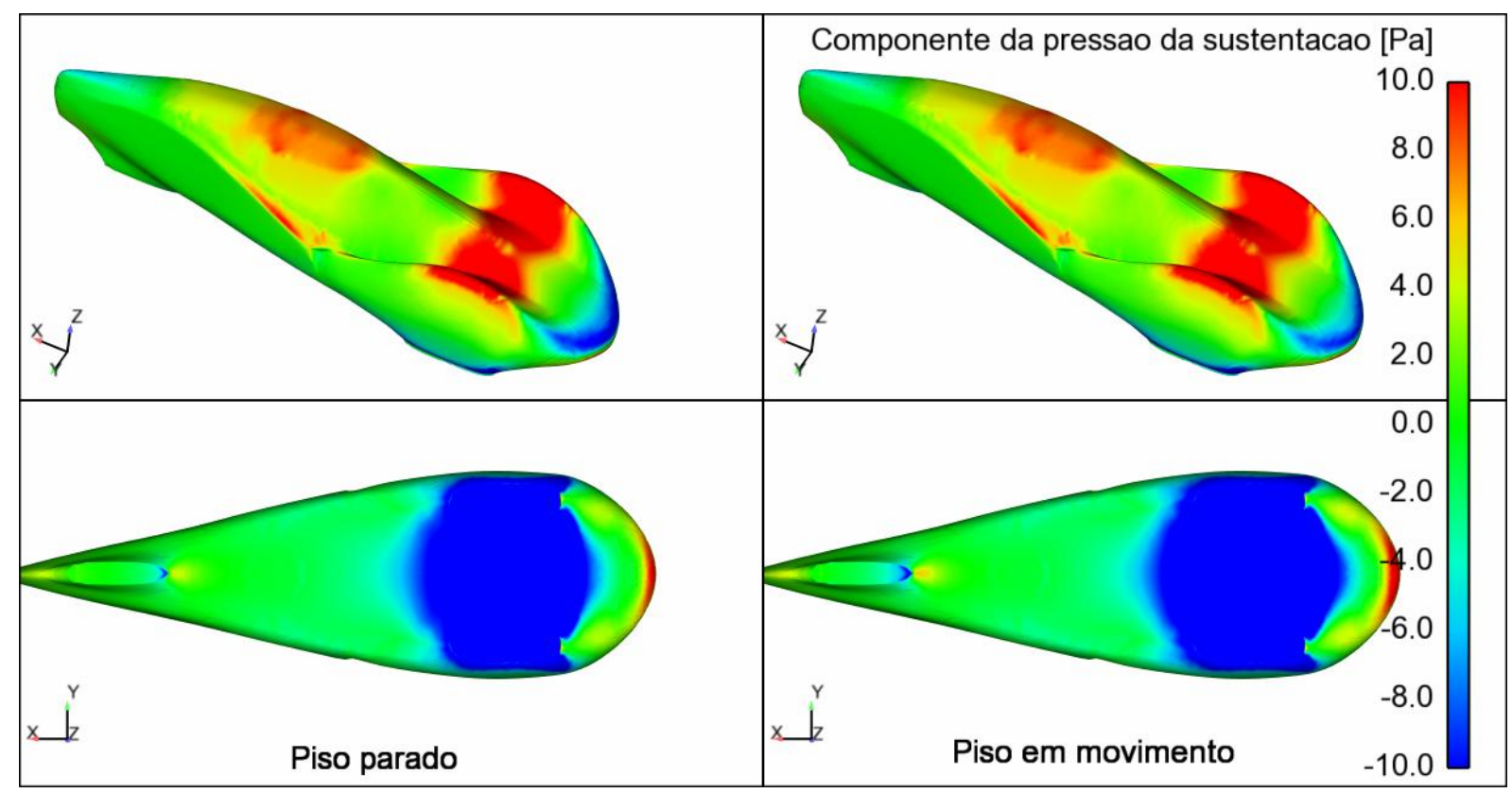

Figura 6-30: Componente da pressão da sustentação para o piso parado e em movimento (Spallart-Almaras, $\mathrm{v}=$ $7.2 \mathrm{~m} / \mathrm{s}$ e $\left.\operatorname{Re}=12.3 \times 10^{5}\right)$.

Observando as figuras das componentes da pressão de arrasto e sustentação é difícil distinguir os dois casos. Na sustentação nota-se um pequeno aumento da área de baixa pressão na região inferior do veículo, o que é suficiente para a diminuição do $\mathrm{C}_{\mathrm{L}}$. 
Vale ressaltar que o modelo com o piso parado foi escolhido como base das simulações para tentar se aproximar da situação encontrada no canal de água onde foram realizados os ensaios experimentais.

\subsubsection{Malha poliédrica}

O solver Ansys Fluent, por ser baseado em faces, suporta malhas poliédricas (ANSYS FLUENT, 2009a, p. 6-58), e outras duas análises foram realizadas com esse tipo de malha: com o solo parado e com o solo em movimento.

A principal vantagem das malhas poliédricas é uma redução significativa do número de elementos comparados com a malha original tetraédrica ou híbrida (tetraedros e prismas, pois o Ansys Fluent v12 não converte malhas com núcleos de hexaedros), da ordem de 3 a 5 vezes (ANSYS FLUENT, 2009a, p. 6-58).

No começo do processo de conversão o Ansys Fluent automaticamente decompõe cada elemento que não for hexaédrico em múltilplos sub-volumes chamados "duals", a região hachurada na Figura 6-31. Cada "dual" é associado com um dos nós originais da célula. Então são aglomerados em elementos poliédricos ao redor dos nós originais. Assim um agrupamento de "duals" de todos os elementos que compartilham um nó em particular gera cada célula poliédrica. Os outros nós não são mais necessários e são removidos (ANSYS FLUENT, 2009a, p. 6-58). 


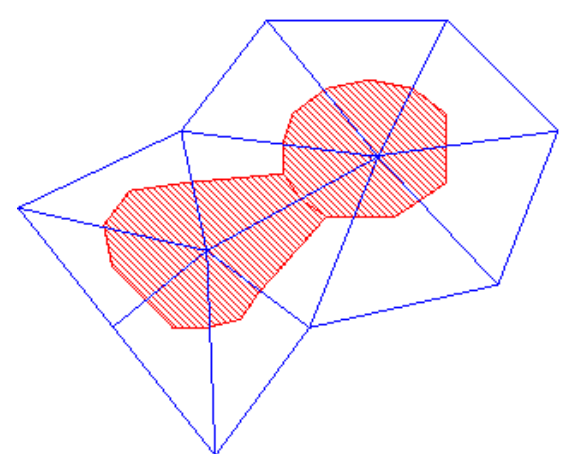

Figura 6-31: Formação dos "duals” da malha poliédrica. (ANSYS FLUENT, 2009a, p. 6-59).

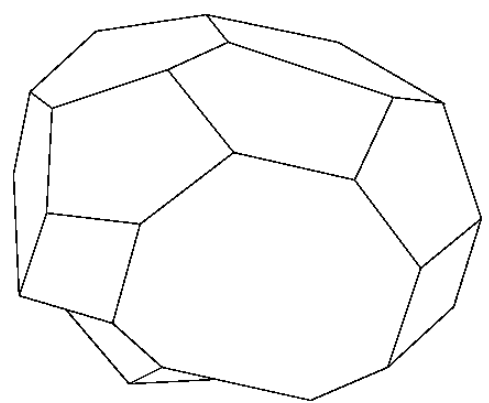

Figura 6-32: Elemento poliédrico (ANSYS FLUENT, 2009a, p. 59).

Os “duals" são formados a partir da união dos centróides das faces aos centróides das arestas ao redor de um nó específico. Eles são as faces do elemento poliédrico A divisão dos triângulos que formam os elementos tetraédricos para formação dos "duals" é ajustada de forma a diminuir o número de faces dos elementos poliédricos (ANSYS FLUENT, 2009a, p. 6-58).

Nas malhas que empregam elementos prismáticos para uma melhor definição da camada limite, que é o caso desse trabalho, a conversão ocorre de maneira um pouco diferente. Os elementos são decompostos somente no plano das superfícies de contorno, e não na direção normal. Assim, os poliedros resultantes preservarão a espessura original da camada de prismas. Na maioria dos casos a contagem de células na nova camada de prismas será menor do que a original (ANSYS FLUENT, 2009a, p. 6-61). 


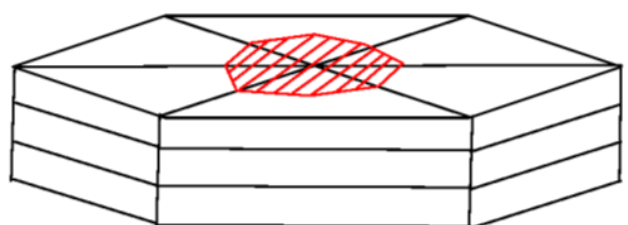

Figura 6-33: Transformação da camada de prismas em poliedros (ANSYS FLUENT, 2009a, p. 6-51).

No presente trabalho, a malha poliédrica resultante, ilustrada na Figura 6-34 e na Figura 6-35, teve 749871 elementos, ante 2341389 da malha original, o que implica numa redução de aproximadamente 3 vezes.

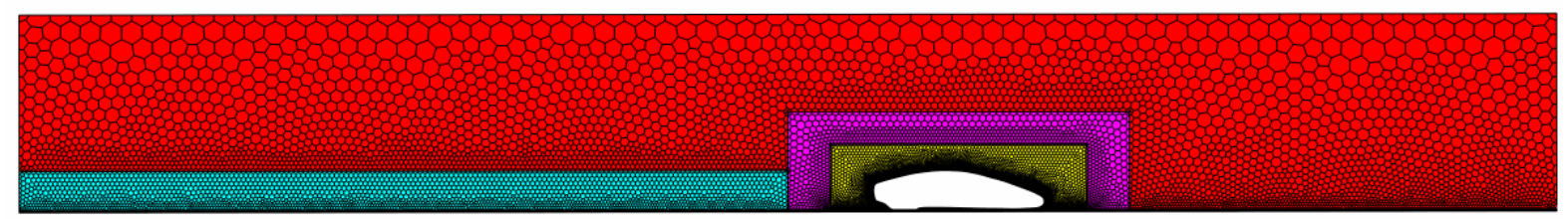

Figura 6-34: Vista geral plano de simetria da malha poliédrica.

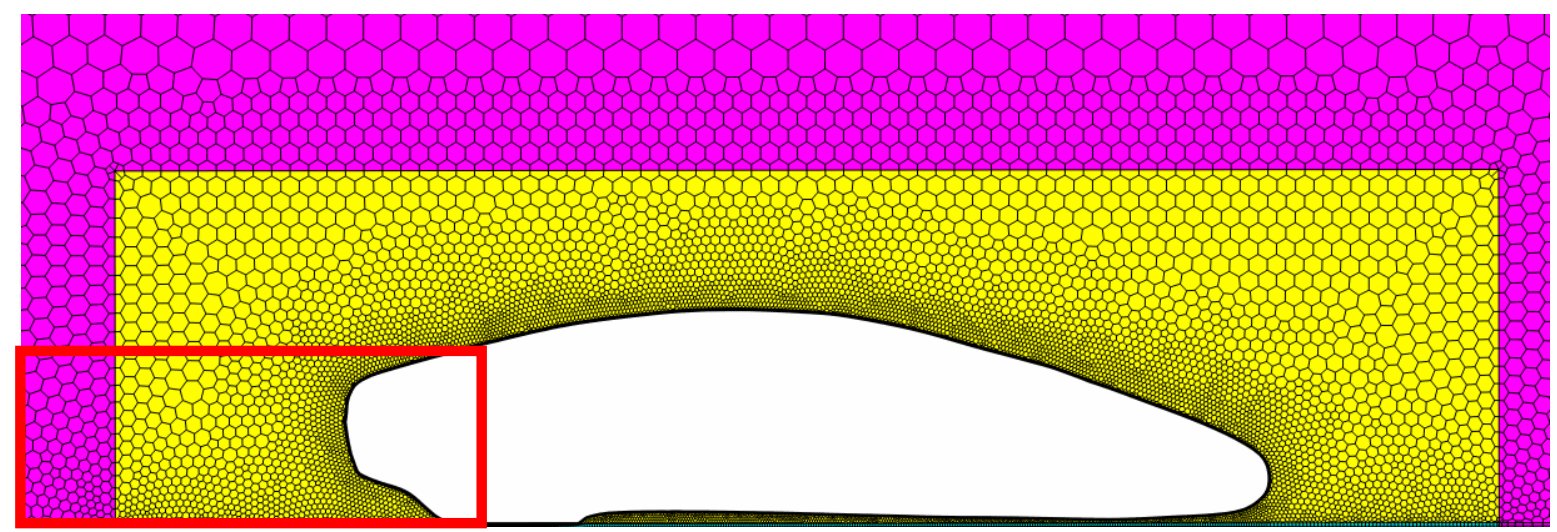

Figura 6-35: Vista aproximada do veículo do plano de simetria da malha poliédrica. Destaque mostrado na figura seguinte.

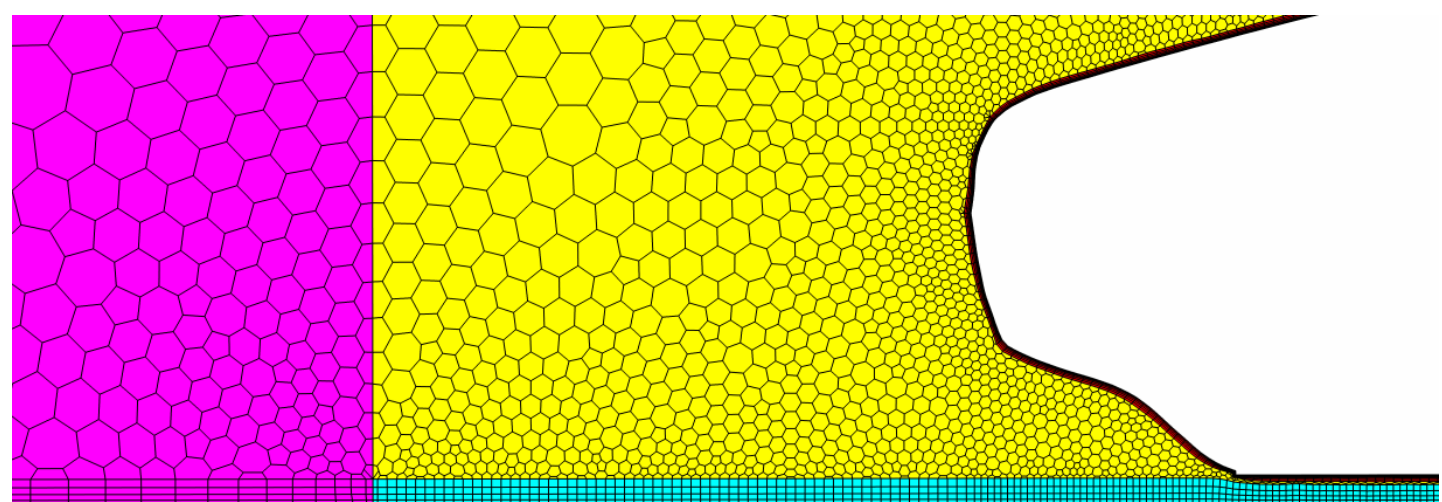

Figura 6-36: Ampliação do detalhe da última figura.O número de faces de cada poliedro é variável. 
Ao se analisar os resultados obtidos com a malha poliédrica a primeira coisa que chamou a atenção foi a convergência da força de arrasto, que difere da malha original conforme mostra aFigura 6-37.

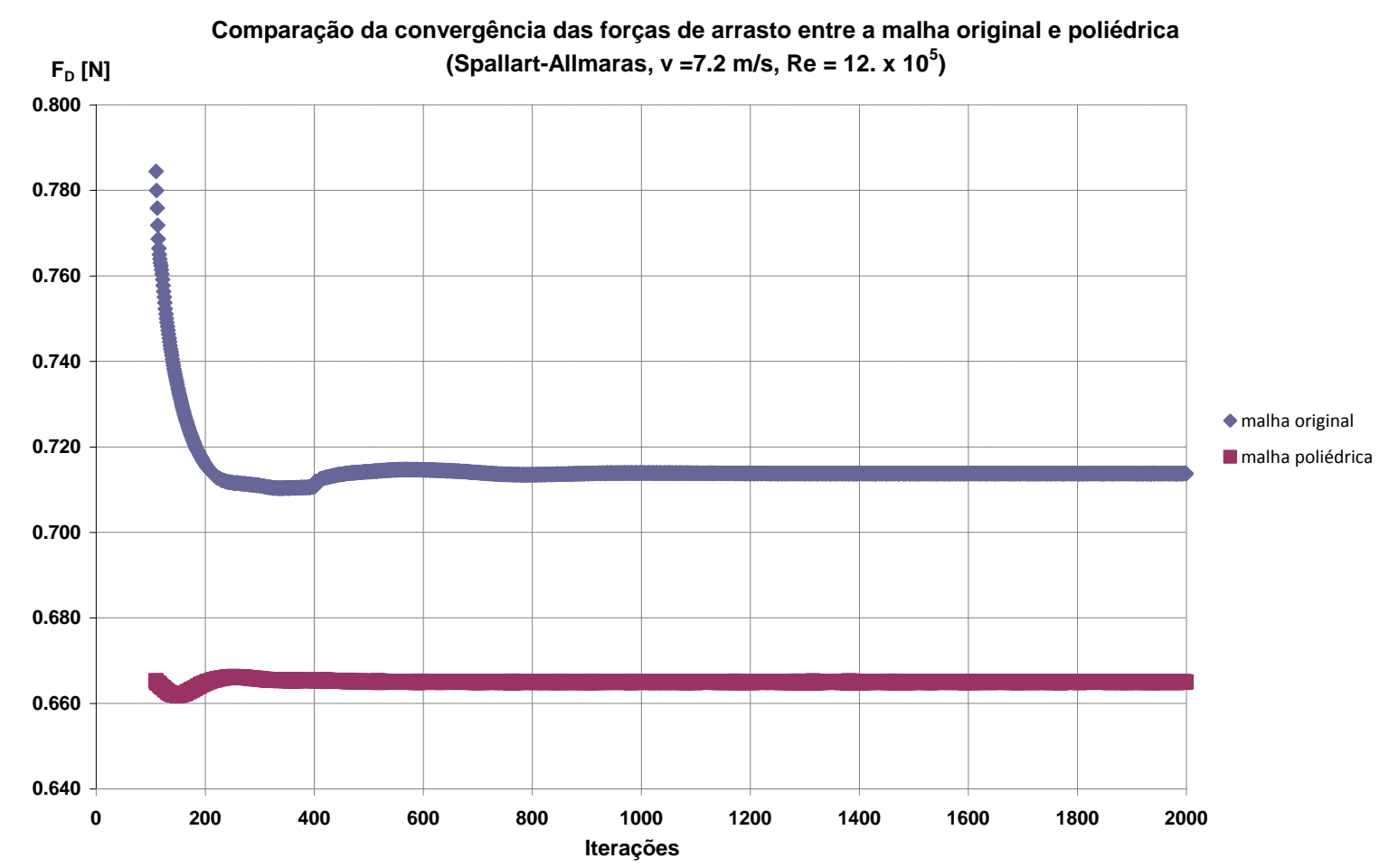

Figura 6-37: Convergência da força de arrasto das malhas original e poliédrica com o piso parado (SpallartAlmaras, $v=7.2 \mathrm{~m} / \mathrm{s}$ e $\mathrm{Re}=12.3 \times 10^{5}$ )

Na escala da Figura 6-37 se observa que a malha poliédrica atinge um patamar médio num número inferior de iterações que a malha original. Entretanto, quando se altera a escala da força de arrasto, para uma diferença entre o máximo e o mínimo valor de $0.01 \mathrm{~N}$, se vê que a malha poliédrica apresenta uma variação maior na sua convergência do que a malha original, ilustrado na Figura 6-38 e na Figura 6-39. 


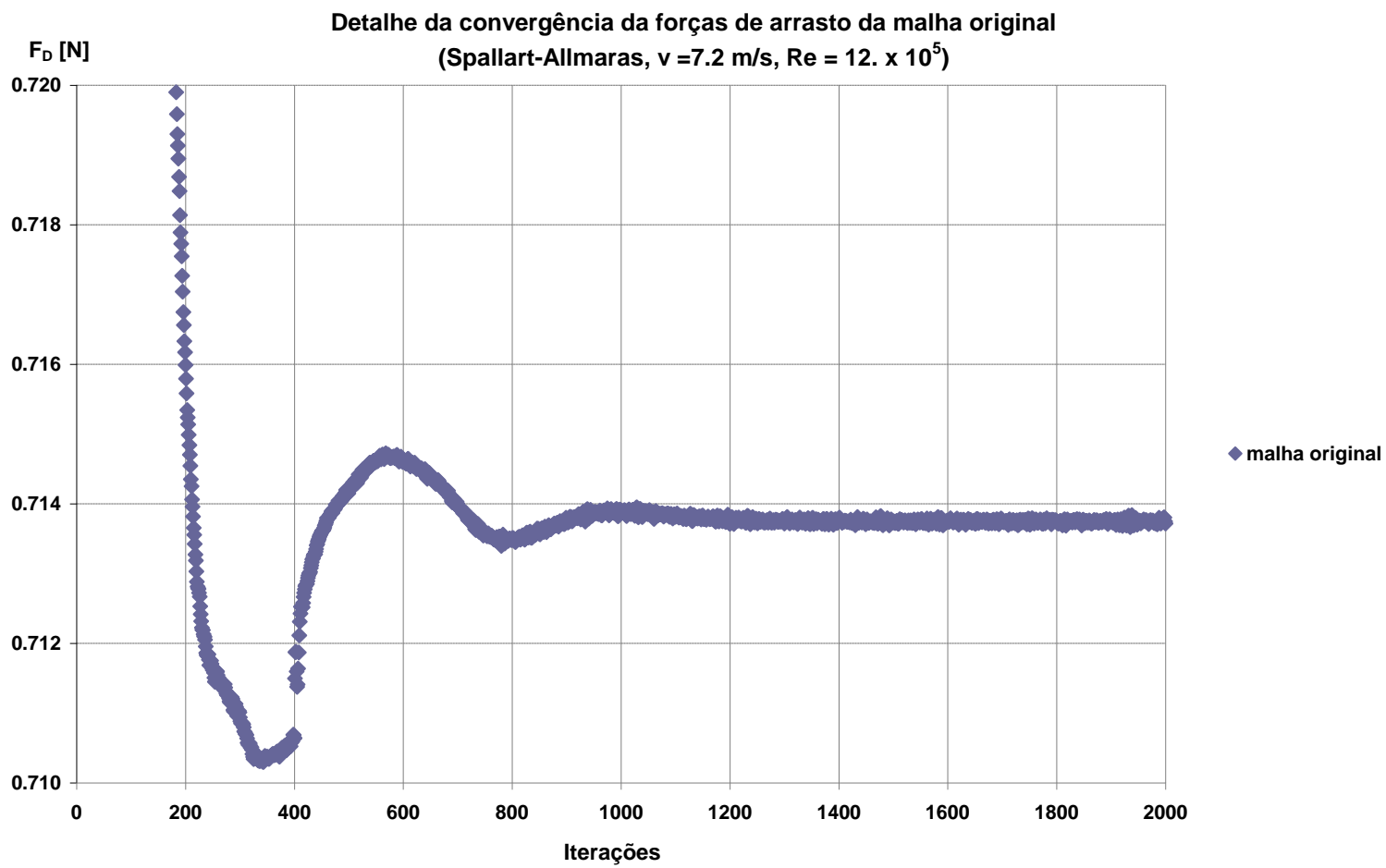

Figura 6-38: Detalhe da convergência da força de arrasto da malha original.

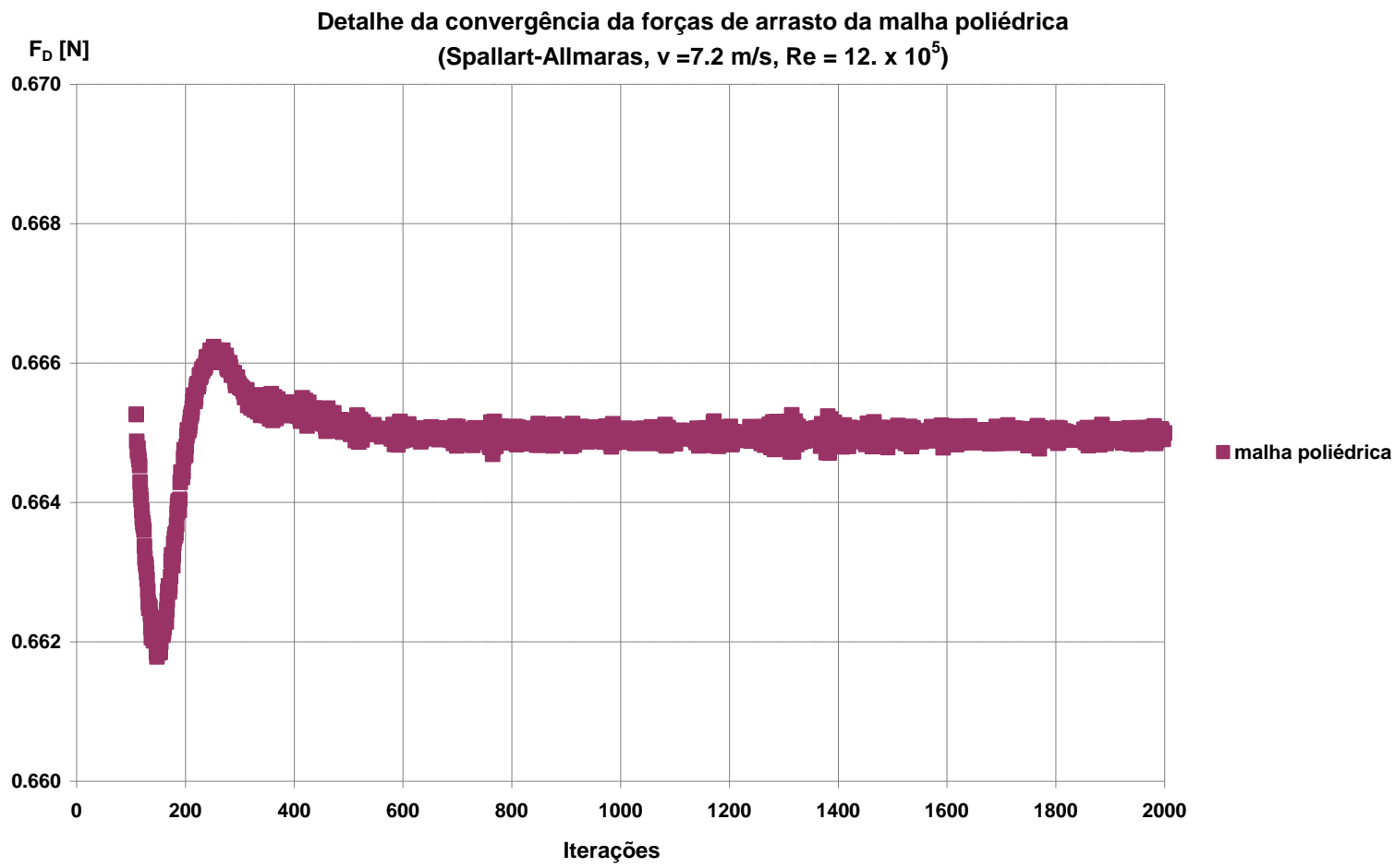

Figura 6-39: Detalhe da convergência da força de arrasto da malha poliédrica 
A metodologia de cálculo dos coeficientes aerodinâmicos foi a mesma da malha original, ou seja, foi considera a média das últimas 500 iterações. Os resultados obtidos com a condição de piso parado, comparados com a malha original, podem ser vistos na Figura 6-40.

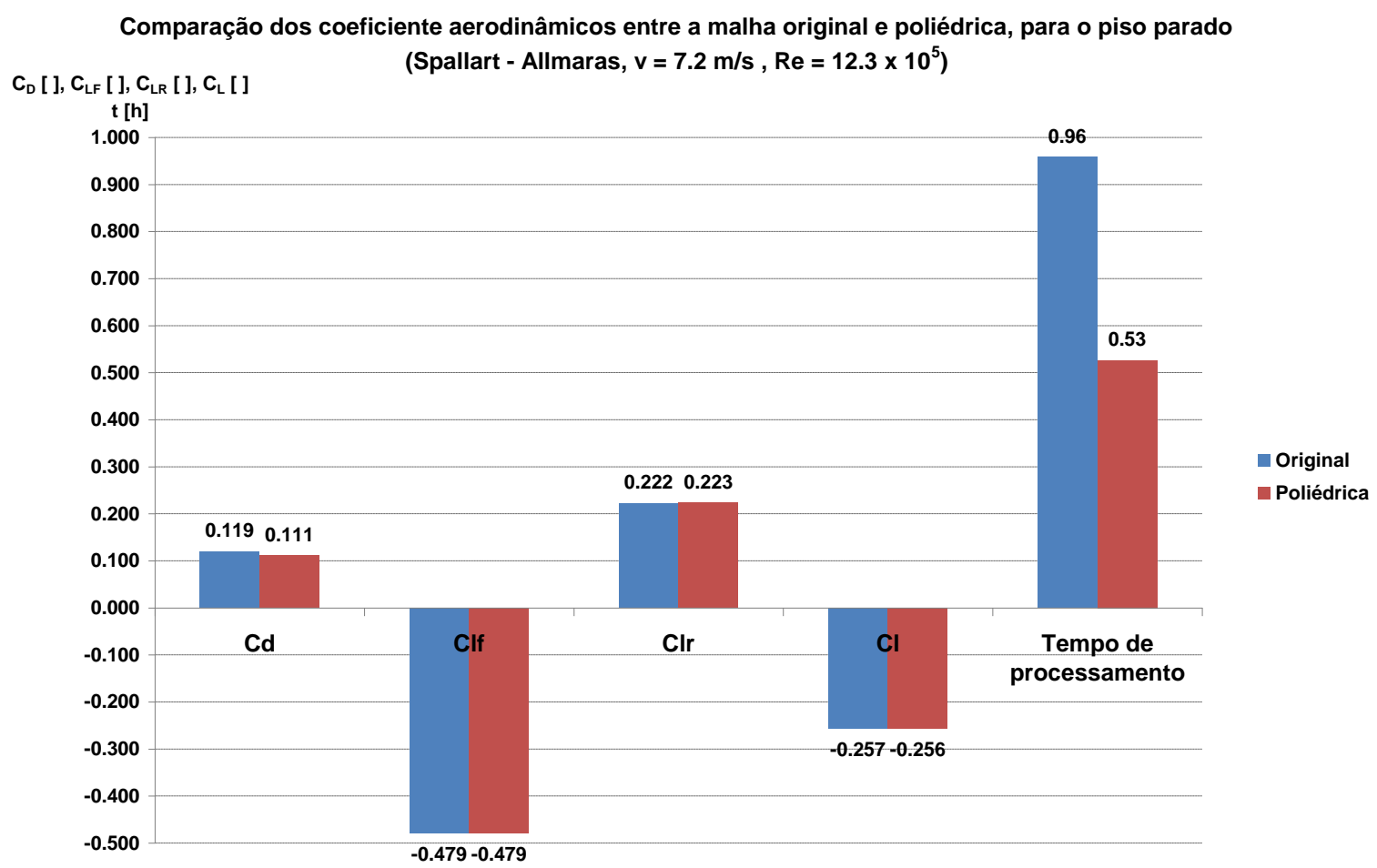

Figura 6-40: Comparação dos coeficientes aerodinâmicos entre a malha original e poliédrica para o piso parado (Spallart-Almaras, $\mathrm{v}=7.2 \mathrm{~m} / \mathrm{s}$ e $\mathrm{Re}=12.3 \times 10^{5}$ ).

Observando-se a Figura 6-40 nota-se que os valores dos coeficientes aerodinâmicos permaneceram praticamente os mesmos. $\mathrm{O} \mathrm{C}_{\mathrm{D}}$ foi o que mais se alterou, com uma queda de $0.008, \mathrm{C}_{\mathrm{LF}}$ manteve-se exatamente o mesmo, $\mathrm{C}_{\mathrm{LR}}$ aumentou 0.001 , e conseqüentemente o $\mathrm{C}_{\mathrm{L}}$ também teve um aumento nessa proporção.

Um dado que pode ajudar a esclarecer essas diferenças é que a força de arrasto é, aproximadamente, $58.5 \%$ originária de forças de pressão e $42.5 \%$ de forças viscosas, enquanto a força de sustentação é $99.5 \%$ de origem de pressão e $0.5 \%$ viscosa. Com isso pode-se concluir que a principal diferença entre a malha tetraédrica com prismas original em 
relação à malha poliédrica, em relação ao cálculo das forças, está na consideração nas de origem viscosa.

Apesar da malha poliédrica ter ficado, em número de elementos, cerca de 3 vezes menor que a malha original, o tempo de processamento caiu para um pouco mais da metade. Isso pode ser explicado pelo fato do número de faces de cada elemento ter aumentado em relação à malha original, exigindo assim um maior número de interpolações.

Foi realizada também a simulação com a malha poliédrica e o piso na mesma velocidade do ar. A Figura 6-41 compara essa simulação com a malha original.

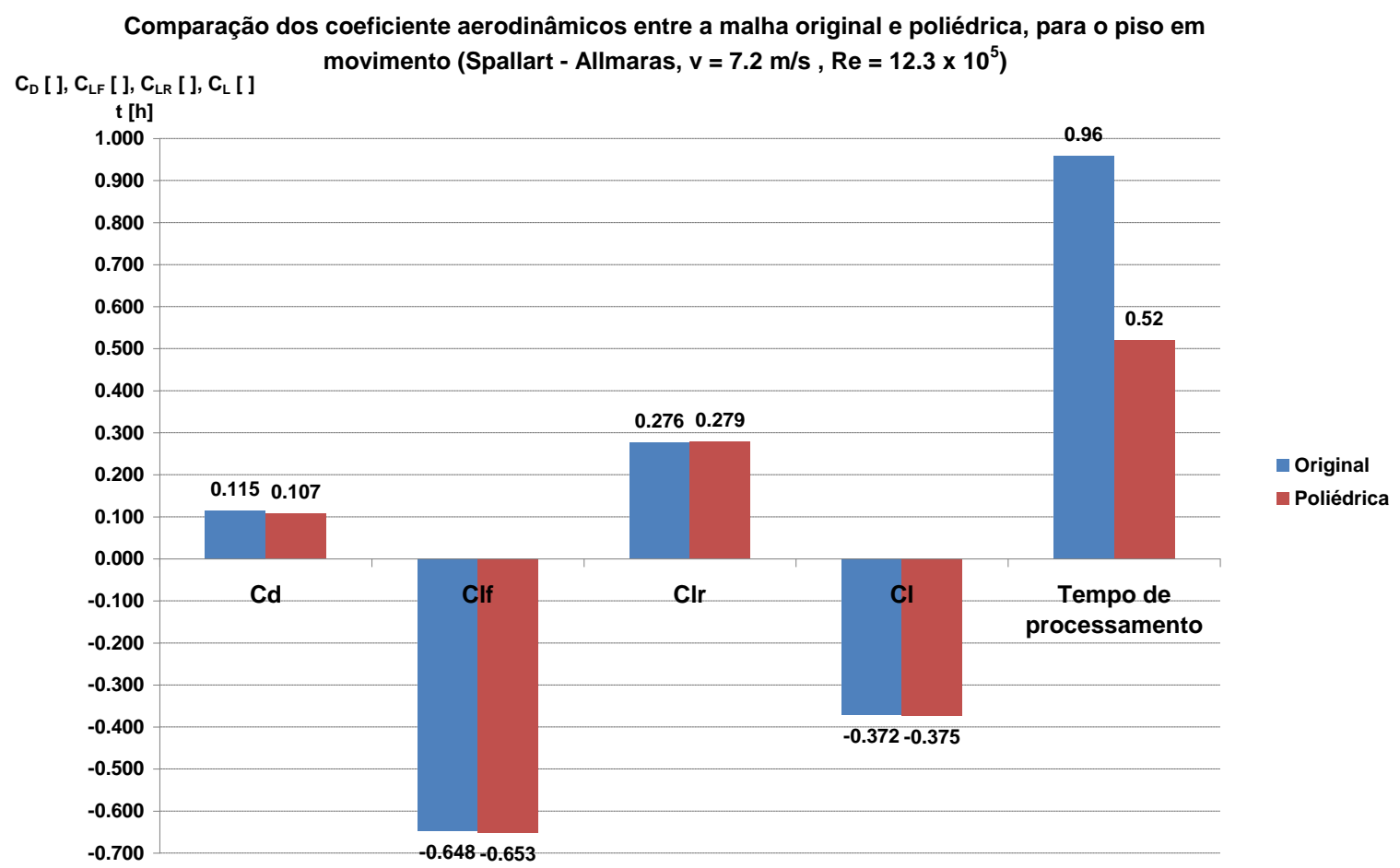

Figura 6-41: Comparação dos coeficientes aerodinâmicos entre a malha original e poliédrica para o piso em movimento (Spallart-Almaras, $\mathrm{v}=7.2 \mathrm{~m} / \mathrm{s}$ e $\operatorname{Re}=12.3 \times 10^{5}$ ).

A variação dos resultados de $C_{D}$ é exatamente a mesma dos casos com o piso parado, 0.008. Entretanto $\mathrm{C}_{\mathrm{LF}}$ sofre um decréscimo de 0.005 com a malha poliédrica, $\mathrm{C}_{\mathrm{LR}}$ um acréscimo de 0.003 , o que resulta numa queda de 0.003 no $\mathrm{C}_{\mathrm{L}}$ (diferença devido aos arredondamentos). A maior diferença ainda se encontra no $\mathrm{C}_{\mathrm{D}}$, o que ajuda a confirmar a tese 
que a malha poliédrica considera as forças viscosas de uma forma diferente da tetraédrica prismática.

Foram comparados também os resultados das duas simulações, piso parado e em movimento, com a malha poliédrica, como pode ser visto na Figura 6-42.

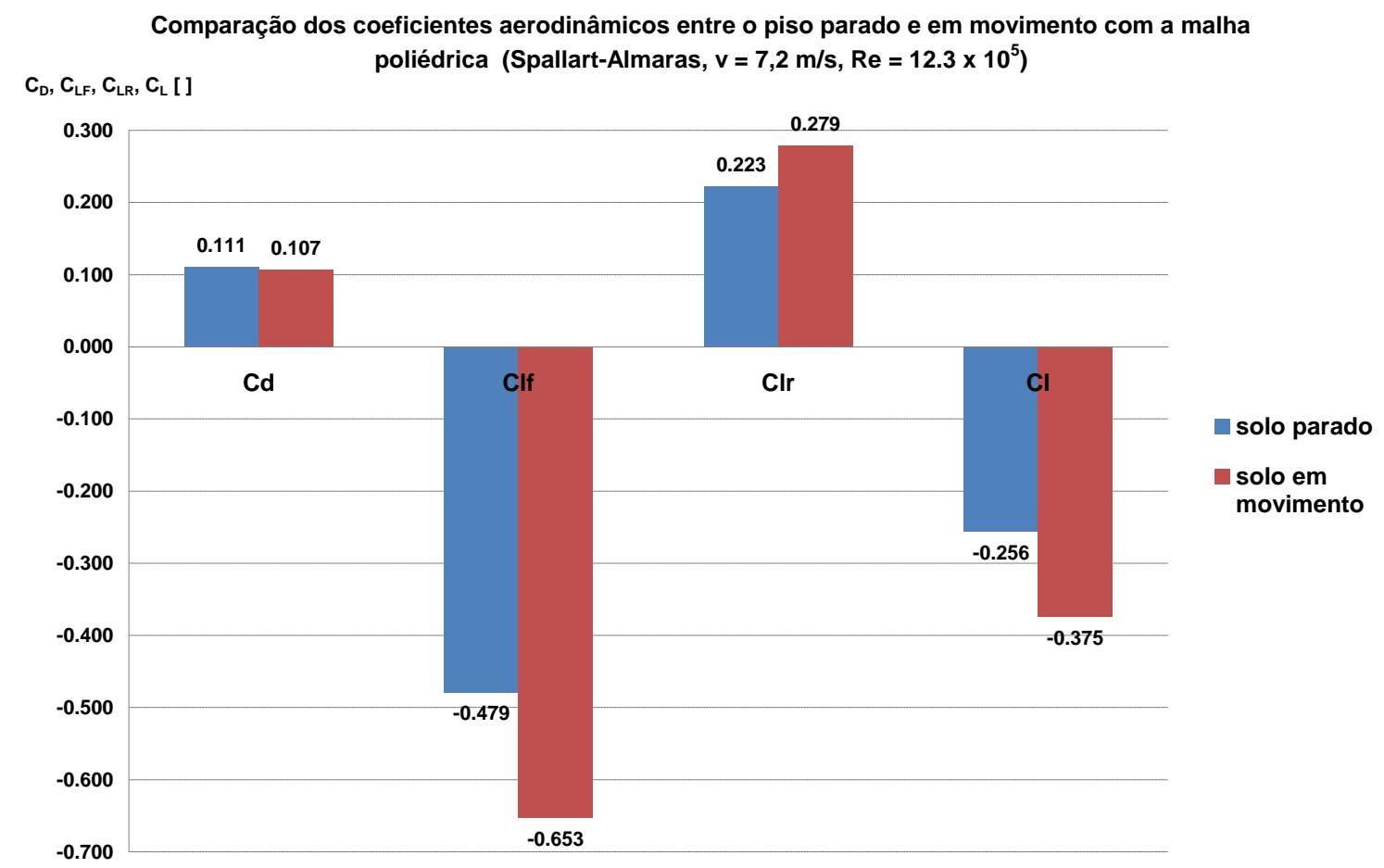

Figura 6-42: Comparação dos coeficientes aerodinâmicos entre o piso parado e em movimento com malha poliédrica (Spallart-Almaras, $\mathrm{v}=7.2 \mathrm{~m} / \mathrm{s}$ e $\mathrm{Re}=12.3 \times 10^{5}$ ).

Nota-se que a variação dos coeficientes aerodinâmicos com a condição do piso parado e em movimento utilizando-se a malha poliédrica apresenta uma tendência muito semelhante a da malha original. Para melhor visualizar essa comparação, o gráfico seguinte mostra o que aconteceu com os coeficientes quando o piso foi posto na mesma velocidade do ar. 
Comparação da variação dos coeficientes aerodinâmicos entre o piso parado e em movimento utilizando as malhas original e poliédrica (Spallart-Almaras, $v=7,2 \mathrm{~m} / \mathrm{s}, \mathrm{Re}=12.3 \times 10^{5}$ )

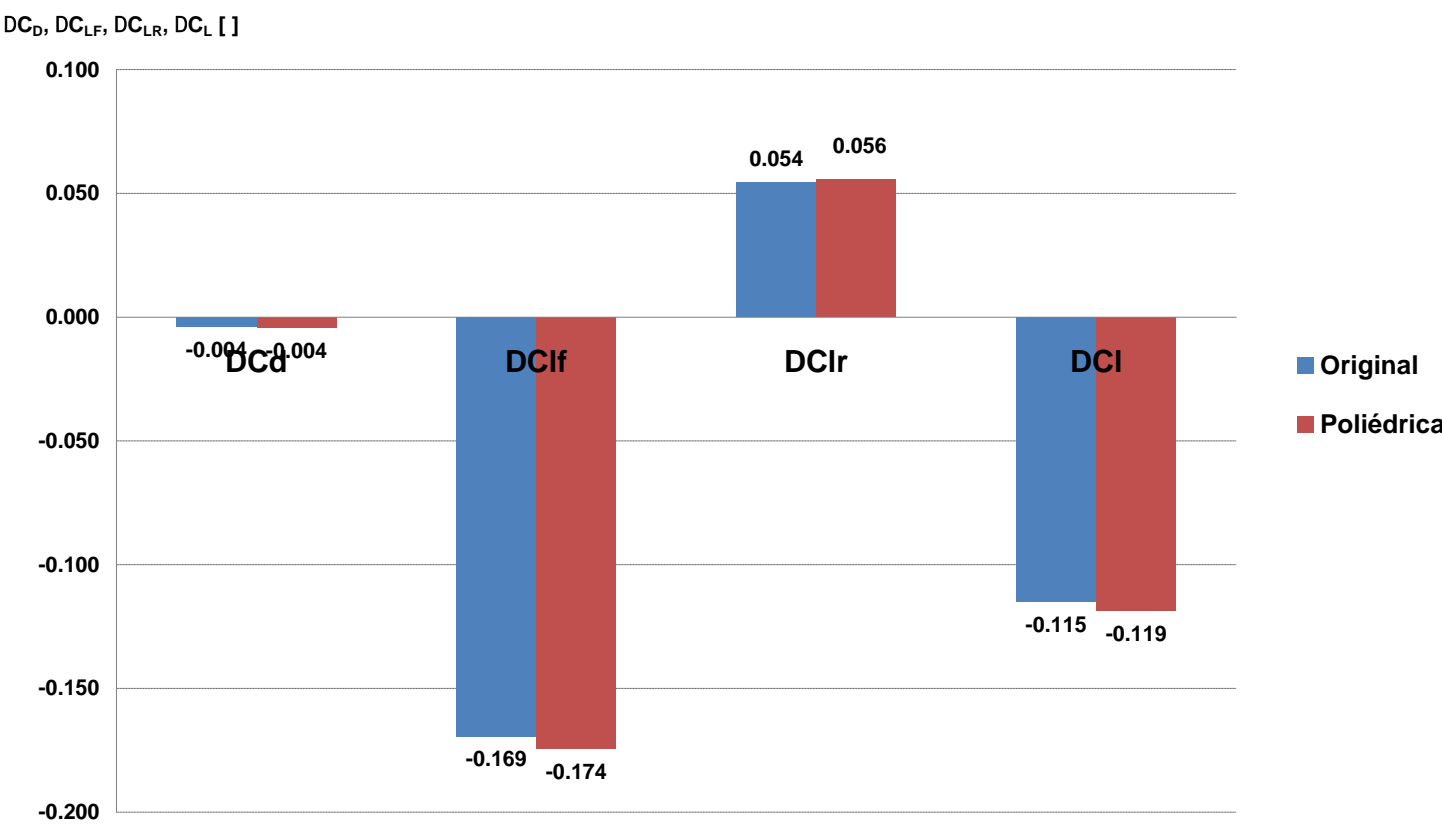

Figura 6-43: Comparação da variação dos coeficientes aerodinâmicos entre o piso parado e em movimento utilizando as malhas original e poliédrica. (Spallart-Almaras, $v=7.2 \mathrm{~m} / \mathrm{s}$ e $R e=12.3 \times 10^{5}$ ).

É interessante observar que o $C_{D}$ foi quem mostrou a maior diferença entre a malha original e a poliédrica. Entretanto, quando se compara a variação piso parado e em movimento, a diferença é exatamente a mesma para os dois tipos de malha. Isso não ocorre com os outros coeficientes, apesar das diferenças não serem muito altas. 


\section{DESENVOLVIMENTO DAS SIMULAÇÕES}

O objetivo desse capítulo é descrever de forma sucinta as dificuldades e o processo utilizado para encontrar as soluções durante o desenvolvimento das simulações.

\subsection{Posicionamento do veículo em relação ao solo}

O modelo do veículo de milhagem estudado possui as rodas totalmente cobertas pela carenagem, e é muito baixo, com a superfície inferior muito próxima ao solo. Por esse fato, pensou-se primeiramente em unir as partes da carenagem que cobrem as rodas com o solo, como mostra a Figura 7-1:

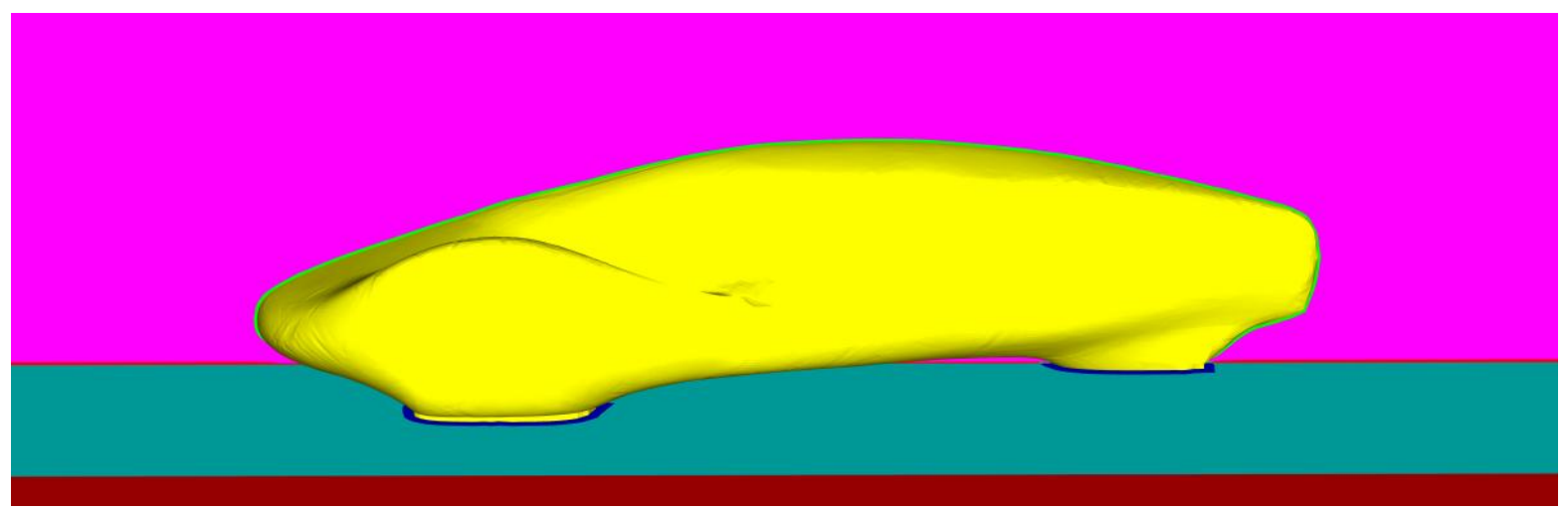

Figura 7-1: Veículo com a carenagem ligada ao piso.

Entretanto não se obteve convergência com essa configuração. Os resíduos da equação da continuidade ficaram acima de $10^{-3}$, e os das equações de $\mathrm{k}$ e $\varepsilon$ ficaram apenas um pouco abaixo desse valor. O que não era esperado para uma simulação de uma geometria tão simples.

Nesse modelo, a camada de prismas do solo foi feita com os mesmos critérios empregados para o veículo. Pensou-se que a variação da altura dessa camada no solo, devido à diferença de tamanho de aresta dos triângulos próximo ao veículo e ao longe, fosse a causa 
da falta de convergência. Então se optou por eliminar os prismas na região próxima ao veículo, parte amarela na Figura 7-2, e fazer com que crescessem uniformemente nas outras zonas do piso.

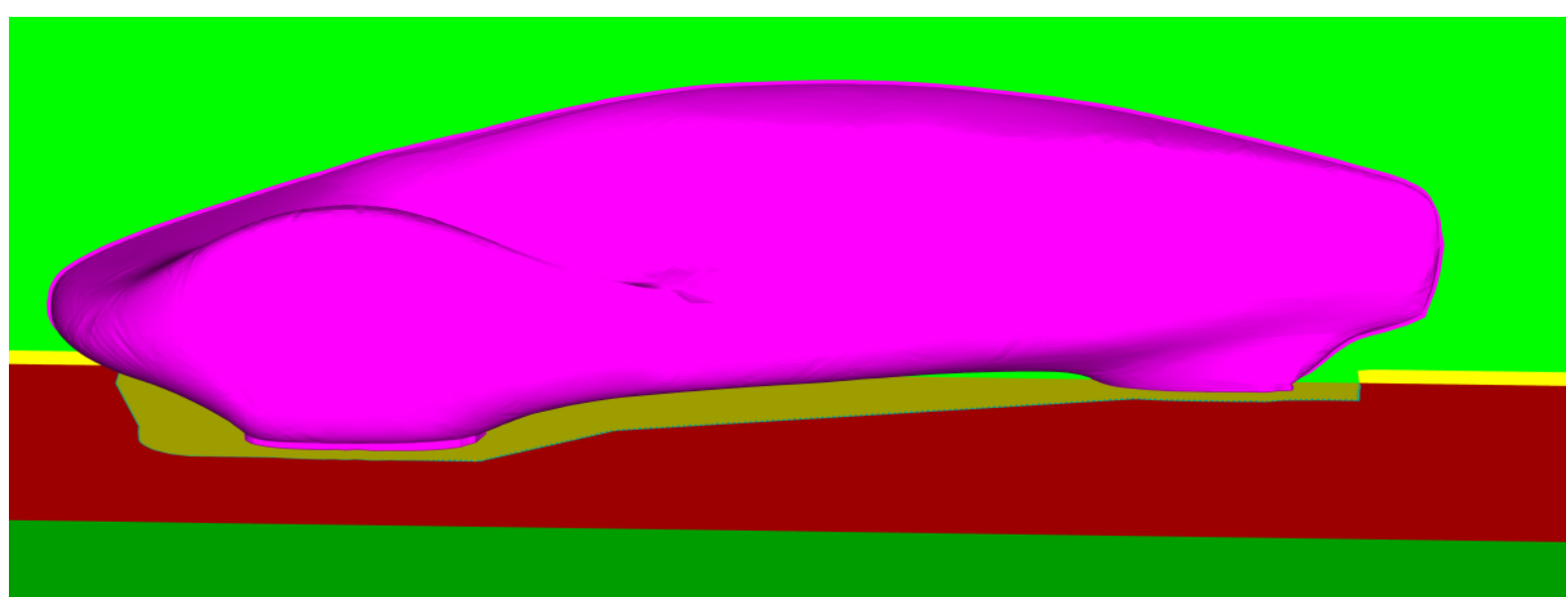

Figura 7-2: Região amarela sem prismas em baixo do modelo.

Contudo o resultado foi o mesmo da versão anterior. Imaginou-se então que a causa da não-convergência fosse o alto gradiente de velocidades entre o veículo e o piso. Assim o modelo foi elevado em relação ao solo, em 10, 20, 30 e $50 \mathrm{~mm}$, como mostra a próxima figura, mas não se obteve um resultado melhor.

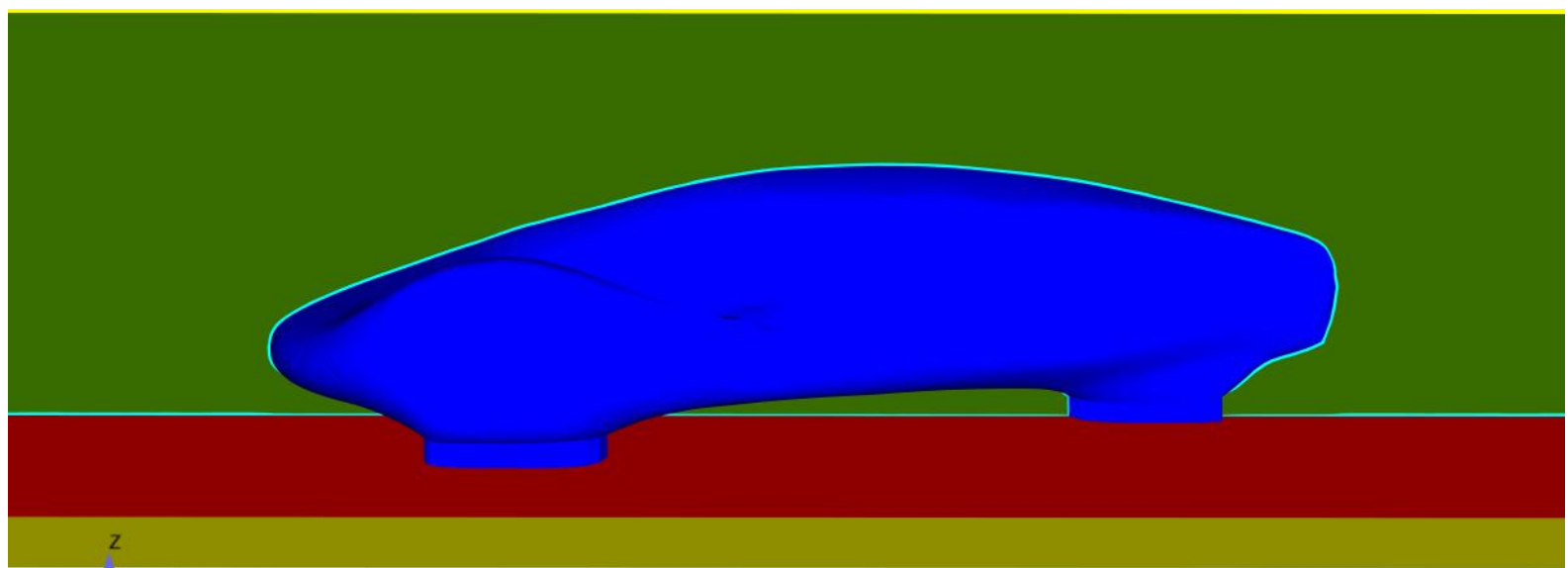

Figura 7-3: Modelo elevado em $50 \mathrm{~mm}$ do solo com uma ligação com a carenagem.

Ao se observar as figuras do trabalho de Gagnon e Richard (2010), Figura 2-9 do presente trabalho, notou-se que há um espaço entre a parte da carenagem que cobre as rodas e 
o piso. Baseado nesse fato foi realizada uma simulação com o veículo elevado a $50 \mathrm{~mm}$ do solo, mas sem a ligação com o solo. Com essa análise obteve-se os bons resultados de convergência esperados.

Contudo conclusões tomadas somente a partir de figuras podem a levar a malentendidos, e por isso se entrou em contato com os autores que confirmaram que o veículo está elevado $30 \mathrm{~mm}$ em relação ao solo (Gagnon, 2010). Então foi realizada uma simulação com o carro a essa mesma distância do piso e se conseguiu a boa convergência esperada. Concluiu-se assim que esse posicionamento seria bom para a realização do presente estudo.

\subsection{Variação dos resultados com o Hardware utilizado}

No capítulo 9, "Procedimento experimental", item 9.1 "Montagem experimental", é descrito que foram realizadas simulações para a determinação da posição do eixo de suporte no veículo. Entre as primeiros testes numéricos feitos e esses com o eixo houve o upgrade do ambiente computacional onde esse trabalho foi realizado, com a instalação de um novo cluster com 8 CPU's.

As primeiras simulações foram rodadas numa máquina local, com 1 processador com dois núcleos, e dependendo da disponibilidade de equipamentos, rodava-se com mais processadores com outras máquinas pela da rede local.

Ao se analisar os resultados do estudo numérico para posicionamento do eixo, todos rodados no novo cluster, se percebeu que os valores de $C_{D}$ eram todos próximos entre si, porém relativamente distantes do modelo base, calculado sem o eixo. Então se resolveu rodar novamente o modelo base, no cluster, e foi obtido um resultado mais parecido das avaliações da posição do eixo. Dessa forma concluiu-se que o hardware influenciava no resultado.

Para minimizar a influência do hardware e da velocidade da rede sobre os resultados, e ainda a necessidade de se avaliar números de Reynolds menores do que os já prontos, 
entendeu-se que a melhor solução seria rodar todos os casos novamente no cluster. O número de processadores e o tempo de simulação foram monitorados nas simulações calculadas nas máquinas locais, entretanto variavam muito o que levava a uma comparação injusta entre os modelos

Assim, todas as simulações apresentadas no capítulo 6 foram calculadas no mesmo cluster, com 8 processadores. A Figura 7-4 e a Figura 7-5 ilustram a diferença de resultados entre os casos rodados nas máquinas locais e no cluster. 

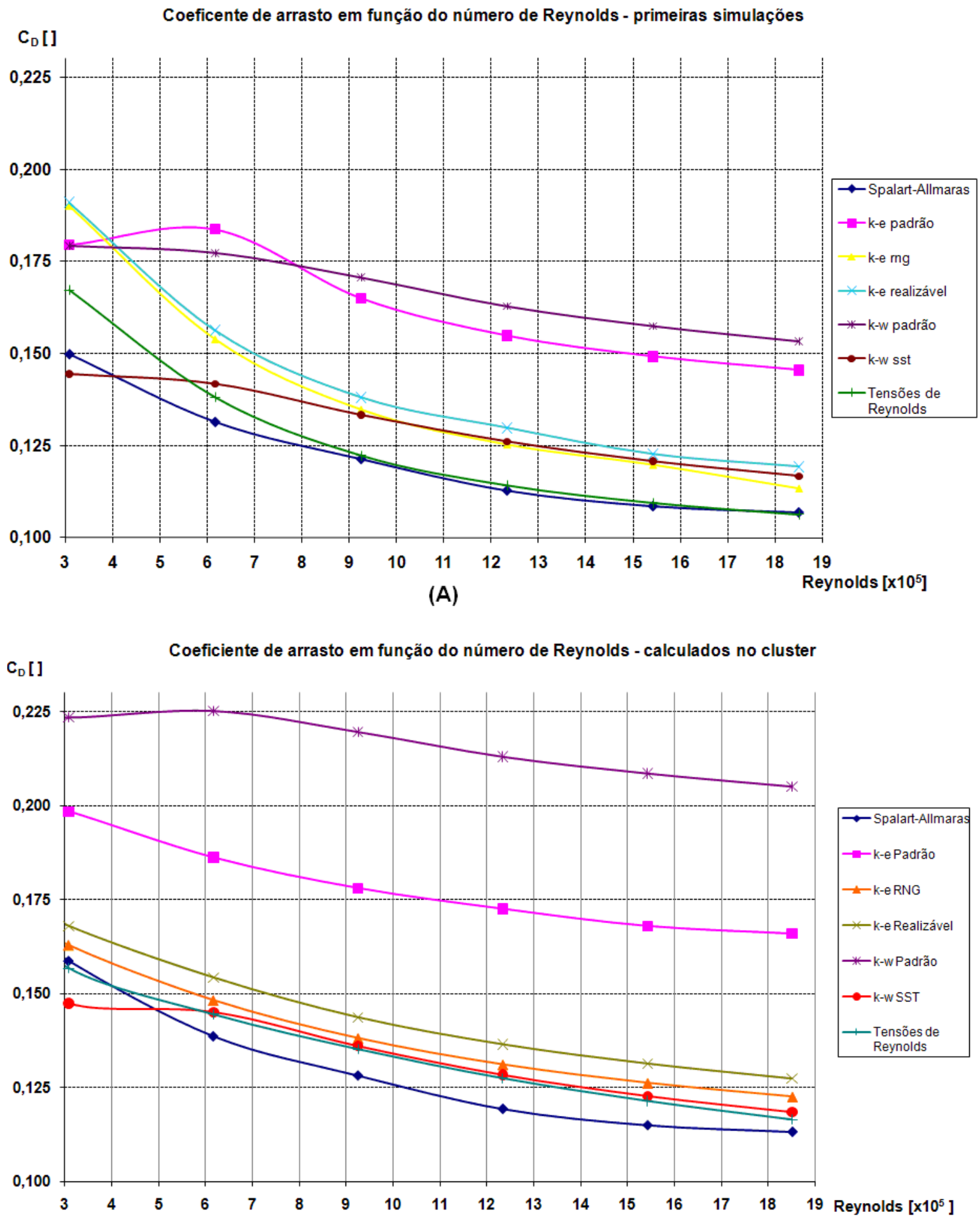

(B)

Figura 7-4: Coeficiente de arrasto em função do número de Reynolds nas primeiras simulações (A) e calculados no cluster (B).

Apesar do comportamento global dos cenários da Figura 7-4 serem semelhantes, em nome de uma análise mais refinada a opção por se rodar os casos novamente se mostrou 
acertada. Os resultados dos coeficientes de sustentação mostrados a seguir apresentaram uma variação ainda maior.

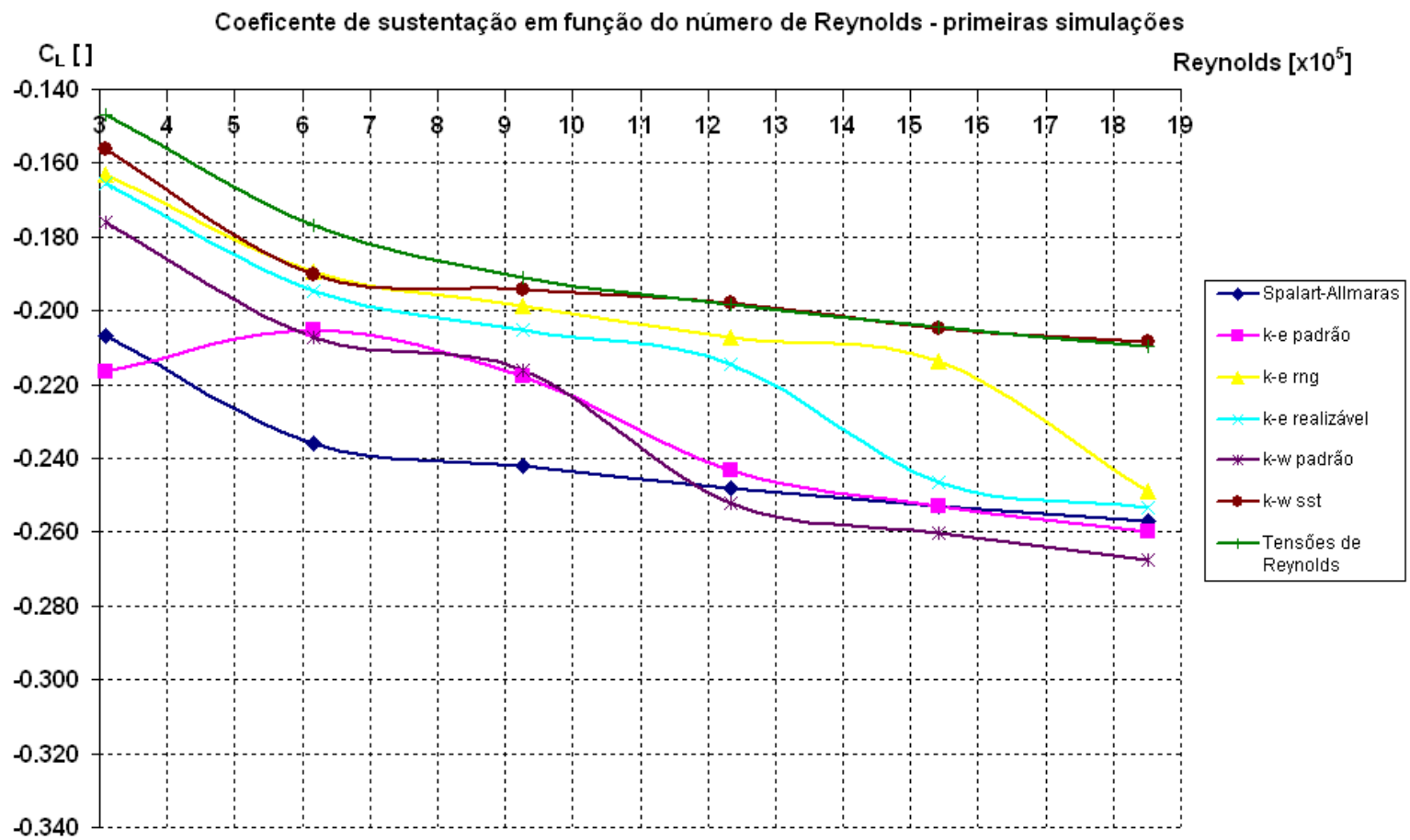

(A)

$\mathrm{C}_{\mathrm{L}}[\mathrm{C}$

Coeficiente de sustentação em função do número de Reynolds

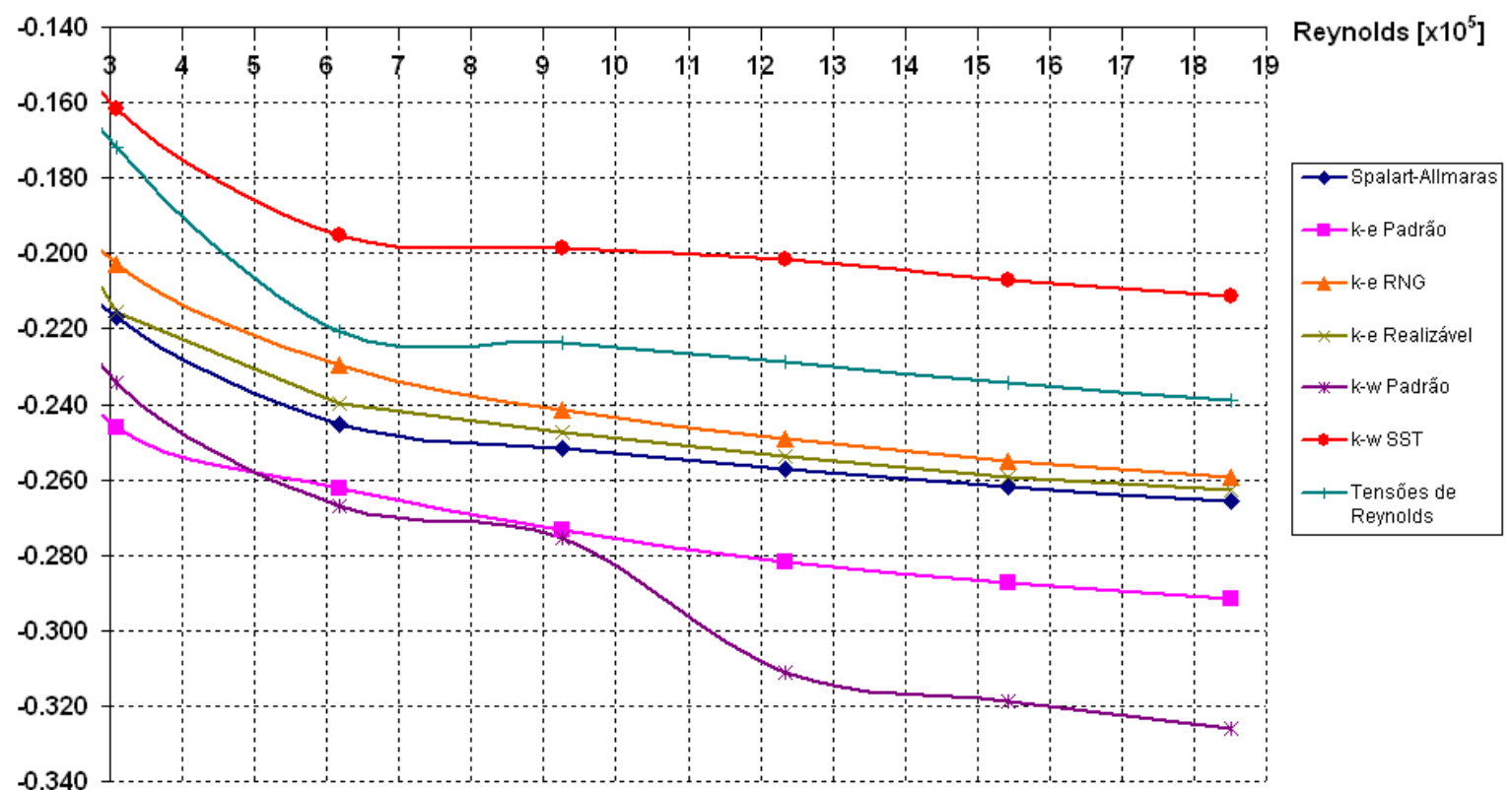

(B)

Figura 7-5: Coeficiente de arrasto em função do número de Reynolds nas primeiras simulações (A) e calculados no cluster (B). 


\section{APARATO EXPERIMENTAL}

O objetivo desse capítulo é descrever os equipamentos que foram utilizados nos ensaios experimentais e apresentar, resumidamente, seus princípios de funcionamento e o porquê da escolha.

\subsection{O modelo experimental}

\subsubsection{Determinação das dimensões}

O modelo experimental foi construído com dimensões que equivalem a $15.2 \%$ do tamanho do veículo real. Para se obter esse valor foi definido que os testes deveriam atingir um número de Reynolds de $1.23 \times 10^{6}$ que equivale a quando o veículo real está a $7.2 \mathrm{~m} / \mathrm{s}$, velocidade média durante a competição (MARATONA, 2010).

Assim foi criada a seguinte tabela, onde os valores da vazão máxima e da largura do canal são fixados (em vermelho), a razão de blocagem (razão entre a área projetada do modelo e a área útil da seção de testes do canal) e a altura de água do canal são variadas (em verde) e os outros valores são calculados a partir desses.

Tabela 8-1: Cálculo das dimensões do modelo experimental

\begin{tabular}{|c|c|c|c|c|c|c|c|}
\hline $\begin{array}{l}\text { Vazão máxima } \\
\text { do canal }\left[\mathrm{m}^{3} / \mathrm{s}\right]\end{array}$ & $\begin{array}{l}\text { Largura do } \\
\text { canal }[\mathrm{m}]\end{array}$ & $\begin{array}{l}\text { Altura de } \\
\text { água }[\mathrm{m}]\end{array}$ & $\begin{array}{l}\text { Área }(A) \text { da } \\
\text { seção de } \\
\text { teste }\left[\mathrm{m}^{2}\right]\end{array}$ & $\begin{array}{c}\text { Velocidade } \\
\text { max na seção } \\
\text { de teste }[\mathrm{m} / \mathrm{s}]\end{array}$ & $\begin{array}{c}\text { Razão de } \\
\text { blocagem } \\
\text { S/A [\%] } \\
\end{array}$ & $\begin{array}{c}\text { Área }(\mathrm{S}) \text { proj } \\
\text { modelo }\left[\mathrm{m}^{2}\right]\end{array}$ & 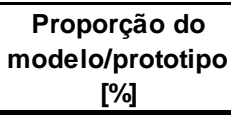 \\
\hline 0,4 & 0,700 & 0,250 & 0,175 & 2,29 & $5,0 \%$ & 0,009 & $15,24 \%$ \\
\hline \multicolumn{8}{|c|}{ Dimensões do modelo [m] } \\
\hline $\begin{array}{c}\text { Comprimento } \\
\text { (L) }\end{array}$ & $\begin{array}{c}\text { Largura } \\
\text { (W) }\end{array}$ & $\begin{array}{c}\text { Altura } \\
\text { (H) }\end{array}$ & & $\mathbf{R e}$ & Re target & & \\
\hline \multirow[t]{3}{*}{0,381} & 0,122 & 0,088 & & $8,68 E+05$ & $1,23 E+06$ & & \\
\hline & $\mathrm{W}_{\text {modelo }} / \mathrm{W}_{\text {canal }}$ & $\mathrm{H}_{\text {modelo }} / \mathrm{H}_{\text {canal }}$ & & & & & \\
\hline & $1 / 6$ & $1 / 3$ & & & & & \\
\hline
\end{tabular}


Com esse procedimento chegou-se com uma altura de água de $0.250 \mathrm{~m}$ no canal, e uma razão de blocagem de $5 \%$, o que é um bom valor de acordo com a referência (REINO UNIDO, 2005). Assim foi atingido um número de Reynolds de 8.68 x 10 ${ }^{5}$, próximo do objetivo, e a razão de dimensões lineares entre o modelo e o protótipo de $15.2 \%$.

Nessa tabela também foram diretamente visualizadas as relações entre o comprimento e a altura do modelo e do canal, $\mathrm{W}_{\text {modelo }} / \mathrm{W}_{\text {canal }}$ e $\mathrm{H}_{\text {modelo }} / \mathrm{H}_{\text {canal }}$ respectivamente, assim observou-se que o modelo teria aproximadamente 1/6 da largura do canal, o que levaria a uma distância de aproximadamente 2.5 larguras do modelo para cada parede e uma altura de 1/3 em relação à altura de água, restando 2 alturas até a superfície livre.

Entretanto durante o procedimento experimental não foi possível chegar a esse valor de altura de água e vazão, pois a superfície livre ficou muito instável para valores de velocidade inferiores ao pretendido. Além disso, o sorvedouro do canal criou um redemoinho para uma altura e vazão inferiores às desejadas, e isso fez com que entrasse um pouco de ar na bomba. Esses dois fatores causaram instabilidade nas medições, especialmente uma variação muito grande na velocidade, que não estabilizava com uma rotação constante do rotor da bomba. Devido às flutuações citadas anteriormente se trabalhou com uma altura de água de 326 mm e o valor máximo de número de Reynolds atingido foi de 1.6 x $10^{5}$.

\subsubsection{O processo de fabricação}

O modelo foi fabricado com uma máquina de prototipagem rápida que utiliza o conceito de impressora 3D. Esse é um processo que utiliza a deposição de material, que também pode ser chamado de "Solid Freeform Fabrication" - fabricação de sólidos de forma livre, pois o termo "prototipagem rápida" vem se tornando cada vez mais comum e apropriado a todo tipo de prototipagem de rápida execução, independente se o processo for de adição ou remoção de 
material, ou ainda do uso ou não de tecnologias computacionais de software e hardware, de acordo com Canciglieri Junior et al. (2007).

As impressoras 3D possuem o mesmo conceito da impressão "convencional" de jato de tinta, mas utilizam um agente aglutinante ao invés de tinta. Em um reservatório contendo pó cerâmico ou, no caso do presente trabalho uma fita polimérica de ABS (acrilonitrilabutadieno-estireno) uma plataforma se movimenta no eixo coordenado Z, conforme a Figura 8-1, onde a fita se funde a $270^{\circ} \mathrm{C}$ formando as camadas do objeto. Na medida em que a plataforma desce um rolo carrega uma nova camada vinda de outra plataforma que sobe. $\mathrm{O}$ movimento do cabeçote aglutinante no plano xy constrói o desenho das camadas do objeto sucessivamente até o fim desse processo (CANCIGLIERI JUNIOR et al., 2007).

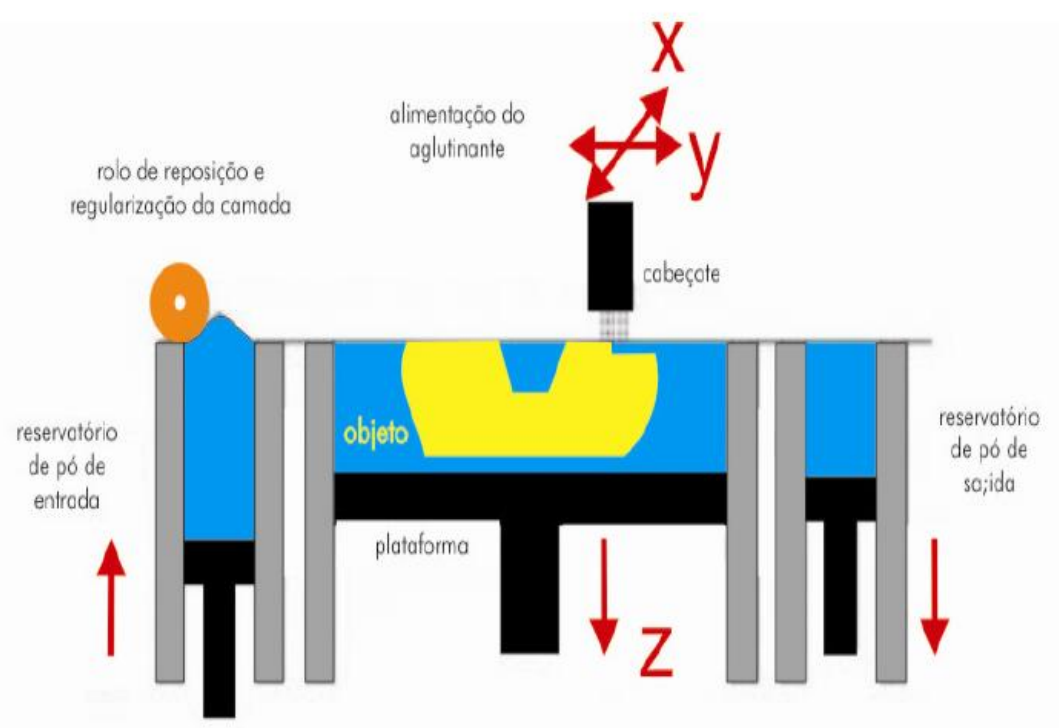

Figura 8-1: Esquema de funcionamento do processo de impressoras 3D ( ZCORP apud CANCIGLIERI JUNIOR et al., 2007)

A impressora também deposita um material de suporte, que serve para sustentar a peça enquanto é fabricada Assim para a forma final do modelo ser revelada é necessário retirar a estrutura de sustentação, manualmente e geralmente com o complemento de um banho em soda cáustica.

O equipamento utilizado na fabricação foi da marca Dimension modelo Elite, ilustrado na Figura 8-2, disponível no laboratório NDF (Núcleo de Dinâmica e Fluidos) do 
departamento de Engenharia Mecânica dessa universidade. A impressora pode fabricar objetos com dimensões máximas de 203 x 203 x 305 mm ( 8 x 8 x 12 pol.) ( 3D PRINTERS, 2011).

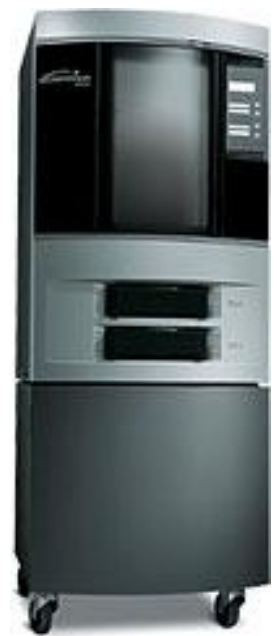

Figura 8-2: Máquina de prototipagem rápida utilizada nesse trabalho (3D PRINTERS, 2011).

Devido à limitação dimensional da máquina o modelo foi projetado em duas partes, com a divisão num plano na seção transversal, como mostram a Figura 8-4. O veículo possui $3 \mathrm{~mm}$ de espessura nas paredes e a região traseira, o "bordo de fuga", é maciça para poder ser feito um furo para encaixe do eixo que sustentou o veículo e transmitiu a força de arrasto durante os ensaios. Foram mantidas as aberturas de ar para o motor do veículo real, assim se pode encher o modelo com água e o empuxo durante os testes foi apenas o resultado pelo volume da casca externa. As próximas figuras ilustram o projeto do modelo. 


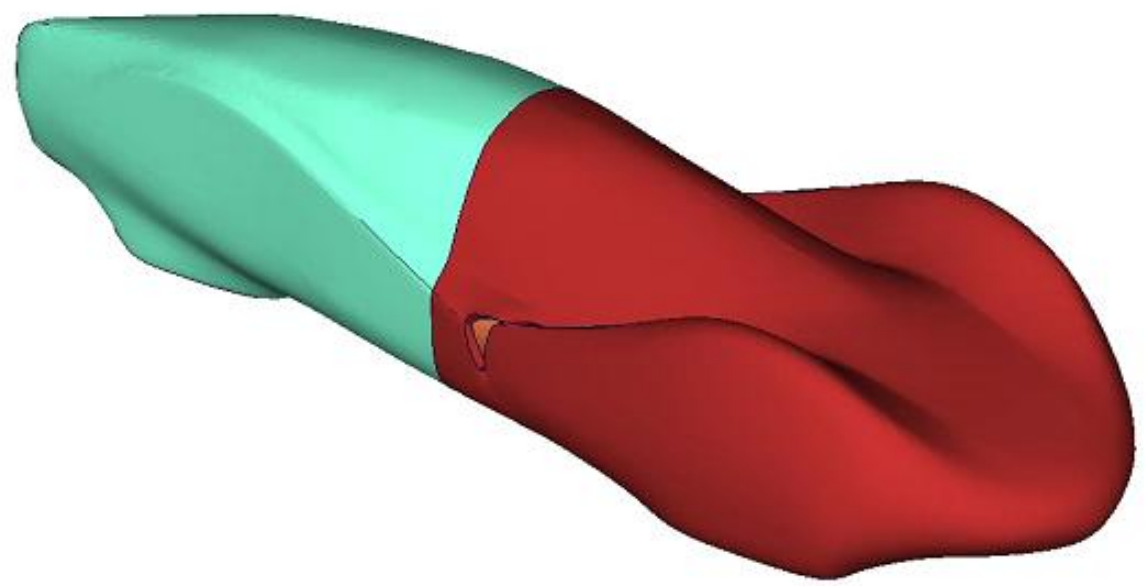

Figura 8-3: Modelo projetado para a impressão 3D.
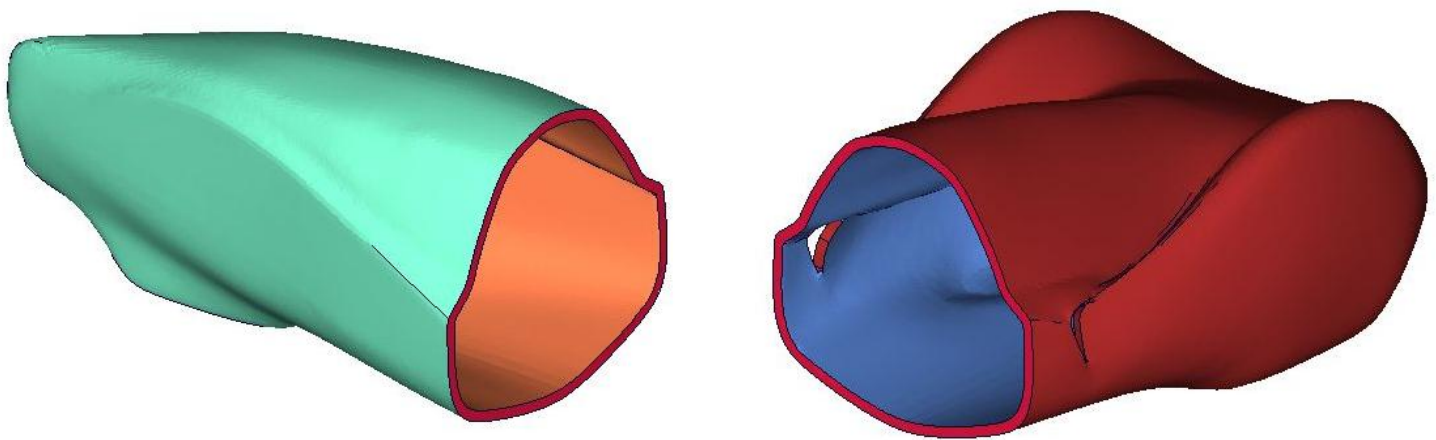

Figura 8-4: As duas partes do modelo.
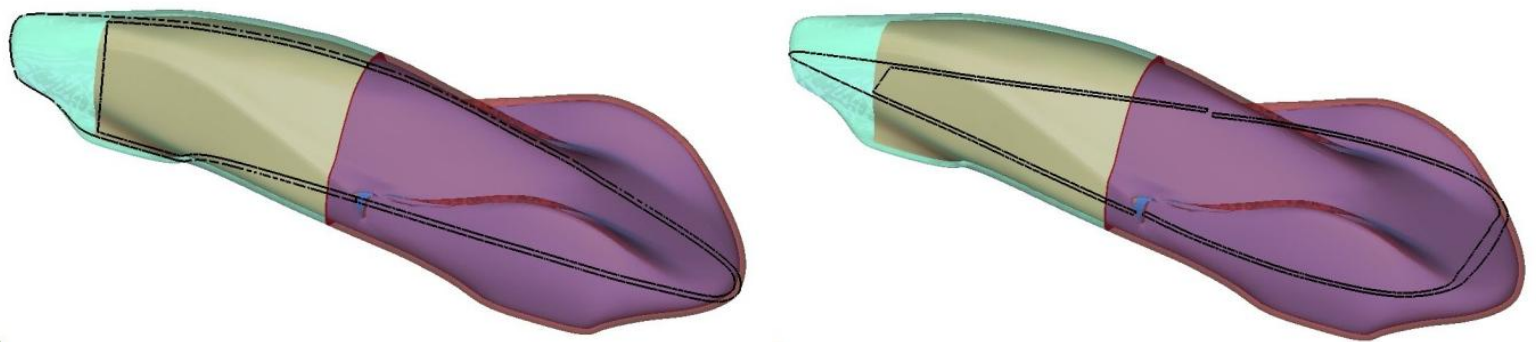

Figura 8-5: Cortes em y $=0 \mathrm{~mm}$ (imagem à esquerda) e $\mathrm{z}=-14 \mathrm{~mm}$ (direita) representados respectivamente na Figura 8-6 e na Figura 8-7 com a geometria do veículo e superfícies externas transparentes. 


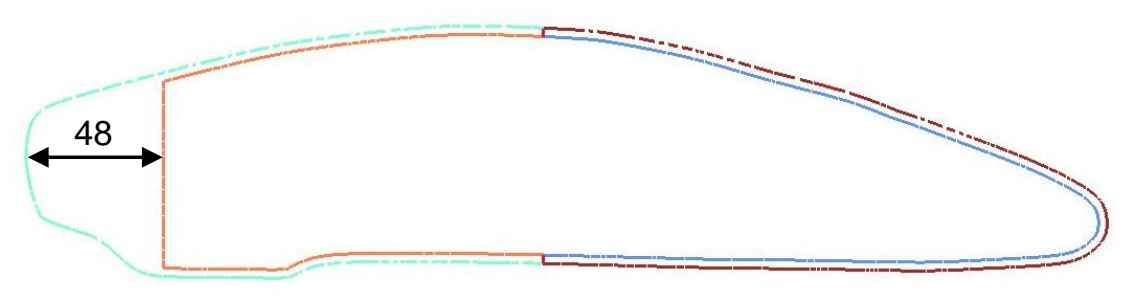

Figura 8-6: Corte em y=0 no modelo. Dimensões em mm.

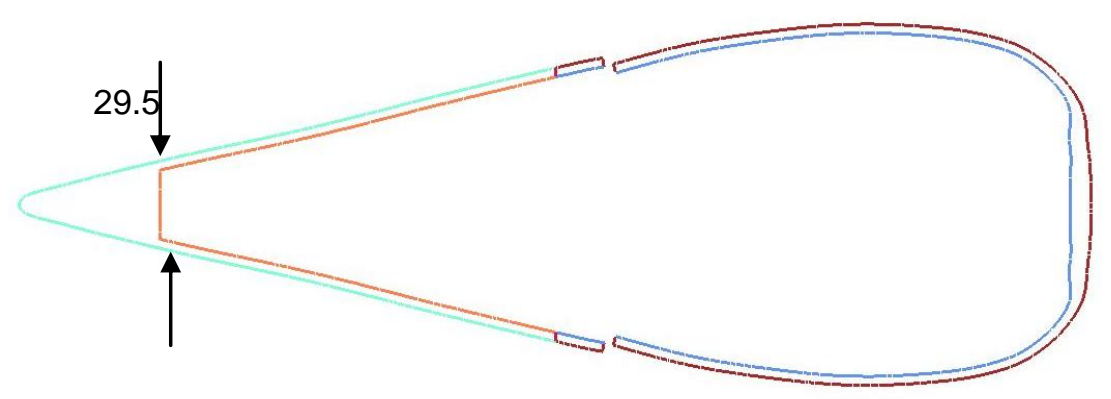

Figura 8-7: Corte em $\mathrm{z}=-14 \mathrm{~mm}$ no modelo.

Após o fim da impressão o modelo foi lixado em água corrente para se obter um melhor acabamento superficial. Esse procedimento foi necessário porque, por experiência de membros do laboratório NDF, o processo de lixa de peças feitas por prototipagem rápida fora da água deteriora a superfície. O modelo, ao sair da impressora, teve a seguinte aparência:

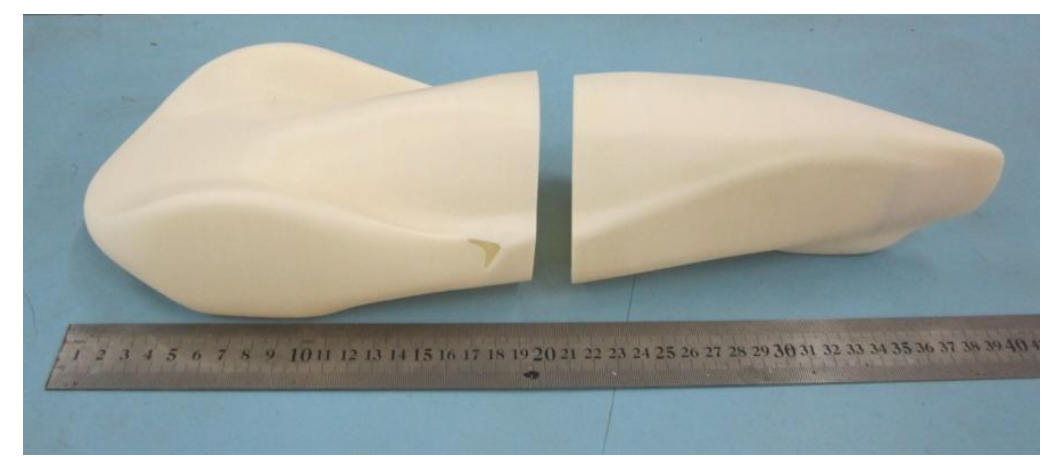

Figura 8-8: Modelo após sair da impressora.

Com o intuito de diminuir a absorção de água das peças, o que as tornariam com dimensões diferentes das especificadas, dificultaria o encaixe com o eixo de suporte e introduziria mais um desvio em relação às simulações numéricas, o modelo foi pintado, 
inclusive na sua porção interior, de vermelho. Essa cor tem o objetivo estético de produzir um contraste com a tinta fluorescente empregada no canal de água para a visualização do escoamento. Utilizou-se tinta spray automotiva, assim foi possível obter um acabamento superficial ainda melhor além de brilho. $\mathrm{O}$ modelo durante a pintura pode ser observado na Figura 8-9:

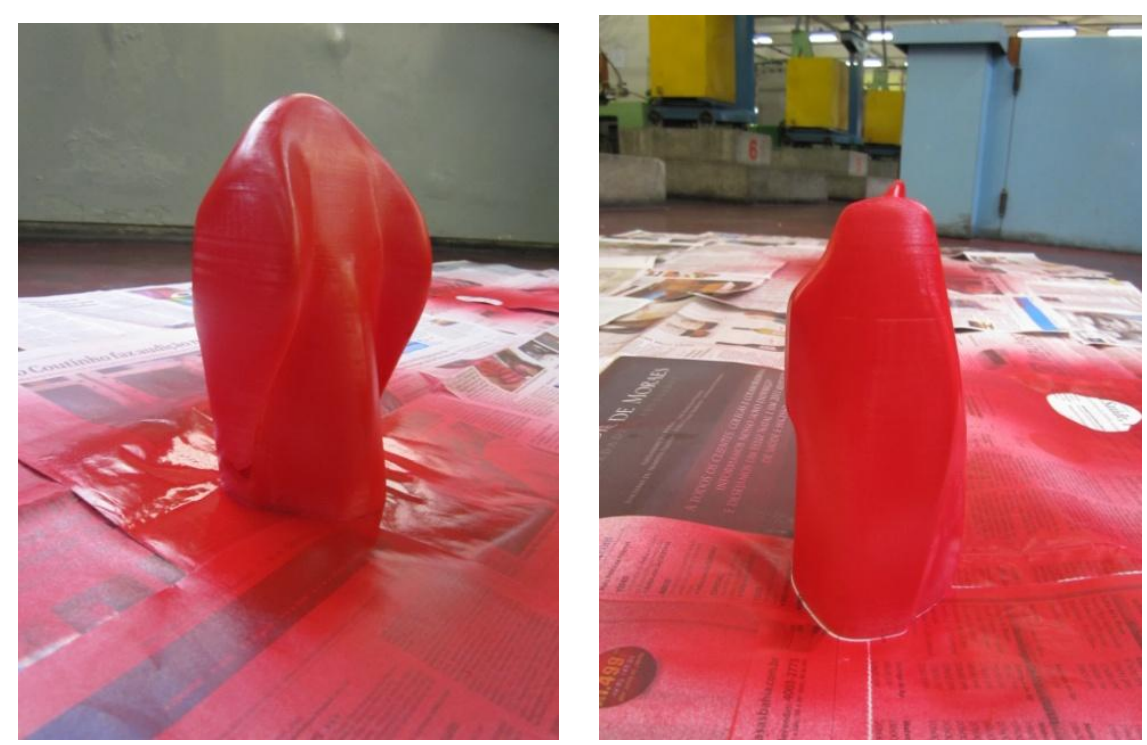

Figura 8-9: Modelo durante o processo de pintura, parte frontal e traseira. 
As duas peças foram unidas com cola Super Bonder. Tomou-se alguns cuidados nesse procedimento, como lixar a superfície de contado entre as peças para que não fosse coladas duas superfícies com tinta, mas as diretamente no material do modelo. Além disso, foram coladas três pequenas chapas plásticas, ilustradas na Figura 8-10, no interior da peça frontal, para evitar que uma peça rotacionasse em relação à outra.

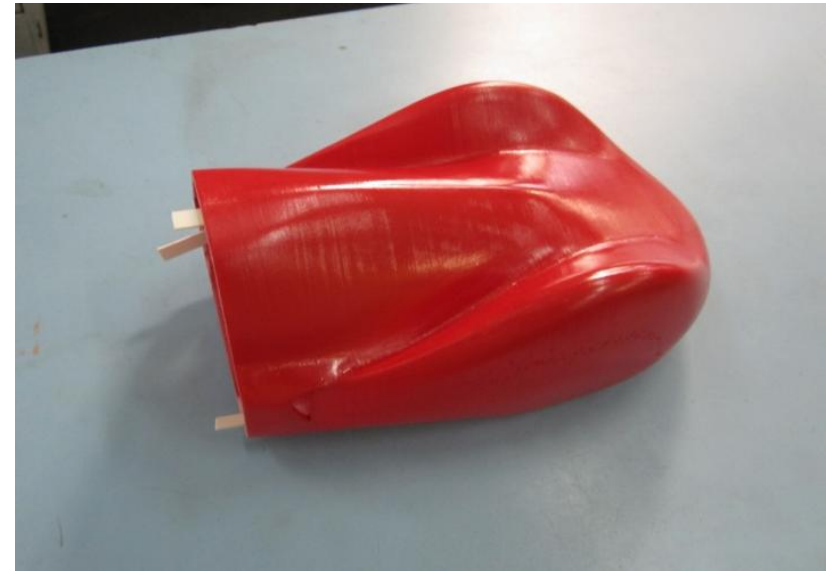

Figura 8-10: Detalhe das peças plásticas coladas para evitar a rotação dos modelos durante a colagem. 
Após a finalização do processo, o modelo ficou com o seguinte aspecto:
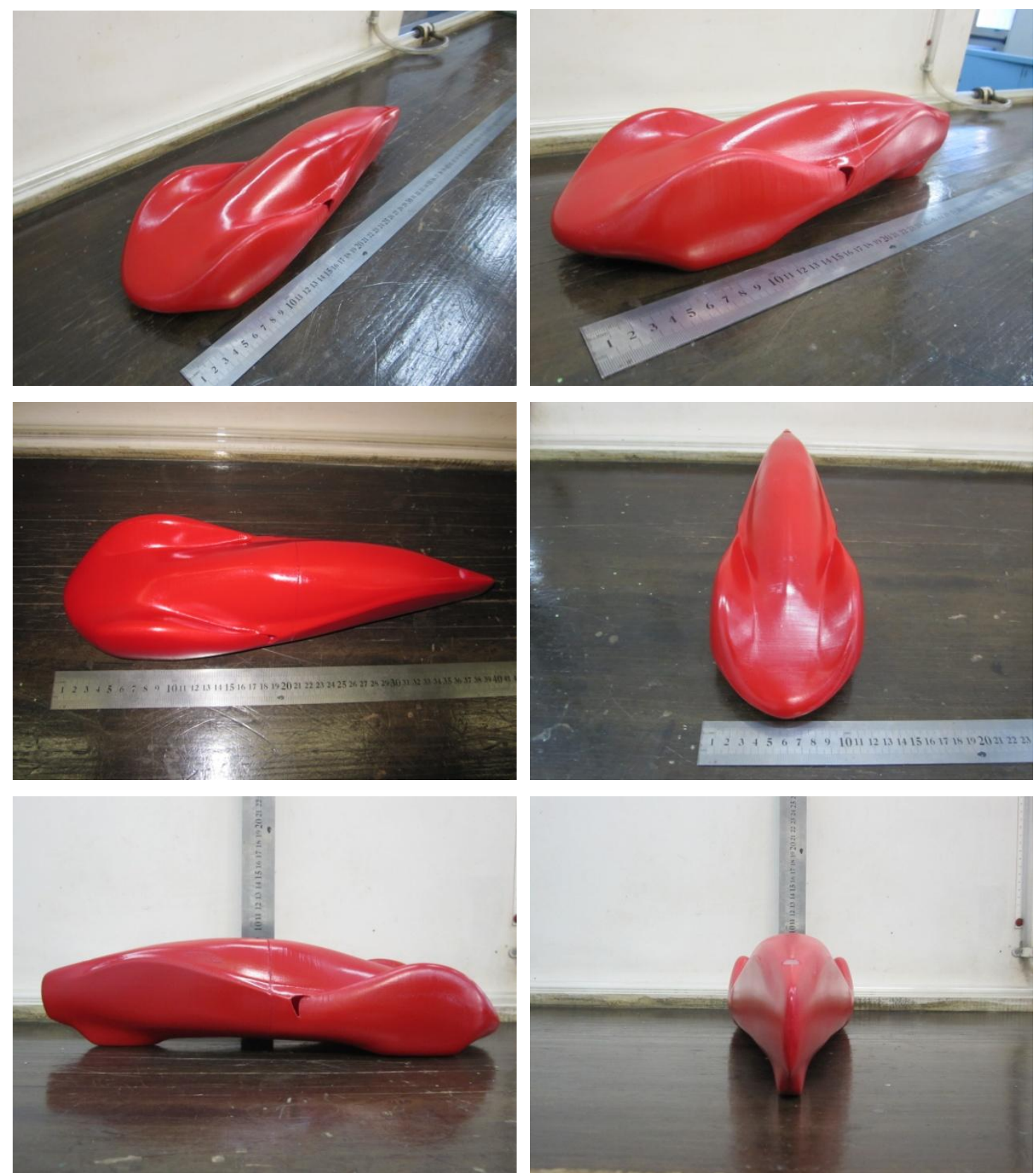

Figura 8-11: Perspectivas do modelo finalizado.

\subsection{O canal de água circulante}

O presente trabalho foi realizado no canal de água circulante localizado no laboratório NDF.

Esse canal foi concebido de forma a ser o mais versátil possível para abrigar testes de 
diferentes áreas, como engenharia do petróleo, hidrodinâmica de embarcações, aerodinâmica veicular, aerelasticidade, dentre muitas outras (ÁSSI, 2005, p. 261).

A seção de testes possui dimensões úteis de $0.7 \mathrm{~m}$ de largura, $0.9 \mathrm{~m}$ de altura e $7.5 \mathrm{~m}$ de comprimento. $\mathrm{O}$ grupo propulsor foi projetado para entregar uma vazão máxima de 0.5 $\mathrm{m}^{3} / \mathrm{s}$. Detalhes sobre o desenvolvimento do projeto do canal podem ser encontrados em Ássi (2005, p. 249).

As vantagens, dentre outras, desse comprimento de canal é a possibilidade de realização de experimentos de reboque (de embarcações, por exemplo), e de mais de um teste ser preparado ao mesmo tempo, em diferentes porções do canal, fato que ocorreu durante os ensaios desse trabalho.

As Figura 8-12 e Figura 8-13 ilustram o canal de água. Ao fundo da foto observa-se os computadores que são ligados ao sistema de aquisição de dados.

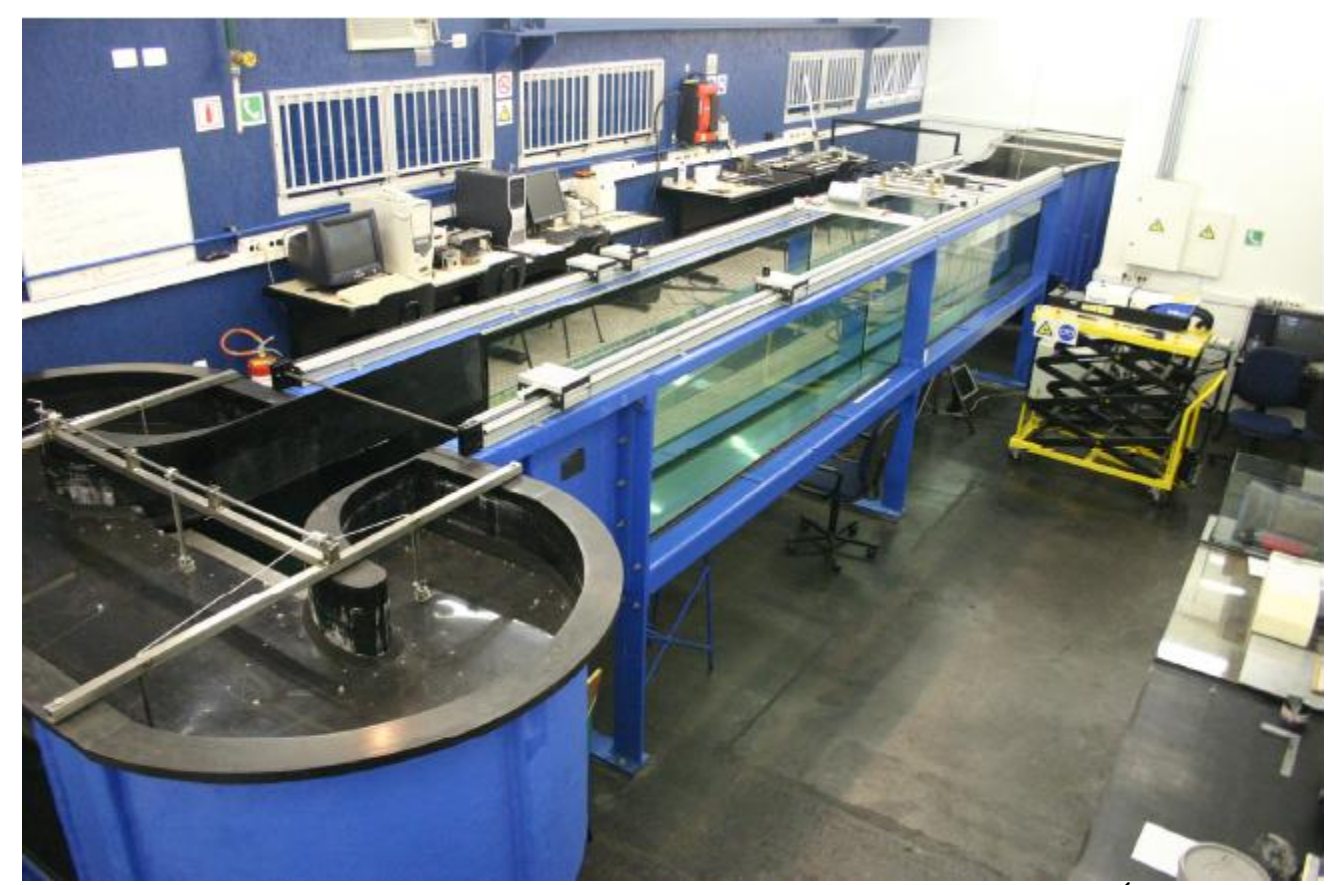

Figura 8-12: Canal de água circulante do laboratório NDF utilizado nesse trabalho (ÁSSI, 2005, p. 268). 

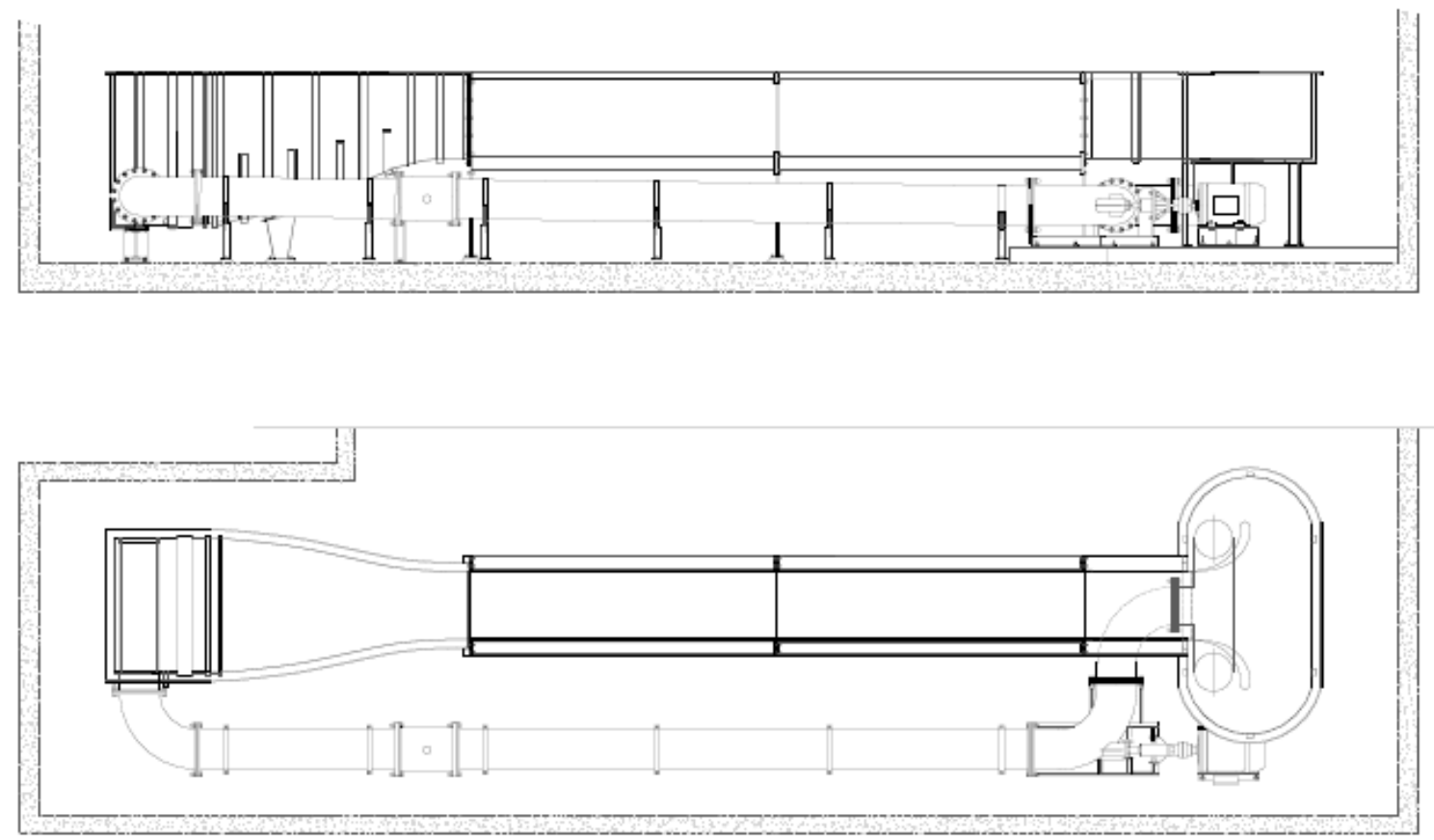

Figura 8-13: Representação em vistas do canal de água (Ássi, 2005, p. 268).

Freire (2009, p. 210) apresenta em um de seus apêndices um manual de práticas experimentais no canal de água circulante em questão.

\subsection{A célula de carga}

Para atingir um dos objetivos do presente trabalho de avaliar o $C_{D}$ e $C_{L}$ do veículo experimentalmente foi utilizada uma célula de carga para medir as força de arrasto e sustentação. Esse equipamento é amplamente empregado em vários setores da economia, pois muitas transações comerciais envolvem a variável peso, além disso, nosso país passou a dominar a tecnologia de fabricação do equipamento, antes restrita às nações desenvolvidas (PORTAL, 2011).

O funcionamento desse sensor é baseado no princípio de que corpos metálicos submetidos a forças e/ou momentos estão sujeitos a deformações. Essas deformações são medidas por sensores denominados extensômetros (strain gages), que relacionam variações em suas dimensões com uma variação da resistência ôhmica. Essa variação provoca uma nova 
diferença de potencial num circuito e é então relacionada com a força que foi exercida na célula de carga.

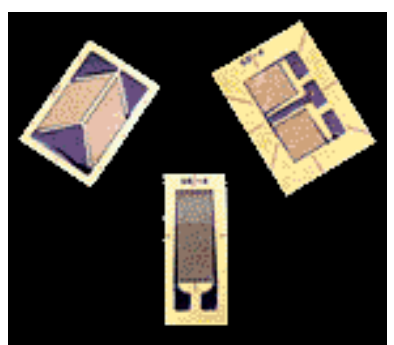

Figura 8-14: Exemplo de extensômetros (PORTAL, 2011).

Comumente são utilizados quatro extensômetros ligados ao corpo da célula de carga (transdutor) de modo que formem um circuito Ponte de Wheatstone, e assim obter a máxima sensibilidade e compensação térmica. Usualmente dois extensômetros estão em tração e dois em compressão (KORKISCHKO, 2006, p. 15).

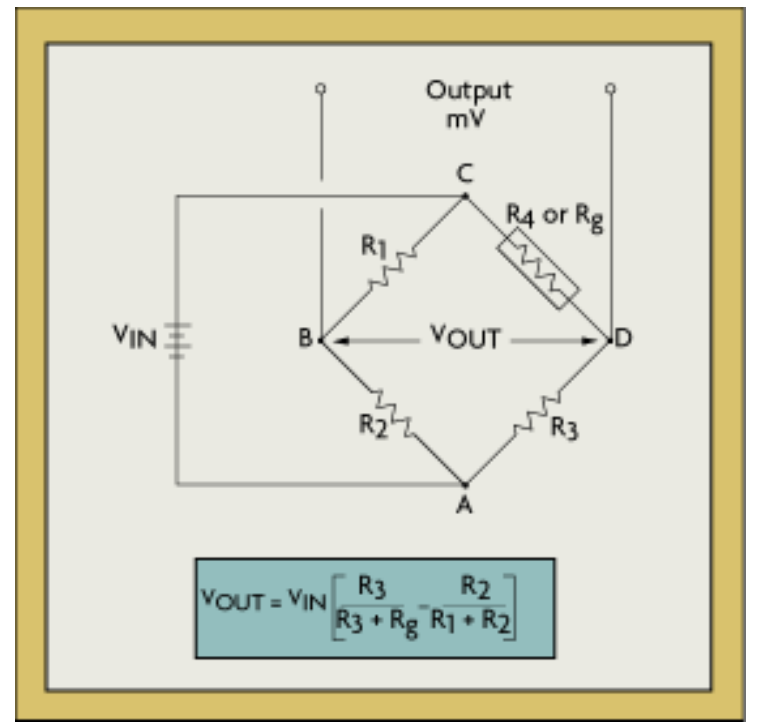

Figura 8-15: Esquema de funcionamento de um circuito em Ponte de Wheatstone (THE STRAIN, 2011).

Podem ser ressaltadas as seguintes vantagens na utilização de células de carga, de acordo com Korkischko (2006, p. 16).

- Praticamente livre de manutenção; 
- Baixa probabilidade de falhas;

- Respostas rápidas;

- Requer menos espaço para ser instalada;

- Alta freqüência natural;

- Ausência quase completa de histerese devido à fluência;

- Sensibilidade;

- Repetitividade;

- Exatidão.

As células de carga podem ser internas, montadas dentro do modelo, ou externas, localizada fora da seção de testes (KORKISCHKO, 2006, p. 14). No presente trabalho foi utilizada uma célula de carga externa de seis eixos (medição de força e momento nos três eixos) disponível no laboratório NDF, do fabricante ATI, modelo Mini 40, com os fundos de escala e resolução mostrados na Tabela 8-2:

Tabela 8-2: Fundo de escala e resolução da célula de carga utilizada (ATI, 2011).

\section{Fundo de escala}

\begin{tabular}{cccccc}
\hline Fx $[\mathrm{N}]$ & Fy $[\mathrm{N}]$ & Fz $[\mathrm{N}]$ & $\mathrm{Tx}[\mathrm{Nm}]$ & $\mathrm{Ty}[\mathrm{Nm}]$ & $\mathrm{Tz}[\mathrm{Nm}]$ \\
20 & 20 & 60 & 1 & 1 & 1 \\
\multicolumn{5}{c}{ Resolução } \\
\hline Fx [N] & Fy [N] & Fz [N] & Tx [Nm] & Ty [Nm] & Tz [Nm] \\
0,01 & 0,01 & 0,02 & 0,00025 & 0,00025 & 0,00025
\end{tabular}

Freire (2009, p. 81) descreve uma metodologia para o processo de seleção de uma célula de carga. 


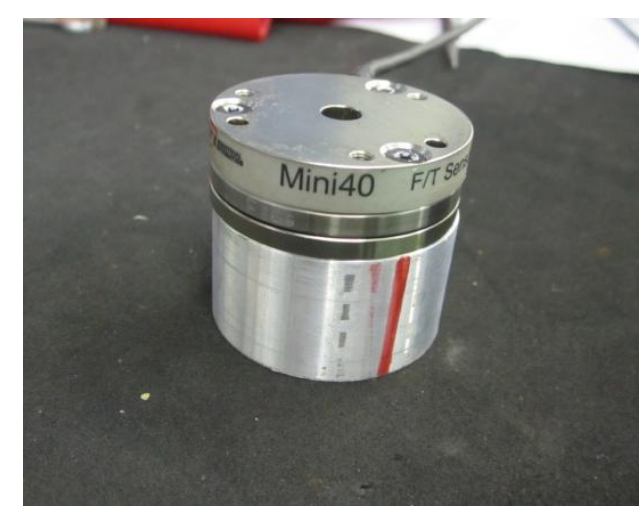

Figura 8-16: Célula de carga utilizada.

\subsection{O medidor de vazão}

O medidor de vazão instalado no canal é o Siemens Sitrans FM Magflo. O princípio de medição é baseado na lei de Faraday da indução eletromagnética, onde o sensor converte o escoamento num sinal elétrico de tensão proporcional à velocidade do fluido. Esse medidor consiste num sensor do tipo MAG 1100, MAG 3100 ou MAG 5100 W e um transmissor do tipo MAG 5000 ou MAG 6000 (SIEMENS, 2011).

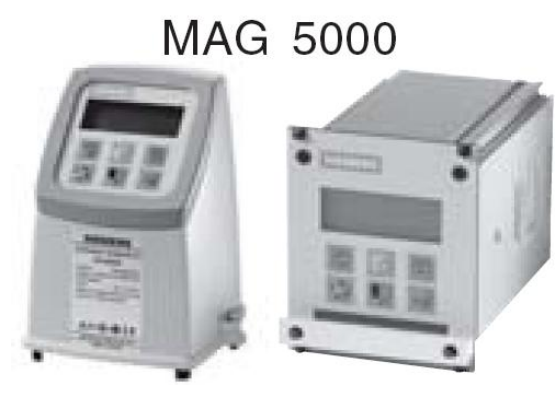

Figura 8-17: Transmissor MAG 5000 (SIEMENS, 2011).

A lei de Faraday da indução eletromagnética expressa que um campo magnético variável produz corrente elétrica num circuito. Ou também é induzida corrente num circuito elétrico em movimento num campo magnético constante. 


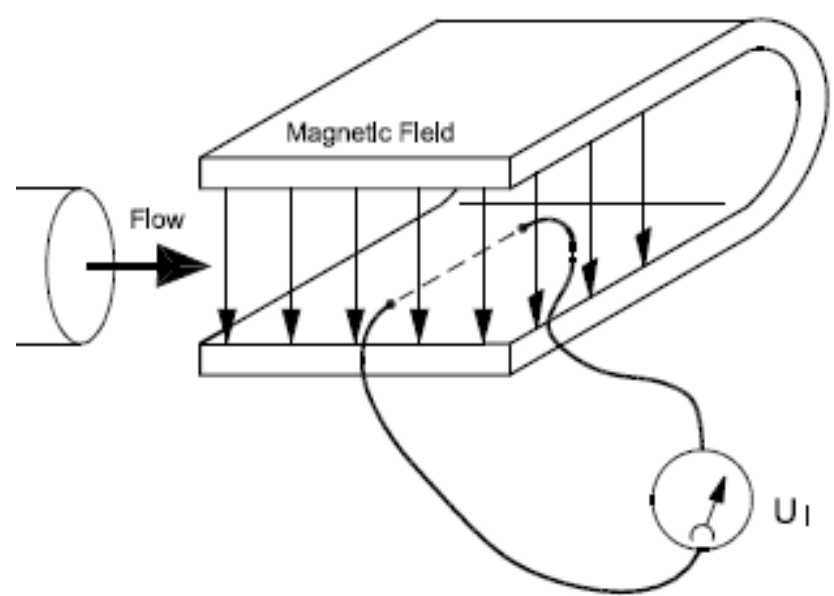

Figura 8-18: Esquema de funcionamento da indução eletromagnética provocada pelo escoamento (SIEMENS, 2011).

Quando um condutor elétrico de comprimento L é movido com uma velocidade v, perpendicular às linhas de fluxo de um campo magnético de intensidade $B$, a tensão $U_{i}$ é induzida nos terminais do condutor (SIEMENS, 2011).

$$
\mathrm{U}_{\mathrm{i}}=\mathrm{L} \times \mathrm{B} \times \mathrm{v}
$$

Onde:

$\mathrm{U}_{\mathrm{i}}=$ tensão induzida.

$\mathrm{L}=$ comprimento do condutor $=$ diâmetro interno do duto $=\mathrm{k}_{1}$.

$\mathrm{B}=$ intensidade do campo magnético $=\mathrm{k}_{2}$.

$\mathrm{v}=$ velocidade média do condutor.

Fazendo:

$$
\mathrm{k}=\mathrm{k}_{1} \times \mathrm{k}_{2}
$$


Pode-se concluir que q velocidade do escoamento é diretamente proporcional ao sinal dos eletrodos com a seguinte equação (SIEMENS, 2011):

$$
\mathrm{U}_{\mathrm{i}}=\mathrm{k} \times \mathrm{v}
$$

A função do sensor é converter o escoamento numa tensão elétrica proporcional à velocidade $\left(\mathrm{U}_{\mathrm{i}}\right)$. É feito de um duto de aço inoxidável, duas bobinas, eletrodos, forro de isolamento, carcaça e, onde aplicável, flanges conectoras. O transmissor consiste num aparelho com algumas funções que convertem a tensão elétrica do sensor em leituras do escoamento (SIEMENS, 2011). 


\section{PROCEDIMENTO EXPERIMENTAL}

\subsection{Montagem experimental}

Como dito anteriormente, o ensaio experimental têm dois objetivos: avaliar os coeficientes $C_{D}$ e $\mathrm{C}_{\mathrm{L}}$, além de visualizar o escoamento ao redor do veículo de milhagem. Para medir as forças no veículo e mantê-lo próximo ao fundo do canal foi utilizada uma barra de aço inox com $9.53 \mathrm{~mm}$ (3/8 pol) de diâmetro, aproximadamente $1300 \mathrm{~mm}$ de comprimento. Essa barra foi fixada por ajuste forçado através de um furo na porção traseira do modelo, fabricada maciça, como descrito no item 8.1.2. Esse furo foi feito utilizando uma broca de $9.5 \mathrm{~mm}$ de diâmetro numa furadeira de bancada, disponível no laboratório NDF.

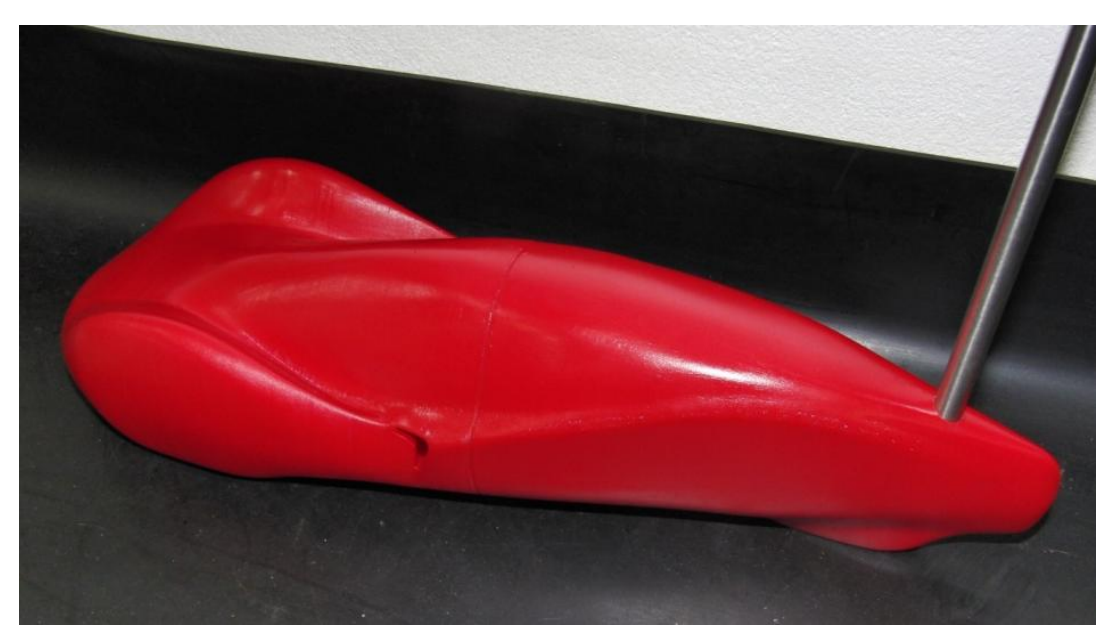

Figura 9-1: Modelo com o eixo montado.

Para se definir um local apropriado para o posicionamento do eixo de suporte foram realizadas simulações numéricas, com o modelo de turbulência Spalart-Allmaras e um eixo na horizontal partindo do bordo de fuga e o eixo vertical subindo do primeiro. Foi variada a posição do eixo vertical em relação ao bordo de fuga com incrementos de L/10, além de uma simulação com o eixo vertical em 40/L do bordo de fuga para dentro do veículo. A Figura 9-2 ilustra a montagem dos testes virtuais e os resultados das forças de arrasto medidas na 
superfície do veículo para cada caso são mostrados na Figura 9-3. Não foi realizado o teste na distância 5L/10, pois o eixo ficaria exatamente na superfície que divide dois volumes de refinamento da malha, descritos no item 5.1.

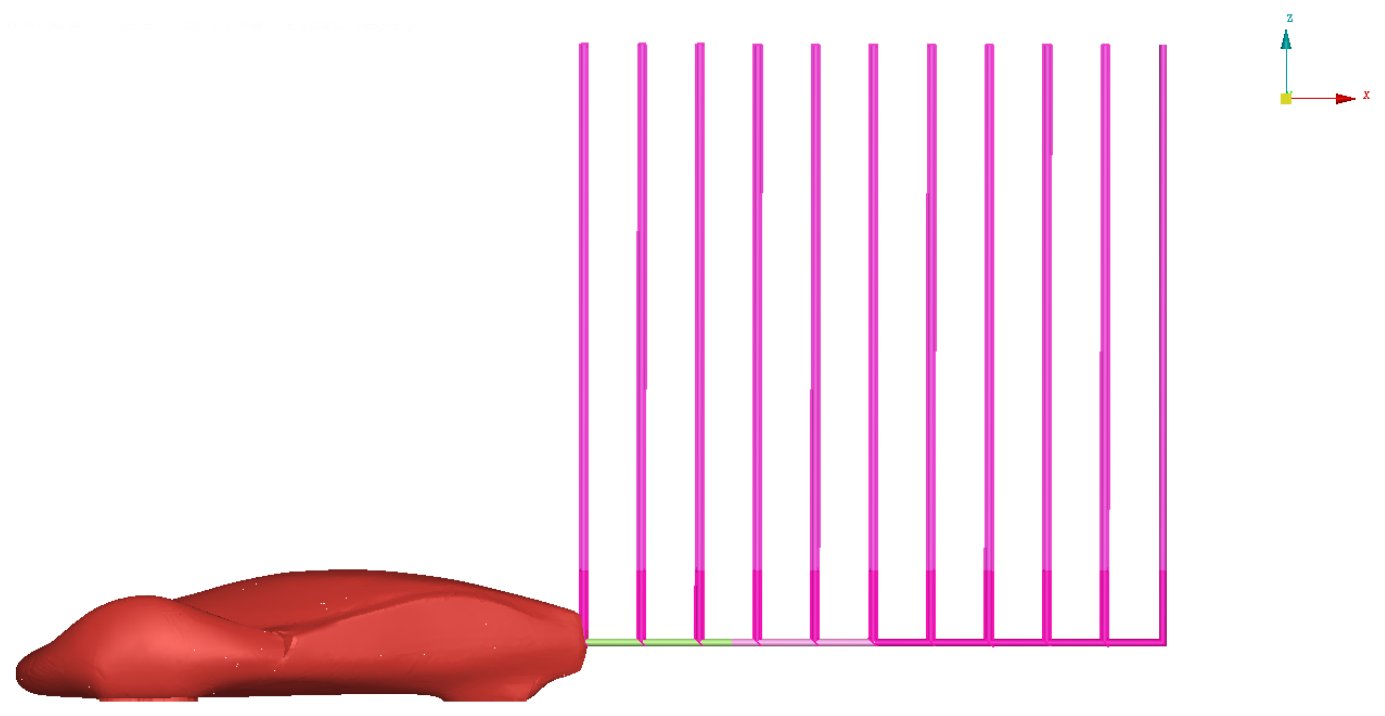

Figura 9-2: Modelo numérico com todos os eixos verticais representados na mesma figura.

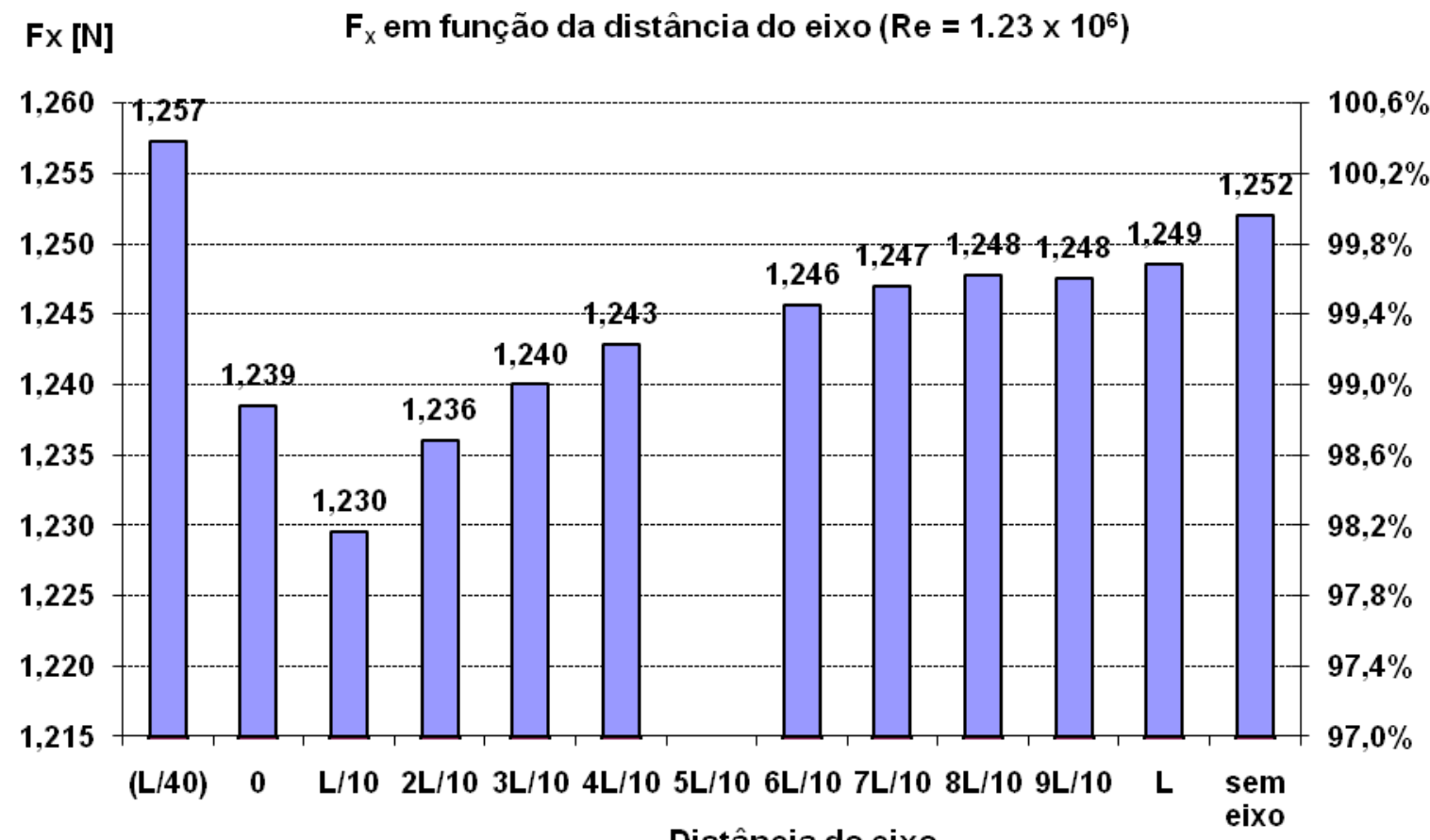

Figura 9-3: Forças em função da distância do eixo vertical em relação ao bordo de fuga do veículo

Na Figura 9-3 o eixo y à esquerda representa a força de arrasto no veículo, enquanto o eixo y à direita é a porcentagem desse valor em relação à simulação sem eixo (100\%). Pode- 
se concluir que a posição do eixo influi pouco na força de arrasto no veículo, dessa forma optou-se por posicionar-lo de forma a facilitar a fabricação e montagem.

A célula de carga utilizada, como citado anteriormente, pode medir tanto forças quanto momentos nas três direções. Esse fato permite montar o eixo de suporte diretamente no sensor, com o auxílio de uma peça cilíndrica de alumínio, como se pôde ver na Figura 8-16 (diferenciada da célula por uma linha vermelha).

Essa peça de ligação à célula de carga possui uma rosca fêmea, então se usinou no eixo de suporte, com o torno, uma rosca macho. Para garantir a fixação foi utilizada ainda uma porca. A Figura 9-4 ilustra o esquema da montagem:

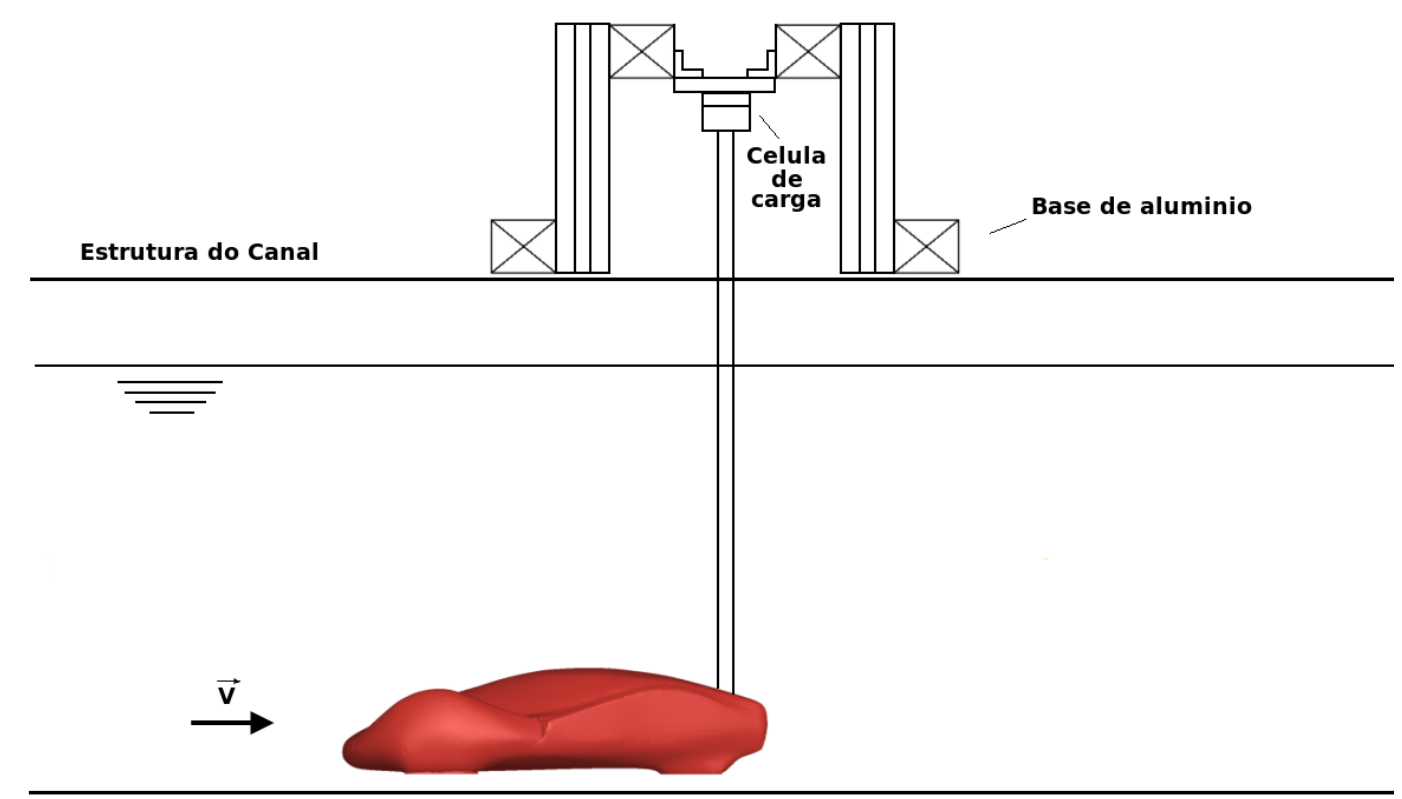

Figura 9-4: Esquema da montagem experimental (sem escala). 


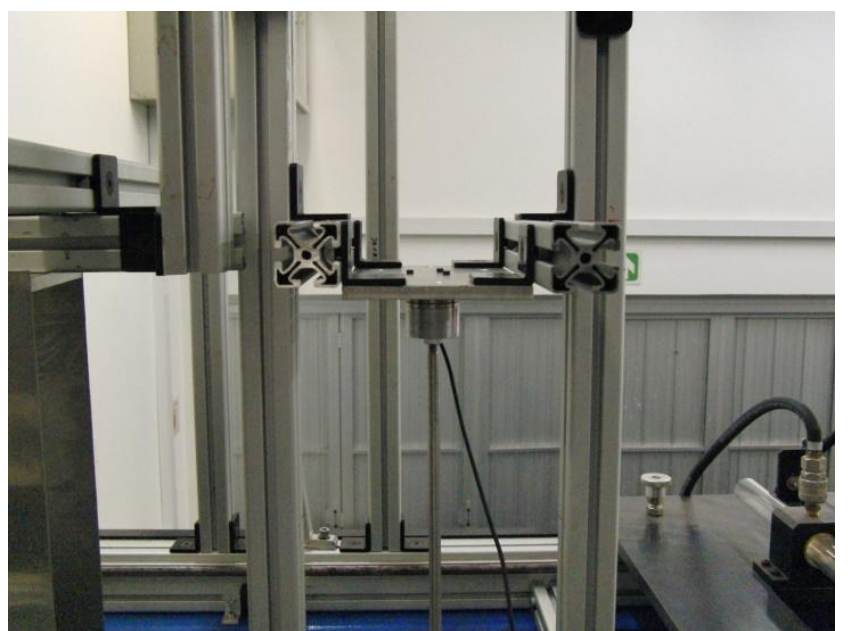

Figura 9-5: Estrutura de barras com a célula de carga e o eixo de suporte montados.

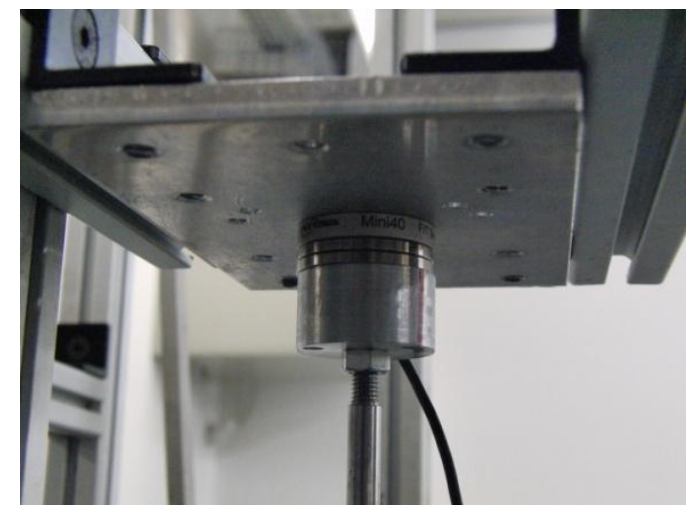

Figura 9-6: Detalhe da célula de carga com o eixo montado.

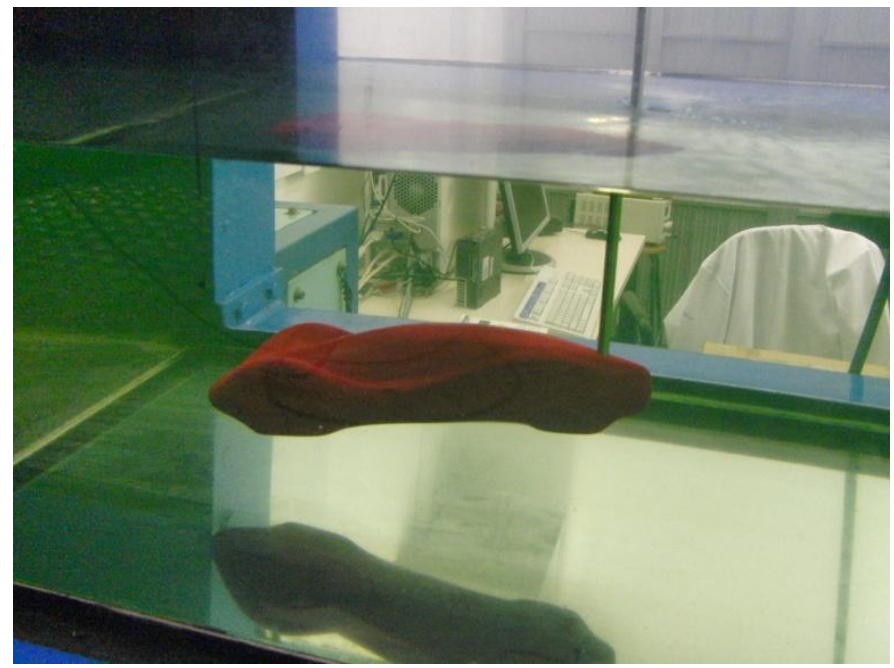

Figura 9-7: Detalhe do modelo no fundo do canal.

Com o experimento completamente montado, observou-se um "ângulo de ataque" do veículo em relação ao escoamento. Isso ocorreu porque o furo para a fixação do eixo de 
suporte, apesar de ter sido feito numa furadeira de bancada, não ficou perfeitamente perpendicular ao eixo longitudinal do veículo.

\subsection{Procedimento de aquisição de dados}

Foram realizadas 4 séries de medições, (consideradas válidas, pois muitas outras foram feitas durante o desenvolvimento do ensaio) onde a velocidade do canal foi aumentada até quando se percebeu a instabilidade devido aos fatores citados no item 8.1.1. "Determinação das dimensões".

Há duas formas de se alterar a velocidade no canal: variando a rotação da bomba ou a altura da água. Em cada uma das séries de medições o nível de água foi mantido constante em 326 mm e variou-se a rotação da bomba, sempre com um passo de 5 RPM, da seguinte maneira:

- $1^{\text {a }}$. série: de 140 a 195 RPM, o que totalizou 12 velocidades diferentes.

- $\quad 2^{\mathrm{a}}$. série: igual a $1^{\mathrm{a}}$. série.

- $\quad 3^{\mathrm{a}}$. série: de 120 a 195 RPM, 16 velocidades;

- $4^{\text {a }}$. série: 125 a 200 RPM, 16 velocidades.

Antes do início de cada série também se aquisitou os dados com a água parada, para se obter o offset das forças e momentos medidos pela célula de carga, que depois seriam subtraídos dos resultados finais.

Em cada uma das rotações da bomba os sinais de forças e momentos na célula de carga e da velocidade da água foram aquisitados durante $90 \mathrm{~s}$ com uma freqüência de $100 \mathrm{~Hz}$. Como os sistemas de aquisição da célula de carga e do medidor da velocidade estavam conectados em computadores diferentes os valores não foram tomados exatamente ao mesmo tempo, mas bem próximos. 


\subsection{Cálculo de $C_{D}$}

Para o cálculo de $\mathrm{C}_{\mathrm{D}}$ mediu-se a força que a barra fazia na célula de carga na direção contrária ao escoamento $\left(\mathrm{F}_{\mathrm{s}}\right)$, considerando os mesmos eixos do estudo numérico, na direção x. Então se mediu o comprimento imerso da barra de suporte, chamado de $1_{i}$, e considerou-se que o $C_{D}$ da barra $\left(\mathrm{C}_{\mathrm{Db}}\right)$, que é circular com diâmetro D, fosse 1 (MUNSON et al., 1997, p. 525).

Assim, para o de cálculo de $C_{D}$ subtraiu-se da força medida em x na célula com a água em movimento a força medida com a água parada $\left(\mathrm{F}_{\mathrm{s} 0}\right)$ e a força da barra $\left(\mathrm{F}_{\mathrm{b}}\right)$, calculada por:

$$
\mathrm{F}_{\mathrm{b}}=\mathrm{C}_{\mathrm{Db}} \cdot \frac{1}{2} \rho \cdot \mathrm{l}_{\mathrm{i}} \cdot \mathrm{D} \cdot \mathrm{v}^{2}
$$

O comprimento imerso medido da barra $\left(\mathrm{l}_{\mathrm{i}}\right)$ foi de $200 \mathrm{~mm}$, e o diâmetro (D) de 9.53 $\mathrm{mm}$.

A força de arrasto $\left(F_{D}\right)$ inserida na equação ( 3-5 ) é:

$$
\mathrm{F}_{\mathrm{D}}=\mathrm{F}_{\mathrm{s}}-\mathrm{F}_{\mathrm{s} 0}-\mathrm{F}_{\mathrm{b}}
$$

\subsection{Cálculo de $\mathrm{C}_{\mathrm{L}}$}

No cálculo de $C_{L}$ considerou-se que a barra, devido à sua geometria simétrica, não exercia sustentação. Assim, da força em z medida na célula de carga com o canal em funcionamento $\left(F_{z}\right)$, subtraiu-se a força em $z$ medida previamente com a bomba do canal desligada $\left(F_{z 0}\right)$ :

$$
\mathrm{F}_{\mathrm{L}}=\mathrm{F}_{\mathrm{z}}-\mathrm{F}_{\mathrm{z} 0}
$$


Então substituiu-se a força $F_{L}$ encontrada na equação ( 9-3 ) na fórmula de cálculo de $C_{L}$, equação ( 3-6 ).

\subsection{Correção da blocagem}

A maioria dos testes em túneis de vento e canais de água que visam medir as forças que agem num determinado corpo tem por objetivo saber como serão os carregamentos que atuarão no objeto real, num ambiente aberto, sem o confinamento provocado pelas paredes do canal de água, ou do túnel de vento As paredes de um canal de água ou túnel de vento impõem restrições ao escoamento ao redor do modelo de uma forma tal que os valores medidos relativos às forças diferem daquelas do escoamento livre e requerem uma correção (REINO UNIDO, 1998).

Correções de blocagem só podem ser negligenciadas se o modelo é muito pequeno em relação ao túnel de vento: a área projetada do objeto deve ter em torno de $1 \%$ da área da seção transversal do túnel. Em estudos de engenharia esse fato entra diretamente em conflito com a necessidade de se testar modelos grandes com o objetivo de se obter número de Reynolds adequados, representar pequenos detalhes da forma da estrutura e criar forças grandes o suficiente para permitir uma boa medição. Conseqüentemente relações de blocagem (razão entre a área projetada do modelo e a área útil da seção de testes do canal) de 5\% são comuns e até de $10 \%$ a $15 \%$ são utilizadas (REINO UNIDO, 1998). 


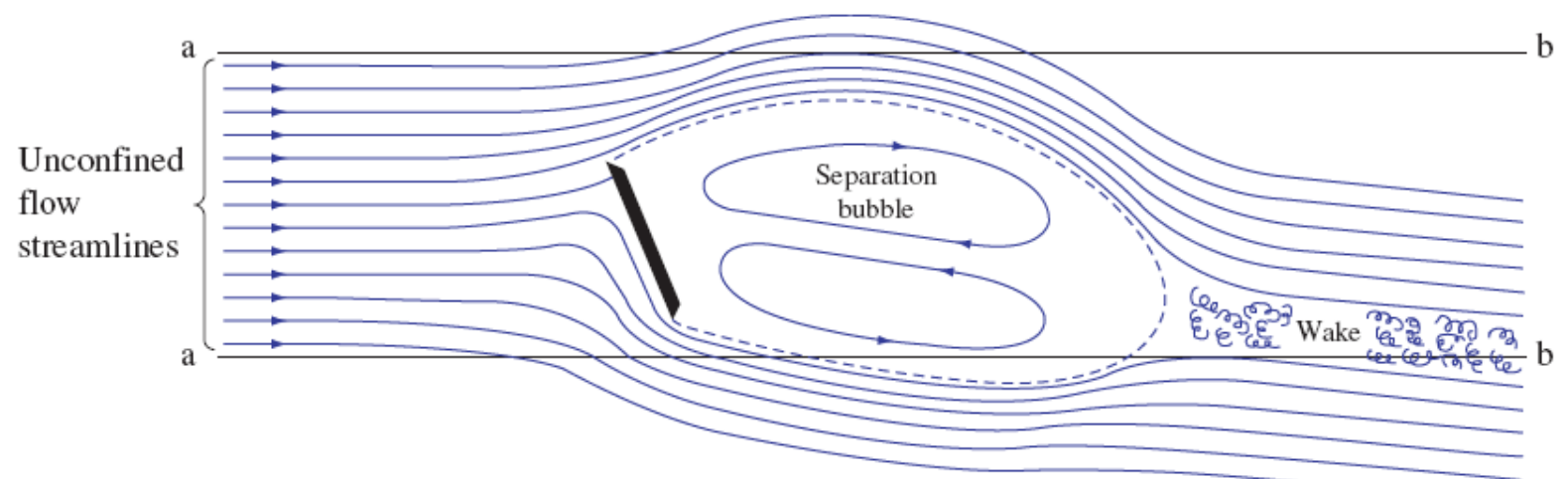

Figura 9-8: Esquema do efeito de blocagem no escoamento (REINO UNIDO, 1998).

A Figura 9-8 esquematiza o efeito de blocagem no escoamento. Fica evidente que para um escoamento confinado as linhas de corrente se modificam para se adequarem à geometria do canal, nesse caso tendendo a ficarem paralelas às paredes a-b. Outro resultado é o aumento da velocidade ao redor do modelo e na esteira (REINO UNIDO, 1998).

A área projetada do modelo é de $0.009 \mathrm{~m}^{2}$, a largura do canal e a altura do nível de água eram, respectivamente, $0.7 \mathrm{~m}$ e $0.326 \mathrm{~m}$, o que levou a uma razão de blocagem de $3.9 \%$. O método recomendado para o caso do carro de milhagem é o do Escoamento Quase-Afilado (Quasi-streamlined Flow Method). Considerando que o modelo está posicionando na linha de centro do canal, a correção fica:

$$
\frac{\mathrm{C}_{\mathrm{Ff}}}{\mathrm{C}_{\mathrm{F}}}=1-\lambda_{1} \lambda_{3}\left(1+0.51 \frac{\sqrt{\mathrm{S}}}{\mathrm{c}}\right) \frac{\mathrm{cS}}{\mathrm{A}^{1.5}}-0.5 \mathrm{C}_{\mathrm{F}} \frac{\mathrm{S}}{\mathrm{A}}
$$

Onde o índice "f” indica o coeficiente para o escoamento livre e

$$
\lambda_{1}=0.72\left(\frac{\mathrm{b}_{\mathrm{d}}}{\mathrm{H}_{\mathrm{d}}}+\frac{\mathrm{H}_{\mathrm{d}}}{\mathrm{b}_{\mathrm{d}}}\right)
$$




$$
\lambda_{3}=\frac{(\text { volumedo modelo })}{\mathrm{cS}}
$$

Onde:

$\mathrm{S}=$ área projetada do modelo $\left(0.009 \mathrm{~m}^{2}\right)$

$\mathrm{c}=$ comprimento do modelo $(0.381 \mathrm{~m})$;

$\mathrm{A}$ = área útil do canal $\left(0.228 \mathrm{~m}^{2}\right)$;

$\mathrm{b}_{\mathrm{d}}=$ altura útil do canal $(0.326 \mathrm{~m})$;

$\mathrm{H}_{\mathrm{d}}=$ largura útil do canal $(0.700 \mathrm{~m})$.

\subsection{Descrição das incertezas}

\subsubsection{Definições e conceitos de incertezas}

A incerteza num teste experimental pode ser definida como uma indicação da diferença entre a grandeza medida e o valor real. Se forem realizadas n medições idênticas, ou seja, da mesma maneira e com os mesmos instrumentos, os n resultados serão geralmente diferentes. Essa variação ocorre devido às várias fontes de erros, e em geral podem ser divididas em dois grupos (VUOLO, 1999):

- Erro aleatório: os resultados se distribuem de maneira aleatória em torno do valor verdadeiro. É devido a fatores que não podem ou não são controlados, como vento, vibrações etc.

- Erro sistemático: os resultados são parecidos, mas afastados do valor real por uma constante.

Os erros sistemáticos podem ser divididos ainda em:

- Instrumental: resultado de erro de calibração dos instrumentos utilizados. 
- Teórico: resultado do uso de fórmulas teóricas aproximadas, ou de aproximações em grandezas físicas utilizadas nos cálculos.

- Observacional: resultado de limitações do observador. Por exemplo, o tempo de reação típico do ser humano é de $0.1 \mathrm{~s}$. Se fizer alguma medição utilizando um cronometro acionado manualmente esse valor pode ser a ordem de grandeza do erro (VUOLO, 1999).

Há ainda os erros grosseiros ou enganos, que não são erros do ponto de vista da teoria dos erros. Isso ocorre, por exemplo, quando uma balança marca 138 g e o observador anota 183 g. Para evitar esse tipo de erro as regras básicas são repetir as medições e conferir os procedimentos ou cálculos experimentais (VUOLO, 1999).

\subsubsection{Propagação de incertezas}

Dada uma grandeza w que é uma função de grandezas independentes $x, y, z, \ldots$ e admitindo que $\mathrm{x}, \mathrm{y}, \mathrm{z}$.... são valores experimentais, cujo os erros $\sigma_{\mathrm{x}}, \sigma_{\mathrm{y}}, \sigma_{\mathrm{z}}$.. são completamente independentes entre si, a incerteza de $\mathrm{w}, \sigma_{\mathrm{w}}$, é dada em primeira aproximação por (VUOLO, 1999):

$$
\sigma_{\mathrm{w}}^{2}=\left(\frac{\partial \mathrm{w}}{\partial \mathrm{x}}\right)^{2} \sigma_{\mathrm{x}}^{2}+\left(\frac{\partial \mathrm{w}}{\partial \mathrm{y}}\right)^{2} \sigma_{\mathrm{y}}^{2}+\left(\frac{\partial \mathrm{w}}{\partial \mathrm{z}}\right)^{2} \sigma_{\mathrm{z}}^{2} \ldots
$$

Para o cálculo das incertezas de $C_{D}$ considerou-se que este fosse uma função de variáveis independentes entre si. Lembrando a equação ( 3-5 ) que define $C_{D}$ é: 


$$
\mathrm{C}_{\mathrm{D}}=\frac{\mathrm{F}_{\mathrm{D}}}{\frac{1}{2} \cdot \rho \cdot \mathrm{A} \cdot \mathrm{v}^{2}}
$$

Assim, aplicando a equação ( 9-7 ) na ( 3-5 ), e fazendo algumas manipulações erro $\sigma \mathrm{C}_{\mathrm{D}}$ pode ser calculado por:

$$
\sigma \mathrm{C}_{\mathrm{D}}=\mathrm{C}_{\mathrm{D}} \cdot\left[\left(\frac{\sigma \mathrm{F}_{\mathrm{D}}}{\mathrm{F}_{\mathrm{D}}}\right)^{2}+\left(\frac{\sigma \rho}{\rho}\right)^{2}+\left(\frac{\sigma \mathrm{A}}{\mathrm{A}}\right)^{2}+\left(2 \frac{\sigma \mathrm{v}}{\mathrm{v}}\right)^{2}\right]^{\frac{1}{2}}
$$

Onde

$$
\sigma \mathrm{F}_{\mathrm{D}}=\sqrt{\sigma \mathrm{F}_{\mathrm{s}}^{2}+\sigma \mathrm{F}_{\mathrm{s} 0}^{2}+\sigma \mathrm{F}_{\mathrm{b}}^{2}}
$$

$\mathrm{E} \sigma \mathrm{F}_{\mathrm{s}}=0.01$ (resolução da célula de carga) $[\mathrm{N}]$;

$\sigma \mathrm{F}_{\mathrm{s} 0}=0.01$ (resolução da célula de carga) $[\mathrm{N}]$;

$$
\sigma \mathrm{F}_{\mathrm{b}}=\mathrm{F}_{\mathrm{b}} \cdot\left[\left(\frac{\sigma \mathrm{C}_{\mathrm{Db}}}{\mathrm{C}_{\mathrm{Db}}}\right)^{2}+\left(\frac{\sigma \rho}{\rho}\right)^{2}+\left(\frac{\sigma \mathrm{l}_{\mathrm{i}}}{\mathrm{l}_{\mathrm{i}}}\right)^{2}+\left(\frac{\sigma \mathrm{D}}{\mathrm{D}}\right)^{2}+\left(2 \frac{\sigma \mathrm{v}}{\mathrm{v}}\right)^{2}\right]^{\frac{1}{2}}
$$

Foram utilizados os seguintes valores:

$$
\begin{aligned}
& \sigma \mathrm{C}_{\mathrm{Db}}=0.05[] ; \\
& \sigma \rho=5\left[\mathrm{~kg} / \mathrm{m}^{3}\right] ; \\
& \sigma \mathrm{l}_{\mathrm{i}}=0.002[\mathrm{~m}] ; \\
& \sigma \mathrm{D}=0.0001[\mathrm{~m}] .
\end{aligned}
$$


$\sigma \mathrm{V}=\mathrm{o}$ desvio padrão do sinal da velocidade $[\mathrm{m} / \mathrm{s}]$.

Um equacionamento similar foi realizado para o cálculo do erro dos coeficientes de sustentação, trocando-se apenas $\mathrm{F}_{\mathrm{D}}$ por $\mathrm{F}_{\mathrm{L}}$. 
10. RESULTADOS EXPERIMENTAIS

\subsection{Valores de $C_{D}$ e $C_{L}$ obtidos}

Pelos motivos mencionados anteriormente não foi possível atingir o número de Reynolds do veículo em condição de competição. Com as rotações da bomba citadas no capítulo anterior e a altura do nível de água do canal de $326 \mathrm{~mm}$ a faixa do adimensional em questão foi de $9.3 \mathrm{x}$ $10^{4}$ até $1.6 \times 10^{5}$.

Foram obtidos os seguintes valores de $C_{D}$ e $C_{L}$, em cada uma das 4 séries de teste, descritas no item 9.2 "Procedimento de aquisição de dados".

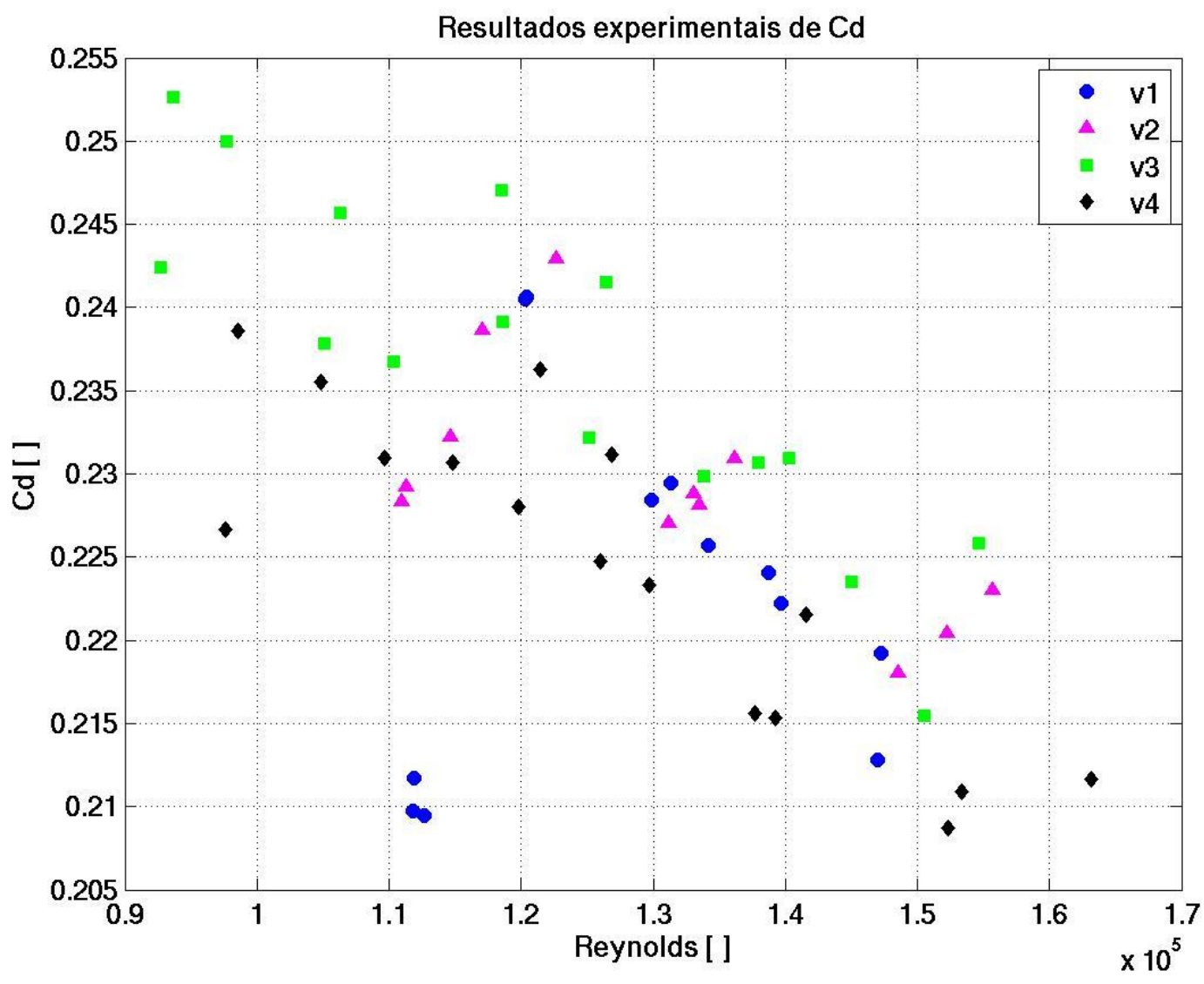

Figura 10-1: Resultados experimentais de $C_{D}$ para as 4 séries de ensaios. 


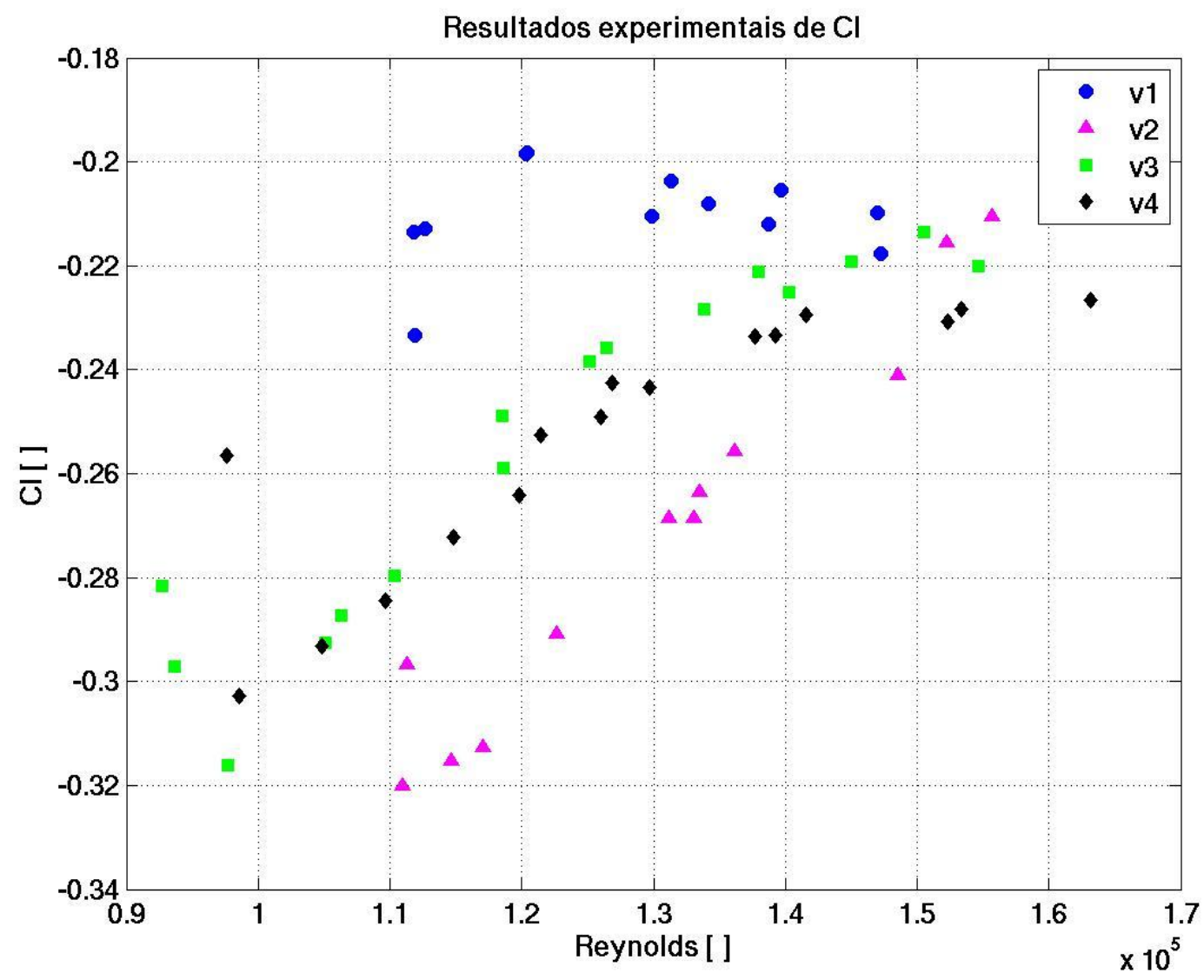

Figura 10-2: Resultados experimentais de $\mathrm{C}_{\mathrm{L}}$ para as 4 séries de ensaios.

Nota-se claramente que para todas as séries os valores de $C_{D}$ diminuem com o aumento do número de Reynolds, o que concorda com os resultados numéricos representados na Figura 6-1. Entretanto os valores de $C_{L}$ medidos experimentalmente aumentam com o número de Reynolds, o que vai à direção oposta aos resultados do modelo virtual, mostrados na Figura 6-3. Um fato que possa explicar essa discrepância é que nos testes experimentais o veículo não está tão próximo do solo quanto no modelo virtual, onde se observou que a alta velocidade entre as rodas dianteiras, devido à proximidade com a pista, é um fator decisivo para a sustentação negativa. Talvez essa dificuldade em obter-se bons resultados de $C_{L}$ explique o fato de apenas um dos trabalhos exemplificados no capítulo 2 tratar sobre o tema.

Os resultados apresentados levam em consideração a correção do efeito de blocagem. Entretanto, como se pode verificar na Figura 10-3 (arrasto) e na Figura 10-4 (sustentação), 
não houve grande influência do bloqueio do escoamento pelo modelo. Esse fato deveu-se à baixa razão de blocagem (3.9\%) nas condições de realização do teste. Os marcadores sem preenchimento e com legenda "sc" são aqueles sem correção para a blocagem.

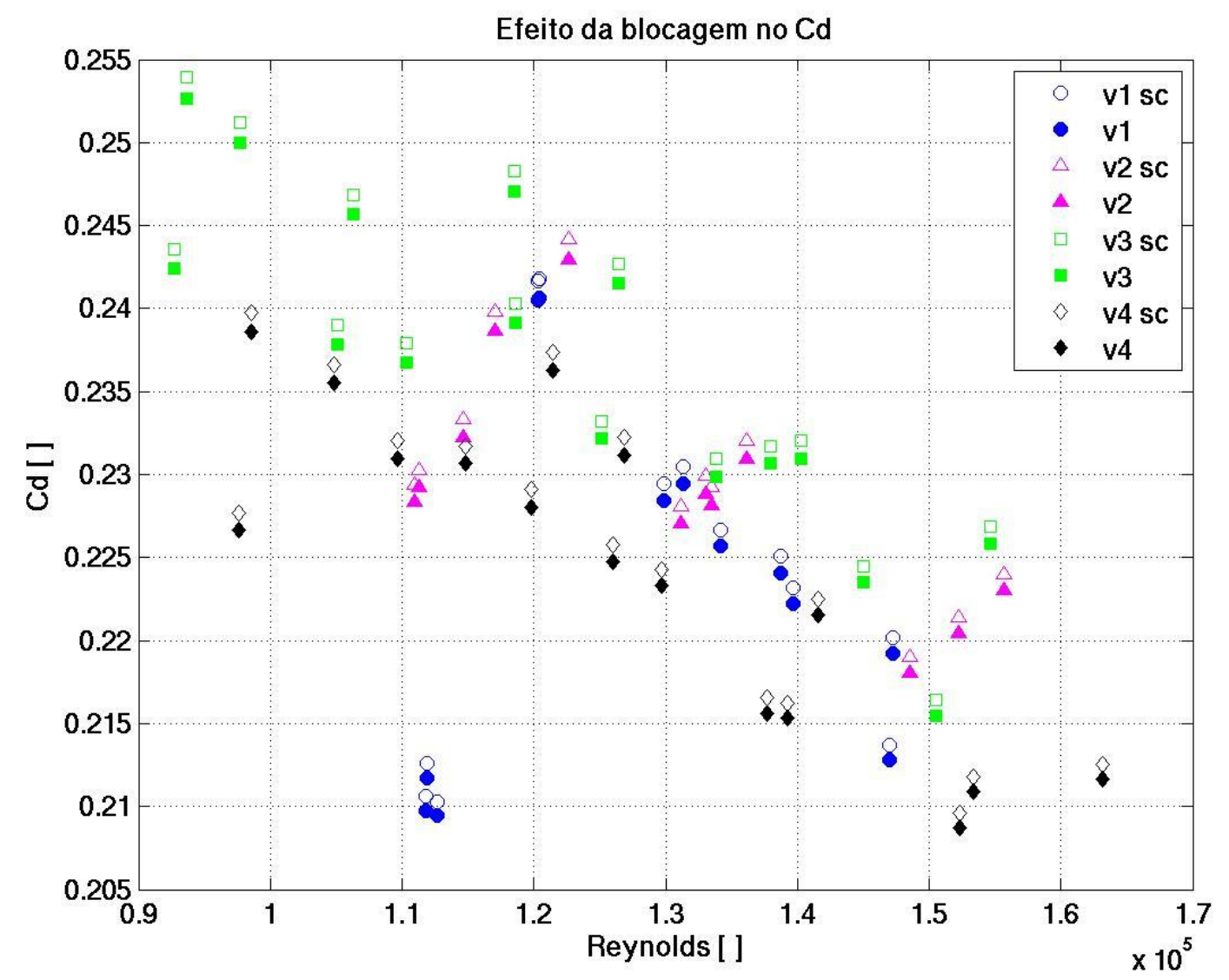

Figura 10-3: Comparação dos resultados experimentais de $C_{D}$ com e sem a correção da blocagem. 


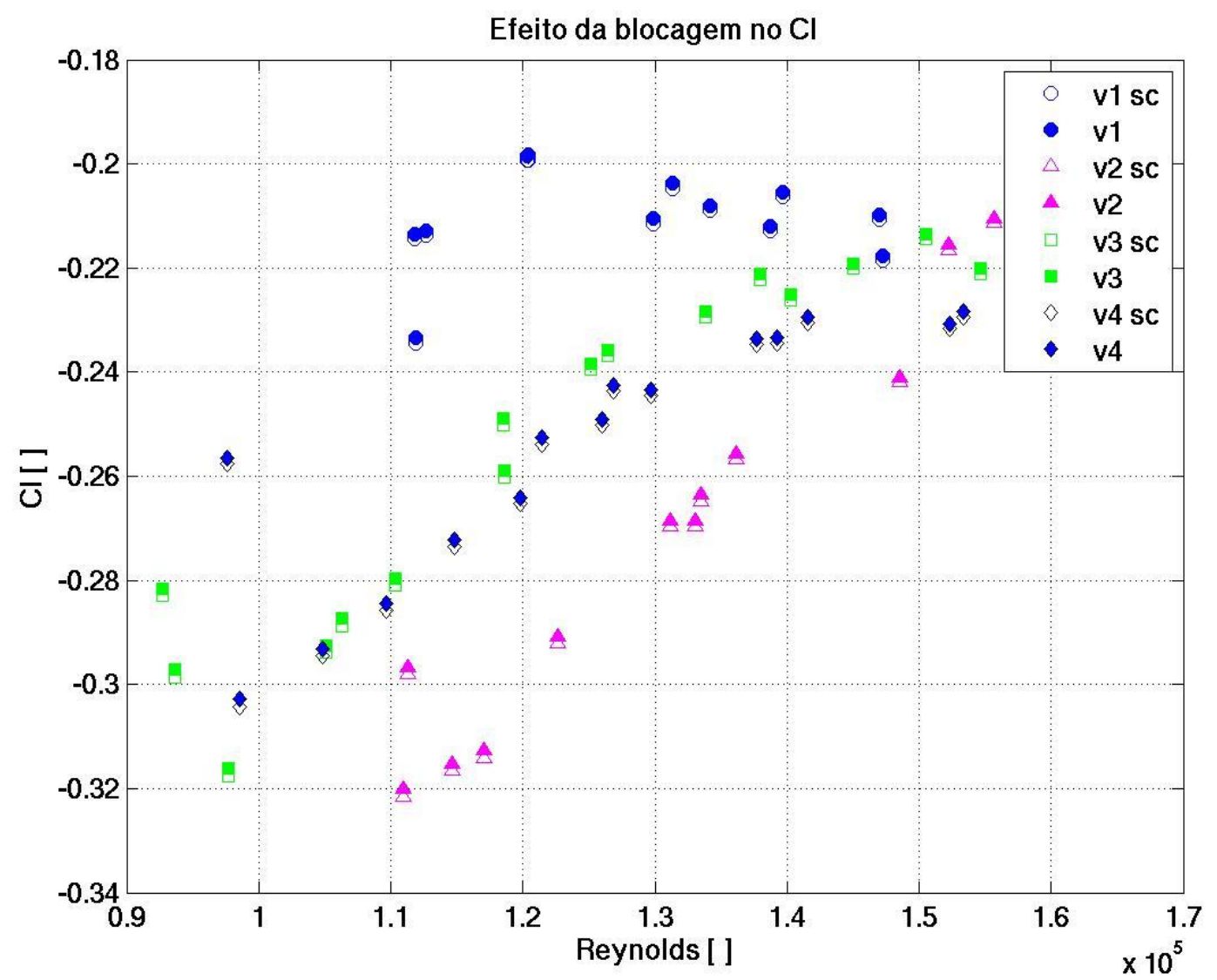

Figura 10-4: Comparação dos resultados experimentais de $C_{L}$ com e sem a correção da blocagem.

Apesar da influência ser pequena em ambos, nota-se que a blocagem tem um menor efeito na sustentação do que no arrasto. Outro fato interessante é que as tendências são opostas nessas forças: enquanto os valores sem correção são maiores no coeficiente de arrasto, no coeficiente de sustentação são menores.

Considerando-se agora a margem de erro os resultados de $C_{D}$ e $C_{L}$ ficaram: 


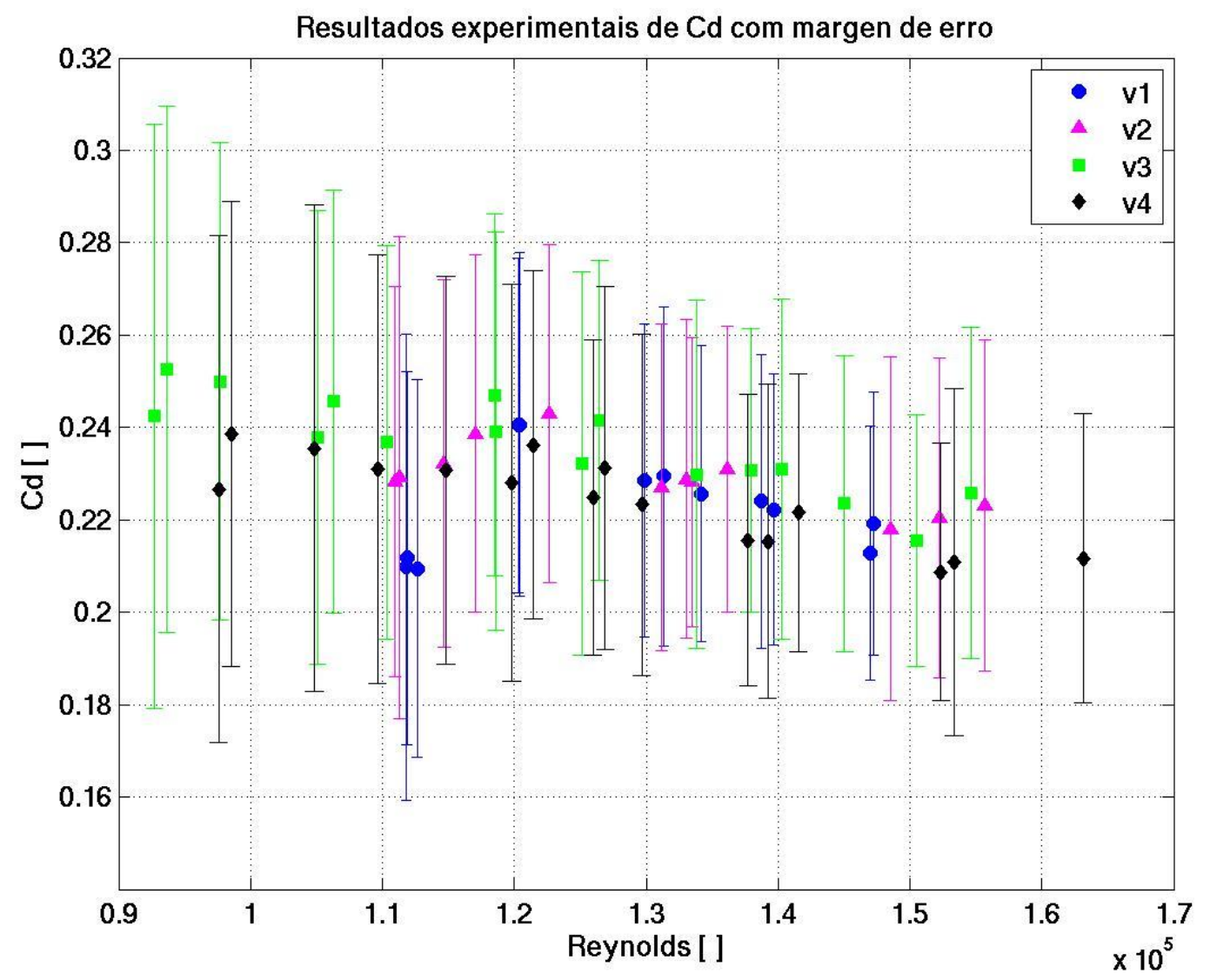

Figura 10-5: Resultados experimentais de $C_{D}$ considerando a margem de erro calculada. 


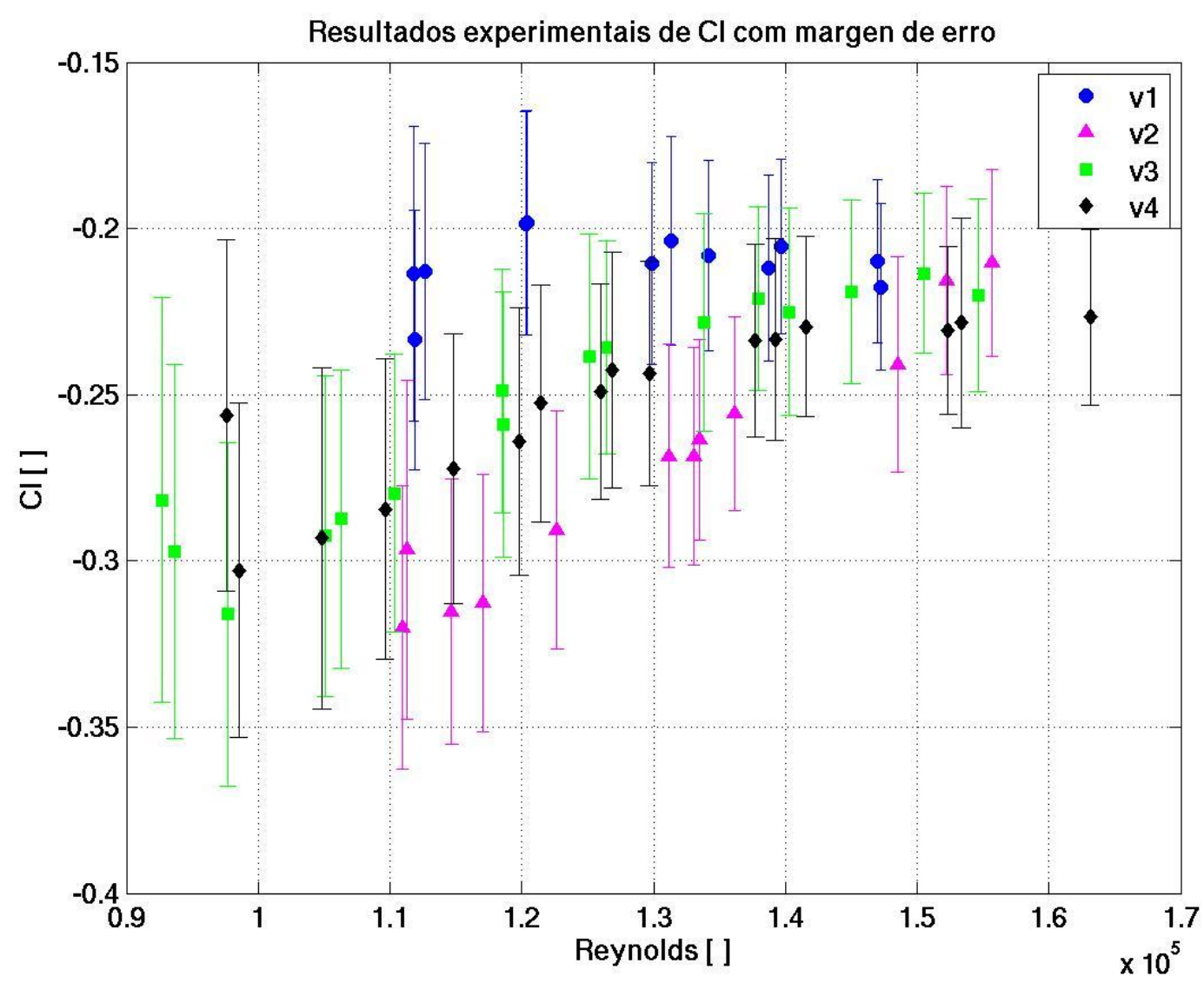

Figura 10-6: Resultados experimentais de $C_{L}$ considerando a margen de erro calculada.

Optou-se por mostrar os resultados com e sem a margem de erro para uma melhor visualização da tendência, especialmente no caso de $C_{D}$. Isso mostra que os erros calculados foram menores para o coeficiente de sustentação, pois o aumento dos valores com o número de Reynolds continua claro, mesmo alterando-se a escala com a introdução das margens de erro. Esses valores de incerteza estão próximos aos calculados por Carregari (2006), como foi observado na Figura 2-3.

\subsection{Visualização do escoamento}

Foram realizadas algumas imagens do escoamento ao redor do modelo utilizando uma tinta fluorescente verde. Essas figuras foram feitas com um número de Reynolds bem inferior aos testados experimentalmente para que a tinta não passasse muito rápido pelo modelo. 
Uma dificuldade encontrada foi o ângulo de realização das imagens. Apesar do canal possuir paredes e piso de vidro, não foi possível fazer boas fotos com uma vista do fundo do modelo e das laterais devido ao reflexo da luz. Ainda assim algumas ficaram interessantes, especialmente as vistas de cima, e decidiu-se por colocá-las no texto.

Vale ressaltar que devido à própria turbulência do escoamento livre do canal ao se colocar a tinta na água eram geradas estruturas vorticais. Essas estruturas eram então transladas e passavam pelo modelo sem grandes alterações. O método de visualização empregado não distingue os vórtices do escoamento livre transladados dos produzidos pela perturbação do modelo no escoamento.

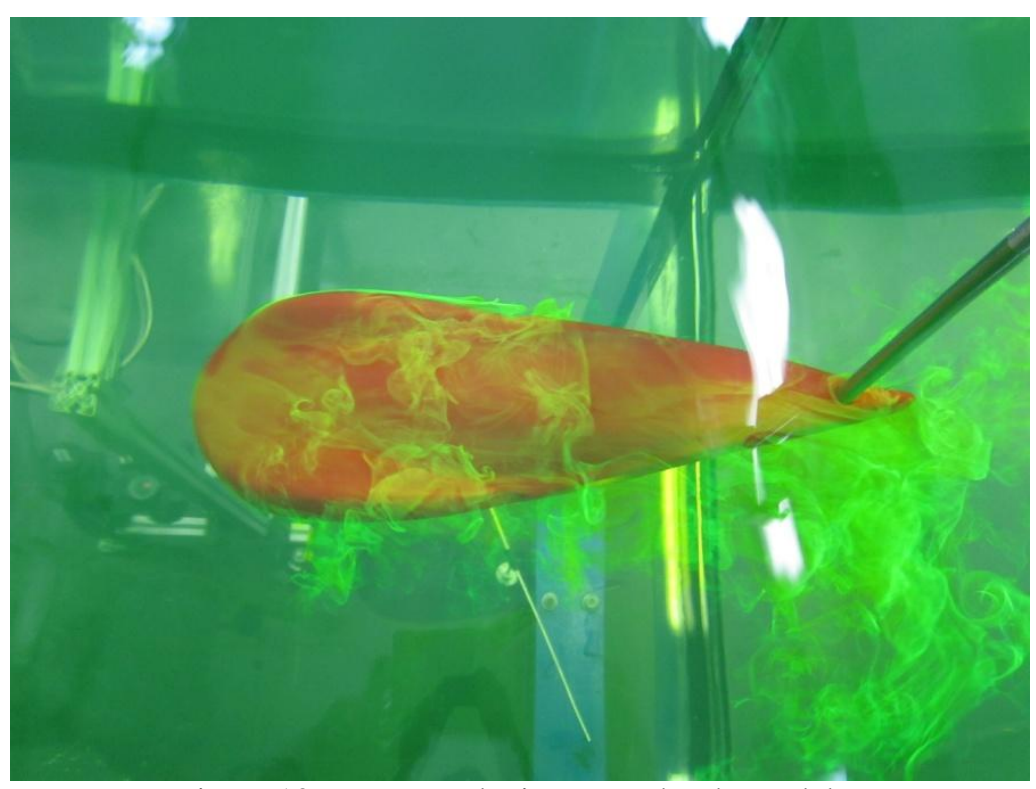

Figura 10-7: Nuvem de tinta ao redor do modelo. 


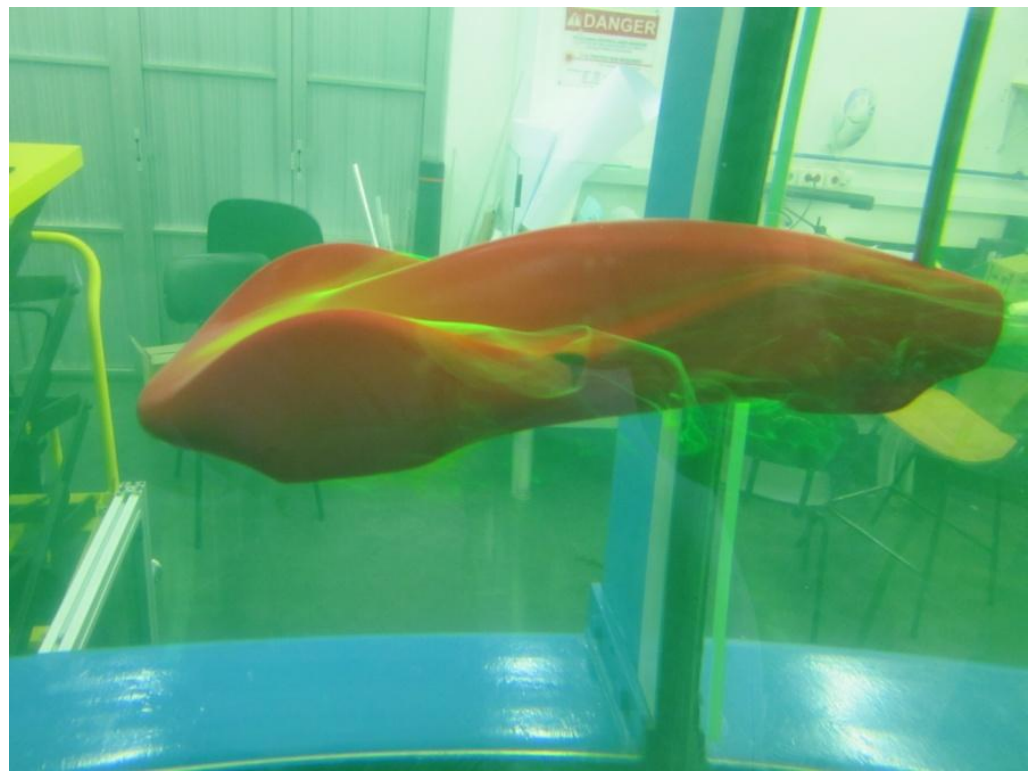

Figura 10-8: Vista lateral do escoamento.

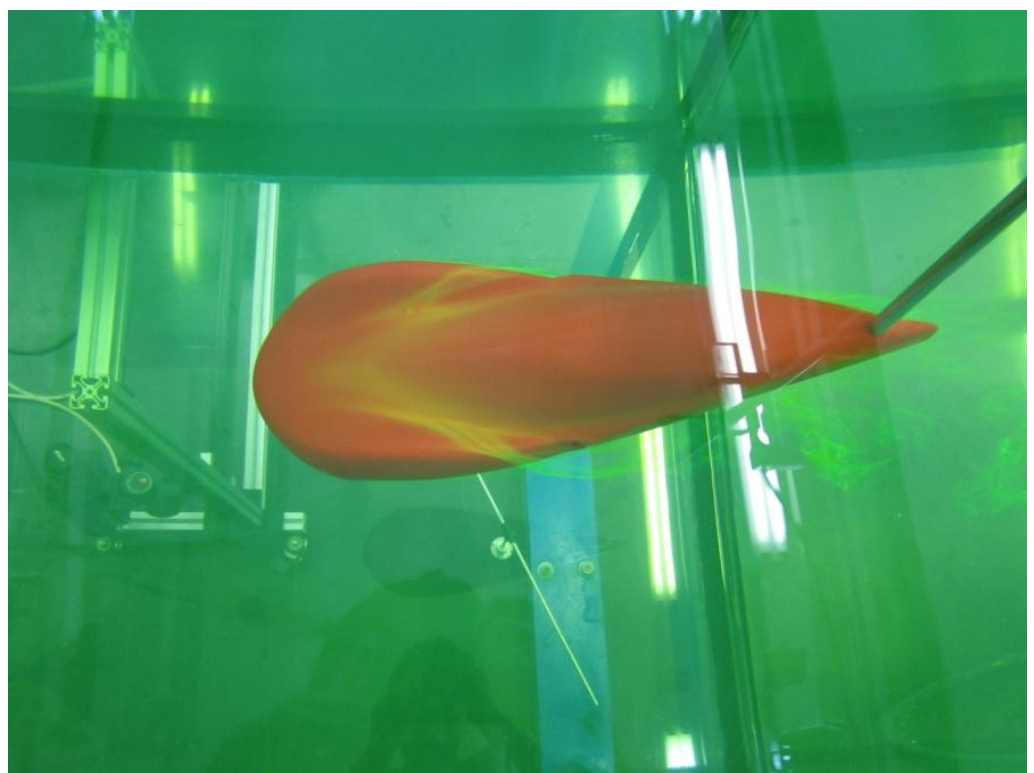

Figura 10-9: Importante concentração de tinta entre a cobertura das rodas e o cockpit. 


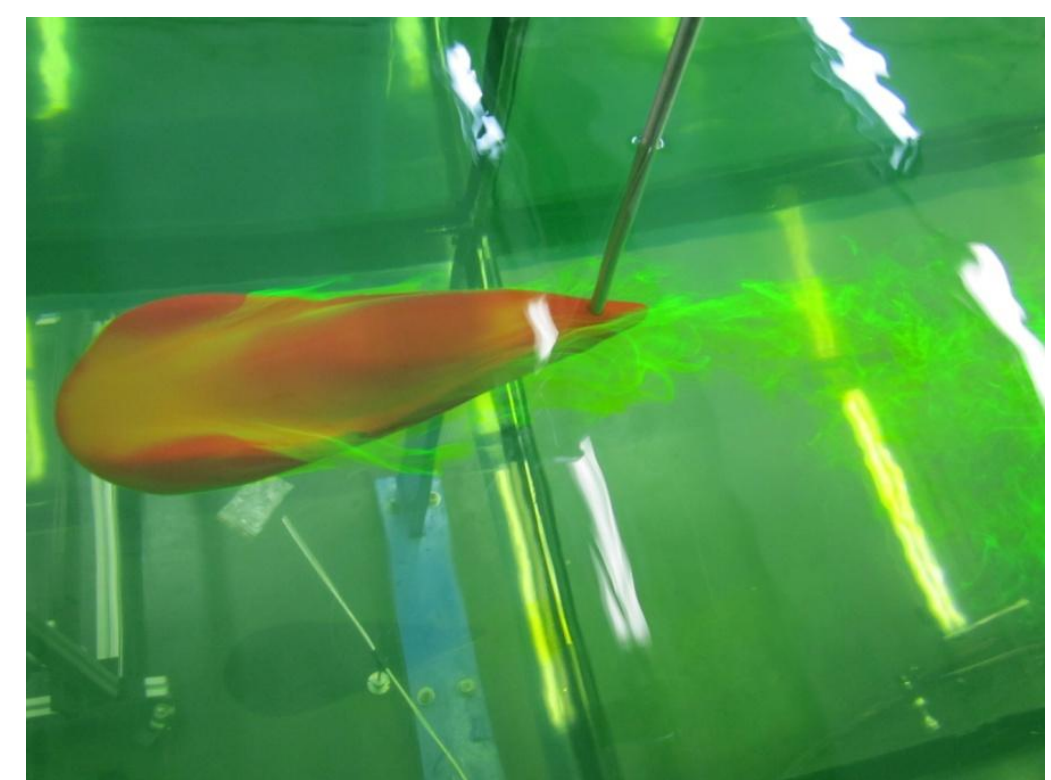

Figura 10-10: O escoamento sobre a cobertura das rodas desce para as laterais.

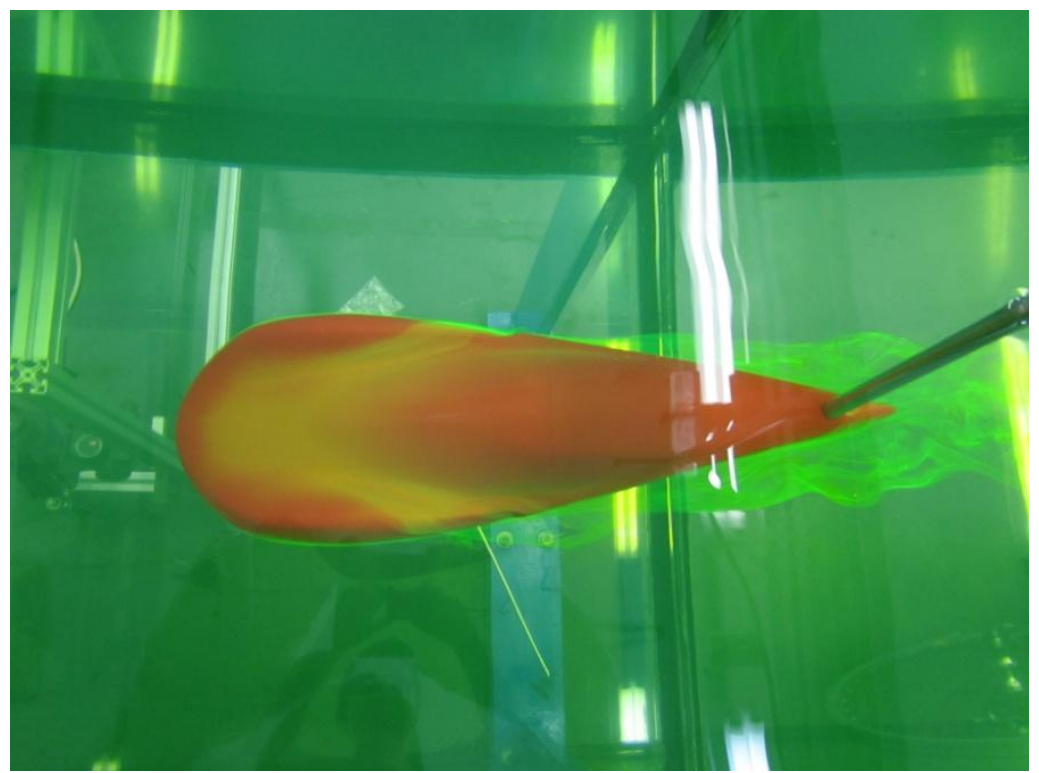

Figura 10-11: A separação num plano horizontal ocorre logo após as entradas de ar.

Os resultados experimentais de visualização do escoamento são em parte semelhantes aos do modelo numérico, especialmente a clara concentração do fluxo entre a caixa de roda e o cockpit, e o fato do fluido descer após passar por essa região (comparação com a Figura 6-15). Esse acúmulo do escoamento próximo a superfície na região frontal confirma a hipótese dessa porção do veículo ser a maior responsável pelas forças de arrasto e sustentação.

Durante a realização dessas fotos notou-se algo que infelizmente é muito difícil de mostrar por figuras paradas. Ao se lançar uma "nuvem" de tinta sobre o veículo percebeu-se 
que ela passava praticamente inalterada pelo modelo, quase como se ele não existisse. Comportamento diferente apresentava uma "nuvem" semelhante ao passar pelo eixo de suporte: suas características eram claramente afetadas. Esse fato confirma a eficiência aerodinâmica da forma da geometria ensaiada. 


\section{DESENVOLVIMENTO DOS ENSAIOS EXPERIMENTAIS}

Esse capítulo visa descrever, de maneira resumida, as dificuldades e soluções encontradas na realização do estudo experimental.

\subsection{Desenvolvimento da montagem experimental}

Pensou-se primeiramente em se utilizar uma célula de carga uniaxial, ou seja, projetada para receber um carregamento de força em uma única direção, pois essa faz parte dos projetos de pesquisa do eng. Cesar Monzu Freire, que estava envolvido na parte experimental do presente trabalho.

Montar o eixo de suporte do modelo diretamente nessa célula de carga provocaria um momento, o que poderia interferir em seu bom funcionamento e, além disso, a força a ser medida era esperada baixa. Por esses motivos foi decidido construir um sistema de alavanca, assim a força aquisitada pela célula de carga seria amplificada e numa única direção. A Figura 11-1 ilustra um esquema desse mecanismo.

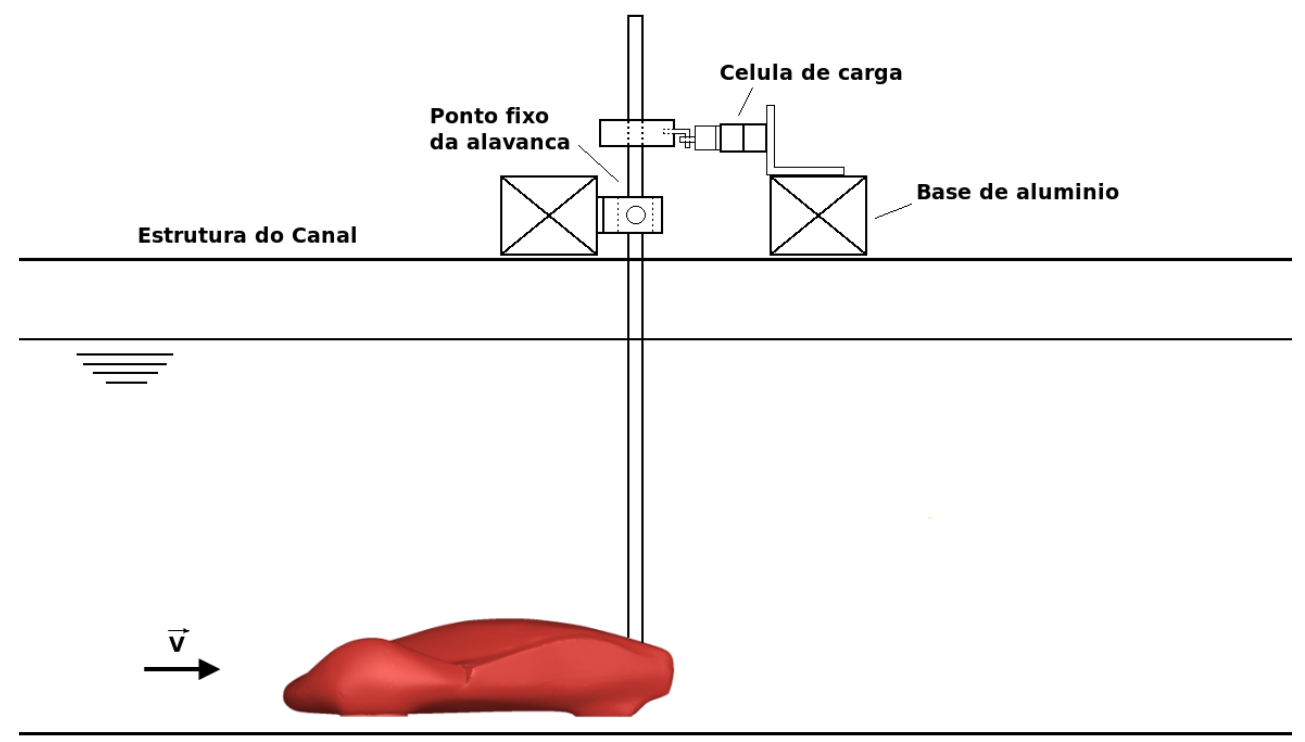

Figura 11-1: Esquema da primeira montagem experimental (sem escala). 

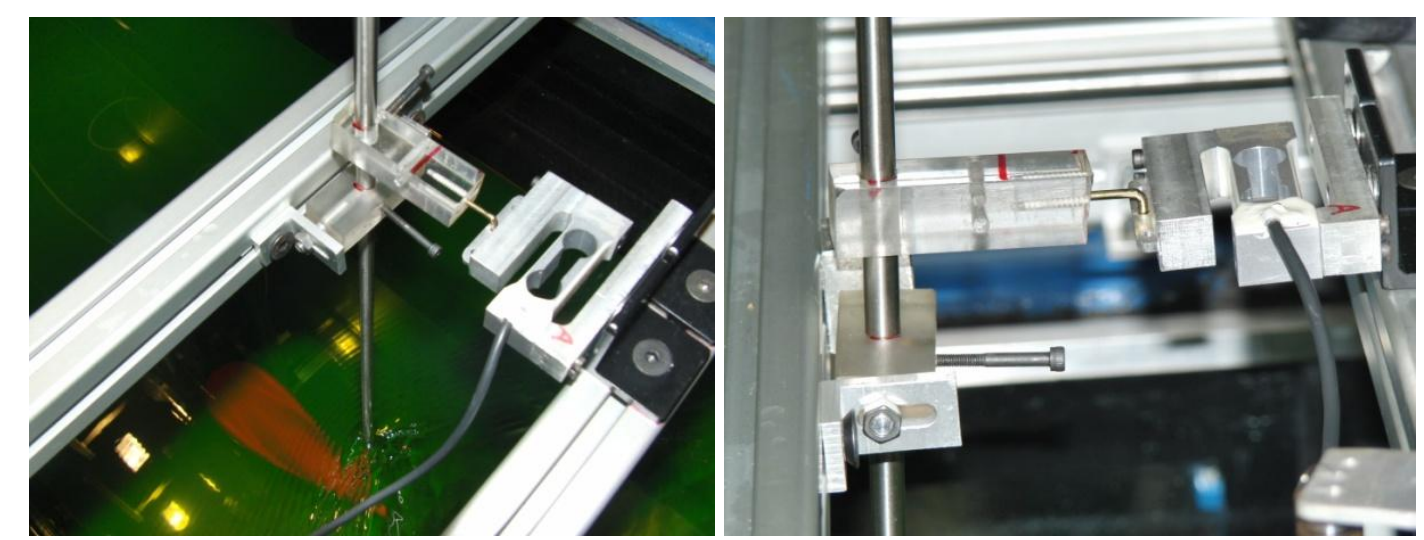

Figura 11-2: Primeira montagem experimental e detalhe do ponto fixo da alavanca e transmissão da força para a célula de carga.

Como pode ser observado na Figura 11-2 o ponto fixo da alavanca foi feito com uma pequena barra retangular de acrílico, preso à base por duas chapas em "L". Nessa peça de acrílico há dois furos longitudinais, nos quais são presos dois parafusos com folga, porém firmes nas chapas em "L". Esses parafusos são os responsáveis pelo giro da alavanca. Existem também nessa peça dois furos transversais, um por onde passa o eixo de suporte do modelo e outro um parafuso para fixar esse eixo.

Para fazer a ligação do eixo de suporte com a célula de carga também foi escolhida uma barra retangular de acrílico. O objetivo de uma peça rígida fazer essa ligação foi eliminar o giro inerente a um mecanismo de alavanca. Entretanto, devido à flexibilidade do sistema que suporta a célula de carga, a rotação do eixo de suporte não foi completamente suprimida, mas muito reduzida se comparada com uma solução anterior de um fio de nylon. Essa peça é composta de dois furos transversais, com os mesmos objetivos que os da peça de rotação, e mais um furo longitudinal, onde foi colocado um parafuso em forma de gancho, para encaixar numa peça de ligação da célula de carga. Os outros dois furos que podem ser vistos na Figura 11-2 não tiveram objetivos no presente trabalho.

O conceito desse mecanismo impede que o modelo esteja muito próximo ao fundo do canal, como o veículo real do solo, pois com o escoamento todo o sistema tenderá a girar no sentido anti-horário, conforme as figuras, e a porção frontal do modelo, se esse começar o 
ensaio muito próximo do fundo, irá encostar no vidro, e o atrito entre o modelo e o canal impedirá que a alavanca transmita a força que água está exercendo.

Para calibrar o mecanismo da alavanca, projetou-se o um sistema de polias, ilustrado na Figura 11-3, onde massas conhecidas (parafusos pesados em balança de precisão e identificados) eram adicionadas ao copo de plástico.

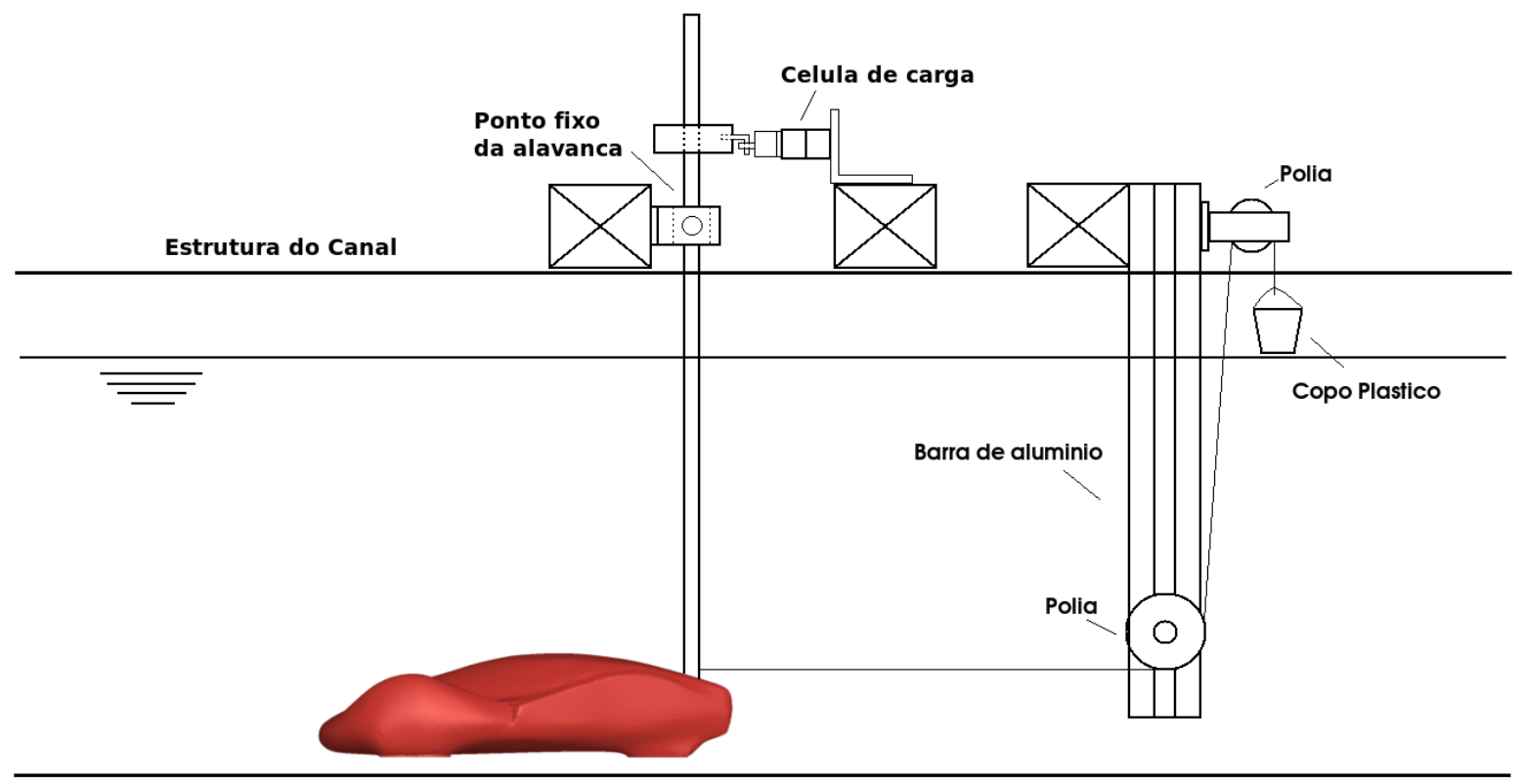

Figura 11-3: Sistema de polias para a calibração do mecanismo de alavanca (sem escala).

Entretanto, durante o procedimento de calibração notou-se que a relação entre o braço maior da alavanca (L) e o braço menor (l) não se mantinha constante, e diminuía conforme se aumentava a massa dentro do copo. Além disso, o parafuso em forma de gancho da peça de ligação entre o eixo e a célula de carga se soltava do sensor com o aumento da massa.

Esses fatos foram creditados ao próprio conceito do sistema, pois mesmo que por um ângulo pequeno, ainda havia o giro da alavanca. Assim quanto mais parafusos eram postos no copo, mais a alavanca girava, e como a célula só media a componente da força na horizontal, e o fio da primeira polia só transmitia força nessa direção o cálculo considerando uma alavanca simples não era mais válido. A Figura 11-4 ilustra essa situação. 


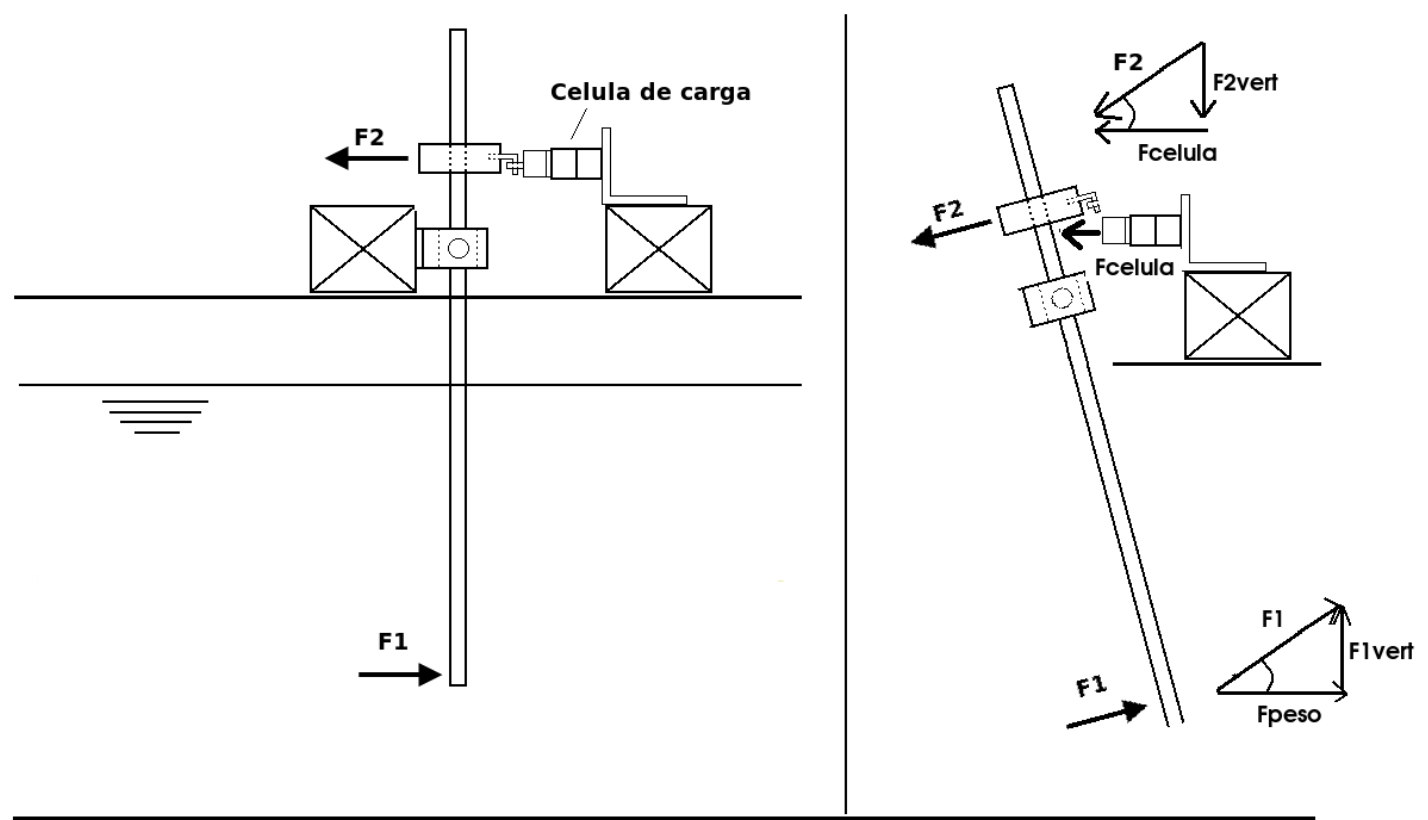

Figura 11-4: Esquema (sem escala) da projeção das forças no mecanismo de alavanca.

Pensou-se então em fazer uma função de calibração: força medida (na célula de carga) em função da força conhecida (peso dos parafusos). Porém não se obtinha uma repetibilidade dos resultados. Acredita-se que esse fato se deveu a uma das polias, mais especificamente a posicionada fora da água, que talvez não girasse na precisão necessária para os ensaios.

Por tudo isso se decidiu trocar todo o sistema, utilizando a célula de carga de 6 componentes, descrita no item 8.3 capítulo 8 “Aparato experimental”, ao invés do mecanismo de alavanca.

\subsection{Desenvolvimento de uma carenagem para o eixo de suporte}

Para diminuir a força de arrasto produzida pelo eixo de suporte do modelo, e evitar vibrações induzidas por vórtices (VIV - Vortex-Induced Vibration), foi feita uma carenagem com o formato de um perfil NACA0030 extrudado. Foram realizados testes sem essa carenagem e observou-se claramente a existência do fenômeno de VIV. Essa peça também foi construída por prototipagem rápida, e passou pelo mesmo procedimento de lixa e pintura que o modelo 
do veículo. Possui $60 \mathrm{~mm}$ de corda, $18 \mathrm{~mm}$ de largura máxima, $290 \mathrm{~mm}$ de altura e $2.5 \mathrm{~mm}$ de espessura. Foram construídos dois anéis com $9.5 \mathrm{~mm}$ de diâmetro e $6 \mathrm{~mm}$ de altura interiores ao perfil nas regiões superior e inferior para a fixação do eixo de suporte.

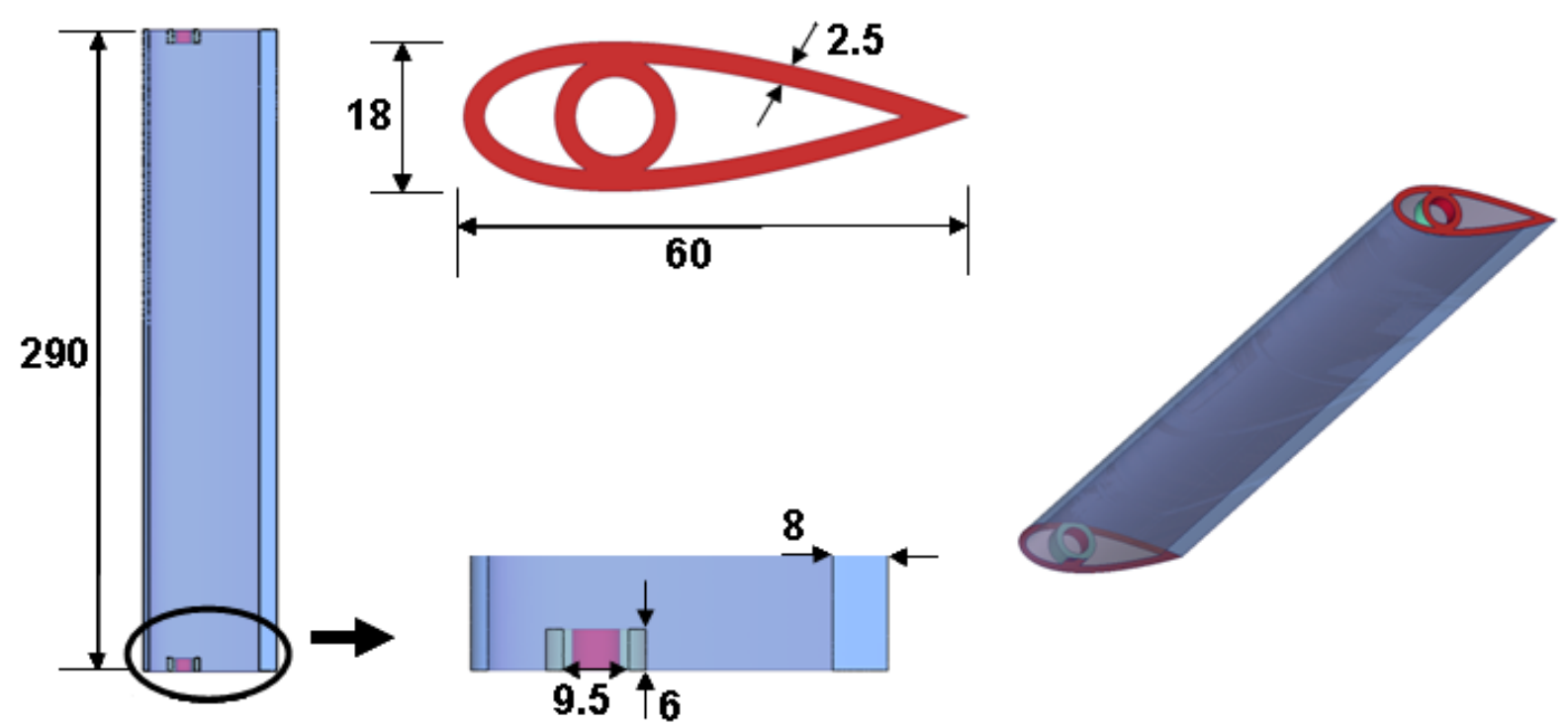

Figura 11-5: Modelo da carenagem com o perfil NACA0030 extrudado.

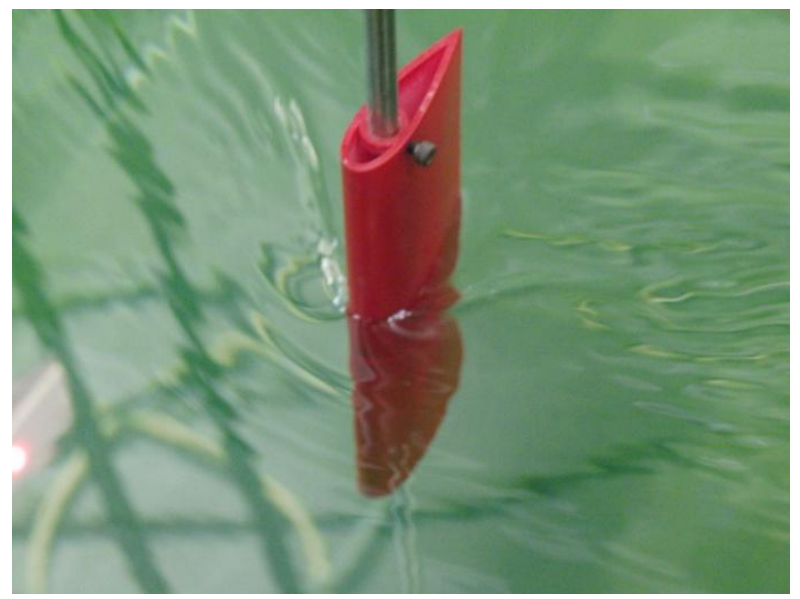

Figura 11-6: Carenagem sendo ensaiada.

Entretanto, se percebeu que com a carenagem havia um desprendimento de vórtices e uma vibração ainda maior do que apenas com o cilindro. Por esse motivo decidiu-se retira-la dos ensaios. Cogitaram-se alguns motivos dessa geometria perturbar mais o escoamento que o cilindro, como por exemplo, a largura ser quase o dobro do diâmetro do eixo, dificuldade em alinhar com o escoamento e ainda o próprio perfil NACA0030 que não se tem informações na literatura sobre o comportamento. 


\section{COMENTÁRIOS FINAIS}

\subsection{Comparação dos resultados numéricos e experimentais}

Após realizados os ensaios experimentais percebeu-se que todos os testes estavam entre apenas dois valores de número Reynolds calculados numericamente $\left(0.9\right.$ e 1.7 x $\left.10^{5}\right)$. Por esse motivo foi decidido realizar mais uma série de simulações com um Reynolds de $1.3 \mathrm{x}$ $10^{5}$

Para facilitar a comparação entre os resultados numéricos e experimentais de $C_{D}$ e $C_{L}$ ambos são mostrados juntos respectivamente na Figura 12-1 e na Figura 12-2.

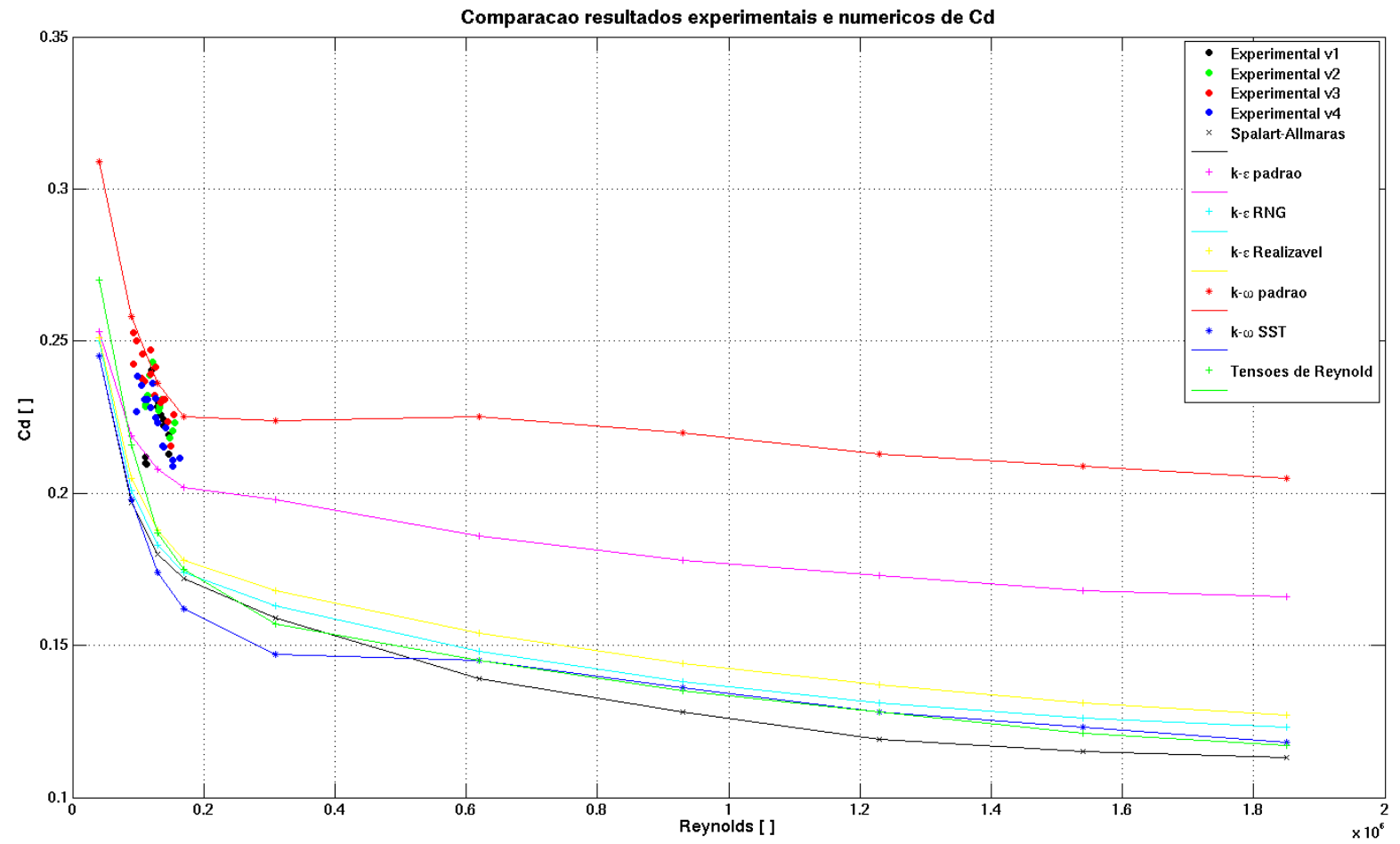

Figura 12-1: Comparação dos resultados experimentais e numéricos de $C_{D}$. 


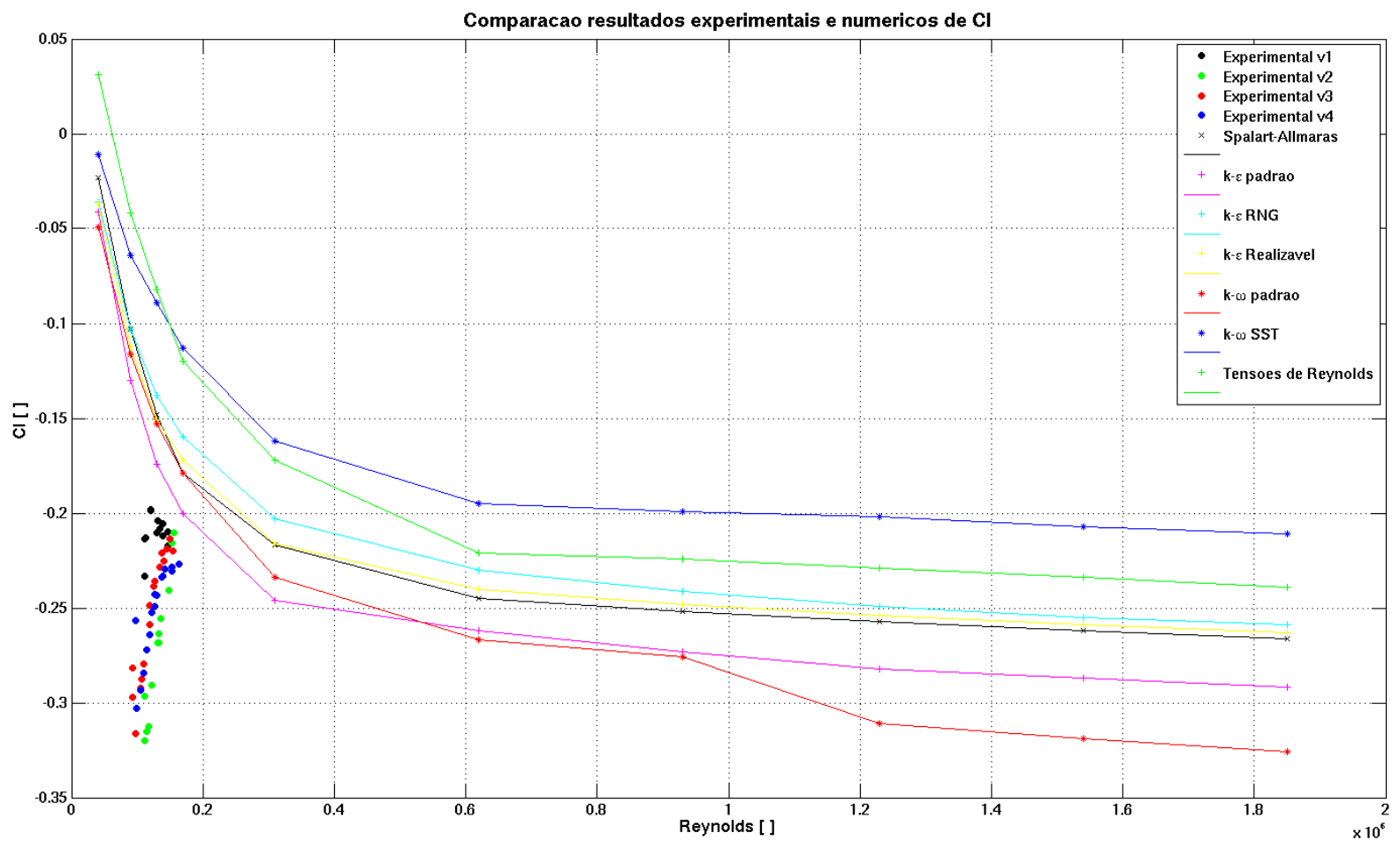

Figura 12-2: Comparação dos resultados experimentais e numéricos de $C_{L}$.

Quando se limita a escala de Reynolds e se introduz as barras de erros experimentais os gráficos ficam:

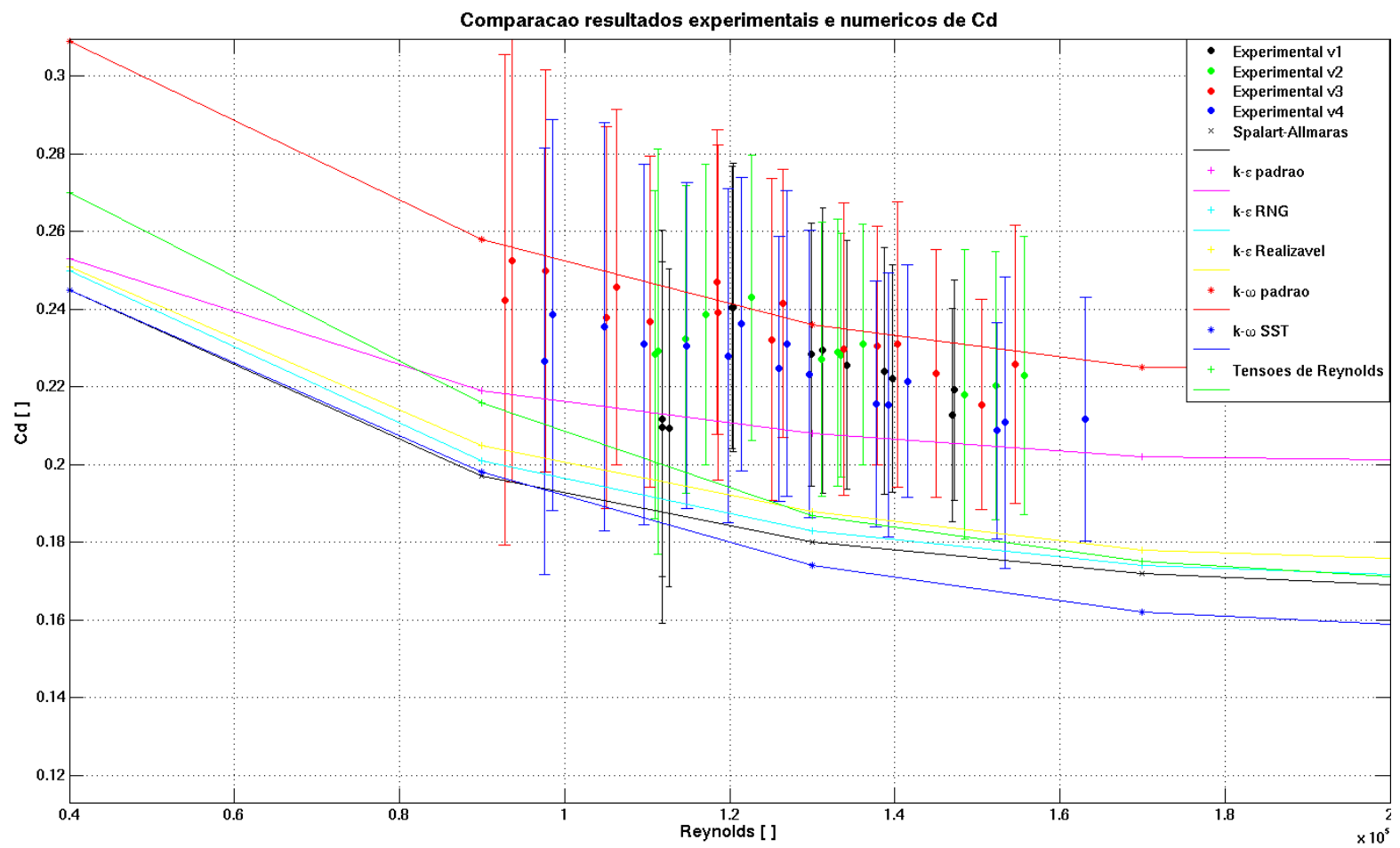

Figura 12-3: Comparação dos resultados de $C_{D}$ experimentais e numéricos com escala de Reynolds reduzida e barras de erros experimentais. 


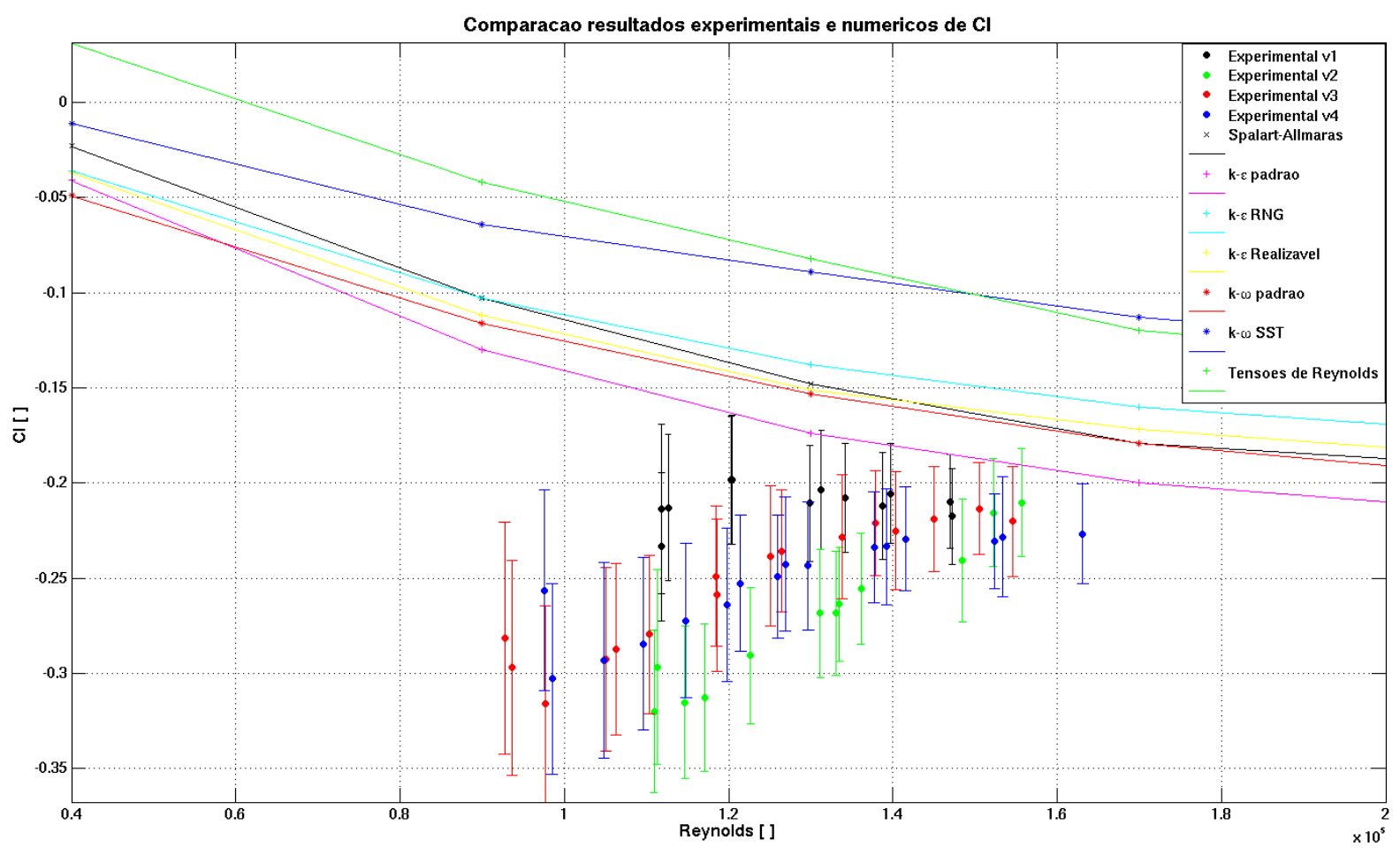

Figura 12-4: Comparação dos resultados de $C_{L}$ experimentais e numéricos com escala de Reynolds reduzida e barras de erros experimentais

Observando a Figura 12-1 e a Figura 12-3 fica claro que os coeficientes experimentais de arrasto acompanham a mesma tendência de queda com o número de Reynolds que os obtidos numericamente. Além disso, os valores obtidos estão dentro do previsto pela simulação, abaixo do modelo k- $\omega$ padrão e acima dos outros. Acredita-se que devido ao ângulo de ataque provocado pelo furo do eixo de suporte os coeficientes de arrasto experimentais tenham sofrido um acréscimo em relação aos que seriam medidos com um furo perfeitamente perpendicular ao modelo.

Dessa forma, apesar do modelo k- $\omega$ padrão ser o mais próximo dos resultados experimentais, como se nota na Figura 12-3, prefere-se não concluir que esse modelo é o melhor para esse tipo de simulação. Conta ainda a favor dessa decisão o fato do k- $\omega$ padrão destoar dos demais modelos, sempre com valores maiores de $\mathrm{C}_{\mathrm{D}}$. 
Já os coeficientes de sustentação experimentais não acompanharam sequer a tendência dos resultados numéricos. Se não bastasse, os valores obtidos caíram completamente fora da faixa dos resultados de simulação. Como citado anteriormente, de acordo com as simulações numéricas a pequena distância entre o veículo e o piso provocou altas velocidades entre as rodas dianteiras, e esse fato é importante para a sustentação negativa do modelo, como observado na Figura 6-14. Devido à montagem, não foi possível manter a mesma curta distância entre o modelo e a superfície inferior do canal de água. A dificuldade em se obter bons valores de $\mathrm{C}_{\mathrm{L}}$ ajuda a explicar o fato de apenas um trabalho citado no capítulo 2 tratar sobre o tema. No item 6.3 foi mostrado que de acordo com os resultados numéricos a força de arrasto é, aproximadamente, $58.5 \%$ originária de forças de pressão e $42.5 \%$ de forças viscosas, enquanto a força de sustentação é $99.5 \%$ de origem de pressão e $0.5 \%$ viscosa, o que também pode ajudar a explicar a diferença entre os resultados experimentais e numéricos.

Observando-se os resultados experimentais e numéricos de visualização do escoamento é possível notar semelhanças, especialmente na região entre a cobertura das rodas e o cockpit. Além disso, há também a tendência do escoamento se dividir ao deixar essa região, indo uma parte para cima e outra para baixo, que também foi observada tanto no ensaio numérico quanto no experimental, como se nota na Figura 12-6. 

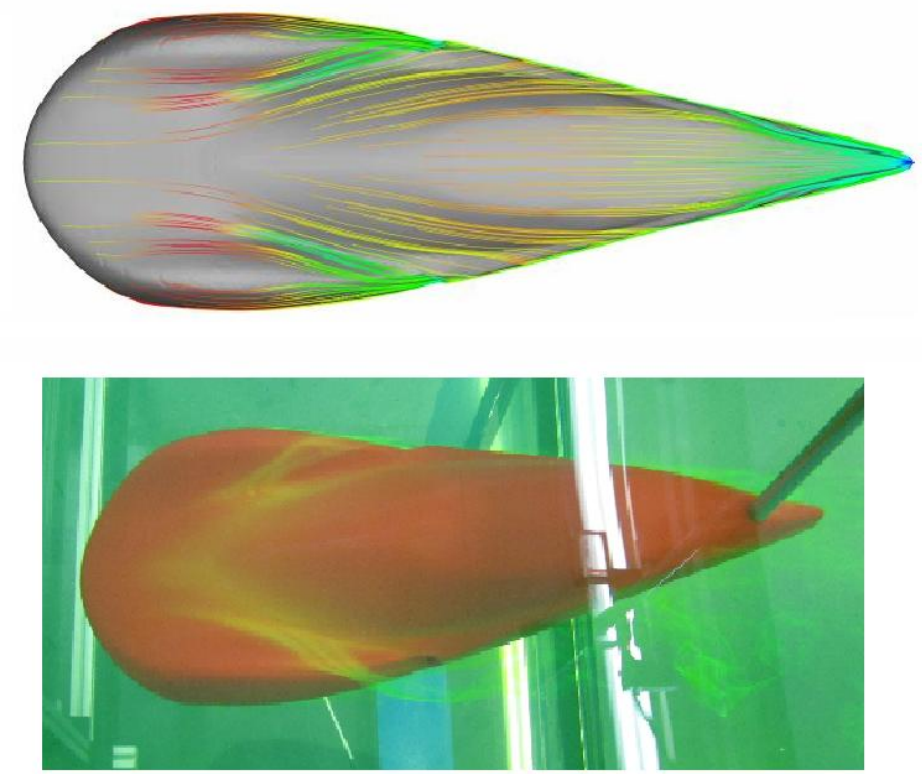

Figura 12-5: Visualização dos resultados numéricos e experimentais do escoamento: vista superior.
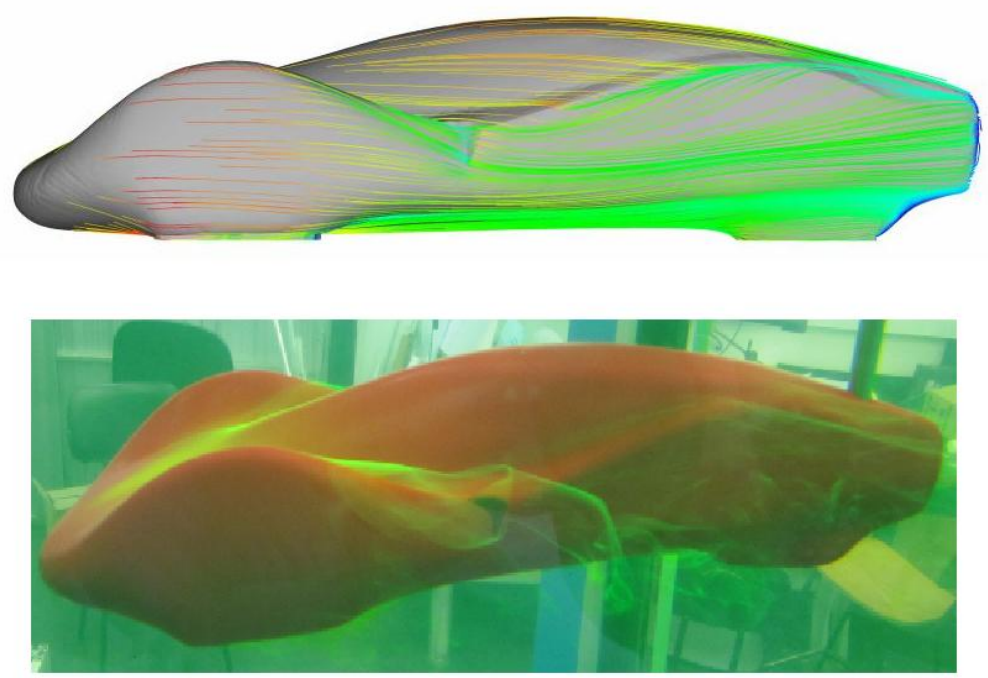

Figura 12-6: Visualização dos resultados numéricos e experimentais do escoamento: vista lateral.

\subsection{Considerações finais}

O presente trabalho permitiu um melhor entendimento do escoamento ao redor de um veículo de competição de milhagem, pois se pode identificar quais características do fluxo influem no arrasto e na sustentação do modelo, tanto de forma numérica quanto experimental. 
Foi feita uma pesquisa na internet para comparar resultados do coeficiente de arrasto de outras equipes, e o resultado é mostrado na Tabela 12-1. Vale ressaltar que as equipes não informam a velocidade ou o número de Reynolds que o $\mathrm{C}_{\mathrm{D}}$ foi avaliado, com exceção da universidade Dalhousie que diz que o cálculo foi feito para $85 \mathrm{~km} / \mathrm{h}(40 \mathrm{~km} / \mathrm{h}$ de velocidade máxima do modelo somado a um vento frontal de $45 \mathrm{~km} / \mathrm{h}$ ).

Tabela 12-1: Exemplos de $\mathrm{C}_{\mathrm{D}}$ de equipes de milhagem.

\begin{tabular}{lcc}
\multicolumn{1}{c}{ Equipe } & $\mathbf{C}_{\mathbf{D}}[\mathbf{]}$ & Fonte \\
\hline California Polytechnic State University, USA & 0,120 & Autopia, 2011 \\
University of British Columbia, USA & 0,110 & Green, 2011 \\
Ryerson University, Canada & 0,088 & Ryerson, 2011 \\
University of Windsor, Canada & 0,120 & ASME, 2011 \\
Isfahan University of Technology, Iran & 0,120 & IUT, 2011 \\
Dalhousie University, Canada & 0,150 & Dalhousie, 2011 \\
Université Laval, Canada & 0,100 & Alerion, 2011
\end{tabular}

Nota-se que os valores da Tabela 12-1 são compatíveis com os coeficientes de arrasto obtidos numericamente para número de Reynolds próximos das condições de competição, em torno de $12.3 \times 10^{5}$ (Tabela 6-1)

Ao se avaliar somente as simulações observou-se que em relação ao coeficiente de arrasto, os modelos de turbulência apresentaram resultados muito semelhantes, com exceção dos modelos k- $\varepsilon$ e k- $\omega$ nas formas padrão, que mostraram valores maiores comparados aos demais. Separando a sustentação no eixo dianteiro e na roda traseira notou-se que as curvas no eixo dianteiro tem praticamente o mesmo comportamento da sustentação global, enquanto 
na roda traseira apresenta valores positivos. Esse fato indica que a região frontal do veículo é responsável por grande parte da sustentação resultante.

A partir dos ensaios virtuais notou-se que a alta velocidade na região inferior do modelo entre as caixas de roda dianteiras é responsável por grande parte da sustentação negativa que o veículo possui, e conseqüentemente, pela parcela do arrasto induzido na produção de vórtices resultantes desse efeito. Entretanto essa mesma sustentação não foi observada nos resultados experimentais. Outra conseqüência dessa velocidade mais alta nessa região, observada no modelo numérico, é o momento de arfagem negativo, já que há uma sustentação positiva no eixo traseiro, provocada pela geometria do modelo na região traseira superior.

A Figura 6-13 (parcela da pressão do arrasto) mostrou que a região frontal do veículo é onde se encontra a maior resistência ao movimento, e também zonas que de baixa pressão que contribuem para um baixo coeficiente de arrasto. Com isso se pode dizer que se fossem solicitadas alterações no projeto desse carro visando o aumento da eficiência aerodinâmica elas deveriam ser pensadas primeiro na região frontal pois, de acordo com os resultados de simulação, é onde as modificações surtiriam maior efeito.

Entre as variações possíveis nessa região pode-se propor o aumento do "ângulo de ataque" do veículo ou o aumento de sua altura visando diminuir as velocidades entre as caixas de roda. Poderia se estudar também a possibilidade de deixar as rodas fora da carenagem, como Buban, Hegna e Zaodney (2010) fizeram, semelhante ao veículo de pesquisa da Volkswagen "Sparmobil” na Figura 12-7, diminuindo a área frontal do modelo. Obviamente mudanças na região traseira não são descartadas, como por exemplo, um estudo da geometria do bordo de fuga. 


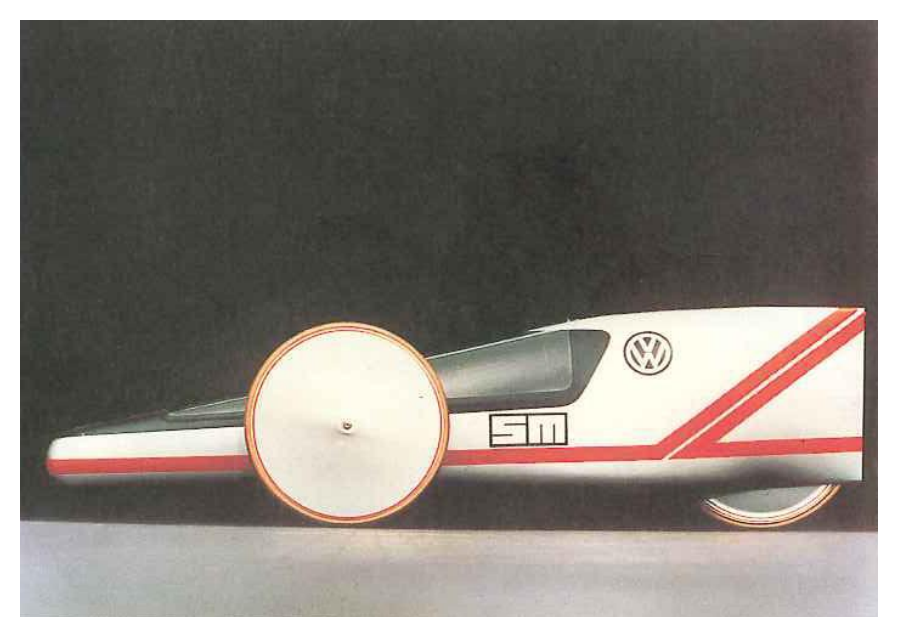

Figura 12-7: Volkswagen "Sparmobil”, $\mathrm{C}_{\mathrm{D}}=0.15, \mathrm{~A}=0.32 \mathrm{~m}^{2}(\mathrm{HUCHO}, 1998$, p. 234).

A variação dos coeficientes de arrasto e sustentação com o número de Reynolds e com diferentes modelos de turbulência também foi realizada. Nos resultados numéricos esses coeficientes diminuíram com o aumento do número de Reynolds, como esperado. Os ensaios experimentais também mostraram que o $\mathrm{C}_{\mathrm{D}}$ diminui com o acréscimo de Reynolds, entretanto o $\mathrm{C}_{\mathrm{L}}$ aumentou além de ficar numa faixa completamente fora dos resultados numéricos.

Infelizmente os ensaios experimentais ficaram numa faixa de número de Reynolds muito baixa, além disso, um ângulo de ataque negativo, mesmo que pequeno, no modelo durante os testes provocou, muito provavelmente, um aumento de $C_{D}$. Acredita-se que esse ângulo e o fato do modelo estar posicionado relativamente distante da parte inferior do canal sejam os responsáveis pela discrepância entre os resultados numéricos e experimentais de $C_{L}$.

O presente trabalho foi desenvolvido na ordem em que está apresentado: primeiro os ensaios virtuais e depois os testes no laboratório. Isso porque o autor possuía experiência com simulações numéricas e um objetivo da realização dos ensaios experimentais era que ele se familiarizasse com os procedimentos. Entretanto seria melhor realizar primeiro os ensaios em laboratório, pois é mais fácil reproduzir as condições ambientais no modelo numérico do que o contrário, e assim a comparação entre ambos pode ser melhor feita.

Por fim, pode-se afirmar que os objetivos do trabalho foram atingidos, já que tanto de forma numérica quanto experimental ficou claro o comportamento do escoamento ao redor do 
veículo de milhagem, os coeficientes de arrasto e sustentação foram obtidos e foi avaliado o comportamento deles em relação ao número de Reynolds dessas duas maneiras.

\subsection{Sugestões para futuros trabalhos}

Durante o desenvolvimento desse trabalho percebeu-se vários assuntos que seriam interessantes para o complemento de um projeto aerodinâmico de um veículo de milhagem, ou até mesmo de aerodinâmica externa veicular em geral.

No tocante à parte numérica sugere-se:

- Um estudo mais aprofundado do tamanho do túnel virtual, das dimensões dos subdomínios de refinamento, e das arestas dos elementos.

- Verificação dos ganhos (tempo de simulação e qualidade dos resultados) utilizando malha hexaédrica.

- Análises em regime transiente, especialmente utilizando o modelo LES (Large Eddy Simulation).

- Estudo da influência do software utilizado: comparação entre diferentes pacotes de CFD.

- Estudo da influência do Hardware empregado: comparação entre diferentes processadores, e até mesmo o número de CPU's de um mesmo modelo.

Em relação à parte experimental seriam interessantes os seguintes trabalhos:

- O projeto de uma balança aerodinâmica a qual fosse possível ficar imersa na água. Assim as forças resultantes de modelos imersos no canal de água, não só automobilísticos mas também de outras áreas como petróleo e gás, aeronáutico e naval poderiam ser medidas com mais precisão.

- Um sistema para a medição das pressões na superfície dos modelos no canal de água. 
- Um método para se aumentar o número de Reynolds dos modelos, sem que o acréscimo da velocidade do canal gerasse instabilidade. Por exemplo, um sistema de tração no qual o modelo se movimentasse em relação ao canal, juntamente com os aparatos de medições.

- Visualização do escoamento ao redor do modelo utilizando técnicas de PIV (Particle Image Velocimetry).

- Realização do ensaio num túnel de vento com uma balança aerodinâmica.

Como complemento de um projeto aerodinâmico de um veículo de milhagem os seguintes assuntos podem ser estudados:

- Comparação entre diferentes geometrias de carenagem do veículo como por exemplo: rodas descobertas, alterações no bordo de fuga, da altura em relação ao solo e conceitos completamente diferentes.

- Experimentos e simulações referentes ao posicionamento das entradas de ar e o resfriamento do motor propriamente dito. 


\section{REFERÊNCIAS}

3D PRINTERS: Dimension Elite 3D Specs: Apresenta especificações técnicas da impressora 3D Dimension Elite. Disponível em: <http://www.dimensionprinting.com/3dprinters/printing-productspecs-elite.aspx > . Acesso em 06 jan.2011.

ALERION Supermilieage. Apresenta informação sobre o coeficiente de arrasto do veículo de milhagem da equipe da Universidade de Laval. Disponível em: <http://alerionsupermileage.ca/blog4.php/2009/11/04/body>. Acesso em 20 fev. 2011.

ANGELO, E.; ANGELO, G.; BARRIOS, D. B. Estudo numérico da influência dos elementos interiores à caixa de roda na aerodinâmica de um veículo de passeio. In: SIMPÓSIO INTERNACIONAL DE ENGENHARIA AUTOMOTIVA, 12., 2009, São Paulo. Anais...

ANSYS FLUENT. Ansys Fluent Theory Guide: Version 12.0. Canonsburg: Ansys Inc. 2009.

*. Ansys Fluent User's Guide: Version 12.0. Canonsburg: Ansys Inc. 2009a.

ASME Digital Library. Apresenta informação sobre o coeficiente de arrasto do veículo de milhagem da equipe da Universidade de Windsor. Disponível em: <http://scitation.aip.org/getabs/servlet/GetabsServlet?prog=normal\&id=ASMECP002009043 826002189000001\&idtype=cvips\&gifs=yes\&ref=no >. Acesso em: 20 fev. 2011.

ÁSSI, G. R. S. Estudo Experimental do Efeito de Interferência no Escoamento ao Redor de Cilindros Alinhados. 2005. 250 f. Dissertação (Mestrado em Engenharia) - Escola Politécnica da Universidade de São Paulo, São Paulo, 2005.

ATI Force / Torque Sensor: Mini40: Apresenta as especificações técnicas da célula de carga Mini 40 ATI. Disponível em <http://www.ati-ia.com/products/ft/ft_models.aspx?id=Mini40>. Acesso em 30 jan. 2011.

AUTOPIA: Apresenta informação sobre o coeficiente de arrasto do veículo de milhagem da equipe da Universidade Politécnica Estadual da Califórnia, USA. Disponível em:

<http://www.wired.com/autopia/2010/02/take-that-chevy-volt-cal-poly-car-gets-27523mpg/>. Acesso em 20 fev. 2011.

BLAZEK, J. Computational Fluid Dynamics: Principles and Applications. $1^{\text {st }}$ edition. Baden-Daettwil: Elsevier, 2001. 440 p. 
BURBAN, M. P.; HEGNA, H. A.; ZAVODNEY, L. D. Role of CFD in Undergraduate Research in Design of a Supermileage Competition Vehicle. In: ASSE NORTH CENTRAL SECTION CONFERENCE, 2008. Proceedings of..., American Society of Engineering Education, 2008. 10 p.

BUSCARIOLO, F. F. Estudo de diferentes tipos de solo de túnel de vento através de simulação numérica. 2009. 130 f. Dissertação (Mestrado em Engenharia) - Escola Politécnica, Universidade de São Paulo, São Paulo, 2009.

CANCIGLIERI JUNIOR, O.; SELHORST JUNIOR, A.; IAROZINSKI NETO, A. Processos de prototipagem rápida por deposição ou remoção de material na concepção de novos produtos - uma abordagem comparativa. In: ENCONTRO NACIONAL DE ENGENHARIA DE PRODUÇÃO, 27., 2007, Foz do Iguaçu. Anais...

CARREGARI, A. L. Estudo do Escoamento de Ar sobre a Carroceria de um Ônibus usando um Programa de CFD e Comparação com Dados Experimentais. 2006. 125 f. Dissertação (Mestrado em Engenharia) - Escola de Engenharia de São Carlos, Universidade de São Paulo, São Carlos, 2006.

CHUNG, T. J. Computational Fluid Dyanamics. $1^{\text {st }}$ printing. Cambridge: Cambridge University Press, 2002. 1012 p.

DALHOUSIE: Apresenta informação sobre o coeficiente de arrasto do veículo de milhagem da equipe da Universidade de Dalhousie. Disponível em <http://poisson.me.dal.ca/ dp_09_16/>. Acesso em 20 fev. 2011.

FERREIRA, T. A. Simulação numérica de ambientes com o insuflamento de ar frio pelo piso: estudo de sensibilidade de modelos de radiação e de densidade do ar. 2006. $121 \mathrm{f}$. Monografia (Trabalho de Formatura em Engenharia) - Escola Politécnica da Universidade de São Paulo, São Paulo, 2006.

FREIRE, C. M. Um estudo experimental sobre Vibrações Induzidas por Vórtices com dois graus de liberdade. 2009. 268 f. Monografia (Trabalho de Formatura em Engenharia) Escola Politécnica da Universidade de São Paulo, São Paulo, 2009.

GAGNON, L.; RICHARD, M.J., 2010. Parallel CFD of a prototype car with OpenFOAM. In: OPENFOAM WORKSHOP, 5., 2010, Gothenburg, Sweden. 13 p.

GAGNON, L. Publicação eletrônica [mensagem pessoal]. Mensagem recebida por <tales.ferreira@volkswagen.com.br>em 11 ago. 2010. 
GREEN Car Congress. Apresenta informação sobre o coeficiente de arrasto do veículo de milhagem da equipe da Universidade de British Columbia. Disponível em:

<http://www.greencarcongress.com/2006/06/university_of_b.html> . Acesso em 20 fev. 2011.

HOFFMAN, A. K.; CHIANG, S. T. Computational Fluid Dynamics vol. 3. $1^{\text {st }}$. printing. Wichita: Engineering Education System, 2000 . 175 p.

HUCHO, W. H. (Editor). Aerodynamics of Road Vehicles: From Fluid Mechanics to Vehicle Engineering. Fourth edition. Warrendale: SAE International, 1998. 918 p.

IUT Supermileage Team. Apresenta informação sobre o coeficiente de arrasto do veículo de milhagem da equipe da Universidade de Tecnologia de Isfahan. Disponível em: <http://www.iutsupermileage.com/2007/12/car.html>. Acesso em 20 fev. 2011.

KORKISCHKO, I. Investigação experimental e simulação numérica do escoamento ao redor de um modelo automobilístico: corpo de Ahmed. 2006. 100 f. Monografia (Trabalho de Formatura em Engenharia) - Escola Politécnica da Universidade de São Paulo, São Paulo, 2006.

LANFRIT, M. Best practice guidelines for handling Automotive External Aerodynamics with FLUENT. Darmstadt, Germany. 2005. 14 p. Disponível em :<www.fluentusers.com>. Acesso em 20 de maio 2010.

LOMAX, H. PUlliAM, T. H., ZINGG, D. W. Fundamentals of Computational Fluid Dynamics. 1999, 267 p.

MARATONA Universitária da Eficiência Energética 2010. Apresenta os resultados da competição de milhagem brasileira desde 2004 a 2010. Disponível em <http://www.maratonadaeficiencia.com.br/>. Acesso em 2 ago.2010.

MUNSON, B. R.; YOUNG, D. F.; OKIISHI, T. H. Fundamentos da Mecânica dos Fluidos. Tradução da 4a edição americana. São Paulo: Editora Edgard Blücher, 2004.571 p.

PEB - Programa de Engenharia Biomédica. Apresenta informações sobre análise de sinais e ruídos. Disponível em <http://www.peb.ufrj.br/cursos/COB781/Ref-02.pdf>. Acesso em 11 jan. 2011.

POPE, S. B. Turbulent Flows. Cambridge: Cambridge University Press, 2000. 749 p. 
PORTAL Célula de Carga. Apresenta informações sobre os princípios de funcionamento de células de carga. Disponível em < http://www.celuladecarga.com.br//>. Acesso em 09 jan. 2011.

REINO UNIDO. ESDU, v. 1, n. 80024. Dispõe sobre correções para cálculo de grandezas medidas em escoamentos confinados ao redor de corpos rombudos. ESDU. Blockage corrections for bluff bodies in confined flows. 1998.

RYERSON Supermileage: Apresenta informações sobre o coeficiente de arrasto do veículo de milhagem da equipe da Universidade de Ryerson. Disponível em: $<$ http://ryersonsupermileage.wikispaces.com/Ryerson+Supermilage+2009-2010>. Acesso em 20 fev. 2011.

SHELL Eco-marathon. Apresenta dados sobre a Shell Eco-marathon, como história, regras e recordes. Disponível em < http://www.shell.com/home/content/ecomarathon/>. Acesso em 11 ago. 2010.

SAE Collegiate Design Series: Supermileage. Apresenta dados sobre a competição de milhagem organizada pela SAE. Disponível em:

<http://students.sae.org/competitions/supermileage/>. Acesso em 11 ago. 2010.

SIEMENS. Apresenta informações sobre o funcionamento do medidor de vazão instalado no canal de água do NDF. Disponível em:

<http://cache.automation.siemens.com/dnl/jIzNDQ3MwAA_17532493_HB/SFIDKPS027W4 02.pdf>. Acesso em 30 jan. 2011.

TANNEHIL, J. C; ANDERSON, D. A.;. PLETCHER, R. H. Computational Fluid Mechanics and Heat Transfer. 2a. edição. Taylor \& Francis. 1997. 792p.

TENNEKES, H.; LUMLEY, J. L. A First Course in Turbulence. Massachusetts: The MIT Press. 1972. $300 \mathrm{p}$.

THE STRAIN Gage. Apresenta informações sobre o funcionamento de extensômetros. Disponível em: < http://www.omega.com/literature/transactions/volume3/strain2.html>. Acesso em 09 jan. 2011.

TOLEDO, D. Publicação eletrônica [mensagem pessoal]. Mensagem recebida por <tales.ferreira@volkswagen.com.br>em 06 abr. 2010. 
VERSTEEG, H.K.; MALALASEKERA, W. An introduction to computational fluid dynamics: The finite volume method. New York: Longman Scientific \& Technical, 1995. $257 \mathrm{p}$.

VUOLO, J. H. Introdução à Teoria de Erros. 3a. edição. São Paulo: Instituto de Física da Universidade de São Paulo, 1999. 68p.

WILCOX, D. C. Turbulence Modeling for CFD. 2a.edição. La Cañada, California: DCW Industries, Inc. 1994. 460 p. 
Apêndices 


\section{A. Códigos de MatLab para o tratamento dos sinais experimentais}

Foram feitos, com o auxílio do eng. Cesar Monzu Freire, dois códigos em linguagem MatLab para o processamento dos sinais experimentais. No primeiro eram lidos os arquivos resultantes de cada uma das quatro séries de medições, calculados os coeficientes de arrasto e sustentação, os respectivos erros e então gravado um arquivo com o resumo da série. Além disso, eram feitas algumas figuras para análises preliminares dos resultados. Como exemplo, abaixo segue o código da $1^{\mathrm{a}}$ rodada de testes.

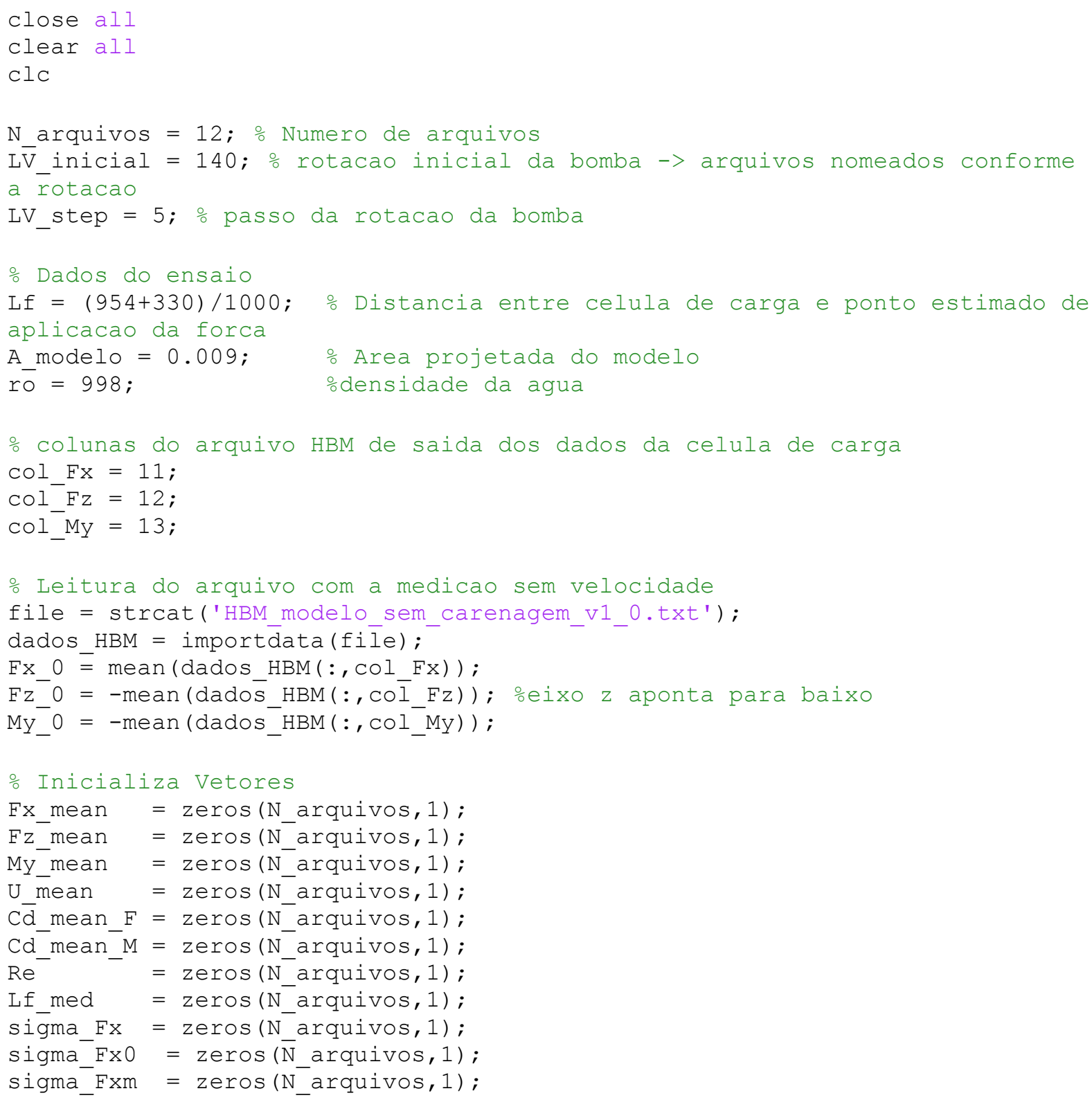




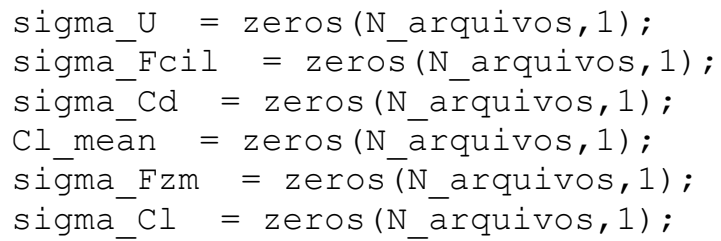




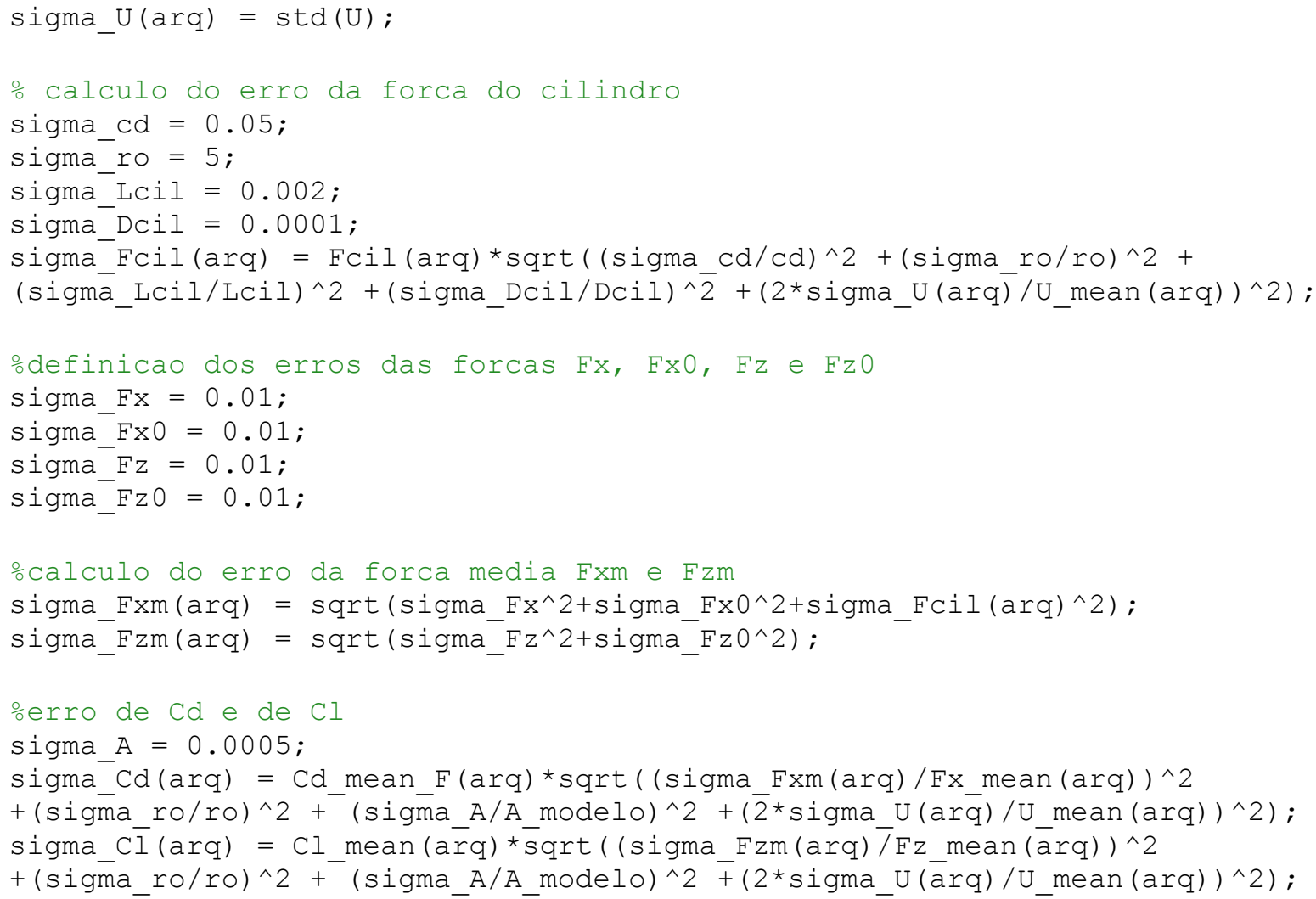

end

응믕 Figuras para análises preliminares 응응 figure 


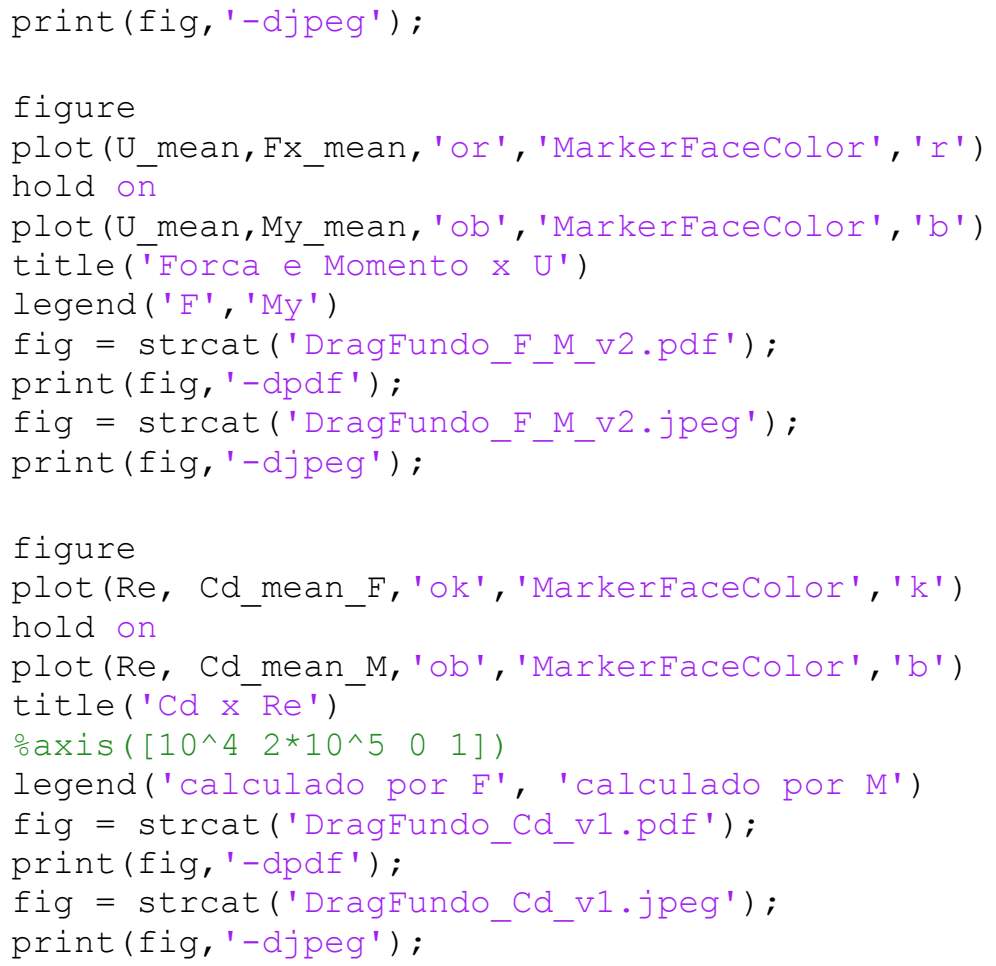


Depois de feito o tratamento acima para as quatro séries de medições os arquivos de resumo dos eram lidos com o auxílio do código de MatLab abaixo. Nele foram calculadas as correções de blocagem e também feitos os gráficos que constam no corpo do texto.

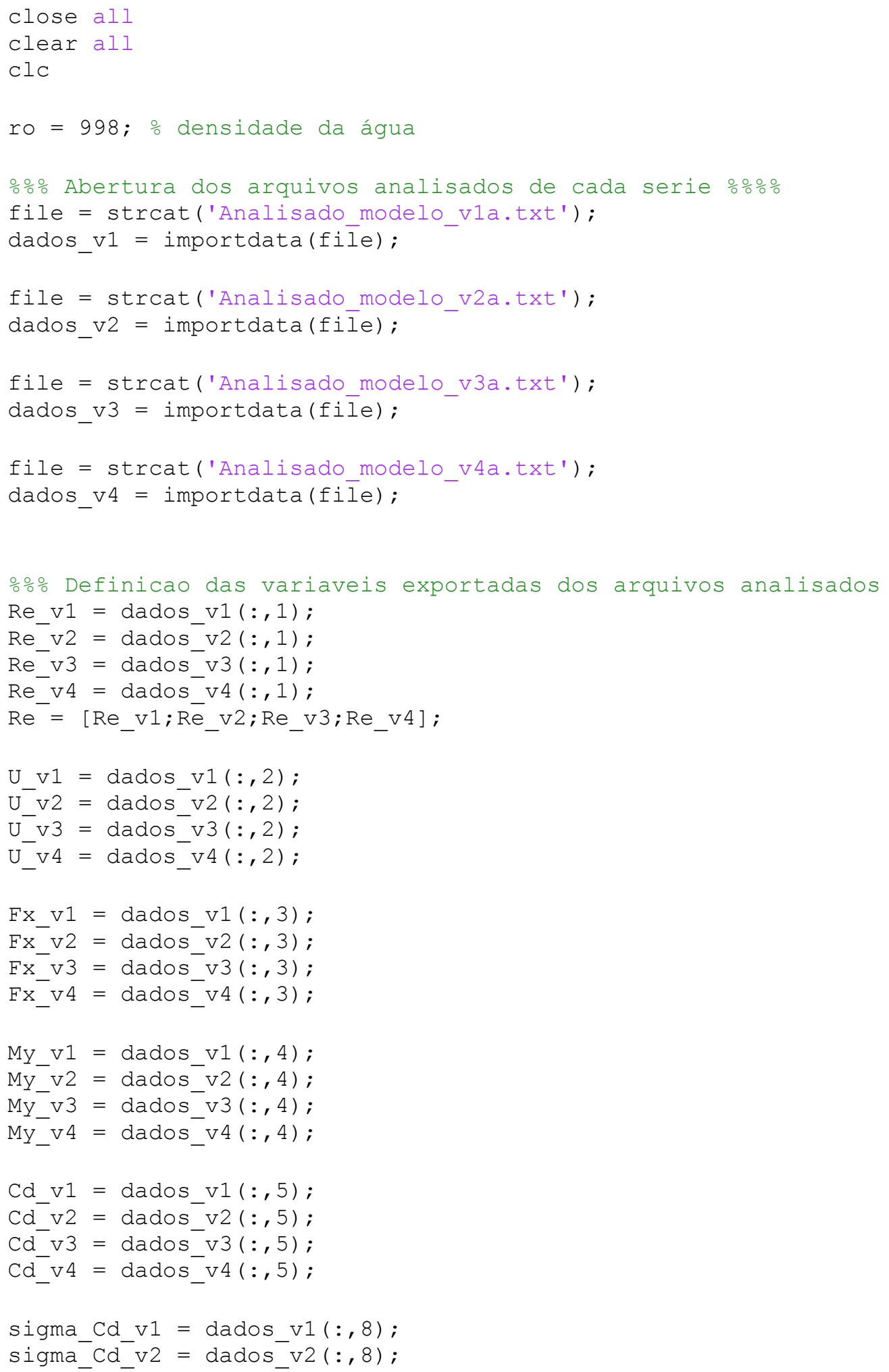




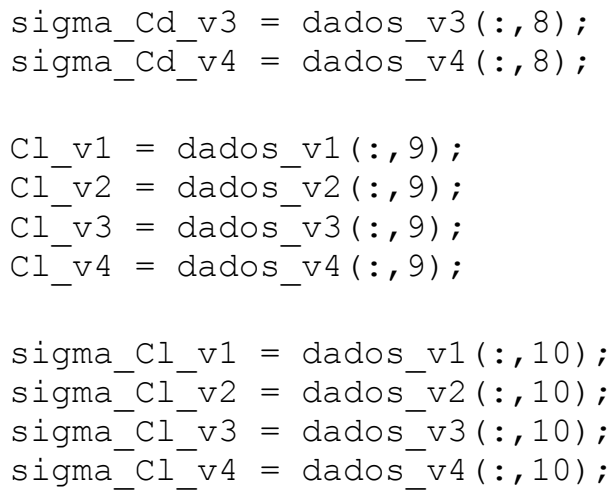

\section{응응응응응 FIGURAS 응응응응 $\frac{0}{0} \circ \frac{0}{0}$}

Resultados de Cd

figure

plot(Re_v1,Cd_v1_bloc, 'ob', 'MarkerFaceColor', 'b') 
grid on

hold on

plot(Re v2, Cd v2 bloc,'^m', 'MarkerFaceColor', 'm')

hold on

plot(Re_v3,Cd_v3_bloc,'sg', 'MarkerFaceColor', 'g' )

hold on

plot(Re v4, Cd v4 bloc,'dk', 'MarkerFaceColor', 'k')

title('Resultādos experimentais de Cd', 'fontsize', 14, 'FontWeight', 'bold')

xlabel ('Reynolds [ ] ','fontsize', 12, 'FontWeight', 'bold')

ylabel ('Cd [ ] ', 'fontsize', 12, 'FontWeight', 'bold')

set (gca, 'fontsize', 12, 'FontWeight', 'bold')

legend ('v1', 'v2', 'v3', 'v4')

fig = strcat('Resultados Cd.pdf');

print (fig, '-dpdf');

fig = strcat('Resultados Cd.jpeg');

print (fig,' '-djpeg');

- Comparacao de cds sem e com a correcao de blocagem

figure

plot (Re_v1, Cd_v1, 'ob')

grid on

hold on

plot(Re_v1,Cd_v1_bloc,'ob', 'MarkerFaceColor', 'b')

hold on

plot (Re_v2, Cd_v2,' ^m')

hold on

plot (Re_v2,Cd_v2_bloc,'^m', 'MarkerFaceColor', 'm')

hold on

plot (Re_v3, Cd_v3, 'sg')

hold on

plot (Re_v3,Cd_v3_bloc,'sg', 'MarkerFaceColor', 'g')

hold on

plot ( $R e$ v4, Cd v4, 'dk')

hold on

plot (Re_v4,Cd_v4_bloc,'dk', 'MarkerFaceColor', 'k')

legend ('v1 SC', 'V1', 'v2 SC', 'v2', 'v3 SC', 'v3', 'v4 SC', 'v4')

title('Efeito da blocagem no Cd', 'fontsize', 14,'FontWeight', 'bold')

xlabel ('Reynolds [ ] ', 'fontsize', 12, 'FontWeight', 'bold')

ylabel ('Cd [ ] ','fontsize', 12,'FontWeight', 'bold')

set (gca, 'fontsize', 12, 'FontWeight', 'bold')

fig = strcat('Cd com e sem blocagem.pdf');

print (fig,' '-dpdf');

fig = strcat('Cd com e sem blocagem.jpeg');

print (fig,' '-djpe ' $\left.^{\prime}\right)$;

- Resultados de $\mathrm{Cl}$

figure

plot(Re v1, Cl v1 bloc,'ob', 'MarkerFaceColor','b')

grid on

hold on

plot (Re_v2,Cl_v2_bloc,'^m', 'MarkerFaceColor', 'm' )

hold on

plot (Re_v3, Cl_v3_bloc,'sg', 'MarkerFaceColor', 'g')

hold on

plot (Re_v4,Cl_v4_bloc,'dk', 'MarkerFaceColor','k')

title('Resultādos experimentais de Cl', 'fontsize', 14, 'FontWeight', 'bold')

xlabel ('Reynolds [ ] ', 'fontsize', 12, 'FontWeight', 'bold')

ylabel ('Cl [ ] ','fontsize', 12,'EontWeight', 'bold')

set (gca, 'fontsize', 12, 'FontWeight', 'bold')

legend ('v1', 'v2', 'v3', 'v4') 


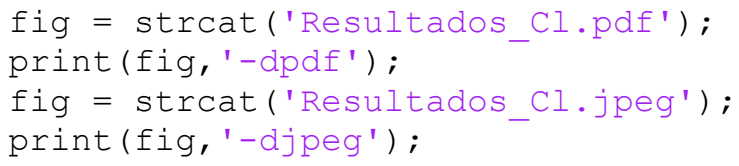


grid on

hold on

errorbar(Re_v2, Cl_v2_bloc, sigma_Cl_v2,'^m', 'MarkerFaceColor', 'm') hold on

errorbar(Re_v3, Cl_v3_bloc, sigma_Cl_v3,'sg', 'MarkerFaceColor', 'g') hold on

errorbar(Re_v4, Cl_v4_bloc, sigma_Cl_v4,'dk', 'MarkerFacecolor', 'k') title('Resultados experimentais de $\mathrm{C} \bar{l}$ com margen de

erro', 'fontsize', 14, 'FontWeight', 'bold')

xlabel ('Reynolds [ ] ', 'fontsize', 12, 'FontWeight', 'bold')

ylabel('Cl [ ] ','fontsize',12, 'FontWeight', 'bold')

set (gca, 'fontsize', 12, 'FontWeight', 'bold')

legend ('v1', 'v2', 'v3', 'v4')

fig = strcat ('Resultados $\mathrm{Cl}$ com erro.pdf');

print (fig, '-dpdf') ;

fig = strcat('Resultados_Cl_com_erro.jpeg') ;

print (fig,' '-djpeg');

응응응응 Comparacao com os resultados numericos de $\mathrm{Cd}$ 응 $\frac{0}{0} \% \frac{0}{0}$

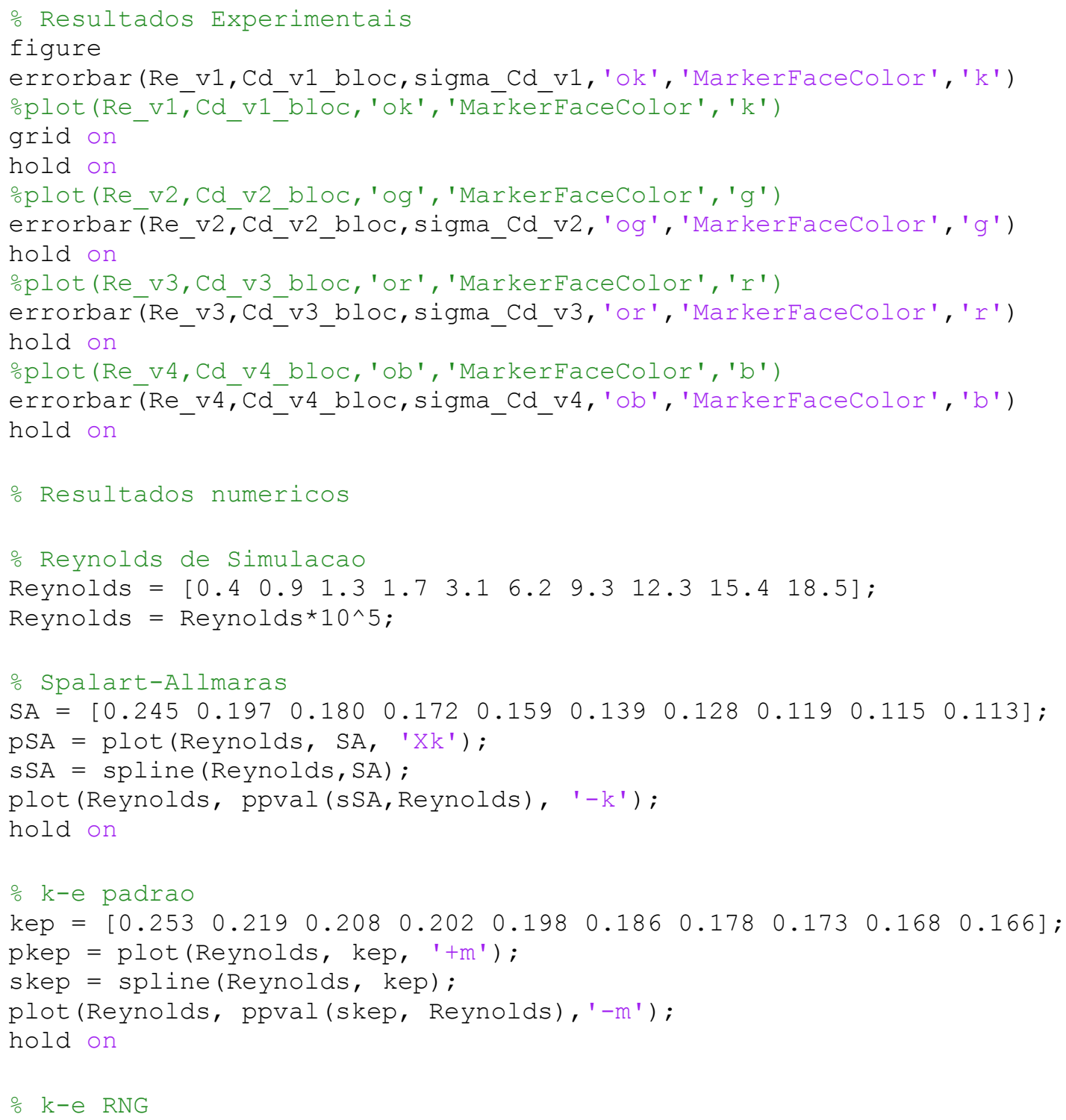




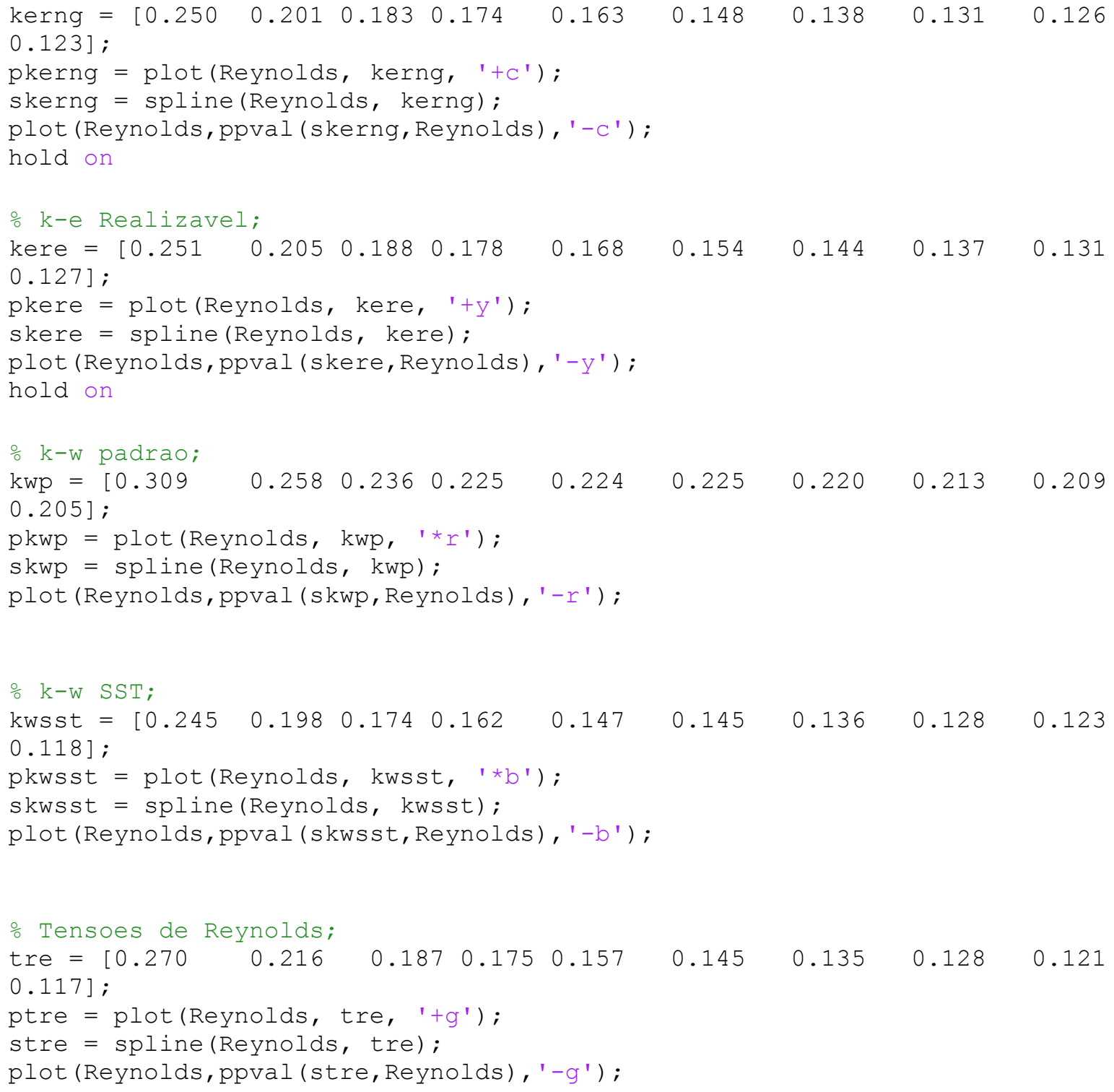

set (gca, 'fontsize', 12, 'FontWeight', 'bold')

legend('Experimental v1','Experimental v2','Experimental v3','Experimental v4', 'Spalart-Allmaras', ' ', 'k-\epsilon padrao', ' ', 'k-\epsilon RNG', ' ', 'klepsilon Realizavel','','k-\omega padrao',' ','k-\omega SST','', 'Tensoes de Reynolds', ' ') ;

title('Comparacao resultados experimentais e numericos de Cd', 'fontsize', 16, 'FontWeight', 'bold')

xlabel ('Reynolds [ ] ','fontsize', 14, 'FontWeight', 'bold') axis([40000 200000 -Inf Inf])

ylabel ('Cd [ ] ','fontsize', 14, 'FontWeight', 'bold')

fig = strcat('Resultados_Cd_numerico_exp.pdf');

print (fig,' '-dpdf') ;

fig = strcat('Resultados Cd numerico exp.jpeg');

print (fig, '-djpeg') ; 


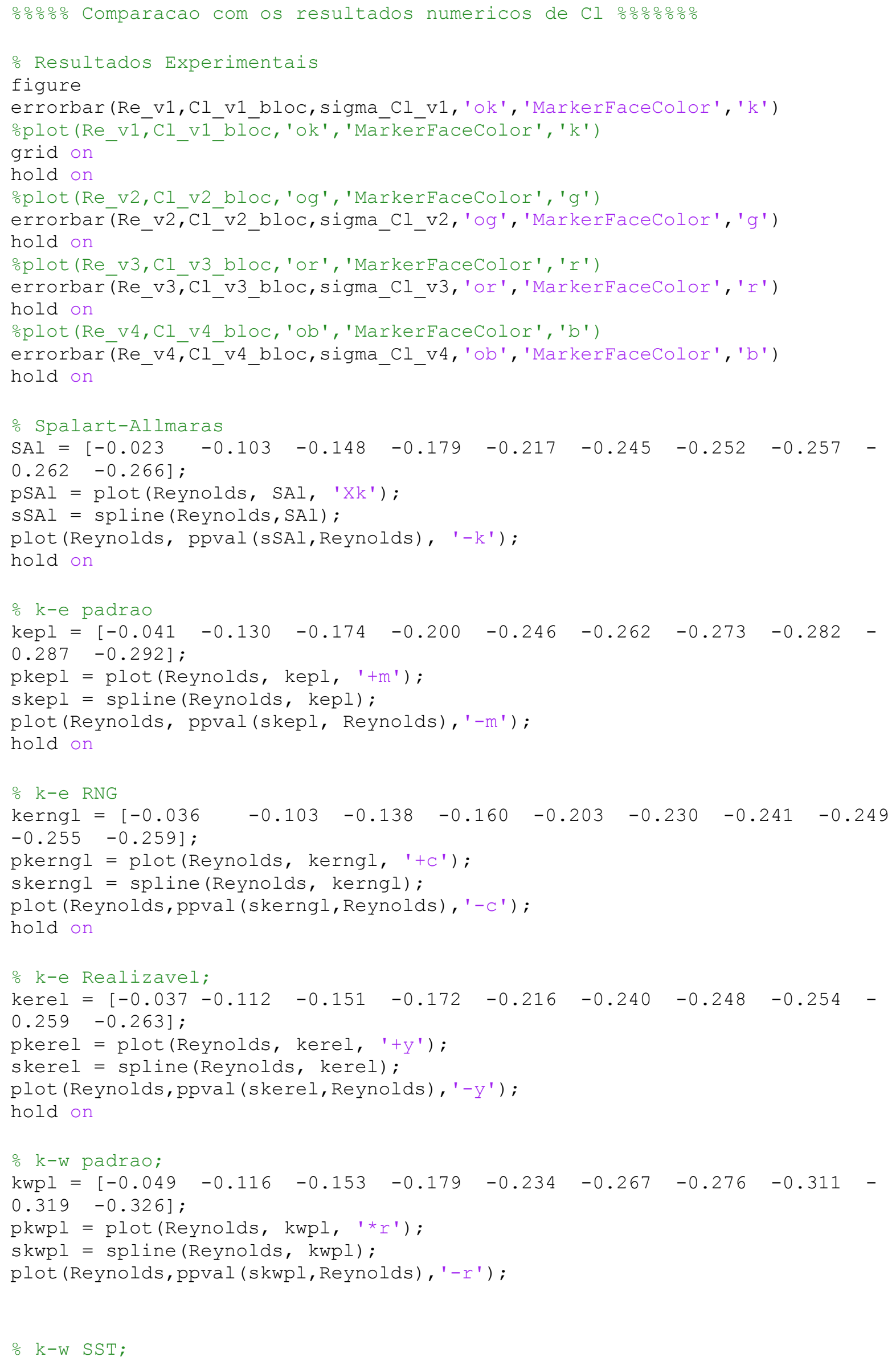




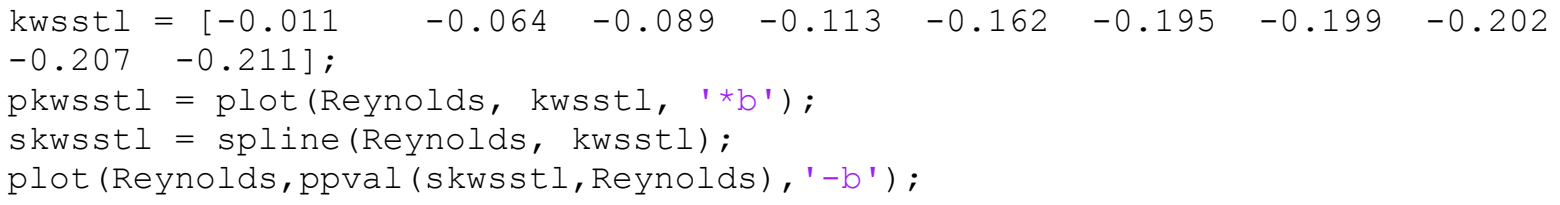




\section{B. Script para cálculo das simulações}

Para o cálculo das simulações foi utilizado scripts, chamados pelo Ansys Fluent de journals, onde vários comandos são feitos automaticamente, em batch, durante as simulações, sem a necessidade de que o usuário faça interrupções. Como exemplo, abaixo segue o journal utilizado para o teste do modelo Spalart-Allmaras com Reynolds de 12.3 x $10^{5}$.

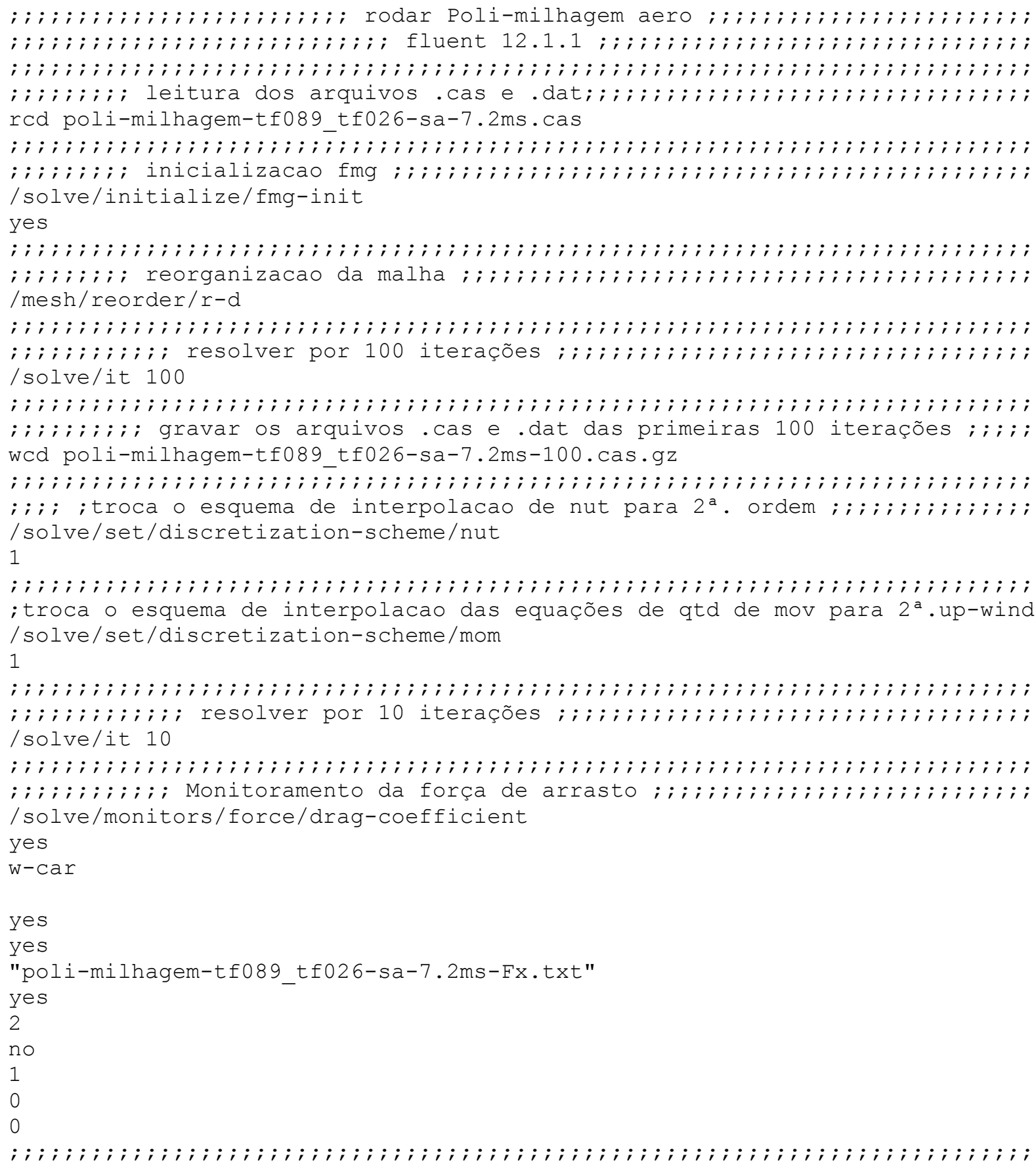


; ; ; ; ; ; ; ; ; Monitoramento da força de sustentação ; ; ; ; ; ; ; ; ; ; ; ; ; ; ; ; ; ; ; ; /solve/monitors/force/lift-coefficient

yes

w-car

yes

yes

"poli-milhagem-tf089_tf026-sa-7.2ms-Fz.txt"

yes

3

no

0

0

1

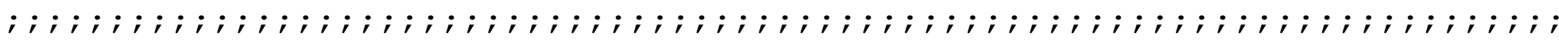

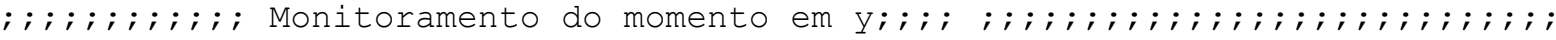
/solve/monitors/force/moment-coefficient

yes

w-car

yes

yes

"poli-milhagem-tf089_tf026-sa-7.2ms-My.txt"

yes

4

no

0

0

0

0

1

0

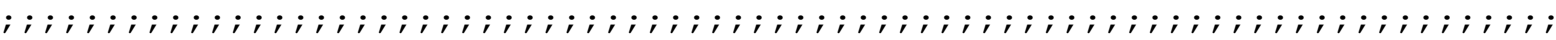

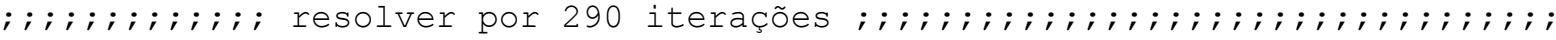
/solve/it 290

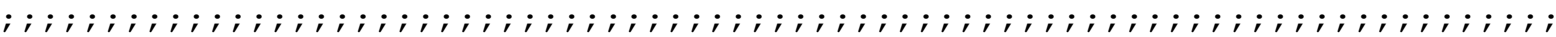
; $;$; $;$; ; ; ; gravar os arquivos . cas e .dat das primeiras 400 iterações ; ; ; ; wcd poli-milhagem-tf089_tf026-sa-7.2ms-2ord1-400.cas.gz

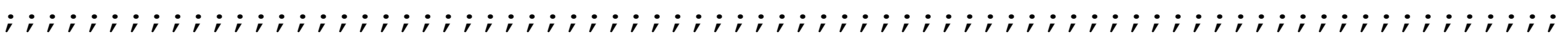
; ; ; ; troca o esquema de interpolacao da pressão para $2^{a}$. ordem ; ; ; ; ; ; ; ; ; /solve/set/discretization-scheme/pressure

12

; ; ; ; ; ; ; ; ; ; ; ; ; ; ; ; ; ; ; ; ; ; ; ; ; ; ; ; ; ; ; ; ; ; ; ; ; ; ; ; ; ; ; ; ; ; ; ; ; ; ; ; ; ; ; ; ; ; ; ;

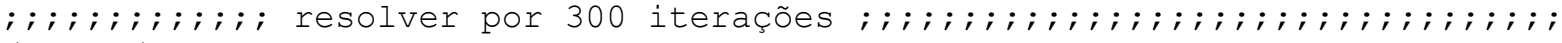
/solve/it 300

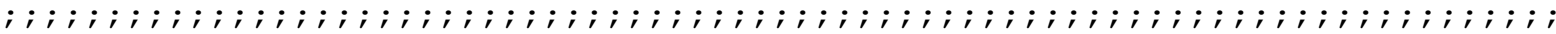
; ; ; ; ; ; ; gravar os arquivos . cas e .dat das primeiras 700 iterações ; ; ; ; wcd poli-milhagem-tf089_tf026-sa-7.2ms-2ord-700.cas.gz

; ; ; ; ; ; ; ; ; ; ; ; ; ; ; ; ; ; ; ; ; ; ; ; ; ; ; ; ; ; ; ; ; ; ; ; ; ; ; ; ; ; ; ; ; ; ; ; ; ; ; ; ; ; ; ; ; ; ; ; ; ; ; ; ; ; ; ; ; ; ; resolver por 1300 iterações $;$; $;$; ; ; ; ; ; ; ; ; ; ; ; ; ; ; ; ; ; ; ; ; ; ; /solve/it 1300

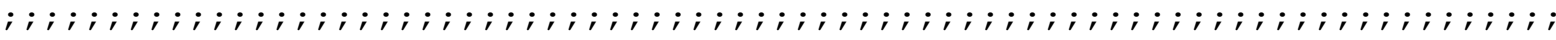
; $;$; $;$; $;$; $;$ gravar os arquivos . cas e . dat das finais da 2000 iterações ; $;$; $;$; wcd poli-milhagem-tf089_tf026-sa-7.2ms-2ord-2000-a.dat.gz

; ; ; ; ; ; ; ; ; ; ; ; ; ; ; ; ; ; ; ; ; ; ; ; ; ; ; ; ; ; ; ; ; ; ; ; ; ; ; ; ; ; ; ; ; ; ; ; ; ; ; ; ; ; ; ; ; ; ; ; $;$; $;$; $;$ exportação de algumas variáveis para o arquivo do Ensight $; \boldsymbol{i} ; \boldsymbol{i} ; \boldsymbol{i} ; \boldsymbol{i} ;$ /file/export/ensight-gold

poli-milhagem-tf089_tf026-sa-7.2ms-2ord-2000

pressure

pressure-coefficient

vorticity-mag 


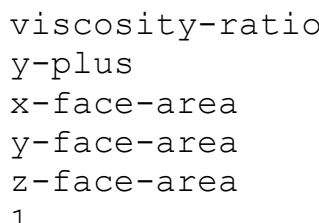

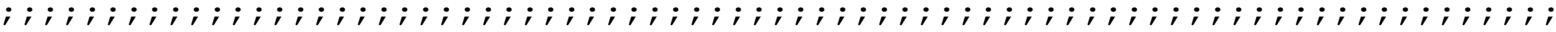

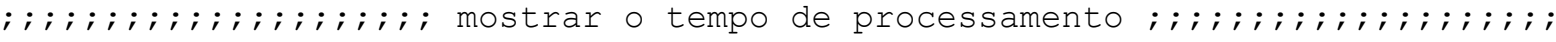
/parallel/timer/usage 